\title{
Cytoskeletal and nuclear changes during apoptosis
}

Citation for published version (APA):

van Engeland, M. (1999). Cytoskeletal and nuclear changes during apoptosis. [Doctoral Thesis, Maastricht University]. Datawyse / Universitaire Pers Maastricht. https://doi.org/10.26481/dis.19991119me

Document status and date:

Published: 01/01/1999

DOI:

10.26481/dis.19991119me

Document Version:

Publisher's PDF, also known as Version of record

\section{Please check the document version of this publication:}

- A submitted manuscript is the version of the article upon submission and before peer-review. There can be important differences between the submitted version and the official published version of record.

People interested in the research are advised to contact the author for the final version of the publication, or visit the DOI to the publisher's website.

- The final author version and the galley proof are versions of the publication after peer review.

- The final published version features the final layout of the paper including the volume, issue and page numbers.

Link to publication

\footnotetext{
General rights rights.

- You may freely distribute the URL identifying the publication in the public portal. please follow below link for the End User Agreement:

www.umlib.nl/taverne-license

Take down policy

If you believe that this document breaches copyright please contact us at:

repository@maastrichtuniversity.nl

providing details and we will investigate your claim.
}

Copyright and moral rights for the publications made accessible in the public portal are retained by the authors and/or other copyright owners and it is a condition of accessing publications that users recognise and abide by the legal requirements associated with these

- Users may download and print one copy of any publication from the public portal for the purpose of private study or research.

- You may not further distribute the material or use it for any profit-making activity or commercial gain

If the publication is distributed under the terms of Article $25 \mathrm{fa}$ of the Dutch Copyright Act, indicated by the "Taverne" license above, 


\section{Cytoskeletal and nuclear changes during apoptosis}


Manon van Engeland, Maastricht 1999 Maastricht: Universitaire Pers Maastricht ISBN 90-5278-254-7

Cover illustration: Aniek Peters 


\title{
Cytoskeletal and nuclear changes during apoptosis
}

\author{
Proefschrift
}

ter verkrijging van de graad van doctor aan de Universiteit Maastricht, op gezag van de Rector Magnificus, Prof. Dr. A.C. Nieuwenhuijzen Kruseman, volgens het besluit van het College van Decanen, in het openbaar te verdedigen

op vrijdag 19 november 1999 om 14.00 uur

door

Manon van Engeland

geboren op 14 december 1971 te Sittard

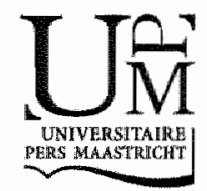




\section{Promotor:}

Prof. Dr. F.C.S. Ramaekers

\section{Co-promotores:}

Dr. A.H.N. Hopman

Dr. B. Schutte

\section{Beoordelingscommissie:}

Prof. Dr. J.P.M. Geraedts (voorzitter)

Prof. Dr. J.W. Arends

Prof. Dr. M. Borgers

Prof. Dr. R. van Driel (Universiteit van Amsterdam)

Prof. Dr. C. Hemker

This thesis was prepared at the Department of Molecular Cell Biology \& Genetics, Research Institute Growth \& Development of the University of Maastricht.

The studies described in this thesis were financially supported by Becton Dickinson.

Adeitional financial support for the publication of this thesis was provided by Nexins Research, Euro-Diagnostica, Beun-de Ronde, DAKO A/S, Bio-Rad and the Dr. Ir. van der Laar Stichting 
Neet te veul denke

't het toch gen nut

want vanaf 't begin

zien ow kaarte geschud

Jack Poels 



\section{Contents}

1. General introduction 9

2. The molecular mechanisms of apoptosis 15

3. Anmexin $V$-affinity assay: a review on an apoptosis detection system based on phosphatidylserine exposure 37

4. A novel assay to measure loss of plasma membrane asymmetry during apoptosis of adherent cells in culture

5. Plasma membrane alterations and cytoskeletal changes during apoptosis

6. Differential cleavage of nuclear lamin proteins during apoptosis

7. Chromosome degradation during apoptosis

8. Summary and generall discussion

Samemvatting

Dankwoord

Curriculum vitae

List of publications

Color illustrations 

1

\section{General introduction}

\section{Contents}

1.1 Introduction

1.2 Aim of this study

1.3 References 


\subsection{Introduction}

In multicellular organisms, tissue homeostasis is maintained by a delicate balance between cell proliferation and cell death. Two types of cell death can be distinguished, i.e. accidental cell death (necrosis) and programmed cell death (apoptosis).

Necrosis results from acute cellular injury induced by ischemia, hyperthermia or toxins and is therefore also called 'cell death by murder'. The damage inflicted often interferes with ATP synthesis, which leads to swelling of the cell and subsequent loss of plasma membrane integrity. The cell content is spread into the surrounding tissue space and evokes an acute inflammatory response (Wyllie et al., 1980; Majno and Joris, 1995) (see figure 1.1).

In response to specific internal and external signals and at specific moments, single cells can 'commit suicide'. This mode of cell death, called apoptosis, is considered to be physiological, since it plays an essential role in normal organ or tissue organization and during development (Vaux and Korsmeyer, 1999; Wyllie et al., 1980).

Apoptosis is characterized by cell shrinkage and fragmentation (Wyllie et al., 1980) (see figure 1.1). Apoptotic cells are immediately eliminated by phagocytes or neighboring cells, which prevents the onset of an inflammatory response. In cell cultures, where no phagocytosis occurs, apoptotic cells will finally lyse and undergo (secondary) necrosis. During normall embryonic development, superfluous cells are removed by apoptosis. In this way cavities are formed, digits are separated and structures that served a transient function are eliminated (Raff, 1998). Apoptosis also plays a role in the maturation of the immune system and of the nervous system. Neurons that fail to make correct connections die via apoptosis. In adult animals, apoptosis regulates tissue homeostasis, elimination of damaged or abnormal cells and defense against viral infections (Steller, 1995).

Although necrosis and apoptosis are two different routes leading to cell death, intermediate forms possibly exist.

Apoptosis and necrosis can occur simultaneously in tissues and cell cultures. Often the intensity of the insult determines whether a cell undergoes apoptosis or necrosis. Furthermore, when intracellular ATP levels are insufficient, activation of a part of the apoptosis program is prevented and apoptosis stimuli will result in necrosis, indicating that completion of the apoptosis program requires energy (Leist and Nicotera, 1997; Leist et al., 1997; Tsujimoto, 1997).

Deregulation of apoptosis is associated with many diseases. A decreased frequency of apoptosis can lead to cancer, while increased apoptosis may contribute to neurodegenerative disorders such as Alzheimer's disease and Parkinson's disease. Furthermore, autoimmune diseases are characterized on the one hand by a decreased ability to eliminate self-reactive T-or B-cells and/or on the other hand by impaired clearance of apoptotic cells by macrophages (Thompson, 1995). 


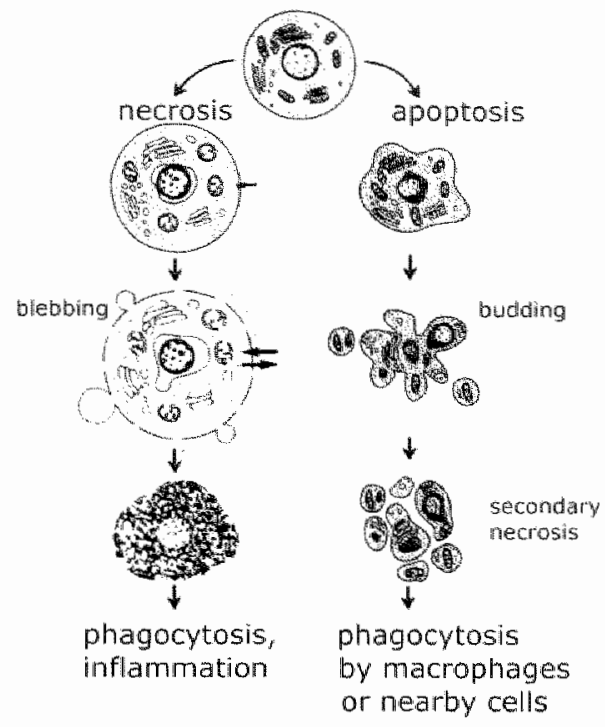

Figure 1.1. Two pathways leading to cell death. Necrosis is characterized by swelling and blebbing, while apoptosis is characterized by shrinkage and budding. (Modified from Majno and Joris, 1995).

The process of apoptosis consists of several phases: 1) an induction phase, 2) an execution phase and 3) a degradation phase (see figure 1.2). After induction of apoptosis by so-called "death signals" (e.g. DNA damage or withdrawal of growth factors), a highly conserved family of proteases, the caspases, is activated in the execution phase. These enzymes cleave specific substrates at a conserved cleavage site. Caspase substrates include stressresponse proteins, apoptosis inhibitory proteins, caspases themselves and structural proteins.

The result of caspase cleavage of the above-mentioned proteins is manifestation of the characteristic morphological changes of apoptosis, such as condensation and fragmentation of DNA and formation of apoptotic bodies. Furthermore, changes in the outer plasma membrane of the apoptotic cell serve as a trigger for phagocytes to remove the dying cell. Eventually, the apoptotic cell disintegrates into membrane-enclosed bodies which, in vivo, are phagocytosed by neighboring cells.

A review on the molecular mechanisms of apoptosis is provided in chapter 2 of this thesis. 
In

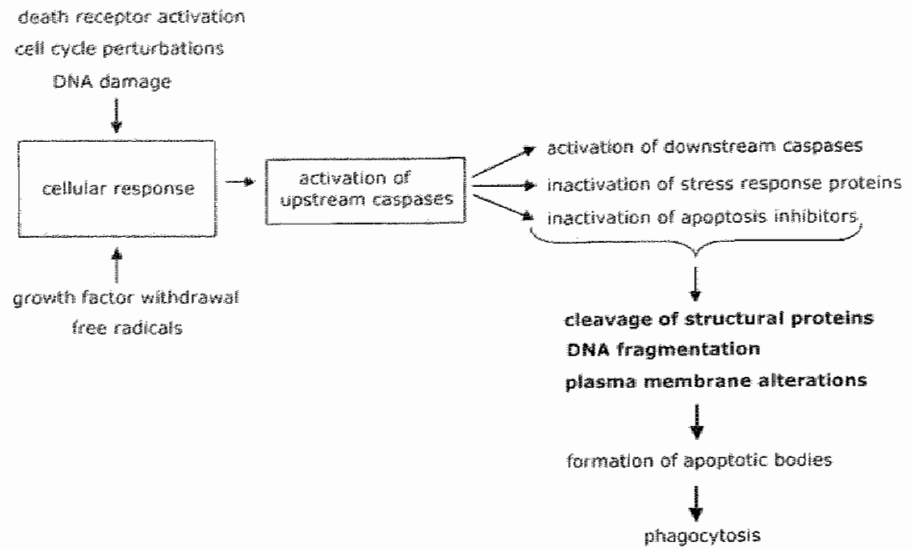

Figure 1.2: The process of apoptosis can be divided into three phases. In the induction phase, internal or external insults result in a cellular response. This response leads to activation of the caspase family of proteases (execution phase). Amongst the substrates for caspases are other caspases, which function downistream in the apoptosis cascade and which are activated by proteolytic cleavage. These caspases cleave structural proteins such as cyto- and nucleoskeletal proteins, and inactivate stress response proteins as well as apoptosis inhibitory proteins. Finally, the apoptotic cell is packaged and phagocytosed by neighboring cells or macrophages.

The machinery needed for apoptosis is present in every healthy cell. All multicellular eukaryotes, including plants, can undergo apoptosis. Only those cells that manage to inactivate this machinery will survive (Raff, 1992). It is hypothesized that apoptosis has emerged with multicellularity, which implies functional interactions of individual cells in a given spatial and temporal framework. The onganism will survive only when its cells cooperate in such a way that it will allow the organism to remain adapted to its environment (Ameisen, 1998).

\subsection{Aim of this study}

The degradation phase of apoptosis is characterized by coordinated disassembly and packaging of specific cellular and nuclear constituents, instead of total degradation of the cell. In this study, we examined cleavage of structural proteins, in particular cyto- and nucleoskeletal proteins, and DNA fragmentation during apoptosis in human tumor cell lines. The working hypothesis of this study was that cleavage and reorganization of cyto- and nucleoskeletal proteins and DNA during apoptosis is not only dependent on activation of enzymes that act on specific cleavage sites in these constituents, but also on the supramolecular organization of the cytoplasm and the nucleus. 
Therefore, the aims of this study were:

1. To develop an assay that could reliably quantitate apoptosis in adherent cell lines (chapter 3 and 4 ).

2. To study the relationship between plasma membrane atterations and cytoskeletal changes during apoptosis (chapter 5).

3. To study whether cleavage of specific cyto- and nucleoskeletal proteins during apoptosis is dependent on the molecular organization of these cellular scaffolds (chapter 5 and 6 ).

4. To study whether degradation of functionally different regions in the genome is dependent on a higher structural organization of the nucleus (chapter 7 ).

\subsection{References}

- Ameisen, J.C. 1998. The evolutionary origin and role of programmed cell death in singlecelled organisms: a new view of executioners, mitochondria, host-pathogen interactions, and the role of death in the process of natural selection. In When cells die. Lockshin, R.A., Zakeri, Z. and Tilly, J. editors. (New York: Wiley-Liss) pp. 3-56.

- Leist, M., Single, B., Castoldi, A.F., Kühnle, S. and Nicotera, P. 1997. Intracellular adenosine triphosphate (ATP) concentration: a switch in the decision between apoptosis and necrosis. J. Exp. Med. 21:1481-1486.

- Leist, M. and Nicotera, P. 1997. The shape of cell death. Biochem. Biophys. Res. Comm. 236:1-9.

- Majno, G. and Joris, I. 1995. Apoptosis, oncosis and necrosis. An overview of cell death. Am. J. Pathol. 146:3-15.

- Raff, M. 1992. Social controls on cell survival and cell death. Nature 356:397-400.

- Raff, M. 1998. Cell suicide for beginners. Nature 396:119-122.

- Steller, H. 1995. Mechanisms and genes of cellular suicide. Science 267:1445-1449.

- Thompson, C.B. 1995. Apoptosis in the pathogenesis and treatment of disease. Science 267:1456-1462.

- Tsujimato, '.' 1997. Apoptosis and necrosis: intracellular ATP level as a determinant for cell death modes. Cell Death Differ, 4:429-434.

- VauX, D.L. and Korsmeyer, S.L. 1999. Cell death in development. Cell 96:245-254.

- Wyllie, A.H., Kerr, J.F.R. and Currie, A.R. 1980, Cell death: the significance of apoptosis. Int Rev. Cytol 68:251-306. 



\section{The molecular mechanisms of apoptosis}

Partly published as:

Manon van Engeland, Bert Schutte, Anton H.N. Hopman, Frans C.S. Ramaekers and Chris P.M. Reutelingsperger. 1999.

Cytochemical detection of cyto- and nucleoskeletal changes during apoptosis. In: Apoptosis: a practical approach. Studzinski, G. editor.

(Oxford: Oxford University Press) in press.

\section{Contents}

2.1 Introduction

2.2 The players

2.3 The kick-off: induction of apoptosis

2.4 The game

2.5 Part of the apoptotic cascade is used during cytosalic and nuclear remodeling

2.6 The winner is......

2.7 References 


\subsection{Introduction}

Apoptosis is an evolutionary conserved form of physiological cell death by which redundant and damaged cells are eliminated during embryogenesis and which maintans tissue homeostasis in the adult organism. Apoptotic cells are characterized by cell shrinkage, membrane budding and formation of apoptotic bodies.

The machinery for apoptosis is present in every living cell, although inactive. This indicates that apoptosis is mediated by a default pathway, which can be activated any moment. Complex interactions between apoptosis promoting proteins and apoptosis inhibiting proteins keep the system inactive. However, when a cell becomes redundant, genetically mutated or infected by viruses, the apoptosis machinery is activated and the cell kills itself in a coordinated fashion. Apoptotic cells are immediately cleared by phagocytes, which prevents the onset of an inflammatory response.

The process of apoptosis can be divided into three phases:

1) the induction phase, in which a cell is triggered to die.

2) the execution phase, in which a highly conserved family of proteolytic enzymes called caspases, is activated. Activation occurs either by direct activation of caspases or by inthibiting caspase-inhibitory proteins.

3) the degradation phase, in which caspases cleave structural proteins, activate nucleases and inactivate apoptosis inhibitory proteins and stress response proteins. This leads to disassembly of the cell and appearance of the characteristic apoptotic morphology.

Apoptosis research has been facilitated by the use of the nematode Caenorhabditis Elegans as a model system. Using this model system, some of the 'main players' in the 'game of apoptosis' have been identified. In more recent years, mammalian homologues of these molecules have been identified.

In this review, the molecular mechanisms of apoptosis in mammallan cells are discussed. Firstly, the "players" are introduced, secondly the 'game' of apoptosis is explained, and finally the outcome of the 'game' is discussed.

\subsection{The players}

Much of the understanding of the molecular mechanisms and identification of the 'main players' of apoptosis has come from genetic studies in the nematode C. Elegans. During development of C. Elegans, 1090 cells are generated of which 131 undergo apoptosis. Apoptosis in C. Elegans can be studied in living animals by scoring the presence or absence of apoptotic cells using Nomarski optics (Gartner and Hengartner, 1998).

Mutation analyses of $C$. Elegans have identified the genes and proteins that control apoptosis. The proteins CED-3, CED-4 and EGL-1 are essentiall for all apoptosis in this nematode (Metzstein et al., 1998).

Inhibition of apoptosis in C. Elegans is controlled by CED-9, a protein which prevents cell death and acts upstream in the cascade of CED-3 and CED-4 (see figure 2.1). Overexpression of EGL-1 induces apoptosis in cells that normally live, but only in the presence of CED-3 and CED-4. This indicates 
that EGL-1 functions upstream of CED-3 and CED-4 as an inhibitor of the apoptosis inhibitor CED-9 (Conradt and Horvitz, 1998).

Six proteins (CED $-1,-2,-5,-6,-7,-10$ ) have been identified to be required for the phagocytosis of dying cells in C. Elegans (Ells et al., 1991) (see figure 2.1). In animal mutants for the genes of these proteins, apoptosis occurs as usual, however, many of the dying cells are not phagocytosed. During phagocytosis, the dying cell fragments into membrane-bound particles and the DNA of the dead cell is digested by the nuclease NUC-1. (Hedgecock et al., 1983).

healthy cell cell committed to die apoptotic cell phagocytosing cell

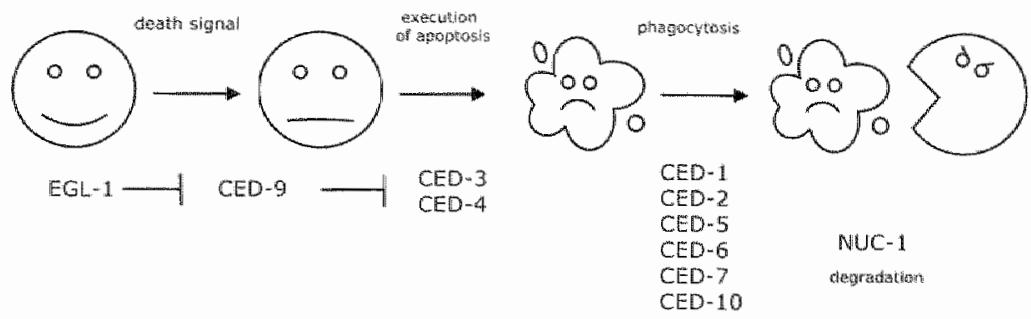

Figure 2.1. The apoptosis pathway in C. Elegans. $\rightarrow$ positive regulatory interaction; $(-1)$ negative regullatory interaction. CED-3 and CED-4 promote apoptosis, while CED-9 prevents apoptosis. EGL-1 promotes apoptosis by inhibiting the apoptosis inhibitor CED-9. (Modified from Gartner and Hengartner, 1998).

Also in Drosophila melanogaster large numbers of cells undergo apoptosis during embryonic development and metamorphosis. Induction of apoptosis in Drasophila is controlled by the proteins reaper, hid and grim. These proteins kill cells by activating the Drosophila caspases DCP-1, drICE and DCP-2, which are structurally and biochemically related to CED-3 (Steller, 1995; Bergmann et al, 1998).

Recently, structural and functional homologues of CED-3, CED-4, CED-9 and EGL-1 are identified in mammalian cells (see table 2.1). The discovery of these protelns revealed that the overall similarities between the nematode and the mammalian cell death programs are striking.

CED-3 has sequence simillarity to mammalian interleukin-1p-converting enzyme (ICE), also called caspase-1, a member of a family of cysteine proteases consisting of multiple mammalian homologues (ruan et al., 1993; Alnemri et al., 1996).

Apoptotic protease-activating factor 1 (Apaf-1) (Zou et al., 1997) and FLICEassociated huge protein (FLASH) (Imall et al., 1999) are the mammalian homologues of CED-4. Apaf-1 was identified by virtue of its participation in the activation of caspase-3 (Zou et al., 1997), while FLASH is involved in activation of caspase-8 (Imai et al., 1999).

Multiple mammalian homologues of CED-9 have been identified. These proteins belong to the $\mathrm{BCl}-2$ protein family and can be divided into two 
subgroups that either inhibit or promote apoptosis (Hengartner and Horvitz, 1994). Bcl-2 and the apoptosis inhibitors protect cells from apoptosis by acting upstream of caspases to prevent their activation, just as CED-9 inhibits CED-3 activation. The apoptosis promotor proteins of the Bd-2 family of proteins can interact with and inhibit the apoptosis inhibitory proteins of the BCl -2 family, just as EGL-1 binds and inhibits CED-9.

The observation that expression of human $\mathrm{BCl}-2$ in $\mathrm{C}$. Elegans prevents CED3 and CED-4-mediated apoptosis also points to a cell death mechanism which is conserwed between species (vaux et al., 1992).

\begin{tabular}{|c|c|c|c|}
\hline C. Elegans protein & \multicolumn{2}{|c|}{ mammallian homologue } & function/substrate \\
\hline $\operatorname{CED}+4$ & \multicolumn{2}{|c|}{ Apar- B NASH } & CEL-3/cespase activation \\
\hline \multirow[t]{9}{*}{$\mathrm{CEO} \cdot 3$} & \multicolumn{2}{|l|}{ caspases: } & pratedysis of: \\
\hline & $\begin{array}{l}\text { cospagent } \\
\text { caspasen-2 }\end{array}$ & $\begin{array}{l}\text { (ICE) } \\
\text { (Nedd } 2 / \mathrm{HCH}-1)\end{array}$ & 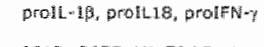 \\
\hline & 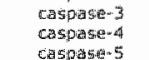 & 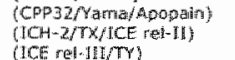 & ICAD, PARAE, U1-70 kD etC. \\
\hline & caspatse. 6 & $(\operatorname{lol} c+52)$ & muchear iamiras \\
\hline & Cantaser & (MCHB/ICE LAP3/CMAN-1) & PARP \\
\hline & $\begin{array}{l}\text { Taspasen-8 } \\
\text { caspase-9 }\end{array}$ & 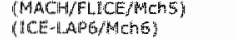 & $\begin{array}{l}\text { caspase }-1.3,-1.4 \\
\text { caspdase- } 3\end{array}$ \\
\hline & caspase- 10 : & $\begin{array}{l}\text { (MChAAfFLICE.Z) } \\
(\text { (ICH }-3)\end{array}$ & casposie-1.4 \\
\hline & colspase- $12^{*}$ & & \\
\hline & $\begin{array}{l}\text { caspage-13 } \\
\text { calsrase-14 }\end{array}$ & $\begin{array}{l}\text { (ERICE) } \\
\text { (PACE) }\end{array}$ & \\
\hline \multirow[t]{6}{*}{ CED- } & \multicolumn{2}{|c|}{ Apoptosis intheitors of Bel-2 Pamily } & inthitheten of apoptosis \\
\hline & \multicolumn{2}{|l|}{$\operatorname{sen} 2$} & \\
\hline & \multirow{2}{*}{\multicolumn{2}{|c|}{ 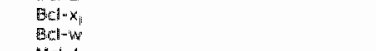 }} & \\
\hline & & & \\
\hline & \multirow{2}{*}{\multicolumn{2}{|c|}{ Al. }} & \\
\hline & & & \\
\hline \multirow[t]{8}{*}{ Eat-1 } & \multicolumn{2}{|c|}{ Hpoptasis prornotors of ecl-2 family } & premotion of apoptosis \\
\hline & \multicolumn{2}{|l|}{ Bas } & \\
\hline & \multirow{2}{*}{\multicolumn{2}{|c|}{$\begin{array}{l}\text { Bak } \\
\text { Bo:k }\end{array}$}} & \\
\hline & & & \\
\hline & \multicolumn{2}{|l|}{ 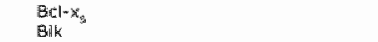 } & \\
\hline & \multirow{2}{*}{\multicolumn{2}{|c|}{ 些h }} & \\
\hline & & & \\
\hline & \multicolumn{2}{|l|}{$\begin{array}{l}\text { Ead } \\
\text { gied }\end{array}$} & \\
\hline
\end{tabular}

Table 2.1: Apoptosis regulatory proteins in C. Elegans and mammals. The identified mammalian caspases have distinct roles in apoptosis and inflammation. The caspase family includes two murine homologues ( $($ ). (Modified from Dorstyn et al., 1998).

\section{Caspases}

Since the identification of ICE (Caspase-1), several mammalian homologues of CED-3 have been identified and cloned. This structurally related family of proteins is called caspases, cysteine proteases with aspartate specificity and a conserved QACXG pentapeptide being the catalytic site (Alnemri et al., 1996; Salvesen and Dixit, 1997; Cryns and Yuan, 1998a; Thormberry and Lazebinik, 1998).

All caspases are constitutively and ubiquitously expressed in the cytosol as inactive proenzymes composed of a variable length amino-terminal prodomain, a large subunit and a small subunit amino acid sequence (see figure 2.2) (Thornberry, 1998; Villa et al., 1997; Cryns and Yuan, 1998a). Prodo- 
mains play a role in binding of procaspases to other proteins as Apat-1 and adapter-molecules as Fas and TNF (discussed below) (Fraser and Evan, 1996; Zou et al., 1997; Vincenz and Dixit, 1997).

Activation of the procaspase into a functional caspase requires proteolytic cleavage events at specific aspartate residues, separating these three domains. These cleavages result in the removal of the prodomain and the formation of a heterodimer containing one large and one small subdomain. Two heterodimers assemble into an active enzyme with two active sites (figure 2.2) (Cryns and Yuan, 1998a).

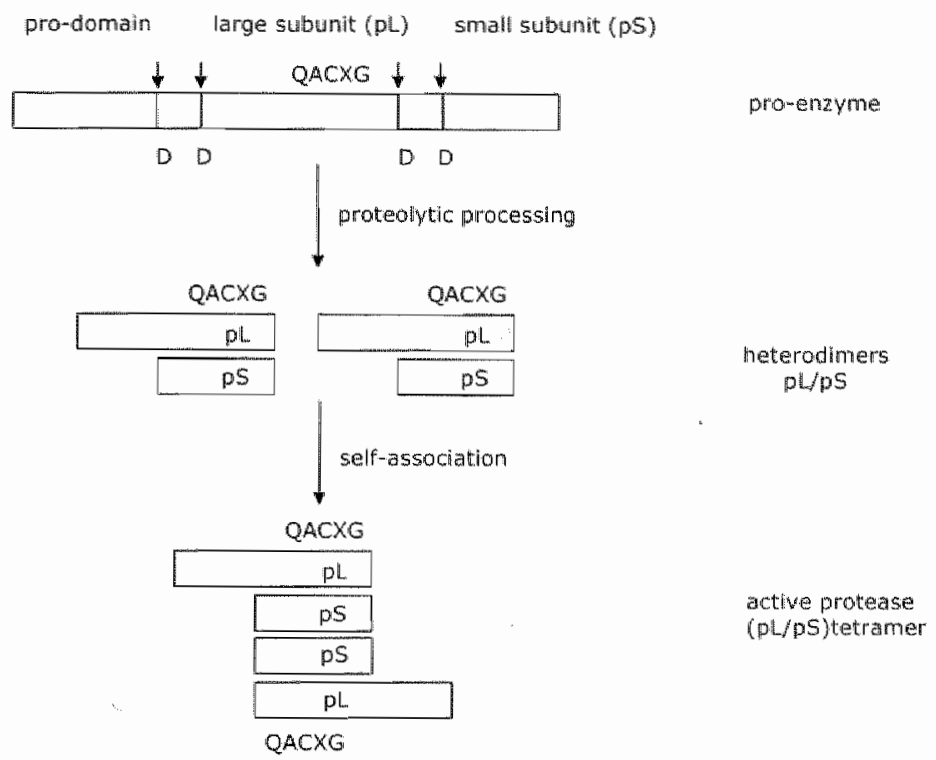

Figure 2.2. Proteolytic processing and oligomerization of caspases. Caspases are expressed as inactive proenzymes and are activated by proteolytic cleavage at Asp (D) residues, resulting in the removal of the regulatory $\mathbb{N}$-terminal prodomain and generation of large and small subunits. The active protease is a tetramer composed of two self-associating large and small subunit heterodimers. (Adapted from Cryns and Yuan, 1998b).

On basis of the size of the prodomains, caspases can be divided into class I and class II caspases. Class I caspases have a large prodomain and include caspase-1, $-2,-4,-5,-8,-9,-10$ and -11 .

These caspases act early in the apoptotic cascade or are involved in procytokine activation and are also called effector caspases or upstream caspases. Many of these caspases activate other, downstream caspases by proteolytic cleavage.

Class II caspases have a short prodomain and include caspase $-3,-6$, and -7 . These caspases, the executioner caspases, target cellullar substrates, which are cleaved during apoptosis (Dorstyn et al., 1998).

Caspases are amongst the most specific of proteases with an absolute requirement for cleavage after an aspartic acid residue at the so-called P1 
position. Recognition of at least four amino acids $\mathrm{N}$-terminal to the P1 posittion is necessary for efficient proteolysis. Although all caspases cleave substrates at an aspartic acid residue at the P1 position, individual caspases differ substantially in their preference for amino acids next to the aspartic acid residue ( $\mathrm{P} 2-\mathrm{P} 4$ position), which leads to divergent substrate specificities of the different caspases (Cryns and Yuan, 1998a). Limited proteolysis of substrates, often at a single site, results in disassembly of cell structures, deregulation of protein activity and inactivation of inhibitors of apoptosis (Thornberry and Lazebnik, 1998).

\section{Caspase regulation}

The observation that caspase precursors are present in living cells and that apoptosis can be induced instantaneously indicates an efficient and sophisticated regulation of the caspase system. Caspases can be activated and inhibited by several pathways. Several caspase activation pathways have been identified, including release of apoptogenic proteins from the mitochondria, activation of death receptors at the plasma membrane, and activation by granzyme B (discussed below) (Green, 1998).

Furthermore, caspase inhibitors have recently been identified, which may establish thresholds that determine the concentration of active caspase required for apoptosis, thus preventing the consequences of accidental or spontaneous proenzyme activation (Thormberry and Lazebnik, 1998).

Caspase inhibitors were first identified in viruses and prevent apoptosis in their host cells to allow viral replication and survival (for review see Uren and Vaux, 1997). Some of these proteins, such as the Epstein-Barr wirus protein BHRF1 and adenovirus E1B-19 kD, are Bcl-2 homologues (Uren and Vaux, 1997). Other viral proteins inhibit apoptosis by direct inhibition of caspases, as for example the cowpox virus cytokine response modifier (CrmA) and baculovirus $\mathrm{p} 35$. The CrmA gene encodes a serpin, which cain inhibit caspase1 and granzyme B by irreversible binding (Bird, 1998). p35 is a baculovirus protein, which inhibits CED-3, caspase-1, caspase-2, caspase-3 and caspase4, but not granzyme B. Recently, a new family of viral apoptosis-inhibitory proteins ( $\boldsymbol{v}$-FLIPS) has been identified, which prevents recruitment of caspase-8 to the Fas receptor (Thome et al., 1997). Furthermore, cellular homologues of $V$-FLIP genes (C-FLIPS) have been identified in the genome of insects, birds and manmals. These proteins posses sequence homology with the prodomains of caspase- 8 and caspase-10 and they prevent the delivery of these caspases to ligand bound death receptors (Uren and Vaux, 1998).

Recently, also human inhibitors of apoptosis proteins (IAPS) have been discovered, amongst which survivin. Survivin is not expressed in adult, differentiated tissue, but is present in most transformed cell ines and cancers (Ambrosini et al., 1997).

Prevention of caspase activation is further accomplished by transcriptional regulation, alternative splicing, subcellular localization of caspases, regulation by cellular proteins such as Apaf-1 and post-translational modifications (Dorstyn et al., 1998; Cardone et al., 1998).

\section{Caspase activators: Apaf-1 and FLASH}

As CED-4 is involved in activation of CED-3, Apaf-1, a mammalian CED-4 homologue, is involved in caspase-3 activation.

Apafm 1 itself must be activated, which occurs through a conformational 
change induced by binding of $\mathrm{dATP}$ and cytochrome $\mathrm{C}$, which is released from the mitochondria (discussed below). Apaf-1 itself is not a caspase but functions as a regulatory protein, which serves as a docking protein for procaspase-9 and cytochrome C (Zou et al., 1997; Li et al., 1997).

FLICE-associated huge protein (FLASH), the other mammalian CED-4 homologue, participates in recruitment and activation of caspase-8 (originally called FLICE) in Fas (CD95)-mediated apoptosis (Imail et al., 1999).

\section{The Bcl-2 family of apoptosis-regulating proteins}

The mammalian homologue of CED-9 is $\mathrm{BCl}-2$, a protein that belongs to a family of proteins, which consists of apoptosis promotors and apoptosis inhibitors. Among the apoptosis inhibitors are $\mathrm{BCl}-2, \mathrm{Bcl}=\mathrm{x}_{1}, \mathrm{BCl}-\mathrm{w}, \mathrm{MCl}-1, \mathrm{~A}-1$, adenovirus E1B-19K and Epstein-Barr virus BHRF1. The apoptosis promotors include Bax, Bak, Bcl-x, Bok/Mtd, Bad, Bik, Bid, Bim, Hrk and Blk (Adams and Cory, 1998). The Bcl-2 protein family shares homology in one to four regions called the $\mathrm{BCl}-2$ homology $(\mathrm{BH})$ domains $\mathrm{BH}, \mathrm{BH} 2, \mathrm{BH} 3$ and $\mathrm{BH} 4$. Some of the proteins have all four regions while others lack some domains.

The $\mathrm{BH} 1$ and $\mathrm{BH} 2$ domains are essential for the survival function of the apoptosis inhibitor proteins. The $\mathrm{BH}-3$ domain is essential for the function of the apoptosis promotors (see figure 2.3).

Most members of the family contain a carboxyterminal transmembrane (TM) region, which targets the proteins predominantly to the outer mitochondrial membrane, the ER membrane and the outer nuclear envelope (for reviews see Kekelar and Thompson, 1998; Reed, 1998; Adams and Cory, 1998; O'Connor and Strasser, 1998; Kroemer, 1997).

apoptosis inhibitors

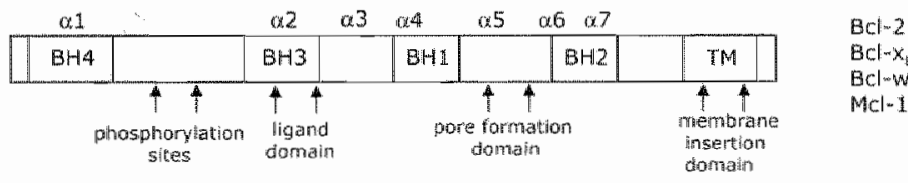

apoptosis promotor's

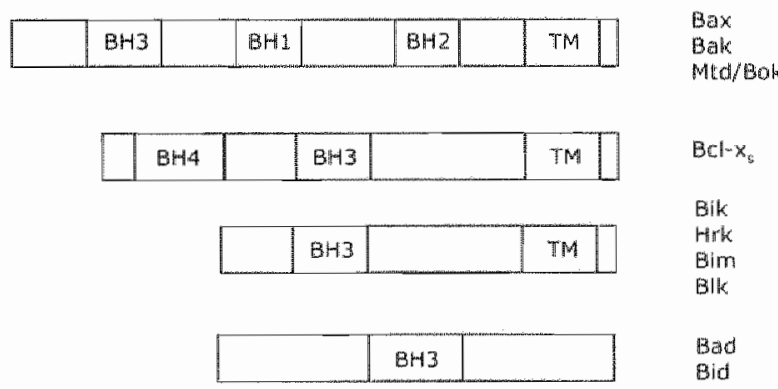

Figure 2.3. Classification of the Bcl-2 family of proteins based on domain organization. (Adapted from Kekelar and Thompson, 1998 and Adams and Cory, 1998). 
The tertiary structure of the $\mathrm{BCl}-2$ protein demonstrates that the protein comprises two central hydrophobic a-helices, $\alpha .5$ and $\alpha 6$, surrounded by five amphipathic helices, $a 1, a 2, a 3, a 4$ and $a .7$. This structure suggests $B C l-2$ to be an ion channel forming protein. The helices are arranged in such a way that $\mathrm{BH} 1, \mathrm{BH} 2$ and $\mathrm{BH} 3$ form a hydrophobic cleft to which a $\mathrm{BH} 3$ amphipathic a-helix can bind. The $\mathrm{BH} 4$ domain forms an amphipathic helix on the opposite face of the molecule (Adams and Cory, 1998).

It is suggested that the apoptosis inhibitar proteins tend to form small channels, which have a closed conformation, with preference for cations, whereas the apoptosis promotor proteins tend to form larger open conformation channels, preferring anions (Schendel et al. 1998 ).

Apoptosis promoting and apoptosis inhibiting $\mathrm{BCl}-2$ proteins can form homoand heterodimers, and form a complex in which the proteins inhibit each other's function. The ratio of promotors and inhibitors determines the cell's susceptibility to apoptosis, suggesting that their relative function may act as a life-death rheostat (Yang and Korsmeyer, 1996).

Not only the relative expression level of promotors and inhibitors determines the susceptibility of a cell to undergo apoptosis. Also post-translational modifications, such as proteolytic cleavage and phosphorylation of $\mathrm{Bcl}-2$ related proteins determine regulation of apoptosis (Kroemer, 1997; McDonnel et al., 1999; Chou et al., 1999; Li et al., 1998a; Zha et al., 1996).

$\mathrm{Bcl}-2$ proteins function by regulating the release of cytochrome $\mathrm{C}$ from mitochondria (discussed below) (Reed, 1998).

\subsection{The kick off: induction of apoptosis}

Survival signals from the cell's environment and internal sensors for cellular integrity contral the apoptosis machinery. When a cell receives a 'death signal', e.g. by exposure to physical and chemical trauma, removal of growth factors, disturbance of the cell cycle, viruses or loss of cell-cell contacts, the apoptosis pathway is activated. Activation can occur via three main pathways: 1) a death receptor-mediated pathway, 2) a mitochondria/Bcl-2mediated pathway and 3) a granule-mediated pathway.

\section{Death receptor-mediated apoptosis}

'Death receptors' are located in the plasma membrane (figure 2.4) and transmit apoptosis signals. These receptors detect the presence of extracellular "death signals" and in response they initiate the cell's apoptosis machinery (Ashkenazi and Dixit, 1998). Death receptors belong to the tumor necrosis factor (TNF) receptor superfamily, and contain a cysteine-rich extracellular domain and a cytoplasmic sequence, named the "death domain" (DD), which is essential for transduction of a death signal into the cell (Ashkenazi and Dixit, 1998; Peter et al., 1998). The best-characterized receptors are Fas (also called CD95 or Apo1) and TNFR (also called p55 or CD 120a). The ligands that activate these receptors are Fas ligand (FasL) and TNF, molecules that belong to the TNF superfamilly. After binding of three ligand molecules, the receptor is activated by trimerization (Peter et al., 1998).

Signaling by Fas and FasL plays an important role in deletion of activated mature T-cells at the end of an immune response and killing of virus-infected 
or cancer cells by cytotaxic $T$ cells and natural killer cells (Ashkenazi and Dixit, 1998). A FasL trimer binds three Fas molecules and because DD's associate with each other, Fas ligation leads to clustering of the receptor's DD. An adapter protein called FADD (Fas associated death domain; also called Mort 1) binds via it's own DD to the clustered receptor DD. FADD also contains a death effector domain (DED), which interacts with the deatheffector recruitment domain (DRD) of FLASH. This death effector domain is also called caspase recruitment domain (CARD) and is found in several caspases. After recruitment, caspase- 8 is activated by FLASH and activates downstream effector caspases (see figure 2.4) (Boldin et al., 1996; Medema et al., 1997; Muzio et al., 1996; Imai et al., 1999).

Recruitment of caspase- 8 by FLASH to FADD results in formation of a complex called death-induced signaling complex (DISC) or apoptosome, that functions to mediate caspase activation (Green, 1998).

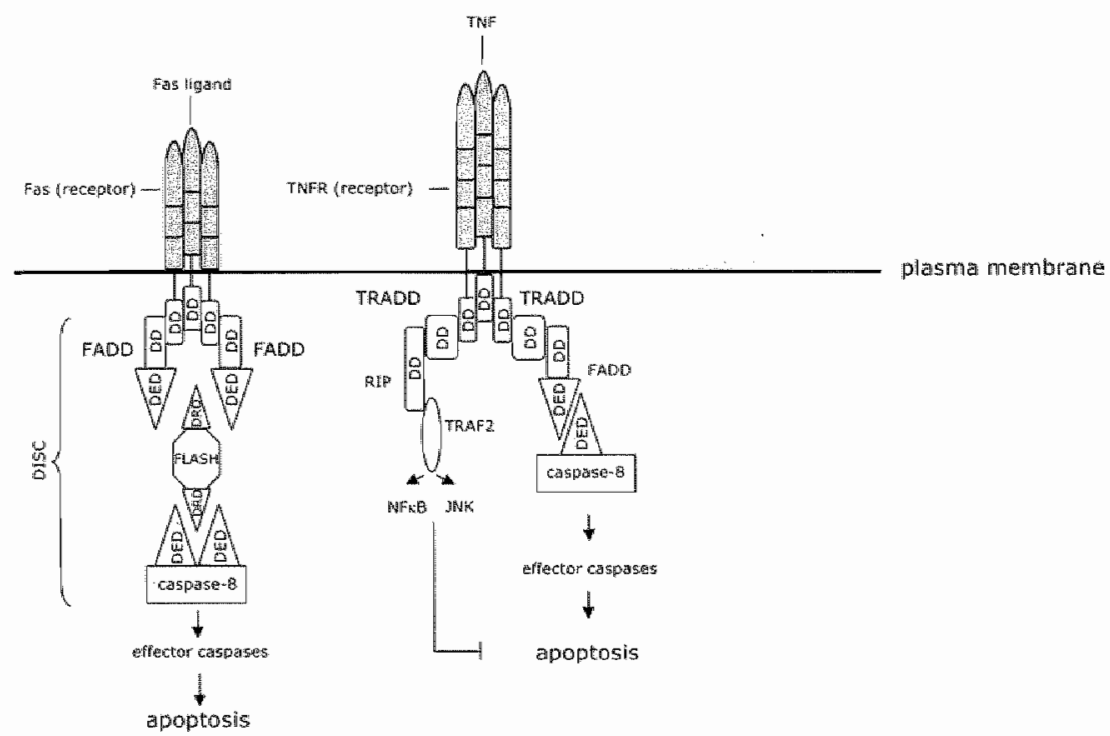

Figure 2.4. Death receptor mediated apoptosis (adapted from Ashkenazi and Dixit, 1998).

The TNF signaling pathway is used by activated macrophages and T cells in response to infection (Ashkenazi and Dixit, 1998). TNF activates the transcription factors $N F-k B$ and $A P-1$, leading to induction of proinflammatory and immunomodulatory genes. TNF trimerizes TNFR upon binding and after association of the receptor's DD, an adaptor molecule called TRADD (TNFRassociated death domain) binds via it's own DD and recruits several signaling molecules to the activated receptor (see figure 2.4 ).

Binding of FADD to TRADD leads to apoptosis, whille binding of RIP to TRADD leads to activation of the NF-KB or JNK-AP1 pathway, and thus to survival of the cell. 


\section{Mitochondrion/Bcl-2 mediated apoptosis}

Various forms of cellular stress can trigger release of apoptogenic factors from mitochondria (Green, 1998; Green and Reed, 1998). These apoptogenic factors include apoptosis-inducing factor (AIF), cytochrome $C$ and the procaspases-2, -3 and -9 . (Susin et al., 1999a; Susin et al., 1999b; Manicini et al., 1998). In healthy cells, these proteins are stored in the mitochondrial intermembrane space where cytochrome $C$ and the flavoprotein AIF function as electron transfer proteins. When a cell receives an apoptotic stimulus, the mitochondrion releases these factors into the cytosol where they function as apoptogenic agents. Cytochrome $C$ is part of the apoptosome, which additionally comprises Apaf-1, UATP, and procaspase-9. Apaf-1 is activated by dATP and cytochrome $C$ and activates caspase-9, which then processes and activates caspase- 3 (see figure 2.5).

The primary translation product of AIF is not apoptogenic, however, after transport into the mitochondria, the folding of AIF makes it apoptogenic. After release from the mitochondria, AIF travels to and accumulates in the nucleus, where it induces chromatin condensation and high molecular weight DNA fragmentation. Furthermore, AIF induces cytochrome $C$ release when injected into the cytoplasm of cells (Susin et al., 1999a). Release of these proteins from the mitochondria is inhibited by $\mathrm{Bcl}-2$ (see figure 2.5) (Green and Reed, 1998).

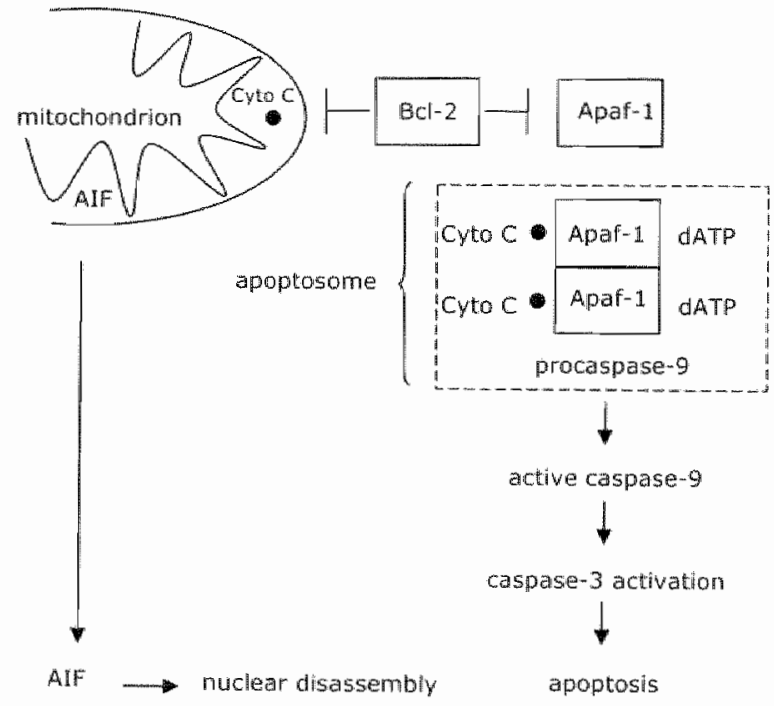

Figure 2.5. Model of mitachondria/Bcl-2 mediated apoptosis. Release of cytochrome C and A.IF from the mitochondria into the cytosol leads to apoptosome formation and subsequent activation of caspase-9 and nuclear disassembly, respectively. Bcl-2 can interfere in apoptosome formation by blocking cytochrome $C$ release from mitochondria and by directly inhibiting Apaf-1. 
Two general mechanisms for release of apoptogenic factors from the mitochondria have been proposed. The first mechanism is that the mitochondrial megachannel (also called permeability transition pore), a complex composed of inner and outer membrane proteins at the contact sites between the inner and outer membrane, is opened. These protens create a channel through which molecules $\leq 1.5 \mathrm{kD}$ can pass.

Opening of this channel leads to the distuption of the inner transmembrane potential ( $\Delta y m$ ) and release of apoptogenic proteins into the cytosol (Green and Kroemer, 1998). However, other investigators observed that cytochrome $C$ release from mitochondria does not require a mitochondrial transmembrane depolarization and suggest that cytochrome $C$ release and loss of mitochondrial transmembrane potential are separate events (Bossy-Wetzel et al., 1998; Yang et al., 1997).

The second mechanism is disturbance of the osmotic equilibrium in the mitochondrion, which leads to expansion of the mitochondrial matrix space, organelle swelling and rupture of the outer mitochondrial membrane. This membrane rupture also releases apoptogenic proteins into the cytoplasm (Reed et al., 1998).

\section{Granzyme-mediated apoptosis}

Cytotoxic $T$ lymphocytes (CTL) can use an alternative route to trigger the apoptotic pathway in virus infected and tumor cells. This route involves enzymes secreted from granules in the cytoplasm of the CTL. These granules are secreted into the intercellular space between target cell and effector cell. The granule is a secretory Iysosome, containing lysosomal and secretory proteins including perforin and granzymes.

Perforin is the granule protein responsible for lytic activity of the $\mathrm{CTL}$. Exocytosis of the granule releases perforin into the extracellular space and after binding to the target cell, perforin monomers aggregate into pore structures and insert into the target cell lipid bilayer. Perforin itself can induce lysis in the target cells, however the primary role of perforin is to allow other granule proteins to enter this cell. Amongst these granule proteins are granzymes, CTL specific serine proteases. These enzymes can cleave and activate their substrates, including caspase-3, $-6,-7,-8,-9$ and -10 , to initiate the apoptotic pathway (Darmon et al., 1998).

\section{PML-mediated apoptosis}

Very recently, a novel route of apoptosis induction, namely by PML nuclear bodies, has been described (Wang et al., 1998; Quignon et al., 1998). The acute promyelocytic leukaemia (PML) gene encodes a tumor suppressor protein. PML is a nuclear matrix-associated protein, located in the periphery of nuclear bodies. It regulates transcription and plays a role in cell cycle control (Hess and Korsmeyer, 1998).

Quignon et al. (1998) reported that PML overexpression induces caspaseindependent cell death in cell lines, while wang and cowarkers (1998) showed caspase-dependent, PML-induced apoptosis in response to Fas and TNF in mice (Quignon et al., 1998; Wang et al., 1998).

\section{Crosstalk between the different apoptosis induction pathways}

Different pathways are involved in regulation of cell death and there is evidence for crosstalk between these different apoptosis induction routes. 
Caspases themselves can cause a disruption of the mitochondrial inner transmembrane potential and can cause inner membrane proteins, including cytochrome $C$ and AIF, to be released (Green and Kroemer, 1998). Furthermore, Bid, an apoptosis promoter from the BCl-2 family, is cleaved by caspase- 8 in response to Fas signaling. After cleavage, the C-terminal fragment of Bid binds to mitochondria, which leads to release of cytochrome C (Dragovich et al., 1998).

\subsection{The game}

Once the apoptosis pathway is actiwated, the game has begun and the cell undergoes characteristic morphological changes such as loss of contact with neighboring cells, cell shrinkage, membrane budding, chromatin condensation and DNA fragmentation. These alterations are due to proteolysis, reorganization and modifications of structural proteins, condensation and fragmentation of DNA, and alterations in the plasma membrane.

\section{Cytoskeletal changes}

The morphological changes of an apoptotic cell are, amongst others, the result of a dramatic reorganization of the cytoskeleton of the dying cell. Therefore, it is not surprising that many of the cytoskeletal components themselves are targets for the caspase family of proteases. However, in addition to caspase cleavage, also post-translational modifications of these proteins, such as phosphorylation, cross-linking and citrullination are reported to contribute to reorganization and modification of cytoskeletal proteins during apoptosis (Utz and Anderson, 1998).

Reorganization of the microfilament network is involved in membrane budding during apoptosis. F-actin, present at the base of the buds during apoptosis (Laster and Mackenzie, 1996; Pitzer et al., 1996; Vemuri et al., 1996), is necessary for formation of apoptotic bodies (Cotter et all., 1992; Levee et al., 1996). Whether actin itself is a direct target for caspases remains elusive. Several groups have proposed that actin is cleaved by caspases during apoptosis (Mashima et al., 1995; Kayalar et al., 1996; McCarthy et al., 1997; Yang et al., 1998). However, Brown and co-workers (1997) reported that in membrane-associated actin, a component of the cytoskeleton that links polymerized actin to the plasma membrane, cleavage occurred at a site devoid of a caspases cleavage site. Song and co-workers (1997) reported protection of actin for proteolysis in vivo. Loss of contacts between nelighboring cells is caused by disassembly of the cytoskeletal organization at the level of cell-cell adheslon sites. In fact, $\beta$-catenin, a known regulator of cell-cell adhesion, is proteolytically processed after induction of apoptosis. $\beta$-catenim cleavage by caspase-3 removes the amino- and carboxy-terminal regions of the protein. The resulting $\beta$-catenin product is unable to bind $\alpha$-catenin that is responsible for actin filament binding and organization (Brancolini et al., 1997). Also cleavage of gelsolin (Kothakota et al., 1997) may be a physiological effector of morphological changes during apoptosis. The function of gelsolin is to bind barbed ends of actin monomers to prevent monomer exchange. Expression of the gelsolin cleavage product in multiple cell types caused the cells to round up, detach from the substratum, and undergo nuclear fragmentation (Kothakota et al., 1997). 
Reorganization of tubulin is an integral part of the apoptotic process, (Pittman et al., 1994). During apoptosis tubulin is reorganized into visible polymerized structures (van Engeland et al., 1997), which display characteristics similar to those observed following treatment with drugs that do interact directly with tubulin (Ireland and Pittman, 1995). Disruption of the microtubule architecture might influence signaling cascades. Recent studies by Blagosklonny et al. (1997) have shown that disruption of microtubular architecture leads to Raf-1. activation and bcl-2 phosphorylation, serving a role similar to p53 induction following DNA damage.

Cytokeratins, the intermediate flament proteins of epithelial cells, are necessary for structural support of cells. During apoptosis, cytokeratin and vimentin filaments reorganize into granular structures (van Engeland et al., 1997; Tinnemans et al., 1995; Caulin et al., 1997; Leers et al., 1999). This process seems to be governed mainly by (hyper)phosphorylation of the cytokeratins during apoptosis (Liao et al., 1997). Furthermore, it has been shown that phosphorylation and de-phosphorylation events also critically control cell junction assembly and stability and also regulate the formation of the cadherincytoskeleton complex (Serres et al., 1997; Aberle et al., 1997), thus influencing the adhesive properties of cells.

Recently Caulin et al. (1997) and Leers et al. (1999) showed that cytokeratin intermediate filament proteins are cleaved by caspases during apoptosis. A conserved caspase- 6 motif is found in the linker region of all intermediate filament proteins, except for the type II cytokeratins. Cytokeratin 18 has an additional caspase cleavage site at the C-terminus, as was suggested by Caulin et al. (1997) and recently identified as the DALD motif by Leers et al. (1999). The functional significance of the coordinated breakdown of the cytokeratins remains unknown, although Caulin et al. (1997) suggest that proteolytic cleavage of these intermediate filaments, which are highly polymerized and are relatively insoluble in normal aqueous solutions, is necessary for the formation of apoptotic bodies.

\section{Nuclear alterations}

The nucleus undergoes dramatic changes during apoptosis (Earnshaw, 1995). Although variations in ultrastructure can occur between different model systems, many consistent changes cam be observed. The chromatin condenses at the nuclear periphery and finally micronuclei are formed. Furthermore, nuclear pores redistribute into clusters (Falcieri et al ", 1994; Relpert et al., 1996).

Fragmentation of DNA is a biachemical hallmark of apoptosis in many cell lines and tissues. Three types of DNA fragmentation can be distinguished: 1) internucleosomal DNA fragmentation, 2) fragmentation into large, 50-300 kbp fragments and 3) single strand cleavage (Bortner et al., 1995). Internucleosomal DNA fragmentation occurs by activation of an endogenous endonuclease that cleaves DNA in the linker region between the histones. However, in some cell types internucleosomal DNA cleavage cannot be detected. The formation of large DNA fragments $(50-300 \mathrm{kbp})$ occurs in all apoptosis model systems, either in the presence or in the absence of oligonucleosomal DNA fragmentation. The size of these large fragments correlates with the size of chromosomal DNA loops (Fillipski et al., 1990; 
Lagarkova et al., 1995) which are attached to the nuclear scaffold at matrix attachment regions (MARs) or scaffold attachments regions (SARs).

Various nucleases, such as DNAse I, DNAse II, L-DNAse II, DNAse $\gamma$, a $97 \mathrm{kD}$ DNAse, cyclophilins and endo-exonucleases have been proposed to be responsible for DNA degradation during apoptosis (Peitsch et al. 1993; Barry and Eastman, 1993; Torriglia et al., 1998; Montague et al., 1997; Pandey et al., 1997; Shiokawa et al., 1994; Fraser et al., 1996).

Recently, Eneri et al. (1998) identified a caspase-activated DNase (CAD) in mouse cells. In non-apoptotic cells CAD is present in the cytosol in a complex with ICAD (inhibitor of caspase activated DNAse) (Sakahira et al., 1998). After induction of apoptosis, ICAD is cleaved by caspase-3 and CAD is able to degrade genomic DNA into oligonucleosomal fragments. The large splice form of ICAD, ICAD-L appears to be homologues with human DFF45, a factor isolated from HeLa cytosol (Liu et al., 1997). DFF (DNA fragmentation factor) is a heterodimer of a $40 \mathrm{kD}$ (DFF40) and $45 \mathrm{kD}$ subunit (DFF 45 ). DFF 45 is cleaved by caspase- 3 to generate an active factor that produces DNA fragmentation. DFF40 itself has no DNAse activity, therefore it is likely that DFF40 activates a nuclease which is present in nuclei, while CAD can cleave chromosomal DNA by itself (Enari et al., 1998; Liu et al., 1997). Controversy exists about the nature of fragmented DNA. Moore et al. (1993) cloned mononucleosomal fragments from a murine myeloid cell line undergoing apoptosis and found no sequence homology between the cloned fragments. In addition, they found no preference for transcribed versus non transcribed DNA. Arends et al. (1990) reported that free chromatin in apoptotic cells shows features of chromatin in an active configuration, which is also confirmed by Chen et al. (1998). However, Vodenicharow and colleagues (1996) reported that heterochromatin sequences are preferentially degraded during apoptosis.

The nuclear matrix, i.e., the structure that remains following high-salt extraction of DNAse and RNAse treated nuclei, and consists of residual nucleoli, a nuclear pore-lamina complex and an internal nuclear matrix of proteins (Berezney et al., 1995), also undergoes dramatic changes (for review see Martelli et al., 1997). Nuclear matrix proteins such as DNA topoisomerase I and II, poly(ADP-ribose) polymerase (PARP), 70 kD $U_{1}$-snRNP and NuMA are proteolysed and redistributed during apoptosis (Tinnemans et al., 1995, Gueth-Hallonet et al., 1997; Casiano et al., 1996). Of the nuclear proteins cleaved during apoptosis, several appear to be involved in DNA-repair processes and in maintaining the proper conformation of chromatin through interactions with the nuclear matrix. Cleavage and reorganization of these proteins may contribute to the collapse of the nucleus in apoptosis. For example, proteolysis of lamin proteins facilitates nuclear disassembly (Rao et al., 1996). Lamins are intermediate filament proteins, which form a lamina underlying the inner nuclear membrane. Lamins have been shown to stabilize the nuclear envelope and to participate in determining the organization of the interphase nucleus (Moir and Goldman, 1993).

Two subtypes of lamins can be distinguished, i.e. the A-type lamins, which comprise lamin $\mathrm{A}$ and lamin $\mathrm{C}$, and the B-type lamins which comprise lamin B1 and lamin B2 (Moir et al., 1995). During apoptosis lamins are cleaved by caspase-6 at a conserved VEID (A-type lamins) or VEVD (B-type lamins) amino
acid sequence (Rao et al, 1996 ). 


\section{Membrane changes}

When the dying cell is packaged into apoptotic bodies, it's fate in wivo is uptake and degradation by phagocytes. This clearance is fast, efficient and injury limiting, and is mediated by professional (macrophages) and semim professional (neighboring cells) phagocytes (Savill, 1997).

In normal epithelia, neighboring cells of the same lineage are capable of efficiently ingesting apoptotic epithelial cells (Savill et al., 1993; Savill, 1997; Hart et al., 1996; Platt et al., 1998). The speed of the phagocytic clearance argues that phagocytosis of apoptotic cells is an efficient means of elimimating unwanted cells. Phagocytes can recognize not only intact apoptotic cells but also apoptotic bodies detached during the process of budding. Failure to clear apoptotic cells may result in swelling and disintegration of cells and release of packets of autoantigen from disintegrating non-ingested apoptotic bodies, thereby eliciting an immune response to self-components of the cell.

The surface of normal cells differs from the surface of cells undergoing apoptosis and it is thought that 'eat me' signals are derived from modifications of existing plasma membrane components (Ren and Savill, 1998). One of these alterations is the exposure of the phospholipid phosphatidylserine (PS) at the outer plasma membrane leaflet. In non-apoptotic cells, the phospholipids of the plasma membrane are distributed asymmetrically. The choline-containing lipids, such as phosphatidylcholine and sphingomyelin, are concentrated at the outer leaflet, whereas the aminophospholipids phosphatidylethanolamine and PS are present at the inner membrane leaflet. During apoptosis PS is translocated from the inner to the outer plasma membrane leaflet and serves as a trigger for macrophages to remove the dying cell (Fadok et al., 1998). Furthermore, loss of sialic acids from membrame carbohydrates (Duvall et al., 1985) and membrane protein cross-linking by tissue transglutaminase (Fesus et al., 1989) has been reported.

The phagocytes taking up apoptotic cells employ receptors an thelr plasma membrane to recognize the "eat me' signals on the apoptotic cell. These receptors include lectins, the thrombospondin receptors CD $36, \alpha_{4} \beta_{3,}$ a not yet characterized PS receptor, scavenger receptors and the murine macrophage ABC-1 molecule, the $C$. Elegans CED-7 homologue (Savill, 1997). Internalized apoptotic material might be extensively degraded and directed to a salvage pathway or in case of virally infected apoptotic cells, presented in the context of $M H \mathrm{HC}$ for recognition by CTLS (Platt et al., 1998).

\subsection{Part of the apoptotic cascade is used during cytosolic and nuclear remodeling}

It is known that caspase-1, $-4,-5,-11$ are primarly involved in procytokine activation (Salvesen and Dixit, 1997). However, recently also novel functions for the executioner caspases have been reported in addition to their role in apoptosis.

Caspase-3 activation is reported in activated T-cells and activated platelets (Miossec et al., 1997; Shcherbina and Remold-O'Donnell, 1999). In activated platelets, caspase-3 seems to play a role during events inwolved in the generation of procoagulant surfaces, such as PS exposure, microparticle release and cleavage of maesin, a cytaskeleton-membrane linker protein. 
Furthermore, Braun et al. (1999) showed that caspase inhibition during acute bacterial meningitis in rabbits inhibits migration of leukocytes to inflammatory reglons, indicating that caspase activation is involved in cell migration.

In addition to platelet activation and cell migration, caspase activation is reported during cell spreading (Watanabe et al., 1999), also indicating that caspase cleavage is necessary during cytoskeletal remodeling.

Furthermore, nuclear remodeling can occur in differentiation processes. Modak et al. (Modak and Perdue, 1970; Appleby and Modak; 1977) report nuclear changes in differentiating chicken lens fiber cells that resemble the morphological changes seen during programmed cell death. Furthermore, TUNEL-positive, differentiating lens cells are observed (Ishizaki et al., 1998; Bassnett and Mataic, 1997). During terminal differentiation of human epidermal keratinocytes, caspase activation also seems to be required for elimination of the nucleus (Weil et al., 1999). Programmed DNA elimination also occurs during cellular conjugation in the sexual pathway of ciliated protozoa, such as Tetrahymena thermophila. During conjugation, an undifferentiated zygotic nucleus gives rise to two distinct nuclei. One nucleus is eliminated by nuclear apoptosis, while the other nucleus undergoes extensive elimination of heterochromatic, repetitive DNA (Madireddi et al., 1996). In this way, a nucleus specialized in efficient gene expression benefits from removal of heterochromatin. This part of the genome often has a negative effect on transcription (Madireddi et al., 1996).

These observations indicate that part of the apoptosis machinery can be used during nuclear and cytoskeletal remodeling, while initiation of parallel degradation routes is prevented. However, when part of the apoptosis machinery is used during remodeling, caspase activity should be strictly regulated.

Caspase activity can be regulated by post-translational modifications of the enzyme itself. Cardone et al. (1998) recently described caspase inactivation through phosphorylation of procaspase-9. Phosphorylated procaspase-9 is resistant to cytochrome $c$ induced processing. Furthermore, caspase-3 zymogens are found to be inactivated by S-nitrosylation (Mannick et al., 1999). Denitrosylation of the cysteine residue in the catalytic site is associlated with increased caspase-3 activity after Fas induction of apoptosis.

In addition, caspase substrates may be protected from cleavage by posttranslational modifications or by interactions with other cellular constituents. In this context, it should be mentioned that the IAP survivim is expressed in the G2/M phase of the cell cycle, where it associates with microtubules in the mitotic spindle (Li et al., 1998b). Survivin inhibits caspase-3 and caspase-7 and dissociation of the interaction between survivin and microtubules results in increased caspase-3 activity ( $\mathrm{Li}$ et al., 1998b). This may suggest a role for survivin in protection of microtubuli or microtubule-associated proteins from caspase cleavage during cytoskeletal remodeling in the $G 2 / M$ phase of the cell cycle.

The existence of cellular IAP's, such as survivin, points to a highly controlled mechanism of protein degradation, not only during apoptosis but also during
other cellular processes. 


\subsection{The winner is}

The apoptosis machinery is present in every healthy cell and can be activated when necessary. Inappropriate regulation of the apoptotic machinery is associated with many diseases. Decreased apoptosis is associated with cancer, while increased apoptosis contributes to neurodegenerative disorders. Part of the apoptotic machinery can be used during differentiation, cell migration or cell division. In this way, rigid structures such as cyto- and nucleoskeletal filaments can be modified, thereby enhancing the cell's flexibility. Thus, when apoptosis and remodeling are regulated properly, the organism is the winner of this 'deadly game'.

\subsection{References}

- Aberle, H., Bauer, A., Stappert, J., Kispert, A. and Kemler, R. 1997. Beta-catenin is a target for the ubiquitin-proteasome pathway. EMBO J. 16:3797-3804.

- Adams, J.M. and Cory, S. 1998. The Bcl-2 protein family: arbiters of cell survival. Science $208: 1322-1326$.

- Ainemri, E.S., Livingston, D.J., Nicholson, D.W., Salvesen, G., Thomberry, N.A., Wong, W.W. and Yuan, J. 1996. Human ICE/CED-3 protease nomenclature. Cell 87:171.

- Ambrosini, G., Adida, C. and Altieri, D.C. 1997. A novel anti-apoptosis gene, survivin, expressed in cancer and lymphoma. Nat. Med. 3:917-921.

- Appleby, D.W. and Modak, S.P. 1977. DNA degradation in terminally differentiating lens fiber cells from chick embryos. Proc. Natl. Acad. Sci. USA. 74:5579-5583.

- Arends, M.J., Morris, R.G. and Wyllie, A.H. 1990. Apoptosis: the role of the endonuclease. Am. J. Pathol. 136:593-608.

- Ashkenazi, A. and Dixit, V.M. 1998. Death receptors: signaling and modulation. Science 281:1305-1308.

- Barry, M.A. and Eastman, A. 1993. Identification of deoxyribonuclease II as an endonuclease involved in apoptosis. Arch. Biochem. Biophys. 300:440-450.

- Bassnett, S. and Mataic, D. 1997. Chromatin degradation in differentiating fiber cells of the eve lens. J. Cell Biol. 137:37-49.

- Berezney, R., Mortillaro, M.J., Ma, H., Wei, X. and Samarabandu, J. 1995. The nuclear matrix: a structural millieu for genome function. Int. Rev. Cytol. 162A:1-65.

- Bergmann, A., Agapite, J. and Steller, H. 1998. Mechanisms and control of programmed cell death in invertebrates. Oncogene 17:3215-3223.

- Bird, P.I. 1998. Serpins and the regulation of cell death. Results Probl. Cell Differ. 24: 63-89.

- Blagosklonny, M.V., Giannakakou, P., el-Deiry, W.S. Kingston, D.G., Higgs, P.I., Neckers, L. and Fojo, T. 1997. Raf-1/bcl-2 phosphorylation: a step from microtubule damage to cell death. Cancer Res. 57:130-135.

- Boldin, M.P., Goncharov, T.M., Goltsev, Y.V. and Wallach, D. 1996. Involvement of MACH, a nowel MORT1/FADD-interacting protease, in Fas/Apo-1- and TNF-receptorinduced cell death. Cell 85:803-815.

- Bortner C., Oldenburg, N.B.E. and Cidlowski ${ }_{r}$ J.A. 1995. The role of DNA fragmentation in apoptosis. Trends Cell Biol. 5:21-26.

- Bossy-Wetzel, E., Newmeyer, D.D. and Green, D.R. 1998. Mitochondrial cytochrome C release in apoptosis occurs upstream of DEVD-specific caspase activation and independently of mitochondrial transmembrane depolarization. EMBO J. 17:37-49.

- Brancolini, C., Lazarevic, D., Rodriquez, J. and Schneider, C. 1997. Dismantling cell-cell contacts during apoptosis is coupled to a caspase-dependent proteolytic cleavage of beta.catenin. J. Cell Biol. 139:759-771.

- Braun, J.S., Novak, R., Herzog, K.H., Bodner, S.M., Cleveland, J.L. and Tuomanen, E.I. 1999. Neuroprotection by a caspase inhibitor in acute bacterial meningitis. Nat. Med. 5:298-302. 
- Brown, S.B., Bailey, K. and Savill, J. 1997. Actin is cleaved during constitutive apoptosis. Biochem. J. 323:233-237.

- Casiano, C.A., Martir, S.J., Green, D.R. and Tan, E.M. 1996. Selective deavage of nuclear autoantigens during CD95 (Fas/APO-1)-mediated $T$ cell apoptasis. 1. Exp. Med. 184:765-770.

- Cardone, M.H. Roy, N., Stennicke, H.R., Salvesen, G.S., Franke, T.F., Stanbridge, E., Frisch, 5. and Reed, J.C. 1998 . Regulation of cell death protease caspase-9 by phosphorylation. Science 282:1318-1321.

- Caulin, C., Salvesen, G.S. and Oshima, R.G. 1997. Caspase cleavage of keratin 18 and reorganization of intermediate filaments during epithelial cell apoptosis. J. Cell Biol. $138: 1379-1394$.

- Chen, D.L., Swe, M. and Sit, K.H. 1998. Guband expression and megabase fragmentations in apoptosis. Exp. Cell Res. 240:293-304.

- Chou, J.J., Li, H., Salvesen, G.S., Ywan, J. and Wagner, G. 1999. Solution structure of BID, an intracellular amplifier of apoptotic signaling. Cell $96: 615-624$.

- Conradt, B. and Horvitz, H.R. 1998. The C. elegans protein EGL-1 is required for programmed cell death and interacts with the Bcl-2-like protein CED-9. Celf 93:519529.

- Cotter, T.G., Lennon, S.V., Glynn, J.M. and Green, D.R. 1992. Microfilament-disrupting agents prewent the formation of apoptotic bodies in tumor cells undergoing apoptosis. Cancer Res. 52:997-1005.

- Cryns, V.L. and Yuan, J. 1998a. Proteases to die for. Genes Dev. 12: 1551-1570.

- Cryns, V.L. and Yuam, J. 1998b. The cutting edge: caspases in apoptosis and disease. In When cells die. Lockshin, R.A., Zakkeri, Z. and Tilly, J. editors. (New York: Willey-Liss) pp. $177-210$.

- Darmon, A.J., Pinkoski, M.J. and Bleackley, R.C. 1998. Granule-mediated cytotoxicity. Results Probl. Cell Differ. 23:103-125.

- Dorstyn, L., Kinoshita, M. and Kumar, 5. 1998. Caspases in cell death. Results Prob/. Cell Differ. 24:1-24.

- Dragowich, T., Rudin, C.M. and Thompson, C.B. 1998. Signal transduction pathways that regulate cell survival and cell death. Oncogene 17:3207-3213.

- Duvall, E., Wyllie, A.H. and Morris, R.G. 1985. Macrophage recognition of cells undergoing programmed cell death (apoptosis). Immunol. 56:351-358.

- Eamshaw, W.C. 1995. Nuclear changes in apoptosis. Curr. Opin. Cell Biol. 7:337-343.

- Ellis, R.E., Jacobson, D.M. and Horvitz, H.R. 1991. Genes required for the engulfment of cell corpses during programmed cell death in Caenorhabditis elegans. Genetics 129:7994.

- Enari, M., Sakahira, H., Yokomaya, H., Okawa, K., Iwamatsu, A. and Nagata, 5. 1998. A caspase-activated DNAse that degrades DNA during apoptosis, and its inhibitor CAD. Nature 391:43-50.

- van Engeland, M., Kuijpers, H.J.H. Ramaekers, F.C.S., Reutelingsperger, C.P.M. and Schutte, B. 1997. Plasma membiane alterations and cytoskeletal changes in apoptosis. Exp. Cell Res. 235:421-430.

- Fadok, V.A., Bratton, D.L., Courtney-Frasch, S., Warner, M.L. and Henson, P.M. 1998. The role of phosphatidy/serine in recognition of apoptotic cells by phagocytes. Cell Death Differ. 5:551-562.

- Falcieri, E., Gobbi, P., Cataldi, A., Zamai, L., Faenza, I., and Vitale, M. 1994. Nuclear pores in the apoptotic cell. Histochem. J. 26:754-63.

- Fesus, L., Thomazy, V., Autuori, F., Ceru, M.P., Tarsca, E. and Piacentini, M. 1989. Apoptotic hepatocytes become insoluble in detergents and chaotropic agents as a result of transgluatminase action. FEBS Lett. 245:150-154.

- Filipski, J., Leblanc, 1., Youdale, T., Sikorska, M. and Walker P.R. 1990. Periodicity of DNA folding in higher order chromatin structures. EMBO J. 9:1319-1327.

- Fraser, A. and Evan, G. 1996. A license to kill. Cell 85:781-784.

- Fraser, M.J., Tymam, S.J., Papaioannou, A., Ireland, C.M. and Pittman, S.M. 1996. Endo-exonuclease of human leukaemic cells: evidence for a role in apoptosis. $\mathrm{J}$. Cell Sci. $109: 2343-2360$. 
- Gartner, A. and Hengartner, M.O. 1998. Genetic approaches to programmed cell death in C. elegans. In When cells die. Lockshin, R.A., Zakeri, Z, and Tilly, J. editors. (New York: Wiley-Liss) pp. 131-146.

- Green, D.R. 1998. Apoptotic pathways: the roads to ruin. Cell 94:695-698.

- Green, D.R. and Kraemer, G. 1998. The central executioners of apoptosis: caspases or mitochondria? Trends Cell Bial. 8:267-271.

- Green, D.R. and Reed, J.C. 1998. Mitochondria and apoptosis. Science 281: 1309-1312.

- Gueth-Hallonet, C. Weber, K. and Osborn, M. 1997. Cleavage of the nuclear matrix protein NuMA during apoptosis. Exp. Cell Res. 233:21-24.

- Hart, S.P., Haslett, C. and Dransfield, I. 1996. Recognition of apoptotic cells by phagocytes. Experientia. 52:950-956.

- Hedgecock, E.M., Sulston, J.E. and Thomson J.N. 1983. Mutations affecting programmed cell death in the nematode Caenorhabditis Elegans. Science 220:1277-1279.

- Hengartner, M.O. and Horvitz, H.R. 1994. C. elegans cell survival gene ced-9 encodes a functional homologue of the mammalian protooncogene $b c /-2$. Cell $76: 665 \sim 676$.

- Hess, J.L. and Korsmeyer, S.J. 1998. Life, death and nuclear spots. Nat. Gen. 20:220 222.

- Imai, Y., Kimura, T., Murakami, A., Yajima, N., Sakamaki, K. and Yonehara, S. 1999. The CED-4-homologous protein FLASH is involved in Fas-mediated activation of caspase8 during apoptosis. Nature 398:777-784.

- Ireland, C.M. and Pittman, S.M. 1995. Tubulin alterations in taxol-induced apoptosis parallel those obserwed with other drugs. 1995. Biochem. Pharmacol. 49:1491-1499.

- Ishizaki, Y., Jacobson, M.D. and Raff, M.C. 1998. A role for caspases in lens fiber differentiation. J. Cell Biol. 140:153-158.

- Kayalar, C., Ord, T., Testa, M.P. Zhong, L.T. and Bredesen, D.E. 1996. Cleavage of actin by interleukin 1 beta-converting enzyme to reverse DNase I inhibition. Proc. Nath. ACad. SCi. USA, 93:2234-2238.

- Kekelar, A. and Thompson, C.B. 1998. Bci-2-family proteins: the role of the BH3 domain in apoptosis. Trends Cell Bial. 8:324-330.

- Kothakota, S., Azuma, T., Reinhard, C., Klippel, A., Tang, J., Chu, K., McGarry, T.J., Kirschner, M.W., Koths, K., Kwiatkowski, D.J. and Willams, L.T. 1997. Caspase-3generated fragment of gelsolin: effector of morphological change in apoptosis. Science 278:294-298.

- Kroemer, G. 1997. The proto-oncogene Bcl-2 and its role in regulating apoptosis. Nat. Med. 3:614-620.

* Lagarkova, M.A., Iarovaia, O.V. and Razin, S.V. 1995. Large scale fragmentation of mammalian DNA in the course of apoptosis preceeds via excision of chromosomal DNA loops and their oligomers. J. Biol. Chem. 270:20239-20141.

- Laster S.M. and Mackenzie, J.M. 1996. Bleb formation and F-actin distribution during initosis and tumor necrosis factor-induced apoptosis. Microsc. Res. Tech. 34:272-280.

- Leers, M.P.G., Kölgen, W., Björkliund, V., Bergman, T., Tribbick, G., Persson, B., Björklund, P., Ramaekers, F.C.S., Björklund, B., Nap, M., Jönvall, H. and Schutte, B. 1999. Immunocytochemical detection and mapping of a cytokeratin 18 neo-epitope exposed during early apoptosis. J. Pathol. 187:567:572.

- Levee, M.G., Dabrowska, M.I., Lelli, J.L. and Hinshaw, D.B. 1996. Actin polymerization and depolymerization during apoptosis in HL-60 cells. Am. J. Physiol. 271:C1981-C1992.

- Li, P., Nijhawan, D. Budihardjo, I., Srinivasula, S.M., Ahmad, M., Alnemri, E.S. and Wang, $X$. 1997. Cytochrome $C$ and dATP-dependent formation of Apaf-1/Caspase-9 complex initiates an apoptotic protease cascade. Cell $91: 479-489$

- Li, H., Zhu, H., XU, C.J. and Yuan, J. 1998a. Cleavage of BID by caspase 8 mediates the mitochondrial damage in the Fas pathway of apoptosis. Cell 94:491-501.

- Li, F., Ambrosini, G., Chu, E.Y., Plescia, J., Tognin, S., Marchisio, P.C. and Altieri, D.C. 1998 b. Control of apoptosis and mitatic spindle checkpoint by survivin. Nature 396:580-583.

- Liao, J., Ku, N.O. and Omary. M.B. 1997. Stress, apoptosis and mitosis induce phosphorylation of human keratin 8 at Ser-73 in tissues and cultured cells. 1. Biol. chem. 272:17565-17573. 
- Liu, X., Zou, H., Slaughter, C. and Wang, X. 1997. DFF, a heterodimeric protein that functions downstream of caspase-3 to trigger DNA fragmentation during apoptosis. Cell $89: 175-184$

- Madireddi, M.T., Coyne, R. S., Smothers, J.F., Mickey, K.M., Yao, M. C. and Allis, C.D. 1996. Pdd1p, a novel chromodomain-containing protein, links heterochromatin assembly and DNA elimination in tetrahymena. Cell 87:75-84.

- Mancini, M., Nicholson, D.W., Roy, S., Thornberry, N.A., Peterson, E.P., CasclalaRosen, L.A. and Rosen, A. 1998. The caspase-3 precursor has a cytosolic and mitochondrial distribution: implications for apoptotic signaling. J. Cell Biol. 140:14851.495.

- Mannick, J.B., Hausiaden, A., Liu, L., Mess, D.T., Zeng, M., Miao, Q. X., Kane, L.S., Gow, A.J., Stamler, J.S. 1999. Fas-induced caspase denitrosylation. Science 284:651654 .

- Martelli, A.M., Bareggi, R., Bortul, R., Grill, V., Narducci, P. and Zweyer, M. 1997. The nuclear matrix and apoptosis. Histochem. Cell Biol. 108:1-10.

- Mashima, T., Naito, M., Fujita, N., Naguchi, K. and Tsurwo, T. 1995. Identification of actin as a substrate of ICE and an ICE-like protease and involvement of an ICE-like protease but not ICE in VP-16-induced U937 apoptosis. Biochem. Biophys. Res. Comm. 217:1185-1192.

- MCCarthy, N.J., Whyte, M.K.B., Gibert, C.S. and Evan, G.I. 1997. Inhibition of Ced3 /ICE-related proteases does not prevent cell death induced by oncogenes, DNA damage, or the Bcl-2 homologue Bak. J. Cell Biol. 136:215-227.

- McDonnell, J.M., Fushman, D., Milliman, C.L., Korsmeyer, S.J. and Cowburn, D. 1999. Solution structure of the proapoptotic molecule BID: a structural basis for apoptotic agonists and antagonists. Cell 96:625-634.

- Medema, J.P., Scaffidi, C., Kischkel F.C., Shevchenko, A., Mann, M. Krammer, P.H. and Peter, M.E. 1997. FLICE is activated by association with the CD95 death-inducing signalling complex (D1SC). EMBO J. 16:2794-2804.

- Metzstein, M.M., Stanfield, G.M. and Horvitz, H.R. 1998. Genetics of programmed cel death in C. Elegans: past, present and future. Trends Genet. 14:410-416.

- Miossec, C., Dutilleul, V., Fassy, F. and Diu-Hercend, A. 1997. Evidence for CPP32 activation in the absence of apoptosis during T-lymphocyte stimulation. J. Biol. Chem. 272: $13459-13462$.

- Modak, S.P. and Perdue, S.W. 1970. Terminal lens cell differentiation. Histological and microspectrophotometric analysis of nuclear degradation. Exp. Cell Res. 59:4356.

- Moir, R.D. and Goldman, R.D. 1993. Lamin dynamics. Curr. Opin. Cell Biol. 5:408-411.

- Moir, R.D., Spann, T.P. and Goldman, R.D. 1995. The dynamic properties and possible functions of nuclear lamins. Int. Rev. Cyt. 162B: 141-182.

- Montague, J.W., Hughes, F.M. and Cidlowski, J.A. 1997. Native recombinant cyclophilins $A, B$ and $C$ degrade DNA independently of peptidylprolyl cis-trans-isomerase activity. J. Bial. Chem. 272:6677-6684.

- Moore, J., Boswell, S., Hoffman, R., Burgess, G. and Hromas, R. 1993. Mutant H-ras over-expression inhibits a random apoptotic nuclease in myeolid leukemia cells. Leuk.

Res. 17:703-709.

Muzio, M., Chinnaiyan, A.M., Kischkel, F.C., Orourke, K., Shevchenko, A., Ni, J., Scaffidi, C., Bretz, J.D., Zhang, M., Gentz, R., Mann, M., Krammer, P.H., Peter, M.E. and Dixit, V.M. 1996. FLICE, a novel FADD-homologues ICE/ced-3-like protease, is recruited to the CD95 (Fas/Apo-1) death-inducing signaling complex. Cell $85: 817-827$.

- O'Connor, L., and Strasser, A. 1998. The BCl-2 protein family. Results Probl. Cell Differ. 23:173-207.

- Pandey, S., Waker, P.R. and Sikorska, M. 1997. Identification of a novel $97 \mathrm{kDa}$ endonuclease capable of internucleosomal DNA cleavage and its possible role in apoptosis. Biochemistry 36:711-720.

- Peitsch, M.C., Polzar, B., Stephan, H., Crompton, T., MacDonald, H.R., Mannherz, H.G. and Tschopp, J. 1993. Characterization of the endogenous deoxyribonuclease involwed in nuclear DNA degradation during apoptosis (programmed cell death). EMBO J. 12:371377. 
- Peter, M.E. Scaffidi, C., Medema, J.P., Kischkel, F. and Krammer, P.H. 1998. The death receptors. Results Probl. Cell Differ. 23:25-63.

- Pittman, S.M., Strickland, D. and Ireland, C.M. 1994. Polymerization of tubulin in apoptotic cells is not cell cycle dependent. Exp. Cell Res. 215:263-272.

- Pitzer, F., Dantes, A. Fuchs, T., Baumeister, W. and Amsterdam, A. 1996. Removal of proteasomes from the nucleus and their accumulation in apoptotic blebbs during programmed cell death. FEBS Lett. 394:47-50.

- Platt, N., da Silva, R.P. and Gordon, S. 1998. Recognizing death: the phagocytosis of apoptotic cells. Trends Cell Biol. 8:365-372

- Quingon, F. De Bels, F., Koken, M. Feunteun, J., Ameisen, J.C. and de Thé, H. 1998. PML induces a novel caspase-independent death process. Nat. Genet. 20:259-265.

- Rao L., Perez, D. and White, E. 1996. Lamin prateolysis facilitates nuclear events during apoptosis. 7. Cell Biol. 135:1441-1455.

- Reed, J.C. 1998. Bcl-2 family proteins. Oncogene 17:3225-3236.

- Reed, J.C., Jurgensmeier, J.M. and Matsuyama, S. 1998. Bcl-2 family proteins and mitochondria. Biochim. Biophys. Acta 1366:127-137.

- Reipert, S., Reipert, B.M., Hickman, J.A. and Allen, T.D. 1996. Nuclear pore clustering is a consistent feature of apoptosis in vitro. Cell Death Differ. 3:131-139.

- Ren, Y. and Savill, 3. 1998. Apoptosis: the importance of being eaten. Cell Death Differ. $5: 563-568$.

- Sakahira, $H$., Enari, M. and Nagata, S. 1998. Cleavage of CAD inhibitor in CAD activation and DNA degradlation during apoptosis. Nature 391:96-99.

- Salvesen, G.S. and Dixit, V.M. 1997. Caspases: intracellular signaling by proteolysis. Cell $91: 443-446$.

- Savill, J. 1997. Recognition and phagocytosis of cells undergoing apoptosis. Br. Med. Bull. 53:491-508.

- Savill, J., Fadok, W., Henson, P. and Haslett, C. 1993. Phagocyte recognition of cells undergoing apoptosis. Immunol. Today 14:131-136.

- Schendel, S., Montal, M. and Reed, J.C. 1998. Bcl-2 family members as lon channels. Cell Death Differ. 5:372-380.

- Serres, M., Grangeasse, C., Haftek, M. Durocher, Y., Duclos, B. and Schmitt, D. 1.997. Exp. Cell Res. 231:163-172.

- Shcherbina, A. and Remold-O'Donnell. E. 1999. Role of caspase in a subset of human platelet activation responses. Blood $93: 4222-4231$.

- Shiokawa, D., Ohyama, H., Yamada, T., Takahashi, K. and Tanuma, S. 1994. Identification of an endonuclease responsible for apoptosis in rat thymocytes. Eur. J. Biochem. 226:23-30.

- Song, Q., Wei, T., Lees-Miller, S., Ainemri, E., Watters, D. and Imavin, M.F. 1997. Resistance of actin to cleavage during apoptosis. Proc. Natl. Acad. SC. USA. 94:157-162.

- Steller, H. 1995. Mechanisms and genes of cellular suicide. Science 267:1445-1449.

- Susin, S.A., Lorenzo, H.K., Zamzami, M., Marzo, I., Snow, B.E., Brothers, G.M., Mangion, 1. Jacotot, E., Costantini, P., Loeffler, M. Larochette, N., Goodlett, D. R., Aebersold, R., Siderovski, D.P., Penninger, J.M and Kroemer, G. 1999 a. Molecular characterization of mitochondrial apoptosis-inducing factor. Nature 397:441-446.

- Susin, S.A., Lorenzo, H.K., Zamzami, N., Marzo, I, Brenner, C., Larochette, N., Prevost, M.C., Alzari, P.M. and Kroemer, G. 1999b. Mitochondrial release of caspases-2 and -9 during the apoptotic process. J. Exp. Med. 189:381-394.

- Thome, M., Schneider, P., Hofmann, K., Finckenscher, H., Meinl, E., Nelpel, Fa, Mattmann, C., Burns, K., Bodmer, J.L., Schrotter, M., Scaffidi, C., Krammer, P. H., Peter, M.E., Tschopp, J. 1997. Viral FLICE-imhibitory proteins (FLIPS) prevent apoptosis induced by death receptors. Nature 386:517-521.

- Thomberry, N.A. 1998. Caspases: key mediators of apoptosis Chem. Biol. 5:R97-R103.

- Thornberry, N.A. and Lazebnik, Y. 1998. Caspases: enemies within. Science 208:13121316.

- Tinnemans, M.M.F.J., Lenders, M.H.J.H., ten Velde, G.P.M., Ramaiekers, F.C.S. and Schutte, B. 1995. Alterations in cytoskeletal and nuclear matrix-associated proteins during apaptosis. Eur. 3. Cell Biol. 68:35-46. 
- Torriglia, A., Perani, P., Brossas, J.Y., Chaudun, E., Treton, J., Countois, Y, and Counis, M.F. 1998. L-Dnase II, a molecule that links proteases and endonucleases in apoptosis, derives from the ubiquitous serpin leukocyte elastase inhibitor. Mol Cell Biol. 18:36123619.

- Uren, A.G. and Vaux, D.L. 1997. Viral inhibitors of apoptosis. Vitam. Horm. 53:175-193.

- Uren, A.G. and Vaux, D.L., 1998. Conservation of baculovirus inhibitor of apoptosis repeat proteins (BIRPs) in viruses, nematodes, vertebrates and yeasts. Trends Biochem. Sci. $23: 159-162$.

- Utz, P.J. and Anderson, P. 1998. Posttransiational protein modifications, apoptosis and the bypass of tolerance to autoantigens. Arthritis Rheum. 41:1152-1160.

- Vauk, D.L., Weissman, I.L. and Kim, S.K. 1992. Prevention of programmed cell death in Caenorhabditis elegans by human bcl-2. Science 258:1955-1957.

- Vemuri, G.S., Zhang, J., Huang, R., Keen, 1.H. and Rittenhouse, S.E. 1996. Thrombin stimulates wortmannin-inhibitable phosphoinositide 3-kinase and membrane blebbing in CHRF-288 cells. Biochem. J. 314:805-810.

- Villa, P., Kaufmann, S.H. and Earnshaw, W.C. 1997. Caspases and caspase inhibitors. Trends Biachem. Sci. 22:388-393.

- Vincenz, C. and Dixit, V.M. 1997. Fas-associated death domain protein interleukin-18converting enzyme 2 (FLICE2), an ICE/CED-3 homologue, is proximally involved in CD95 and p55 mediated death signaling. 1 . Biol. Chem. 272:6578-6583.

- Vodenicharov, D.M. Markova, D.Z. and Djondjurov, L.P. 1996. Spontaneous apoptosis in mouse F4N-S erythroleukemia cells induces a non-raindom fragmentation of DNA. DNA Cell Biol. 15:287-296.

- Wang, Z.G, Ruggero, D., Ronchetti, S., Zhong, S., Gaboli, M., Rivi, R. and Pandolfi, P.P. 1998. Pml is essentiall for multiple apoptotic pathways. Nat. Gen. 20:266-272.

- Watanabe, Y. and Akaike, T. 1999. Possible involvement of caspase-like familly in maintenance of cytoskeletal integrity. 3. Cell. Physiol. 179:45-51.

- Weil, M., Raff, M.C. and Braga, V.M. 1999. Caspase activation in the terminal differentiation of human epidermal keratinocytes. Curr. Biol. 9:361-364.

- Yang, E. and Korsmeyer, S.J. 1996. Molecular thanatopsis: a discourse on the Bd-2 family and cell death. Blood 88:386-401.

- Yang, F., Sun, X., Beech, W., Teter, B., Wu, S., Sigel, J., Vinters, H.V., Firautschy, S.A. and Cole, G.M. 1998. Antibody to caspase-cleaved actin detects apoptosis in differentiated neuroblastoma and plaque-associated neurons and microglia in Alzheimer's disease. Am. 1. Pathol. 152:379-389.

- Yang, J., Liu, X., Bhalla, K., Kim, C.N., Ibrado, A.M. Cai, J. Peng, I., Jones, D.P. and Wang, $X$. 1997. Prevention of apoptosis by $B d-2$ : rellease of cytochrome $C$ from mitochondria blocked. Science 275:1129-1132.

- Yuan, I., Shaham, S. Ledoux, S., Ellis, M.H., and Horvitz, H.R. 1993. The C. Elegans cell death gene ced-3 encodes a protein similar to mammalian interleukin-18 converting enzyme. Cell 75:641,652.

- Zha, J., Harada, H., Yang, E., Jockel, J. and Korsmeyer, S.J. 1996. Sierine phosphorylation of death agonist BAD in response to survival factor resuits in binding to 14-3-3 not Bcl-X. Cell 87:619-628.

- Zou, H., Henzel, W.I., Liu, X., Lutschg, A. and Wang, X. 1997. Apaf-1, a human protein homologous to $C_{\text {. }}$ elegans $C E D-4$, participates in cytochrome C-dependent activation of caspase-3. Cel/ 90:405-413. 


\section{Annexin V-affinity assay: \\ a review on an apoptosis \\ detection system based on \\ phosphatidylserine exposure}

Manon van Engeland, Luc J.W. Nieland, Frans C.S. Ramaekers, Bert Schutte and Chris P.M. Reutelingsperger

Cytometry $199831: 1-9$

\section{Contents}

3.1 Introduction

3.2 Molecular biology of apoptosis

3.3 Plasma membrane changes during apoptosis

3.4 Annexin $V$ and detection of PS exposure in apoptotic cells

3.5 The annexin $V$ affinity assay

3.6 Detection of apoptosis using the annexin $V$ assay for immunocytochemistry

3.7 Quantification of apoptotic cells using the annexin $V$ assay for flow cytometry

3.8 Histochemical detection of apoptotic cells using annexin $\mathrm{V}$

3.9 PS exposure: a universal mechanism during apoptosis?

3.10 PS exposure: an early or late phenomenon in the apoptotic process?

3.11 Conclusion

3.12 References 


\section{Abstract}

Apoptosis is a programmed, physiological mode of cell death that plays an important role in tissue homeostasis. Understanding of the basic mechanisms that underlie apoptosis will point to potentially new targets of therapeutic treatment of diseases that show an imbalance between cell proliferation and cell loss. In order to conduct such research, techniques and tools to reliably identify and enumerate death by apoptosis are essential. This review focuses on a novel technique to detect apoptosis by targeting for the loss of phospholipid asymmetry of the plasma membrane. It was recently shown that loss of plasma membrane asymmetry is an early event in apoptosis, independent of the cell type, resulting in the exposure of phosphatidylserine (PS) residues at the outer plasma membrane leaflet. Annexin $V$, was shown to interact strongly and specifically with PS and can be used to detect apoptosis by targeting for the loss of plasma membrane asymmetry. Labeled annexin $V$ can be applied both in flow cytometry and light microscopy in both vital and fixed material by using appropriate protocols. The annexin $V$ method is an extension to the current avallable methods. This review describes the basic mechanisms underlying the loss of membrane asymmetry during apoptosis and discusses the novel annexin $V$-assay.

\subsection{Introduction}

Tissue homeostasis is maintained by a delicate balance between cell proliferation and cell death. Disturbance of this balance often leads to pathological cell accumulations, for example in cancer. In this respect, much attention has been paid to the process of cell proliferation, while the phenomenon of cell death has long been overlooked. This has changed since it became evident that cell death may arise not only from externally inflicted mechanical or chemical damage, but also from a suicidal process that is controlled from within the cell. During the last decade, cell biology as well as oncology research has focused on this latter process of programmed cell death, referred to primarily as apoptosis. It is anticipated that understanding of the basic mechanisms that underlie apoptosis will offer potential new targets for therapeutic treatment of diseases (Martin and Green, 1994). In order to conduct such research, techniques and tools to reliably identify and enumerate death by apoptosis are essential (for an extensive review, see Darzynkiewicz et al., 1997). This rewiew focuses on a nowel technique designed to detect apoptosis by targeting for the loss of phospholipid asymmetry of the plasma membrane. Apoptotic cell death is accompanied by a change in plasma membrame structure by surface exposure of phosphatidylserine (PS), while the membrane integrity remains unchallenged. Surface exposed PS can be detected by its affinity for annexin V, a phospholipid binding protein. This article reviews the basic mechanisms underlying this loss of membrane asymmetry and discusses the novel annexin $V$-affinity assay to detect apoptosis. 


\subsection{Molecular biology of apoptosis}

A cell is continuously exposed to multiple opposing 'death' and 'survival' triggers. To date, little is known about the molecular events controlling this balance of signals. Multiple triggers of apoptosis are known, such as withdrawal of growth factors, DNA damage, Fas ligand binding, application of chemotherapeutic agents, etc. (Berke, 1995; Collins et al., 1994). Although these triggers initiate a cascade of events that finally results in cell death by apoptosis, they differ in the length of the so-called trigger phase*, i.e. the lag time between exposure to the trigger and the time of the first morphological signs of apoptosis. The duration of this phase depends on the cell type, type of the trigger and growth conditions of the cell. All the different induction mechanisms seem to converge into the activation of a proteolytic cascade, involving interleukin-1 $\beta$-converting enzyme (ICE) and the ICE-like family of proteases, recently renamed caspase family (Martin and Green, 1995; Nagata, 1997). Some genes are reported to govern this initial phase of apoptosis (Steller, 1995; Wyllie, 1995), such as the Bcl-2 gene famlly that is supposed to protect cells against apoptosis by opposing the effect of the bax gene family. Both gene products have been shown to form either homo- or heterodimers and the eventual cellular decision is supposed to be determined by the relative quantities of both gene products (for reviews see Hale et al., 1996; Vaux, 1993; Wyllie, 1995). The activation of the proteolytic cascade seems to determine the beginning of the so-called "execution phase" of the apoptotic process, which is relatively short and shows little variation in duration (Earnshaw, 1995). The activation of the caspase family of proteases results in the breakdown of cellular proteins such as the nuclear matrix, the cytoskeleton, and poly(ADP-ribose)polymerase, either directly or through activation of other cellular proteases such as calpain or proteasomes (Grimm et al., 1996; Machiels et al., 1996). At this stage of the process apoptotic cells also display PS at their outer membrane. However, the molecular mechamisms underlying this process are to date poorly understood.

\subsection{Plasma membrane changes during apoptosis}

Viable cells maintain an asymmetric distribution of different phospholipids between the inner and outer leaflets of the plasma membrane (Bretscher. 1972). This is particularly true for both choline-containing phospholipids, phosphatidylcholine and sphingomyelin, which are primarily located in the viable cells outer leaflet, and for the aminophosphollpids phosphatidylethanolamine and PS, which are found at the cytoplasmic face. This asymmetry of the plasma membrane was first described for erythrocytes and platelets (op den Kamp, 1979; Schroit and Zwaal, 1991) and later also found to hold true for the nucleated cell types (Devaux, 1991; Zachowski, 1993).

The plasma membrane lipid asymmetry in viable cells is thought to be maintained by so called flippases, membrane proteins that facilitate the translocation of lipid molecules from one leaflet to the other (Higgins, 1994). Seigneuret and Devaux (1984), were the first to demonstrate that the erythrocyte membrane contains activities that translocate specifically aminophospholipids from one leaflet to the other. Such an activity was later also found in membranes of platelets (Comfurius et al., 1990) and nucleated 
cell types (Martin and Pagano, 1987; Zachowski, 1993; Zachowski et al., 1987). Connor et al. (1992) provided evidence for the $\mathrm{Mg}^{2 *} / \mathrm{ATP}$-dependence of this process. This translocase activity now appears to be ubiquitously present and contributes significantly to the PS asymmetry in membranes of enucleated and nucleated cell types (for recent reviews, see Diaz and Schroit, 1996; Zwaal and Schroit, 1997).

Other proteins that show phospholipid translocase activity are a recently cloned bovine enzyme, which is a member of the subfamily of P-type adenosine triphosphates described by Tang et al. (1996) and the multidrugresistance protein encoded by the mdr2 gene (reviewed in Gottesman and Pastan, 1993). So far, however, the identity of this translocase has not been resolved satisfactorily, and it is still unclear whether the activity of aminophospholipid translocation is mediated by a single protein or by a group of proteins.

In addition to the potency of maintaining PS asymmetrically at the inner membrane leaflet by flippase activity, cells also possess the ability to translocate PS to the outer leaflet of the plasma membrane. This was first demonstrated for platelets (Bevers et al., 1982; Bevers et al., 1983) and erythrocytes (Connor et al., 1994). Cell surface exposure of PS in these cells is of importance in catalyzing coagulation by activated platelets and elimination through the reticuloendothelial system of senescent erythrocytes (Chancerelle et al., 1994). Later it became clear that nucleated cell types may also expose PS at their cell surface under controlled conditions. Fadok and coworkers $(1992 ; 1993)$ showed that leukocytes during apoptosis expose PS on the outer leaflet of the plasma membrane. This cell surface exposed PS functions as a tag for specific recognition by macrophages and for phagocytosis of the dying cell.

To date, the molecular machinery responsible for cell surface exposure of PS remains unidentified. Activities of scramblases, which are responsible for the inward out-translocation of PS by scrambling the aminophospholipids over the inner and outer membrane leaflet, have been demonstrated to be responsible for PS exposure in platelets and erythrocytes (Diaz and Schroit, 1996; Zwaal and Schroit, 1997). Others claim a role for fodrin (nonerythroid spectrin) in maintaining an asymmetric phospholipid composition of the cytoplasmic membrane by anchoring PS at the cytofacial membrane. As a consequence of fodrin degradation by ICE-like proteases, PS would be exposed during apoptosis (Vanags et al., 1996).

\subsection{Annexin $\mathrm{V}$ and detection of PS exposure in apoptotic cells}

Investigations into the exposure of PS at the outer membrane leaflet of cells is facilitated by the finding that annexin $V$ specifically binds to $P S$ in the presence of callium (Andree et al., 1990; Tait et all, 1989). Annexin V was first reported by Bohn and coworkers (Inaba et al., 1984) who isolated the protein from human placenta and called it placental protein 4 (PP4), and by Reutelingsperger et al. (1985) who isolated it from the umbilical cord by virtue of its anticoagulant activity and called it vascular-anticoagulant- $\alpha$. After cloning and sequencing of the human annexin $V$ CDNA, the protein got its name because of its homology with the family of annexin proteins (Iwasaki et al. 1987; Kaplan et al., 1988; Maurer-Fogy et al., 1988). Successful 
expression in bacterial systems gave a source of recombinant protein that catalyzed numerous investigations exposing biological and physicochemical

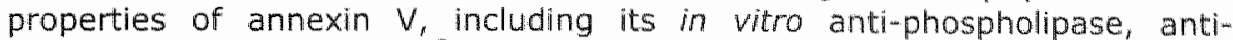
coagulant, anti-kinase, $\mathrm{Ca}^{2+}$-channeling and phospholipid binding activities (for recent reviews see Raynal and Pollard, 1994; Swalrjo and Seaton; 1994; van Heerde et al., 1995). However, the phospholipid binding properties of annexin $V$ appear central in most considerations and are regarded as the key activity elaborated by the organism to serve the as yet unknown role. The availability of biotin- or FITC-labeled annexin $V$ facilitated studies on PS exposure at the outer membrane leaflet, and provides not only a usefull tool to measure the PS exposition of platelets (Dachary-Prigent et al., 1993; Thiagarajan and Tait; 1990) and erythrocytes (Tait et al., 1989), but also in nucleated celis undergoing apoptosis (Koopman et al., 1994; Martin et al., 1995; van Engeland et al., 1996; Vermes et al., 1995).

Verhoven and coworkers (1995) recently showed a scramblase to become active during apoptosis in Iymphocytes. Using fluorescently labeled annexin $V$, it could be demonstrated that the apoptotic lymphocytes expose PS at their outer membrane early after onset of the execution phase of apoptosis. PS appears at the outer leaflet of the plasma membrane, the integrity of which has not been compromised at this stage. PS exposure seems to last from the early execution phase of apoptosis until the final stage, at which the cell has broken up into apoptotic bodies.

\subsection{The annexin V-affinity assay}

Based on the phenomenon that PS is exposed during apoptosis and the ability of annexin $V$ to bind to PS with high affinity, Koopman et al. (1994) were the first to describe a method using extrinsically applied hapten (i.e. FITC or biotin) labeled annexin $V$ to detect apoptosis. As schematically represented in figure 3.1 , hapten-labeled annexin $V$ binds in the presence of $\mathrm{Ca}^{2 *}$ to PS residues that are exposed at the outer leaflet of the plasma membrane of apoptotic cells. Annexin $V$ is not able to bind to normal vital cells since the molecule is not able to penetrate the phospholipid bilaver. In dead cells, however, the inner leaflet of the membrane is available for binding of extrinsically applied annexin $V$, since the integrity of the plasma membrane is lost. To discrimimate between dead and apoptotic cells, a membrane impermeable DNA stain, such as propidium liodide (PI) can be added simultaneously to the cell suspension. In this way, vital, apoptotic and dead cells can be discriminated on basis of a double-labeling for annexin $V$ and PI, and analyzed either by flow cytometry or fluorescence microscopy.

\subsection{Detection of apoptosis using the annexin $V$ assay for immunocytochemistry}

When examined by light microscopy, the cells showing morphological aspects characteristic for apoptotic cells (e.g., bud formation), also show affinity for annexin $V$ (figure 3.2A). Most of these cells are devoid of PI staining indicating the intactness of the membrane. Figure $3.2 \mathrm{~B}$ shows an example of an annexin $\mathrm{V}^{+} / \mathrm{PI}^{-}$cell. When the membrane looses its integrity, the cell be- 
comes annexin $\mathrm{V}^{*} / \mathrm{PI}^{*}$, indicating the necrotic stage of the cell (figure $3.2 \mathrm{C}$ ). In annexin $\mathrm{V}^{+} / \mathrm{PI}$ " cells, addition of the supravital DNA dye Hoechst 33342 allows the study of nuclear morphology. In figures $3.2 \mathrm{~B}$ and $C_{r}$ annexin $v^{*}$ buds can be observed, some showing nuclear remnants, some devold of nuclear material.

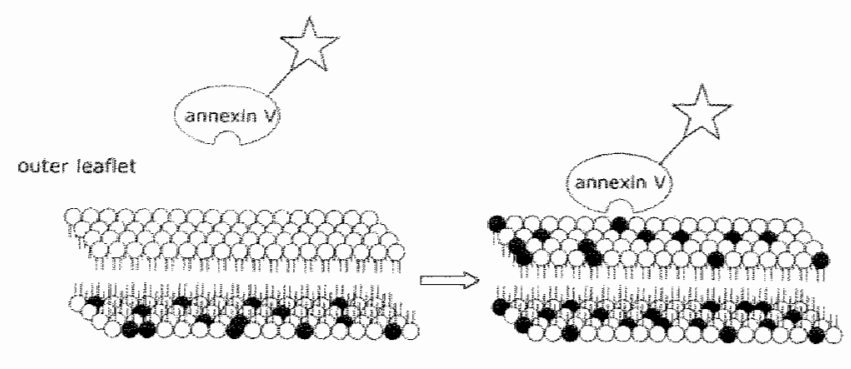

Inner leaflet:

normal cell

apoptotic cell

Figure 3.1: Schematic representation of the lass of membrane lipid asymmetry during apoptosis. Vital cells main tain a strictly asymmetric lipid bilayer composition, with PS residues (black circles) facing the cytosol. During apoptosis these PS molecules become exposed at the outer membrane leaflet. Hapten-labeled annexin $V$ can bind with high affinity to the exposed PS in the presence of $\mathrm{Ca}^{2+2}$.
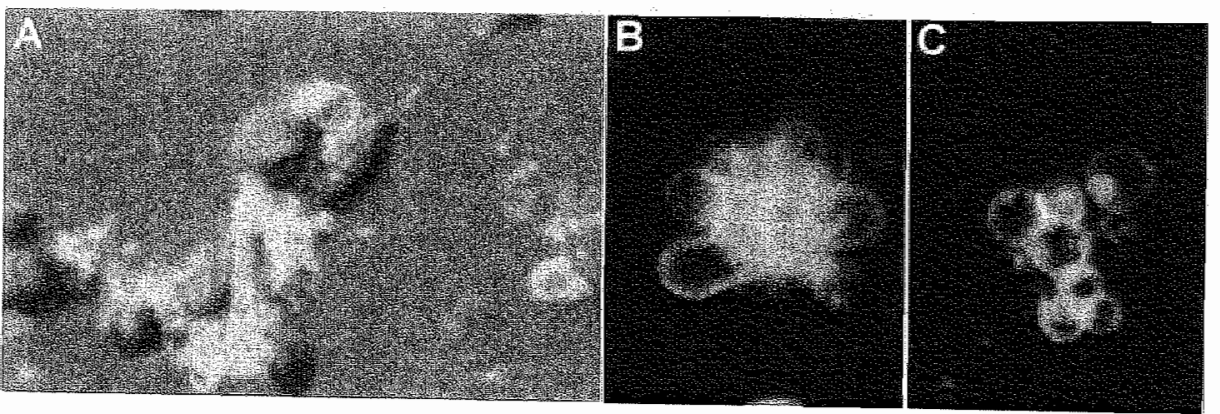

Figure 3.2: MR65 cells, grown on glass slides, are cultured in the presence of $200 \mu \mathrm{M}$ olomoucine. After 6 hours, the vital cultures were incubated with annexin $V-F I T C$, PI and Hoechst 33342. The cell cultures were subsequently analyzed using the Bio-Rad MRC600 confocal scanning laser microscope. A: Merged image of annexin $V$ fluorescence and differential interference contrast. Cells showing the characteristic bud formation are clearly annexin $\mathrm{V}^{+}$, while vital adherent cells, including the metaphase in the center of the mage, are annexin $V$. Note the presence of small annexin $V^{+}$ vesicles. $B$ and $C$ : Merged images of annexin $V$ (green), PI (red) and Hoechst 33342 (blue) fluorescence of a single apoptotic (B) and a single dead (C) cell. Note that some buds are devoid of nuclear remnants. For color illustration see page 135. 


\subsection{Quantification of apoptotic cells using the annexin $V$ assay for flow cytometry}

For the quantification of anmexin $V^{*}$ apoptotic cells, flow cytometry can best be applied using a single cell suspension prepared from the cells or tissue under examination. Figure 3.3 shows an example of a flow cytometric analysis of the annexin $V$ labeling assay to detect apoptosis in a dexamethasone treated rat thymocyte culture. For this purpose, rat thymocyte cultures were exposed to dexamethasone for various periods of time. The cytogram in figure $3.3 a$ shows the bivariate annexin $V / P I$ analysis of the unexposed cell suspension. Vital cells are annexin V/PI (R1), apoptotic cells are annexin $\mathrm{V}^{+} / \mathrm{PI}^{\circ}$ (R2), while dead cells are annexin $\mathrm{V}^{+} / \mathrm{PI}^{+}$(R3). After 4.5 hour exposure to dexamethasone, the number of apoptotic cells increased from $4.1 \%$ in the control culture to $43.6 \%$, while the number of dead cells remained constant (figure $3.3 \mathrm{~b}$ ).

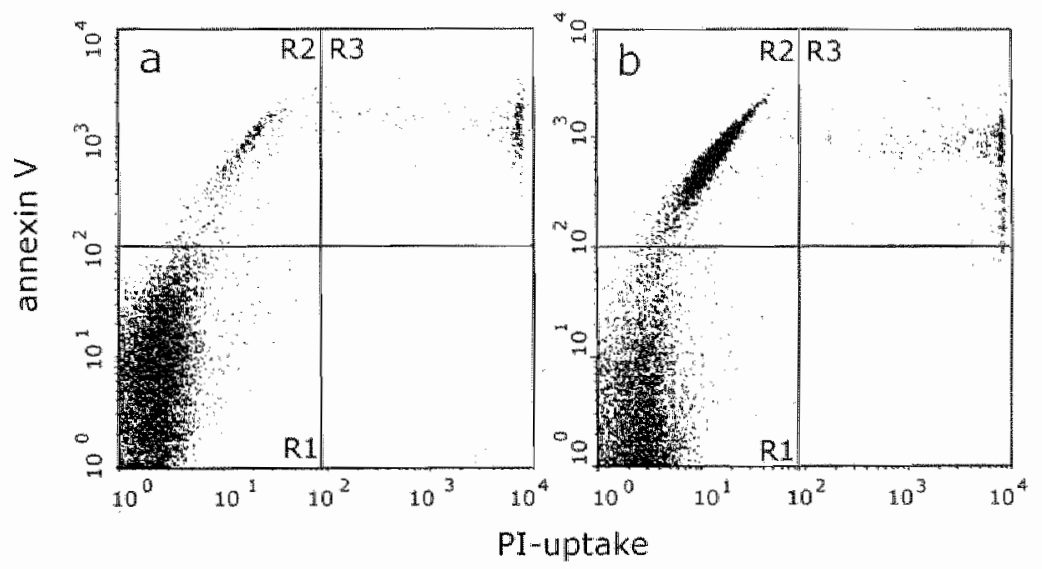

Figure 3.3: Bivariate annexin V/PI analysis of a primary cell culture of rat thymocytes. A single cell suspension was prepared by gently pressing small tissue fragments through a metal mesh, using a glass pestle. Apoptosis was induced by culturing the cells in the presence of $10 \mu \mathrm{M}$ dexamethasone for 4.5 hours. To both untreated (a) and dexamethasone-treated (b) cultures, annexin V-FITC and PI was added prior to flow cytometry. Region R1 contains the vital (annexin V/PI) population, region R2 contains the apoptotic (annexin $\mathrm{V}^{+} / \mathrm{PI}^{-}$) and $\mathrm{R} 3$ contains the dead (annexin $\mathrm{V}^{+} / \mathrm{PI}^{*}$ ) cells.

Recently, van Engeland et al. (1996) showed that it is feasible to use the bivariate annexin V/PI analysis also for adhering cells in cultures. The method does not work after routinely applied cell harvesting techniques, such as trypsinization. Using this technique, membrane changes are induced which result in PS exposure in the outer plasma membrane, probably due to bud formation during harwesting (Allen, 1987).

The method described by us (van Engeland et al., 1996) was designed to overcome these pitfalls. It makes use of adhering cell cultures, which were labeled with annexin $V$ prior to quantitative harvesting with a rubber poli- 
ceman. The cell suspension thus obtained is then counterstained with PI. Figure 3.4 shows an example of the annexin $V$ assay performed on adherent cells, harvested by scraping.

The different labeling patterns in this assay identify the different cell fractions, i.e. annexin V/PI wital cells (RI), annexin $\mathrm{V}^{+} / \mathrm{PI}^{-}$apoptotic cells (R2), annexin $V^{*} / P^{+*}$ dead cells (R3), and $\mathrm{PI}^{+} /$annexin $\mathrm{V}^{*}$ cells, damaged during the isolation procedure (R4).

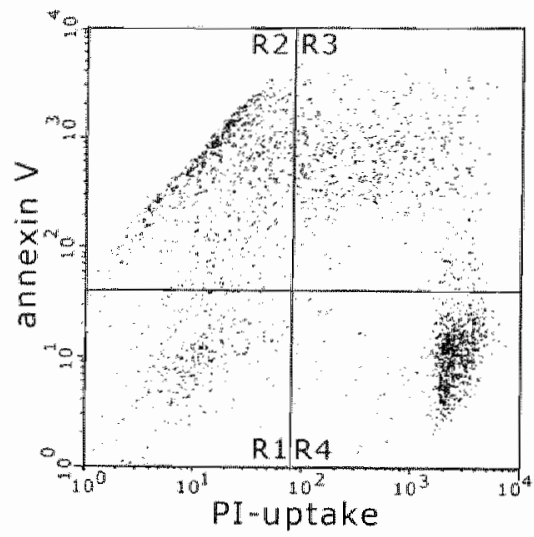

Figure 3.4: Bivariate annexin V/PI analysis of the adherent neuroblastoma cell line CHP212. Apoptosis was induced by treating the cells with $200 \mu \mathrm{M}$ olomoucine for 4 hours. The cells were incubated with annexin V-FITC prior to harvesting. PI was added to the obtained cell suspension before flow cytometric analysis. The different labeling patterns in this assay identify the different cell populations, i.e. region R1: wital cells (annexin $V^{\prime} / P^{-}$), region $R 2$ : apoptotic cells (annexin $V^{*} / P^{\prime}$ ), region $R 3$; dead cells (annexin $\mathrm{V}^{+} / \mathrm{PI}^{*}$ ) and region $\mathrm{R} 4$ : damaged cells (annexin $\mathrm{V} / \mathrm{PI}^{+}$).

The annexin $V$-labeled cells can be fixed in cold methanol, which then enables detection and quantification of other intracellular antigens in the different cell populations. For this purpose, biotin-conjugated annexin $V$ is used for labeling of the cells (van Engeland et al., 1996). After fixation, annexin $V$ binding is visualized with FITC-labeled streptavidin.

For example, figure 3.5 shows an example of lamin B expression during induction of apoptosis in a lung cancer cell line. As shown in figure 3.5a, most of the annexin $V^{+}$apoptotic cells are devoid of lamin B staining. A small proportion of the annexin $V^{-1}$ cells is, however, positive for lamin $B(R 3)$, while low numbers of annexin $V / l a m i n ~ B$ cells are observed (R1), representing mitotic cells (figure $3.5 \mathrm{~b}$ ). This trivariate annexin V/lamin B/DNA analysis also shows that DNA loss, resulting in the characteristic 'sub-G1 peak" in the DNA histogram (figure $3.5 \mathrm{c}$ ), is detected mainly in the apoptotic, annexin $\mathrm{V}^{+} /$lamin $\mathrm{B}^{-}$cells (figure $3.5 \mathrm{e}$ ), while the annexin $\mathrm{V}^{+} /$lamin $\mathrm{B}^{+}$cells show a normal cell cycle distribution (figure $3.5 \mathrm{~d}$ ). 

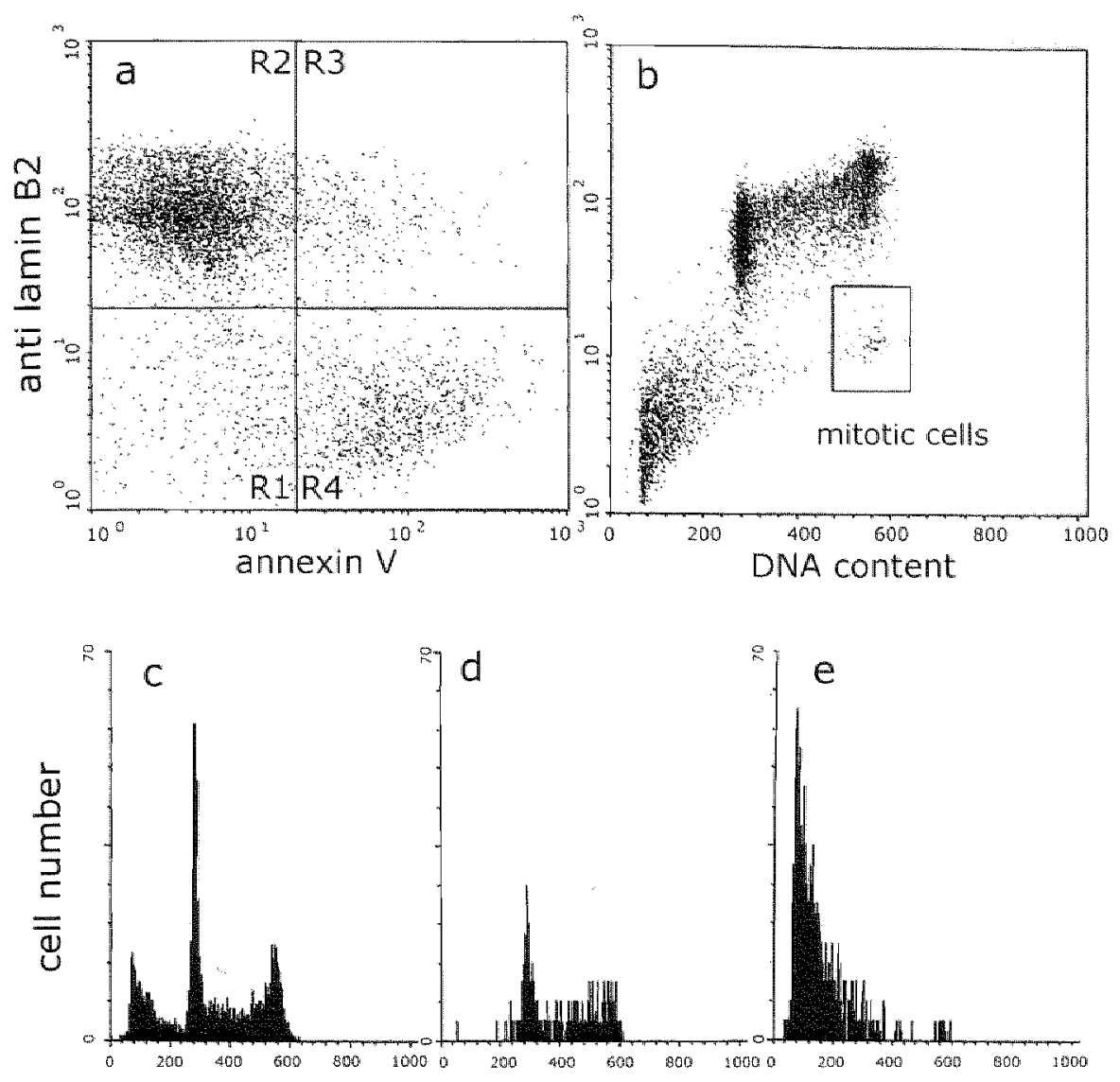

DNA content

Figure 3.5: Trivariate (Schutte et al., 1995) annexin V/lamin B and DNA content analysis of the lung cancer cell line MR65. Cells were cultured in the presence of 200 $\mu \mathrm{M}$ olomoucine for 6 hours, prior to labeling of the cells with biotin-conjugated annexin $V$. Cells were harvested and the cell suspension was subsequently fixed in cold methanol. Lamin B was detected by routine immunacytochemical protocols. Annexin $V$ binding was visualized using FITC-labeled streptavidin, lamin B staining using phycoerythrin-conjugated secondary antibodies and DNA content using PI. Most of the annexin $V^{*}$ apoptotic cells are devoid of lamin $B$ staining $(a, \mathbb{R} 4)$. A small proportion of the annexin $V^{*}$ cells are also positive for lamin $B(R 3)$, whlle a small number of annexin $V$ /lamin $B$ cells are observed (R1). These cells, which appear as lamin $B$ in the cytogram of lamin B versus DNA content (b) represent the mitotic cells. The DNA histograms of the total cell population (c), of the region $R 4$ (e) and of region $\mathbb{R} 3$ (d) show that no signs of DNA loss are present in $d$, the annexin $V^{+} / l a m i n B^{+}$cells $(R 3)$, in

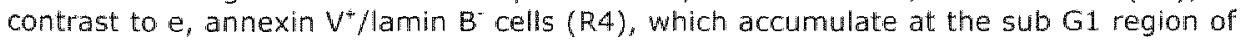
the histogram (for details, see van Engeland et al., 1996). 


\subsection{Histochemical detection of apoptotic cells using annexin $\mathrm{V}$}

In order to use the annexin V-assay for the detection of apoptotic cels in situ, biotin-labeled annexin $V$ was injected into mice. In wivo labeling with blotinylated-annexin $V$ during 30 minutes was followed by dissection and routine formalin fixation and paraffin embedding of the tissues. After dewaxing and rehydration, the tissue sections were incubated with peroxidase-conjugated strepavidin and visualised by enzyme histochemistry. In this way apoptosis could be detected in developing mouse embryos (van den Eijnde et al., 1997). Figure 3.6 shows an example of an in situ-labeled section mouse thymus, dissected approximately 30 minutes after injection with biotin-labeled annexin V. Control sections, which were incubated with annexin $V$ after fixation and embedding of the tissue and stained using peroxidase conjugated strepavidin, show integral membrame staining in all cells as a result of detectability of the PS in the inner leaflet of the plasma membrane. As shown at low magnification, thymocytes, dying by the process of apoptosis, are not randomly scattered troughout the tissue, but die in small groups. At higher magnification, the specific membrane staining of the individual cells can clearly be seen.

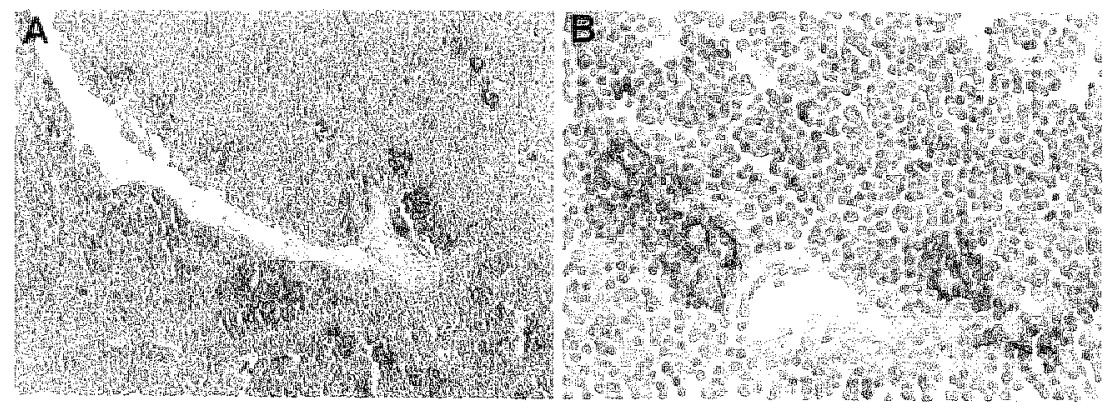

Figure 3.6: Exogenously applied annexin $V$ localization of formalin fixed, paraffinembedded tissue sections of a mouse thymus. The mouse was in situ-labeled by injection of annexin $V$-biotin. The thymus was removed after 30 minutes and routinely processed for paraffin embedding. Sections cleared from paraffin weire incubated with peroxidase-labeled streptavidin to visualize annexin V-biotin, bound to apoptotic cells. The low-magnification field (20x) shows that apoptosis occurs in discrete groups of cells and not randomly dispersed throughout the tissue (A). At higher magnification $(40 x)$ a clear membrane staining in the positive cells can be observed (B). (for details, see van den Eljnde et al., 1997). For collor illustration see page 135.

\subsection{PS exposure: a universal mechanism during apoptosis?}

PS exposuse during apoptosis seems to be a universal phenomenon, not limited to mammalian cells, but also occuring in insect and plant cells (O'Brien et al., 1997). Hence, PS exposure appears as ubiquitous as apoptosis itself and likely constitutes an integral part of this process of cell 
suicide. Martin et al. (1995) recently showed that PS exposure during apoptosis occurs in most if not all cells under the action of most if not all triggers of apoptosis. The authors measured PS exposure in several murine and human cell lines, exposed to a wide variety of initiating stimuli, including ligation of Fas or $\mathrm{CD} 3 / \mathrm{T}$ cell receptor complex, treatment with synthetic ceramides, glucocorticoids, a variety of cytotoxic drugs and UV irradiation. All treatments resulted in PS externalization and binding of FITC-labeled annexin $V$. This annexin $V$ binding could specifically be inhibited by exogenous PS and not by other phospholipids. Furthermore, the autors provided evidence that PS exposure is indeed intimately coupled to the process of apoptosis, since overexpression of known repressors of apoptosis, such as $A$ bl and $B c \mid-2$, inhibit PS externalization. In the same article evidence was provided that loss of membrane asymmetry is a rather early phenomenon in the apoptotic process, since PS exposure preceded both the characteristic morphological changes as well as nuclear condensation.

\subsection{PS exposure: an early or late phenomenon in the apoptotic process?}

Although the molecular mechanisms of apoptosis are not well understood, we know that the family of caspases seem to play a pivotal role in initiating this process (Nagata, 1997; Zhivotovsky et al., 1995). Recent reports in the literature suggests that PS externalization is prevented by inhibitors of the caspase family. (Martin et al., 1996; Naito et al., 1997). These findings are in line with the observations made by Castedo et al. (1996), showing that early during apoptosis, cells undergo a disruption of the mitochondrial transmembrane potential ( $\Delta \psi \mathrm{m})$, prior to exposing PS at the outer membrane leaflet. This sum disrupture is mediated by the opening of so-called mitochondrial permeability transition pores or megachannels. Susin et al. (1996) showed that $\Delta y m$ disrupture leads to the release of an apoptosis inducing factor (AIF), which in a cell free in vitro system causes isolated nuclei to undergo apoptotic changes. AIF is blocked by the caspase inhibitor Z-VAD.

Taken together, these results would indicate that PS externalization is a downstream event of early caspase activation and possibly an early phenomenon of the so-called execution phase. Evidence for this is provided by the kinetics of PS exposure and breakdown of many putative targets of the caspases. For instance, we provided evidence that PS exposure occurs prior to the loss of nuclear lamins. Loss of nuclear lamina architecture during apoptosis was shown to be the result of proteolysis of this nuclear matrix protein, in contrast to the solubilization during mitosis due to hyperphosphorylation by the mitotic cdk/cyclin kinase complex (Oberhammer et al., 1994; Smith et al., 1992). Recently the protease responsible for lamin breakdown was isolated and shown to be a member of the family of caspases (Lazebnik et al., 1995). Neamati et al. (1995) demonstrated that lamin degradation is an early event of apoptosis in thymocytes and suggested that chromatin condensation and breakdown of the nuclear envelope occurs as a result of disruption of the nuclear lamina architecture.

Recently, Tinnemans et al. (1995) observed changes in another member of the intermediate filament family, i.e. the cytokeratins, which were degraded early during apoptosis. Double labeling experiments using annexin $V$ and 
anti-cytokeratin antibodies (van Engeland et al., 1996) showed that loss of membrane asymmetry preceeded the degradation of these cytoskelletal elements. In double labeling experiments, using annexin $V$-binding and couterstaining with the supravital DNA dye Hoechst 33342 , Koopman et al. (1994) showed that all cells showing chromatin condensation were annexin $V$ positive, suggesting that PS exposition in apoptotic cells is at least as early as chromatin condensation. This finding was further substantiated by Stuart et al. (1995), who showed annexin V labeling of cells with condensed chromatin using electron microscopy. However, Vanags et al. (1996) found that the kinetics of ofodrin degradation and plasma membrane budding were similar and difficult to distinguish in time from the nuclear apoptotic changes.

Direct comparison of the TUNEL assay and the annexin $V$-affinity assay, indicates that PS externalization can be measured prior to the detection of DNA strand breaks (O'Brien et al., 1997).

All experimental evidence obtained thus far indicates that loss of membrane asymmetry is a very early phenomenon during apoptosis, initiated at a time following the caspase proteolytic cascade but possibly preceeding nuclear condensation and breakdown of intracellular cytoskeletal and nuclear matrix constituents.

\subsection{Conclusion}

PS exposure at the outer membrane surface of a cell is an universal process occuring during early apoptosis, independent of the species, the cell type, or the apoptosis induction system used. Using the annexin $V$-affinity assay the number of apoptotic cells in suspension can be determined in a fast, simple and sensitive way. In vivo or in situ dletection of apoptotic cells has become feasible by injecting biotinulabeled annexin $V$ in the bloodstream of animals to be examined. Furthermore, this technique can easily be adapted to incorporate detection of other cellular features, such as chromatin condensation, as well as the presence or absence of specific cellular constituents.

\subsection{References}

- Allen, T.D. 1987. Ultrastructural aspects of cell death. In Perspectives on mammalian cell death. Potten, C.S. editor. (Oxford: Oxford University Press) pp. 39-65.

- Andree, H.A., Reutelingsperger, C.P.M., Hauptmann, R., Hemker, H.C., Hermens, W.T. and Willems, G.M. 1990. Binding of vascular coagulant alpha (VACalpha) to planar phospholipid bilayers. 3. Bial. Chem. 265:4923-4928.

- Berke, G. 1995. The CTL's kiss of death. Cell 81:9-12.

- Bevers, E.M. Comfurius, P. van Rin, J.L., Hemker, H.C. and Zwaai, R.F. 1982. Generation of prothrombin-converting activity and the exposure of phosphatidylserine at the outer surface of platelets. Eur. J. Biochem. 122:429-436.

- Bevers, E.M., Comfurius, P. and Zwaal, R.F. 1983. Changes in membrane phospholipid distribution during platelet activation. Biochim. Blophys. Acta 736:57-66.

- Bretscher, M.S. 1972. Asymmetrical lipid bilayer structure for biological membranes. Nature New Biol 236:11-12.

- Castedo, M., Hirsch, T., Susin, S.A., Zamzami, N., Marchetti, P., Macho, A. and Kroemer, G. 1996. Sequential acquisition of mitochondrial and plasma membrane alterations during eariy lymphocyte apoptosis. J. Immunol. 157:512-521. 
- Chancerelle, $Y_{*}$ Mathieu, J. and Kergonou, J.F. 1994. Recognition and elimination of scenescent erythrocytes: Implication of antibodies specific for malonic dialdehydeprotein adducts, as demonstated by flow cytometry. Biochem. Mol. Biol. Int. 34:1259-1270.

- Collins, M.K., Perkins, G.R., Rodriguez Tarduchy, G., Nieto, M.A. and Lopez Rivas, A. 1994. Growth factors as survival factors: regulation of apoptosis. Bioessays $16: 133$ 138.

- Comfurius, P., Senden, J.M., Tilly, R.H., Schroit, A.J., Bevers, E.M. and Zwaal, R.F. 1990. Loss of membrane phospholipid asymmetry in platelets and red cells may be associated with calcium-induced shedding of plasma membrane and inhibition of aminophospholipid translocase. Biochim. Biophys. Acta. 1026:153-160.

- Connor, J., Pak, C.C. and Schroit, A.J. 1994. Exposure of phosphatidylserine in the outer leaflet of human red blood cells. Relationship to cell density, cell age, and clearance by mononuclear cells. J. Biol. Chem. 269:2399-2404.

- Connor, J., Pak, C.H. Zwaal, R.F. and Schrolt, A.J. 1992. Bidirectional transbilayer movement of phospholipids analogs in human red blood cells. Evidence for an ATPdependent and protein-mediated process. J. Biol. Chem. 267:19412-19417.

- Dachary-Prigent, 1., Freyssinet, J.M., Pasquet, J.M., Carron. J.C. and Nurden, A.T. 1993. Annexin $V$ as a probe of aminophospholipid exposure and platelet membrane vesiculation: A flow cytometry study showing a role for free sulfinydryll groups. Blood $81: 2554-2565$

- Darzynkiewicz, Z., Juan, G., Li, X., Gorzyca. W. Muralkami, T. and Traganos, F, 1997. Cytometry in cell necrobiology: Analysis of apoptosis and accidental cell death (necrosis). Cytometry 27:1-20.

- Devaux, P.F. 1991. Static and dynamic lipid asymmetry in cell membranes. Biochemistry 30:1163-1173.

- Diaz, C. and Schroit, A.J. 1996. Role of translocases in the generation of phosphatidylserine asymmetry. J. Membr. Biol. 151:1-9.

- Earnshaw, W.C. 1995. Nuclear changes in apoptosis. Curr Opin. Cell Biol. 7:337 343.

- van Engeland, M., Ramaekers, F.C.S., Schutte, B. and Reutelingsperger, C.P.M. 1996. A novel assay to measure loss of plasma membrane asymmetry during apoptosis of acherent cells in culture. Cytometry 24:131-139.

- van den Eijnde, S.M., Boshart, L., Reutelingsperger, C.P.M., de Zeeuw, C.L., and Vermeij-Keers, C. 1997. Phosphatidylserine plasma membrane asymmetry in wiva: A pancellular phenomenon which alters during apoptosis. Cell Death Differ. 4:311-316.

- Fadok, V.A., Laszlo, D.J., Noble, P.W., Weinstein, L., Riches, D.W. and Henson, P.M. 1993. Particle digestibility is required for induction of the phosphatidy/serine recognition mechanism used by murine macrophages to phagocytose apoptotic cells. J. Immunol. 151:4274 4285.

- Fadok, V.A., Voelker, D.R., Campbell, P.A., Cohen, J.J., Bratton, D.L. and Henson, P.M. 1992. Exposure of phosphatidylserine on the surface of apoptotic lymphocytes triggers specific recognition and removal by macrophages. J. Immunal. 148:2207. 2216.

- Gottesman, M.M. and Pastan, I. 1993 Biochemistry of multidrug resistence mediated by the multidrug transporter. Anru. Rev. Biochem. $62: 385 \cdot 427$.

- Grimm, L.M., Goldberg, A.L., Poirier, G.G., Schwartz, L.M. and Osbonne, B.A. 1996. Proteasomes play an essential role in thymocyte apoptosis. EMBO J. 15:3835-3844.

- Hale, A.J., Smith, C.A., Sutherland, L.C., Stoneman, V.E.A., Longthorne, W.L., Culhane, A.C. and Wiliams, G.T. 1996. Apoptosis: molecular regulation of cell death. Eur. J. Biochem. 236:1-26.

- van Heerde, W.L., de Groot, P.G. and Reutelingsperger, C.P.M. 1995. The complexity of the phospholipid binding protein annexin V. Thromb. Haemost. 73: 172-179.

- Higgins, C.F. 1994. Flip-flop: The transmembrane translocation of lipids. Cell $79: 393$ 395. 
- Inaba, N., Sato, N., Ijichi, M., Fukazawa, I., Nito, A., Takamizawa, H., Luben, G. and Bohn, H. 1984. The immunocytochemical localization of two membrane-associated placetal tissue proteins in human and cynomolgus monkey placentae. Tumour Biol. $5: 75-85$.

- Iwasaki, A, Suda, M., Nakao, H., Nagoya, T., Saino, Y., Arai, K., Mizoguchi, T., Sato, F., Yoshizaki, H., Mirata, M., Miyata, T. Shidara, Y., Murata, M., and Maki, M. 1987. structure and expression of CDNA for an inhibitor blood coagulation isolated from human placenta: A new lipocortin-like protein. J. Biochem. Tokyo 102:1261-1273.

- op den Kamp. 1.A. 1979. Lipid asymmetry in membranes. Annu. Rev. Brachem. $48: 47-71$.

- Kaplan, R., Jaye, M., Burgess, W.H., Schlaepter, D.D. and Haigler, H.T. 1988. Cloning and expression of CDNA for human endonexin $\mathrm{Il}_{\text {, a } \mathrm{Ca}}{ }^{*}$ and phospholipid binding protein. J. Biol. Chem. 263:8037-8043.

- Koopman, G., Reutelingsperger, C.P.M., Kuitten, G.A., Keehnen, R.M., Pals, S.T. and van Oers, M.H. 1994. Annexin $V$ for flow cytometric detection of phosphatidylserine expression on B cells undergoing apoptosis. Blood 84:1415-1420.

- Lazebnik, Y.A., Takahashi, A., Moir, R.D., Goldman, R.D., Poirier, G.G., Kaufmann, S.H. and Earnshaw, W.C. 1995. Studies of the lamin proteinase reveal multiple parallel biochemical pathways during apoptotic execution. Proc. Natl. Acad. SCI. USA. 92:9042-9064.

- Machiels, B.M., Henfling, M.E.R., Schutte, B., van Engeland, M., Broers, J.L.V. and Ramaekers, F.C.S. 1996. Subcellular localization of proteasomes in apoptotic lung bumor cells and persistence as compared to intermediate filaments. Eur. J. Cell Biol. $70: 250-259$.

- Martin, O.C. and Pagano, R.E. 1987. Transbilayer movement of fluorescent analogs of phosphatidylserine and phosphatidylethanolamine at the plama membrame of cultured cells. Evidence for a protein-mediated ATP-dependent process(es). J. Biol. Chem. 262:5890-5898.

- Martin, 5.J "Finucane, D.M. , Amarante-Mendes, G.P., O'Brien, G.A. and Green, D.R. 1996. Phosphatidy/serine externalization during CD95-induced apoptosis of cells and cytoplasts requires ICE/CED-3 protease activity. J. Biol. Chem. 271:28753-28756.

- Martin, S.J. and Green, D.R. 1994. Apoptosis as a goal of cancer therapy. Curr. Opin. Oncol. 6:616-621

- Martin, S.J. and Green, D.R. 1995. Protease activation during apoptosis: death by a thousand cuts? Cell $82: 349-352$.

- Martin, S.J., Reutelingsperger, C.P.M., McGahon, A.J., Rader, J.A., van Schie, R.C., LaFace, D.M. and Green, D.R. 1995. Early redistribution of plasma membrane phosphatidy/serine is a general feature of apoptosis regardless of the initiating stimulus: inhibition by overexpression of Bcl2 and ADl. J. Exp. Med. 182:1545-1556.

- Maurer-Fogy, I., Reutelingsperger, C.P.M., Pieters, J., Bodo, G., Stratowa, C. and Hauptmann, R. 1988. Cloning and expression of CDNA for human vascular anticoagulant, a Ca ${ }^{2+}$ dependent phospholipid-binding protein. Eur. J. Biochem. 174:585592.

- Nagata, S. 1997. Apoptosis by death factor. Cell 88:355-365.

- Naito, M., Nagashima, K., Mashima, T. and Tsuro, T. 1997. Phosphatidylserine externalization is a downstream event of interleukin1-Beta converting enzyme family protease activation during apoptosis. Blood 89:2060-2066.

- Neamati, N., Fernandez, A., Wright, S., Kiefer, J. and McConkey, D.J. 1995. Degradation of lamin B1 precedes aligonucleosomal DNA fragmentation in apoptotic thymocytes and isolated thymocyte nuclei.. J. Immunol. 154:3788-3795.

- Oberhammer, F.A., Hochegger, K., Froschl, G., Tiefenbacher, R. and Pavelka, M. 1994. Chromatin condensation during apoptosis is accompanied by degradation of Iamin $A+B$ without enhanced activation of cdc2 kinase. J. Cell Biol. 126:827-837.

- $\mathrm{O}^{\prime}$ Brien, I.E.W., Reutelingsperger, C.P.M. and Haldaway, K.M. 1997. The use of anmexin $V$ and TUNEL to monitor the progression of apoptosis in plants. Cytometry $29: 28-33$ 
- Raynal, P. and Pollard, H.B. 1994. Annexins: the problem of assessing the biological nole for a gene family of multifunctional calcium- and phospholipid-binding proteins. Biochim. Biophys. Acta. 1197:63-93.

- Reutelingsperger, C.P.M., Hornstra. G. and Hemker, H.C. 1985. Isolation and partial purification of a novel anticoagulant from arteries of human umbilical cord. Eur. $j$. Biochem. 151:625-629.

- Schroit, A.J. and Zwaal, R.F. 1991. Transbilayer movement of phospholipids in red cell and platelet membranes. Biochim. Biophys. Acta. 1071:313-329.

- Schutte, B., Tinnemans, M.M., Pijpers, G.F., Lenders, M.H. and Ranaekers, F.C.S. 1995. Three parameter flow cytometric analysis for simultaneous detection of cytokeratin, proliferation associated antigens and DNA content. Cytometry $21: 177$. 186.

- Seigneuret, M. and Devaux, P.F. 1984. ATP-dependent asymmetric distribution of spin-labeled phospholipids in the erythrocyte membrane: relation to shape changes. Proc. Natl. Acad. SCi. USA. 81:3751-3755.

- Smith, G.K., Duich, D.S., Dev, I.K. and Kaufmann, S.H. 1992. Metabolic effects and kill of human T-cell leukemia by 5-deazacyclotetrahydrofolate, a specific inhibitor of glycineamide ribonucleotide transfomylase. Cancer Res. 52:4895-4903.

- Steller, H. 1995. Mechanisms and genes of cellular suicide. Science 267:1445-1449.

- Stuart, M.C., Bevers, E.M., Comfurius, P., Zwaal, R.F., Reutelingsperger, C.P.M. and Frederik, P.M. 1995. Ultrastructural detection of surface exposed phosphatidylserine on activated blood platelets. Thromb. Haemost. 74:1145-1151.

- Susin, S.A., Zamzami, N., Castedo, M., Hirsch, T., Marchetti, P., Macho, A., Daugas, E., Geuskens, M. and Kroemer, G. 1996. Bd-2 inhibits the mitochondrial rellease of an apoptoglenic protease. J. Exp. Med. 184:1331-1341.

- Swairjo, M.A. and Seaton, B.A. 1994. Annexin structure and membrane interactions: A molecular perspective. Annu. Rev. Biophys. Biomol. Struc. 23:193-213.

- Tait, J.F. Gibson, D. and Fujikawa, K. 1989. Phospholipid binding properties of human placental anticoagulant protein $I$, a member of the lipocortin family. $I$. Biol. Chem. 264:944-7949.

- Tang, X., Halleck, M.S., Schlegel, R.A. and Williamson, P. 1996. A subfamily of P-type ATPases with aminophospholipid transporting activity. Science 272:1495-1497.

- Thiagarajan, P. and Tait, J.F. 1990. Binding of annexin V/placental anticoagulant protein I to platelets. Evidence for phosphatidylserine exposure in the procoagulant repsonse of activated platelets. J. Biol. Chem. 265:17420-17423.

- Tinnemans, M.M., Lenders, M.H., ten Velde, G.P., Ramaekers, F.C.S. and Schutte, B. 1995. Alterations in cytoskeletal and nuclear matrix-associated proteins during apoptosis. Eur. J. Cell Biol. 68:35-46.

- Vanags, D.M., Porn-Ares, M.I., Copolla, S., Burgess, D.H. and Orrenlus S. 1996. Protease involvement in fodrin cleavage and phosphatidylserine exposure in apoptosis. J. Brol. Chem. 271:31075-31085.

- Vaux, D.L. 1993. Toward an understanding of the molecular mechanisms of physiological cell death. Proc. Natl. Acad. Sci. USA. 90:786-789.

- Verhoven, B., Schiegel R.A. and Willamson, P. 1995. Mechanisms of phosphatidylserine exposure, a phagocyte recognition signal, on apoptotic T-lymphocytes. J. Exp. Med. 182:1597-1601.

- Vermes, 1. Haanen, C. Steffens-Naaken, H., Reutelingsperger, C.P.M. 1995. A novel assay for apoptosis flow cytometric detection of phosphatidylserine expression on early apoptotic cells using fluorescein labeled annexin V. I. Immunol. Mathods $184: 39-51$.

- Wyllie, A.H. 1995. The genetic regulation of apoptosis. Curr. Opin. Genet. Dew. 5:97104.

- Zachowski, A. 1993. Phospholipids in animal eukaryotic membranes: Transverse asymmetry and movement. Biachem. J. 294:1-14.

- Zachowski, A. Herrmann, A., Paraf, A. and Devaux, P.F. 1987. Phospholipid outsideinside transiocation in lymphocyte plasma membranes is a proteinmediated phenomenoun. Biochim. Blophys. Acta. 897:197-200. 
- Zhivotovsky, B., Gahm, A., Ankarcrona, M., Nicotera, P. and Orrenius, 5. 1995. Multiple proteases are involved in thymacyte apoptosis. Exp. Cell Res. 221:404-412.

- Zwaal, R.F. and Schroit, A.J. 1997. Pathophysiologic implications of membrane phospholipld asymmetry in bload cells. Blood 89:1121-1132. 


\section{A novel assay to measure loss of plasma membrane asymmetry during apoptosis of adherent cells in culture}

Manon wan Engeland, Frans C.S. Ramaekers, Bert Schutte and Chris P.M. Reutelingsperger

Cytometry $199624: 131-139$

\section{Contents}
4.1 Introduction
4.2 Materials \& methods
4.3 Results
4.4 Discussion
4.5 References 


\section{Abstract}

Early during the process of apoptosis, cells lose their phospholipid membrane asymmetry and expose phosphatidylserine (PS) at the cell surface while maintaining their plasma membrane integrity intact. This process can be monitored for suspended cell types by using annexin $\mathrm{V}$-FITC, which is a $\mathrm{Ca}^{2+}-$ dependent, phospholipid-binding protein with high affinity for PS, and flow cytometry. If adherent cell types are to be studied for this apoptosisassociated phenomenon, then a problem is encountered in that specific membrane damage occurs during harvesting. In this paper, a flow cytometric based method is described that allows the measurement of loss of phospholipid asymmetry during apoptosis of adherent cells in culture. The method relles on the phospholipid binding property of biotinylated annexin $V$. Furthermore, the use of this conjugate allows tricolor flow cytometric analysis of apoptotic cells. Employing the method to MR65 cells, which were initiated by olomoucine to enter apoptosis, it is shown that PS exposure occurs early after the onset of apoptosis and, at the prevalent time-resolution, that PS exposure is accompanied by loss of both cytokeratin and DNA. The annexin $V$ positive cells appear as a characteristic sub-G1 peak in the DNA histogram.

\subsection{Introduction}

Apoptosis is a morphologically distinct process of cell death that constitutes a means of cell suicide for the removal of unwanted cells (Schwartzman and Cidlowski, 1993; Wyllie et al., 1980). It is now appreciated that apoptosis forms a relevant part of physiology as well as pathology. For instance, during embryogenesis, apoptosis is essential in tissue and organ formation (Glücksman, 1951; Zakeri et al., 1994). In the adult organism, apoptosis is responsible for the deletion of autoreactive $T$ cells from the thymus (MacDonald et al., 1990) and low responsive $B$ cells from the germinal center (Liu et al., 1989). Moreover, natural killer cells and cytolytic T cells destroy their target cells by inducing apoptosis (Cohen et al., 1992b). Rapid growth of neoplasias appears to be closely associated with an impairment of the tumor cells to enter apoptosis (Arends et al., 1990). Several genes involved in the apoptotic process have been found to be mutated or to be dysregulated at the transcriptional level. For instance, the p53 gene, which is thought to induce apoptosis, is frequently mutated in many tumor types (Hollstein et al., 1991). In contrast, overexpression of the Bcll-2 gene, which is belleved to protect cells from apoptosis (Bissonnette et al., 1992; Hockenbery et al., 1993), is frequently observed in various malignancies (Arends et al., 1994).

The process of cell death is gene-regulated and elicits degradation of intracellular components and changes of the plasma membrane (PM) structure. These alterations of cellular constitution likely all serve the purpose of elimination by phagocytosis before the dying cell provokes an inflammatory response (Kerr et al., 1972; Wyllie et al., 1980). Methods for the detection of apoptosis and that distinguish it from necrosis are based on the elucidated apoptosis-related features of morphology (cell shrinkage, membrane budding and chromatin condensation (Kerr and Harmon, 1991; Kerr et al., 1995) and biochemistry (endonuclease activity, which cleaves DNA at internucleosomal sites) (Arends et al., 1990; Hockenbery, 1995). The 
standard method for measuring apoptosis is the microscopic detection of these morphological changes. Light and electron microscopy can be employed (Kerr et al., 1995). However, the microscopic method is elaborate, time consuming and cumbersome for quantitative analysis. Changes in morphology of the apoptotic cell can also be monitored by flow cytometry as a change in light-scattering properties. During apoptosis, the cells shift in the cytogram from high forward/low side scatter to low forward/high side scatter signals. To date other assays have been developed based on the activation of endogenous endonucleases (Compton, 1991). Due to this endonuclease activation the DNA is fragmented, and these DNA fragments of nucleosomal size can be visualized by DNA gel electrophoresis. However, morphologically evident apoptosis is not always accompamied by DNA breakdown in nucleosomal fragments (Cohen et al., 1992a). The DNA damage caused by activation of endogenous endonucleases can be visualized on a per cell basis by using the in situ nick translation assay (TUNEL method based on deoxynucleotidyl transferase (Gravieli et al., 1992) (ISEL method based on DNA polymerase I (Wijsman et al., 1993). This technique requires elaborate handling of the cell sample to incorporate hapten-labeled nucleotides at the sites of nicked DNA. Subsequent visualization of the DNA-incorporated hapten may proceed by immunocytochemistry or flow cytometry. Unfortunately, this technique does not discriminate between early and late phase of apoptosis and does not provide information on the PM integrity of the dying cell. Another flow cytometric method has been described that is based on the loss of DNA. Late apoptotic cells reveal themselves by a sub-G1 peak in a DNA histogram (Telford et all., 1992). However, cellular debris also accumulates in this sub-G1 region of the DNA histogram, making this assay ambiguous.

Recently, the PM became appreciated as an attractive target for the analysis of apoptosis. The apoptotic cell changes its PM to signal its process of dying to the environment while maintaining the PM integrity. This results in exclusion of dyes, like trypan blue and propidium iodide (PI), by the apoptotic cell (Darzynkiewicz et al., 1992), with concomitant changes of PM structure. These include a change in carbohydrate profile (Duvall et al., 1985; Morris et al. 1984), a change in surface charge (Savill et al., 1989), a shift from tightly to loosely packaging of the PM phospholipids (Fadok et al., 1992b) and the appearance of phosphatidylserine (PS) in the auter leaflet of the PM (Fadok et al., 1992a, Fadok et al., 1992b). The first two changes have not yet formed the basis for an apoptosis assay, whereas the latter two changes have. Loose packing of PM phospholipids has been probed flow cytometrically by Merocyanine 540, which probably intercalates in these membranes (Mower et al., 1994). The appearance of PS in the outer PM leaflet during apoptosis was successfully elaborated to a flow cytometric assay by Reutelingsperger and coworkers (Homburg et al., 1995; Koopman et al., 1994; Vermes et al., 1995) using annexin $V$, which is a $\mathrm{Ca}^{2+}$-dependent phospholipid-binding protein that binds reversibly and extrinsically to membranes containing PS (van Heerde et al., 1995). The studies with annexin $V$ show that PS exposure starts early after the onset of apoptosis in all of the cell types investigated to date and under the action of a wide variety of initiators of apoptosis (Martin et al., 1995b). Hence, the annexin $V$ assay appears to be a universal method for monitoring the early phase of apoptosis. To date, the annexin $V$ assay has been used to measure apoptosis of cell types that occur 
naturally in suspension. Monitoring apoptosis-related PS exposure by tissuebound or adherent cell types in culture faces the problem of PS exposure by sample handling for flow cytometric analysis. In this paper, we describe an annexin $V$-based method for the quantitative measurement of PS exposure by adherent cell types in culture. This method circumvents the problem of aspecific PS exposure due to cell collection. The method is suitable for tricolor flow cytometric analysis and, hence, allows the comparative study of changes of PM, intracellular antigens and DNA content during apoptosis on a per cell basis.

\subsection{Materials \& methods}

\section{Materials}

Annexin V-FITC (APOPTEST-FITC) and annexin V-biotin (APOPTEST-BIOTIN) were obtained from Nexins Research BV, Hoeven, the Netherlands. Olomoucine, which was a kind gift from Dr. L. Meyer (Station Biologique, CNRS, Roscoff, France) was dissolved in DMSO. FITC-labeled streptavidin and phycoerythrin (PE)-conjugated goat anti-mouse Ig were purchased from DAKO (DAKO A/S, Glostrup, Denmark) and were used in a 1:50 and 1:10 dilution, respectively. The mouse anti-cytokeratin monoclonal antibody RCK102 (EuroDiagnostica, Arnhem, the Netherlands) is directed against cytokeratins 5 and 8 and was used in a 1:10 dilution.

\section{Cell lines}

The human non small cell lung cancer (NSCLC) cell line MR65, which was kindly supplied by Dr. Gropp (Philips Universitäts Klinik, Marburg, Federal Republic of Germany), was cultured in Eagle's modified minimal essential medium (GIBCO, Paisley, Scotland, United Kingdom), supplemented with 1\% non essential amino acid solution (GIBCO), $2 \mathrm{mM}$ L-glutamine (Serva, Heidelberg, Federal Republic of Germany), $10 \mathrm{mM}$ HEPES (GIBCO), 10\% heat-inactivated newborn calf serum (GIBCO) and $50 \mathrm{~kg} / \mathrm{ml}$ gentamycin (AUV, Cuyck, The Netherlands). In some experiments, cells were cultured on 8-well glass slides (Nutacon, Schiphol, The Netherlands), precoated with rat tail collagen $\pi$.

\section{Induction of apoptosis}

Apoptosis was induced by incubating the cultures for several periods of time in the presence of olomoucine, an inhibitor of cyclin dependent kinases (Abraham et al., 1995). Treatment of the cells with $200 \mu \mathrm{M}$ olomoucine (final concentration of DMSO was $0.005 \%$ ) resulted in rapid induction of apoptosis, as evidenced by nuclear condensation (Schutte et al., 1997).

\section{Measurement of PS exposure exposure by annexin $\mathrm{V}$}

Surface exposure of PS by apoptotic MR65 cells was measured by adding annexin $V$-biotin to the culture medium in a final concentration of $3 \mu \mathrm{g} / \mathrm{ml}$. The cells were subsequently incubated for 3 minutes at room temperature (RT). Detached cells were collected with the supernatant, pelleted by centrifugation and washed twice with culture medium to remove excess annexin $V$. The adherent cells were rinsed twice with medium before harvesting. Cells were harvested by four methods: standard trypsinization 
$(0.5 \mathrm{mg} / \mathrm{ml}$ trypsin, $0.2 \mathrm{mg} / \mathrm{ml}$ EDTA in $0.02 \mathrm{mM}$ glucose in phosphatebuffered saline (PBS)), incubation in trypsin without EDTA, incubation in 0.2 $\mathrm{mg} / \mathrm{ml}$ EDTA without trypsin and mechanical scraping with a rubber policeman. Detached and adherent cells were finally pooled and resuspended in culture medium to a final concentration of $1 \times 10^{5} \mathrm{cels} / \mathrm{ml}$. In some expertments, annexin $V$-biotin labeled cells were harvested and reincubated with annexin V-FITC to evaluate the membrane damage during the procedure of harvesting. Cells grown on glass slides were incubated with $3 \mu \mathrm{g} / \mathrm{m}$ annexin $\checkmark$-FITC for 3 minutes at RT. After gently rinsing with culture medium the cells were covered with a coverslip and examined by confocal scanning laser microscopy (CSLM).

\section{Immunocytochemistry}

Annexin $V$-biotin labeled cells were resuspended in culture medium to a final concentration of $1 \times 10^{6}$ cells $/ \mathrm{ml}$. To $0.5 \mathrm{ml}$ of the suspension FITC-llabeled streptavidin and PI $(1 \mathrm{\mu g} / \mathrm{mi}$ final concentration) were added. Samples were kept on ice for 5 minutes before fllow cytometric analysis. For tricolor flow cytometric analysis, annexin $V$-biotin-labeled cells were fixed for 5 minutes in absollute methanol at $-20^{\circ} \mathrm{C}$. Fixed cells were rinsed once with PBS, and once with PBS/bovine serum albumin (BSA; $1 \mathrm{mg} / \mathrm{ml}$, Sigma). To $100 \mu \mathrm{l}$ of resuspended cell pellet, FITC-labeled streptavidin and mouse anti-cytokeratin monoclonal antibody were added. After incubation for 1 hour at RT, the celis were rinsed twice with PBS/BSA and antibody binding was visualized by adding PE-labeled goat anti-mouse Ig to the resuspended pellet. After rinsing twice in PBS/BSA, the cells were finally resuspended in PBS, supplemented with PI ( $5 \mu \mathrm{g} / \mathrm{ml} \mathrm{PI,} \mathrm{Calbiochem,} \mathrm{La} \mathrm{Jolla,} \mathrm{CA)} \mathrm{and} 100 \mu \mathrm{g} / \mathrm{ml}$ RNAse (Serva, Heidelberg, Germany) and kept on ice for 15 minutes prior to flow cytometric analysis.

\section{Flow cytometry}

For flow cytometric analysis a FACSort. (Becton Dickinson, Sunnyvale, CA) equipped with a single argon ion laser was used. Excitation was at $488 \mathrm{~nm}$, and the emission filters used were 515-545 BP (green; FITC), 572-588 BP (orange; PE) and 600 LP (red; PI). A minimum of 10,000 cells per sample were analyzed and data were stored in list mode. Electronic compensation was used to eliminate bleed through of fluorescence. For tricolor analysis, the following settings were used: 400,405 and $350 \mathrm{~V}$ on photomultiplier tubes for FL1 (FITC), FL2 (PE) and FL3 (PI), respectively. Compensation for FL1$\%$ FL2, FL2-\%FL1, FL2-\%FL3 and FL3-\%FL2 was $0.2,38.9,42.8$ and $8.3 \%$ respectively (Schutte et al., 1995). Data analysis was performed with the standard Lysis and Cellfit software (Becton Dickinson). Data were gated on pulse-processed PI signals to exclude doublets and larger aggregates as a standard procedure (Schutte et al., 1995).

\section{CSLM}

Cells cytocentrifuged onto glass slides were analyzed by using the MRC600 confocal scanning laser microscope (Bio-Rad, Hemel Hempstead, UK), equipped with an air-cooled Argon-Krypton mixed-gas laser and mounted onto an Axiophot microscope (Zeiss, Oberkochen, Federal Republic of Germany). The laser scan microscope was used in the dual parameter setup, according to the manufacturer's specification, using dual wavelength exci- 
tation at $488 \mathrm{~nm}$ and $568 \mathrm{~nm}$. Emission spectra were separated by the standard sets of dichroic mirrors and barrier filters. All scans were recorded in photon counting mode. Differential interference contrast images were collected using normal light illumination. The laser pathway was blocked and the filter sets were removed.

\subsection{Results}

Probing PS exposure for apoptosis should solely indicate the loss of PM asymmetry caused by specific cellular processes and not by damage inflicted on cells by handling. Such damage is likely to occur during attempts to detach adherent cells from the culture flask. As illustrated by figure 4.1 , which shows annexin V-FITC binding of MR65 cells that were harvested by trypsinization. The cells were harvested during exponential growth, and, in such cultures, only a few cells will be apoptotic (1-5\%). However, the cytogram in figure 4.1 indicates that approximately $25 \%$ of the cells show annexin $V$-binding and lack of PI uptake.

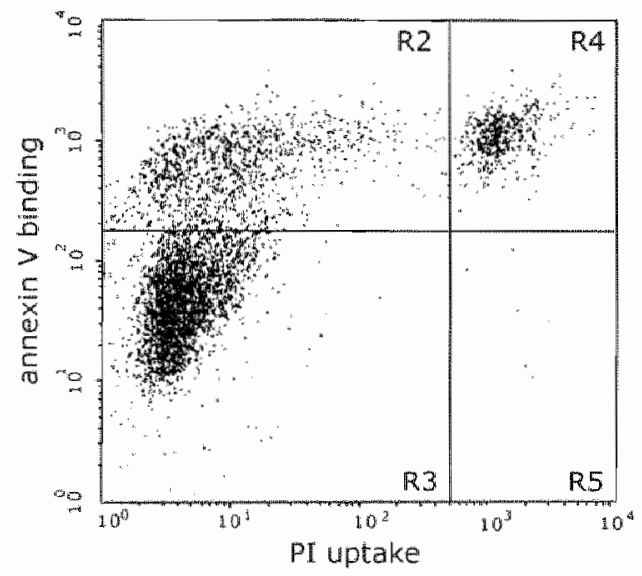

Figure 4.1: Cytogram of annexin $V$ binding ( $y$-axis) versus PI uptake $(x$-axis) in exponentially growing MR65 cells after harvesting by trypsinization. Damaged (annexin $\left.V^{*} / P I\right)$, vital (annexin $\left.V / P I\right)$ and dead cells (annexin $V^{*} / P I^{*}$ ) are shown in R2, R3 and R4 respectively.

To investigate the effects of various harvesting protocols on PS exposure, exponentially growing and olomoucine treated cultures of MR65 cells were labeled with annexin $V$-biotin prior to harvesting. Cells were then harvested using the four protocols described in materials \& methods. After harvesting, the suspensions were split in two. To one part, FITC-labeled streptavidin and PI were added. To the other part, FITC-labeled annexin $V_{\text {, FITC-labelled }}$ streptavidin and PI were added. Numbers of annexin ${ }^{+1} / \mathrm{PI}$ cells were quantified by using flow cytometry (table 4.1). 
Based on the detection by annexin $\vee$-biotin, hardly any annexin ${ }^{+1} / \mathrm{PI}^{-}$cells weire detected in exponentially growing cultures, as is expected with all harvesting protocols. After reprobing with annexin V-FITC all protocols showed high numbers of annexin $\mathrm{V}^{\text {t }}$ cells, indicating the occurrence of membrane damage during harvesting. In the olomoucine treated cultures annexin $V$-biotin binding was only observed after scraping of cells (table 4.1 ). Treatment of cells with trypsim and EDTA, either in combination or separately, resulted in a decrease of annexin $V$-biotin signal.

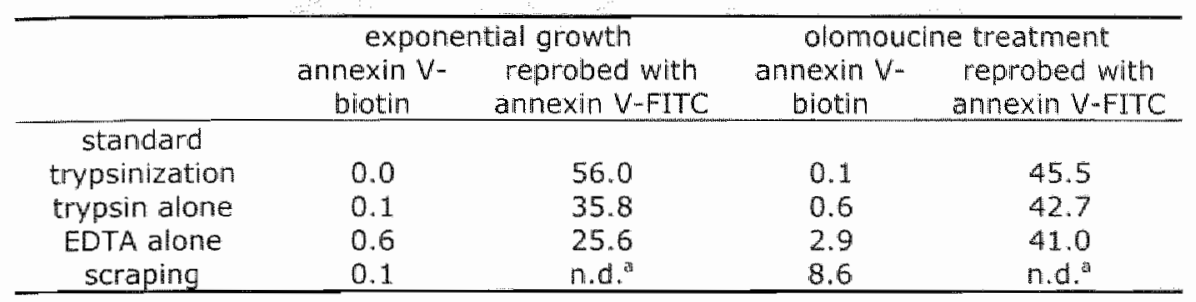

${ }^{a}$ n.d. = not determined

Table 4.1: Effect of harvesting on the percentage of annexin $\mathrm{V}^{*} / \mathrm{PI}^{*}$ cells in exponentially growing and olomoucine treated MR65 celis. Results of a representative experiment.

To verify whether the annexin V-biotin ${ }^{+} / \mathrm{PI}^{\prime}$ cells were indeed apoptotic cells, cells were cytocentrifuged on glass slides. After a brief fixation in cold methanol, the cells were counterstained with PI. Microscopic analysis showed that $95 \%$ of the annexin ${ }^{+}$cells were identified as apoptotic based on their nuclear condensation. On the other hand, less than $5 \%$ of the annexin" cells showed a condensed chromatin pattern. Further evidence came from olomoucine treated cells grown on glass slides. After labeling with annexin VFITC the cells were analyzed directly by CSLM. Figure 4.2 shows an example of a merged image of annexin $V$-binding and cell morphology.

Annexin labeling was exclusively observed in cells showing typical membrane budding in the differential interference contrast image.

For further experiments annexin $V$-biotin labeling in combination with harvesting by scraping was used. In this way, the kinetics of induction of apoptosis by olomoucine in MR65 cells were investigated. Figure 4.3 shows bicolor annexin V/PI analyses of MR65 cells after 0 (control), 4, 6 and 8 hours in the presence of olomoucine. Apoptotic cells appeared in the annexin $\mathrm{V}^{t} / \mathrm{PI}$ fraction, and cells, which were damaged by scraping, appeared in the annexin $\mathrm{V}^{-} / \mathrm{PI}^{+}$fraction, whereas undamaged viable cells remained negative for both parameters. In contrast to apoptosis measurements of suspended cells by FITC-labeled annexin $V$, no significant shift from annexin $V^{+} / \mathrm{PI}^{*}$ to the annexin $\mathrm{V}^{+} / \mathrm{PI}^{+}$compartment was seen after prolonged exposure to olomoucine. 


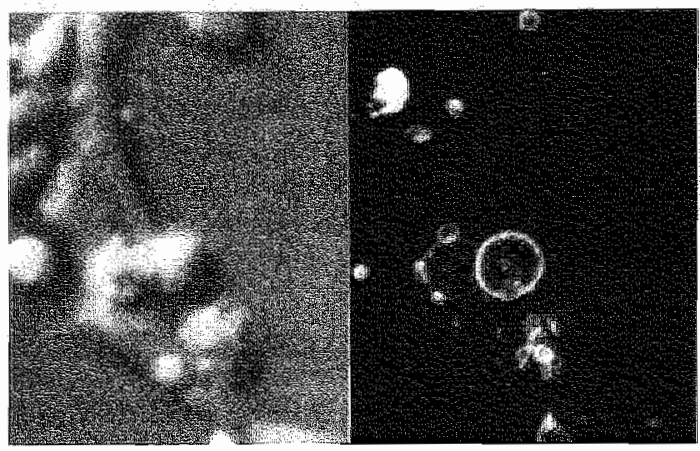

Filgure 4.2: Annexin $V$ binding in an ollomoucine treated culture of MR65 cells analyzed by using confocal scanning laser microscopy. Apoptotic cells are characterized by membrane budding, which can be seen in the differential interference contrast image (left). These cells also show annexin $V$ binding (right). Even small vesicle-like structures are positive for annexin $\mathrm{V}$.
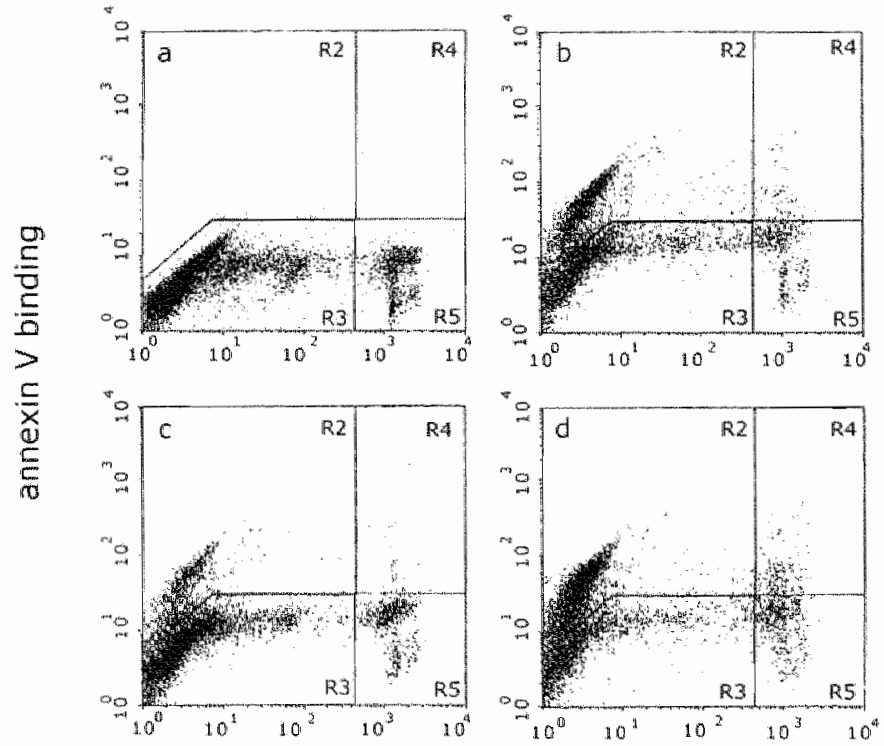

PI uptake

Figure 4.3: a-d: Cytograms of annexin $V$ binding ( $y$-axis) versus PI uptake ( $x$-axis) in olomoucine treated MR65 cells after labeling with annexin $V$-biotin in culture and subsequent harvesting by scraping. Apoptotic (annexin $\mathrm{V}^{+} / \mathrm{PI}^{*}$ ), vital (annexin $\mathrm{V} / \mathrm{PI}^{*}$ ), and damaged (annexin $V^{*} / P^{*}$ ) cells are shown in $R 2, R 3$ and $R 5$ respectively. A control culture is depicted in a and cultures incubated for 4,6 and 8 hours with olomoucine are shown in b, $c$ and d respectively. The control culture shows hardly any apoptotic cells, whereas, with prolonged exposure to olomoucine, the frequency of these cells is increased. 
The number of apoptotic cells was quantitated at various time intervals (shown in figure 4.4). The frequency of apoptotic cells increased gradually up to 8 hours of culture in the presence of olomoucine. In contrast, the frequency of damaged cells remained constant.

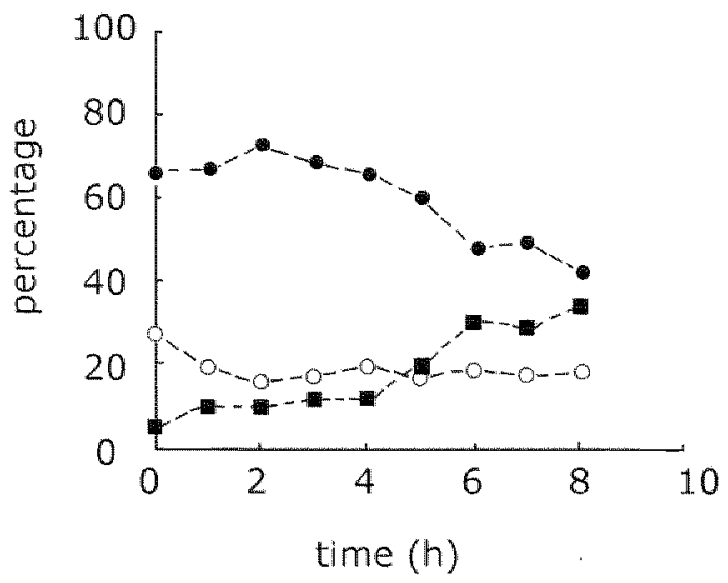

Figure 4.4: Kinetics of induction of apoptosis in MR65 cellls as analyzed by bivariate annexin V/PI flow cytometric analysis. During prolonged incubation in the presence of olomoucine, the frequency of vital cells (1) gradually decreased, whereas the frequency of apoptotic cells ( increased. The number of damaged cells $(0)$ remained relatively constant.

Figure 4.5 shows that it is feasible to study antigen expression in apoptotic cells by using multivariate flow cytometric analysis. To this end, annexin $\mathrm{V}$ biotin-labeled MR65 cells were fixed in cold methanol and stained for the presence of cytokeratins and DNA content. Based on annexin $V$ binding, vital and apoptotic cells could be discriminated and the cytokeratin expression could be analyzed in both populations of cells. In accordance with Tinnemans et al. (1995), apoptotic cells tend to loose their cytokeratin skeleton rapidly (figure $4.5 \mathrm{~b}$ ). It is worth noting that there are annexin $v^{\text {th }}$ cells with high cytokeratin levels, suggesting that the PM changes precede loss of cytokeratin immunoreactivity. Furthermore, it could be shown that annexint $/$ cytokeratin ${ }^{-}$cells are further characterized by loss of DNA (figure $4.5 \mathrm{c}$ and $4.5 d)$. This is further exemplified in figure $4.5 f$ where a characteristic sub-G1 peak is observed in the olomoucine treated culture. 

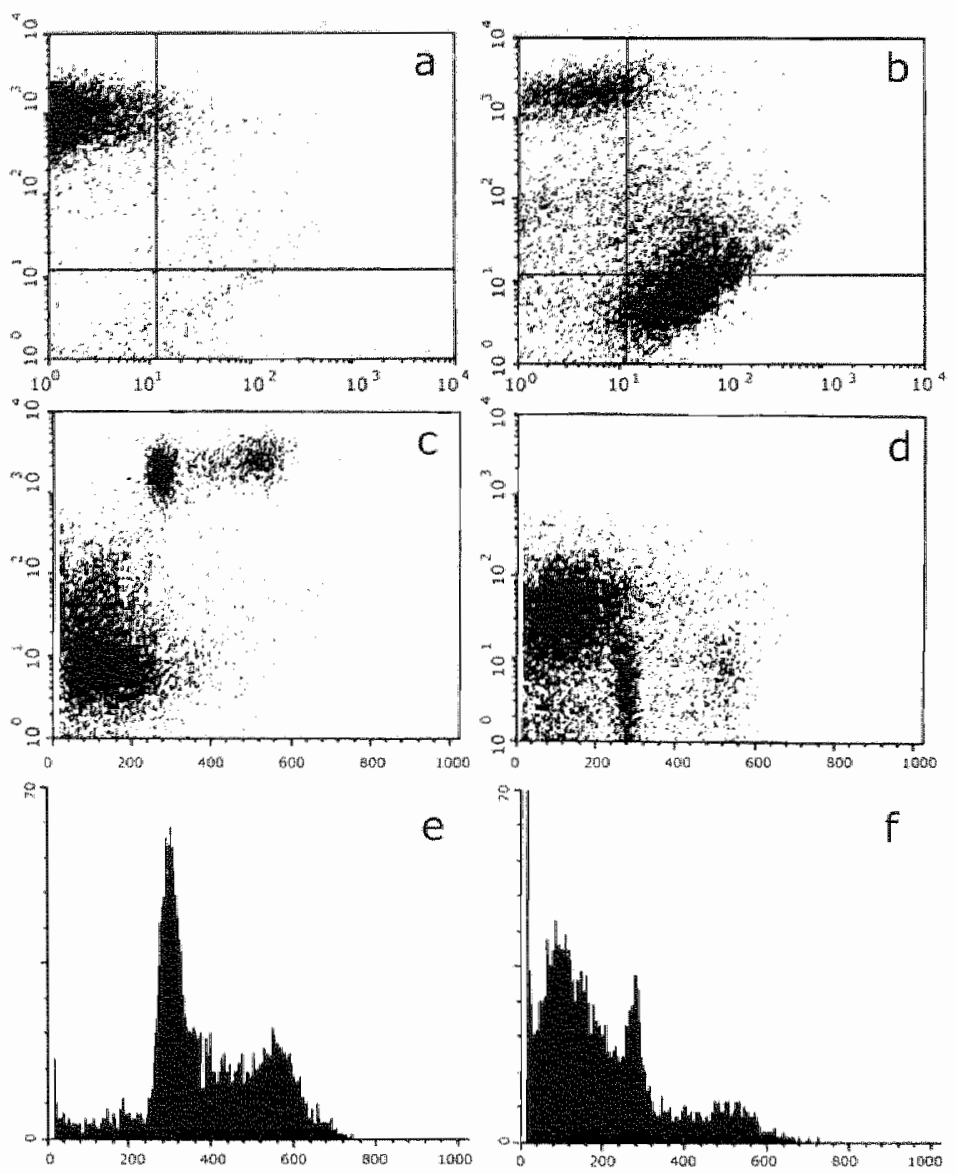

Figure 4.5: a-f: Multivariate analysis of apoptosis in MR65 cells after 8 hours of treatment with olomoucine. Annexin $V$ binding was performed in culture, followed by harvesting of the cells by scraping. The suspended cells were briefly fixed in methanal and were subsequently stained for cytokeratin and DNA content. a: Dotplot of anmexin $\checkmark$ binding ( $y$-axis) versus cytokeratin immunofluorescence $(x$-axis) of control cells. b: dotplot of olomoucine treated cells. In this case, the majority of annexin $v$ cells, were devold of cytakeratin staining. $c$ and $d$ : Dotplots of DNA content ( $x$-axis) versus cytokeratin fluorescence (c) and versus annexin $V$ binding (d). Cytokeratin/annexim $V^{*}$ cells are characterized by loss of DNA, as evidenced by the dotplots shown in $c$ and $d$. This loss of DNA is evidenced by the appearance of a sub G1 peak in the DNA histogram (f). For comparison, the cell cycle distribution of the controll culture is depicted in e. 


\subsection{Discussion}

This paper describes a novel assay for measuring apoptosis-associated PS externalization by adherent cells in culture. With this assay, it is shown that viable MR65 cells in culture maintain an asymmetric distribution of PS over the two leaflets of the PM and that this asymmetry changes during apoptosis. The asymmetric distribution of phospholipids over the two leaflets of the PM. with PS predominantly locating in the leaflet facing the cytosol, was recognized for the erythrocyte about 20 years ago (op den Kamp, 1979). This PM architecture now appears to be shared by enucleated and nucleated mammalian cell types, as were studied in most cases with isolated and suspended cell types in culture (Zachowski, 1993). Now, it is clear that such asymmetry of the PM is a pancellular phenomenon in vivo in the developing mouse embryo (van den Eijnde et al., 1997) and probably in all developing and full grown mammals.

Changes of PM asymmetry have been described to occur under specific conditions. These changes include the cell surface exposure of PS and happen while the PM retains its integrity. Aging erythrocytes in vivo expose PS (Connor et al., 1994), which mediates recognition by and adherence to the reticulloendothelial system (Schroit et al., 1985). Receptor-ligand-activated platelets translocate PS to the outer PM leaflet, where it forms a receptor site that catalyzes specific reactions of the blood coagulation system (Bevers et al., 1982). Fadok and coworkers were the first to recognize that human and murine leukocytes expose PS at their cell surface during apoptosis and that the exposed PS contributes to the recognition and phagocytosis of the apoptotic cell by phagocytes (Fadok et al., 1992a; Fadok et al., 1992b). Hence, PS exposition by cells is likely a specific and regulated process that occurs universally during the terminal phase of existence of the cell. This concept turned the PM into an attractive target to detect apoptosis.

With the use of FITC-labeled annexin $V$, which was shown to discriminate between PS-exposing and non PS-exposing erythrocytes (Tait and Gibson, 1994) and platelets (Dachary-Prigent et al., 1993; Thiagarajan and Tait, 1991), it could be demonstrated that PS externalization is an early and widespread event of apoptosis. It occurs well before nuclear condensation, cell shrinkage and loss of PM integrity (Homburg et al., 1995; Koopman et al. 1994; Martin et al., 1995b; Vermes et al., 1995). This was shown for suspended cell types but has not yet been shown for adherent cell types. The annexin V-FITC-based assay could not be transferred directly to tissue-bound and adherent cell types. Damage to these cells during collection for flow cytometry would allow access of anmexin V-FITC to internally located PS and, hence, give false positive results. To circumvent this problem, we developed an annexin $V$-biotin-based assay to target for specifically exposed PS during apoptosis of adherent cell types. To this end, several harvesting protocols were investigated using exponentially growing MR65 cells with a low incidence of apoptosis. All protocols induced PM damage, as evidenced by annexin $V$ binding to the cells after harvesting. Therefore, the protocol was adapted to allow annexin $V$-biotin binding to the MR65 cells before harvesting. Hence, only the cells exposing PS in culture would bind annexin $V$. Subsequent harvesting with trypsin and EDTA appeared to influence the measurable amount of bound annexin $V$, because trypsin and EDTA remove bound annexin $\mathrm{V}$ from the surface by proteolysis and chelation of $\mathrm{Ca}^{2+}$ tons, 
respectively (Andree et al., 1990; Tait et al., 1989). The other option for harvesting, mechanical scraping, appeared to be a suitable method of cell collection for the purpose of surface exposed PS measurements.

The developed assay allowed us to study the kinetics of apoptosis of olomoucine-treated MR65 cells by bicolor analysis using the annexin $V$ biotin/streptavidin-FITC/PI combination. Olomoucine is an inhibitor of cyclin dependent kinases and induces apoptosis in various cell types (Abraham et al., 1995). With increasing periods of time, we measured an increase of the apoptotic subpopulation (the annexin $\mathrm{V}^{+} / \mathrm{PI}^{-}$cells), indicating that the method was suitable to measure apoptosis in cultures of adherent cells. However, we were expecting to distinguish four subpopulations in the cytograms, namely: the mechanically damaged vital (annexin $V / P I^{+}$), the undamaged vital (annexin $V^{\prime \prime} / P I^{-}$), the apoptotic (annexin $V^{+} / \mathrm{PI}^{-}$) and the secondary necrotic (annexin $\mathrm{V}^{+} / \mathrm{PI}^{+}$) subpopulations. Secondary necrosis is likely the consequence of apoptosis in culture where no phagocytes are present to remove the dying cell. The latter three subpopulations were detected in suspended cell populations upon analysis by using annexin V-FITC (Homburg et al., 1995; Koopman et al., 1994; Martin et al., 1995b; Vermes et al., 1995). However, in the olomoucine treated MR65 cell samples, the secondary necrotic subpopulation was hardly detectable, indicating that loss of PM integrity by the apoptotic cell does not occur significantly under the presented conditions. Because we measured this in the adherent cell population, the secondary necrosis probably occurs in a later stage of apoptosis, when the dying cells themselves have already detached from the surface of the dish and disintegrate immediately in apoptotic bodies. Microscopic analysis confirmed that the olomoucine-treated MR65 cells that bound annexin Vbiotin were indeed apoptotic, as was indicated by concomitant chromatin condensation. In contrast, all cells with a normal nuclear morphology were annexin $V^{-}$. This relationship was also reported for apoptotic hemopolietic cell types (Homburg et al., 1995; Koopman et al., 1994). It was also shown by using combined differential interference contrast microscopy and immunofluorescence microscopy that olomoucine-treated MR65 cells, which displayed severe membrane budding and tended to detach from the glass slides, all showed strong annexin $V$ staining, whereas the adherent cells with normal morphology were negative. Martin and coworkers (1.995b) showed that PS externalization occurs early after the onset of apoptosis of suspended cell types, well before morphological changes are detectable using flow cytometiry. This appears to hold true for the adherent cell type as well. We demonstrated with this assay that, during apoptosis, MR65 cells externalize PS concurrently with nuclear condensation and before loss of PM integrity has accurred. We also detected a small number $(+/-5 \%)$ of annexin $V^{*}$ cells with a normal nuclear morphology, suggesting that cell surface exposure of PS precedes the nuclear condensation. By using this assay, we found that neuroblastoma cells stimulated to enter apoptosis also expose PS with an intact PM (data not shown). These findings strongly support the concept that PS exposure is a universal and early phenomenon of apoptosis that occurs in suspended as well as tissue-bound cell types.

Because we were able to uniquely label apoptotic cells in culture with annexin $\checkmark$-biotin, we further investigated the feasibility of combined antigen expression, DNA content analysis and PS externalization by using multiparameter flow cytometry. To this end, the biotinylated-annexin $V$ labeled cells were 
fixed after harvesting and stained for the presence of eytokeratins and DNA content. It was shown that, in a mixed population, apoptotic cells could be analyzed separately by gating on annexin $V$ fluorescence. The apoptotic nature of these cells was further confitmed by the loss of DNA and shifted scatter properties. In accordance with Tinnemans and coworkers (1995) we observed a rapid loss of cytokeratins in apoptotic cells. Degradation of these cytoskeletal components is probably catalyzed by proteases, such as calpain. the activity of which is involved in the finalization of the apoptotic process (Squier et al., 1994). Cytoskeletal degradation has been suggested to be a universal phenomenon of apoptosis (Martin et al., 1995a), as is the change of PM asymmetry (Martin et al., 1995b). A linkage of both processes is obvious from the structural perspective. However, we found that a minority of the annexin $\mathrm{V}^{+}$cells was still positive for cytokeratin, suggesting that loss of membrane asymmetry precedes degradation of the cytokeratins. Whether this is also the case with other cytoskeletal components like fodrin, which is part of the cortical cytoskeleton and is proteolyzed during apoptosis (Martin et al., 1995a), requires further investigation. Such investigations are now facilitated by the method presented.

In summary, we present a novel flow cytometric assay for the detection of apoptotic cells based on loss of membrane asymmetry in adherent cell cultures. This approach circumvents the problem of measuring false positives due to membrane damage inflicted upon vital cells during their detachment from the culture flasks. Furthermore, annexin $V$ labeled cells can be used for multivariate flow cytometric analysis, which enables the study of antigen expression during apoptosis. This novel assay should contribute to unraveling further the process of apoptosis of tissue-bound and adherent cell types in culture.

\section{Acknowledgments}

The authors are indebted to the technical assistance of Cecile Maasen. The authors thank Dr. L. Meijer (Station Biologique, CNRS, Roscoff, France) for providing us with olomoucine.

\subsection{References}

- Abraham, R.T., Acquarone, M., Andersen, A., Asensi, A., Belle, R., Berger, F., Bergounioux, C., Brunn, G., Buquet-Fagot, C., Fagot, D., Glab, M., Goudeau, H., Goudeaw, N., Geurrier, P., Houghton, P.J., Hendriks, H., Kloareg, B., Lippai, M., Marle, D., Maro, B. Meijer, L., Mester, J., Mulner-Lorillon, O., Poulet, S.A., Schierenberg, E., Schutte, B., Vaulot, D. and Verihac, M.H. 1995. Cellular effects of olomoucine, an inhibitor of cyclin-dependent kinases. Biol Cell 83:1.05-120.

- Andree, H.A. Reutelingsperger, C.P.M., Hauptmann, R., Hemker, H.C., Hermens, W.T. and Willems, G.M. 1990. Binding of wascular anticoagulant alpha (WAC alpha) to planar phospholipid bilayers. J. Bjol. Chem. 265:4923-4928.

- Arends, M.J. Morris, R.G. and Wyllie, A.H. 1990. Apoptosis. The role of the endonuclease. Am. J. Pathol. 136:593-608.

- Arends, M.J., McGregor, A.H. and Wyllie, A.H. 1994. Apoptosis is inversely related to necrosis and determines net growth in tumors bearing contitutively expressed myc. ras and HPV oncogenes. Am. J. Pathol. 144:1045-1057. 
- Bevers, E., Comfurius, E.P., van Rijn, J., Hemker, H.C. and Zwaal, R.F. 1982. Generation of prothrombin-converting activity and the exposure of phosphatidylserine at the outer surface of platelets. Eur. J. Blochem. 122:429-436.

- Bissonnette, R.P., Echeverri, F., Mahboubi, A. and Green, D.R. 1992. Apoptotic cell death induced by c-myc is inhibited by bd-2. Nature 359:552-556.

- Cohen, G.M., Sun, X.M., Snowden, T., Dinsdale, D. and Skiletter, D.N. 1992a. Key morphological features of apoptosis may occur in the absence of internucleosomal DNA fragmentation. Biochem. J. 286:331-334.

- Cohen, 1.J., Duke, R.C., Fadok, V.A. and Sellins, K.S. 1992b. Apoptosis and programmed cell death in immunity. Annu. Rev. Immunol. 10:267-293.

- Compton, M.M. 1991. Development of an apoptosis endonuclease assay. DNA Cel Biol. 10:" $33-141$.

- Connor, 3., Pak, C.C. and Schroit, A.1. 1994. Exposure of phosphatidylserine in the outer leaflet of human red celis. Relationship to cell density, cell age and clearance by mononuclear cells. 3. Biol. Chem. 28:2399-2404.

- Dachary-Prigent, J., Freyssinet, J.M., Pasquet, J.M., Carron, J.C. and Nurden, A.T. 1993. Annexin $V$ as a probe of aminophospholipid exposure and platelet membrane vesiculation: a flow cytometry study showing a role for free sulfhydryl groups. Blood 10:2554-2565.

- Darzynkiewicz, Z., Bruno, S., Del Bino, G., Gorzyca, W., Hotz, M.A., Lassota, P. and Traganos, F. 1992. Features of apoptotic cells measured by flow cytometry. Cytometry 13: 795-808.

- Duvall, E., Wyllie, A.H. and Morris, R.G. 1985: Macrophage recognition of cells undergoing programmed cell death (apoptosis). Immunology 56:351-358.

- van den Eijnde, S.M., Boshart, L., Reutelingsperger, C.P.M., de Zeeuw, C.I. and Vermeij-Keers, C. 1997 . Phosphatidylserine plasma membrane asymmetry in vivo: a pancellular phenomenon which alters during apoptosis. Cell Death Differ. 4: 311-316.

- Fadok, V.A., Savill, J.S. Haslett, C., Bratton, D.L., Doherty, D.E., Campbell, P.A. and Henson, P.M. 1992a. Different populations of macrophages use either the vitronectin receptar or the phosphatidylserine receptor to recognize and remove apoptotic cells. J. Immunol. 149:4029-4035.

- Fadok, V.A., Voelker, D.R., Campbell, P.A., Cohen, J.J., Bratton, D.L. and Henson, P.M. 1992b. Exposure of phosphatidyiserine on the surface of apoptotic lymphocytes triggers recognition and removal by macrophages. J. Immunol. 148:2207-2216.

- Glücksman, A. 1951. Cell deaths in normal vertebrate ontogeny. Biol. Rev. Camb. Philos. Soc. 26:59-86.

- Gravieli, Y., Sherman, Y. and Ben-Sasson, S.A. 1992. Identification of programmed cell death in-situ via specific labeling of nuclear DNA fragmentation. $\lambda$. Cell Biol. 119:493-501.

- van Heerde, W.L., de Groot, P.G. and Reutelingsperger, C.P.M. The complexity of the phospholipid binding protein annexin V. Thromb. Haemost. 73:172-179.

- Hockenbery, D.M. 1995. Defining apoptosis. Am. J. Pathol. 146:16-19.

- Hockenbery, D.M., Oltvai, Z.N., Yin, X.M., Milliman, C.L. and Korsmeyer, S.J. 1993. Bcl-2 functions in an antioxidant pathway to prevent apoptosis. Cell 75:241-251.

- Hollstein, M., Sidransky, D., Vogelstein, B. and Harris, C. 1991. P53 mutations in 6 human cancers. Science 253:49-53.

- Homburg, C.H., de Haas, M., von dem Borne, A.E, Verhoeven, A.J., Reutelingsperger, C.P.M. and Roos, D. 1995. Human neutrophils lose their surface FC gamma RIII and acquire annexin $\mathrm{V}$ binding sites during apoptosis in vitro. Blood 85:532-540.

- Kerr, J.F.R., Wyllie, A.H. and Currie, A.R. 1972. Apoptosis: A basic biological phenomenon with wide-ranging implications in tissue kinetics. Br. J. Cancer 26:239257.

- Kerr, J.F.R and Harmon, B.V. 1991. Defenition and incidence of apoptosis: an historical perspective. In Apoptosis: the molecular basis of cell death. Tomei, L.D. and Cope, F. editors. (New York: Cold Spring Harbor Laboratory Press) pp. 5-29.

- Kerr, J.F.R., Gobe, G.C., Winterford, C.M. and Harmon, B.V. 1995. Anatomical methods in cell death. In Methods Cell Biol. Wilson, L. and Matsudaira, P. editors (San Diego: Academic Press Inc.) pp. 1-26. 
- Koopman, G., Reutelingsperger, C.P.M., Kuijten, G.A.M., Keehnen, R.M.J., Pals, S.T. and van Oers, M.H.J. 1994. Annexin $V$ for flow cytometric detection of phosphatidylserine expression on B cells undergoing apoptosis. Blood 84:1415-1420.

- Liu, Y.J., Joshua, D.E., Willams, G.T., Smith, C.A., Gordon, 1. and McLennan, I.C.M. 1989. Mechanisms of antigen driven-selection in germinal centers. Natwre 342:929931.

- MacDonald, H.R. and Lees, R.K. 1994. Programmed cell death of autoreactive thymocytes. Nature 343:642-644.

- Martin, S.J., O'Brien, G.A., Nishioka, W.K., MacGahon, A.J., Mahboubi, A., Saido, T.C. and Green, D.R. 1995a. Proteolysis of fodrin (non-erythroid spectrin) during apoptosis. 3. Biol. Chem. 270:6425-6428.

- Martin, S.J., Reutelingsperger, C.P.M., McGahon, A.J., Rader, J., van Schie, R.C.A.A., LaFace, D.M. and Green, D.R. $1995 \mathrm{~b}$. Early redistribution of plasma membrane phosphatidy/serine is a general feature of apoptosis regardless of the initiating stimulus. Inhibition by overexpression of Bcl-2 and Abl. . Exp. Med. 182:1545-1557.

* Morris, R.G., Hargreaves, A.D., Duvali, E. and Wyllie, A.H. 1984. Hormone-induced cell death surface changes in thymocytes undergoing apoptosis. Am. J. Pathol. $115: 426-436$

- Mower, D.A., Peckham, D.W., Illera, V.A., Fishbaugh, 1.K., Stunz, L.L. and Ashman, R.F. 1994. Decreased membrane phospholipid packing in mature mouse $B$ cell apoptosis. J. Immunol. 152:4832-4842.

- op den Kamp, J.A.F. 1979. Lipid asymmetry in membranes. Annu. Rev. Biochem. 48: $47-71$.

- Savill, J.S., Henson, P.M. and Haslett, C. 1989. Phagocytosis of aged human neutrophils by macrophages is mediated by a novel 'charge sensitive' recognition mechanism. J. Clin. Invest. 84:1518-1527.

- Schroit, A.J., Madsen, J,W. and Tanaka, Y. 1985. In vivo recognition and clearance of red blood cells containing phosphatidylserine in their plasma membrane 7 . Biol. Chem. 260:5131-5138.

- Schutte, B., Tinnemans, M.M.F.J. „Pijpers, G.F.P., Lenders, M.H.J.H. and Ramaekers, F.C.S. 1995. Three parameter flow cytometric analysis for simultaneous detection of cytokeratin, proliferation associated antigen and DNA content. Cytometry 21:177186.

- Schutte, B., Nieland, L.J.W., van Engeland, M., Henfling, M.E.R., Meijer, L. and Ramaekers, F.C.S. 1997. The effect of the cyclin-dependent kinase inhibitor olomoucine on cell cycle kinetics. Exp. Cell Res. 236:4-15.

- Schwartzman, R.A. and Cidlowski, J.A. 1993. Apoptosis: the biochemistry and molecular biology of programmed cell death. Endocrine Rew. $14: 133-151$.

- Squier, M.K.T., Miller, A.C.K., Malkinson, A.M. and Cohen, J.J. 1994. Calpain activation in apoptosis. J. Cell Physiol. 159:229-237.

- Tait, J.F., Gibson, D. and Fujkawa, K. 1989. Phospholipid binding properties of human placental anticaagulant protein I, a member of the lipocortin farnily. J. Biol. Chem. 264:7944-7949.

- Tait, J.F. and Gibson, D. 1994. Measurement of membrane phospholipid asymmetry in normal and sickle-cell erythrocytes by means of annexin $v$ binding. 3 . Lab. Clin. Med. 123:741-748.

- Telford, W.G. King, L.E. and Fraker, P.J. 1992. Comparitive evaluation of several DNA binding dyes in the detection of apoptosis-associated chromatin degradation by flow cytometry. Cytometry 13:137-143.

- Thiagarajan, P. and Talt, J.F. 1991. Collagen-induced exposure of anionic phospholipid in platelets and platelet-derived microparticles. J. Biol. Chem. 266:24302-24307.

- Tinnemans, M.M.F.J., Lenders, M.H.J.H., ten Velde, G.P.M., Ramaekers, F.C.S. and Schutte, B. 1995. Alterations in cytoskeletal and muclear matrix associated proteins during apoptosis. Eur. J. Cell. Biol. 68:35-46.

- Vermes, I., Haanen, C., Steffens Nakken, H. and Reutelingsperger, C.P.M. 1995. A novel assay for apoptosis: flow cytometric detection of phosphatidylserine expression on early apoptotic cells using fluorescein labelled annexin V. I. Immunol. Methods $184: 39-51$. 
- Wijsman, J.H., Jonker, R.R., Keijzer, R., van de Velde, C.H.J., Cornelisse, C.J. and van Dierendonck, J.H. 1993. A new method to detect apoptosis in paraffin sections: In situ end-labeling of fragmented DNA. J. Histochem. Cytochem. 41:7-12.

- Wyllie, A.H., Kerr, J.F.R. and Currie, A.R. 1980. Cell death: The significance of apoptosis. Int Rev. Cytol. 68:251-306.

- Zachowskl, A. 1993. Phospholipids in animal eukaryotic membranes: Transverse asymmetry and movement. Biochem. J. 294:1-14.

- Zakeri, Z, Quaglino, D. and Sinngh Ahuja, H. 1994. Apoptotic cell death in the mouse limb and its suppression in the Hammertoe mutant. Dev. Biol. 165:294-297. 


\section{Plasma membrane alterations and cytoskeletal changes in apoptosis}

Manon van Engeland, Helma J.H. Kuijpers,

Frans C.S. Ramaekers, Chris P.M. Reutelingsperger

and Bert Schutte

Experimental Cell Research 1997 235: 421-430

\section{Contents}

5.1. Introduction

5.2 Materials \& methods

5.3 Results

5.4 Discussion

5.5 References 


\section{Abstract}

During apoptosis, one of the first membrane changes that can be detected is exposure of phosphatidylserine residues at the outer plasma membrane leaflet, while early apoptosis is also accompanied by changes in the cytoskeletal organization. In this study we investigated the relationship between these two phenomena during olomoucine and rascovitine induced apoptosis in human lung cancer and neuroblastoma cell lines. Loss of membrane asymmetry was detected by biotin-labeled or FITC-labeled annexin $\mathrm{V}$ binding to negatively charged phosphatidylserine, while cytoskeletal components were visualized by immunocytochemistry. The apoptotic, annexin $\mathrm{V}^{+}$cells were analyzed by flow cytometry, confocal scanning laser microscopy and western blotting. We report that cytokeratin and vimentin aggregation in early apoptosis occurs simuitaneously with phosphatidylserine exposure and chromatin condensation. In contrast to these intermediate filament proteins, which were disassembled and proteolytically cleaved in early apoptosis, microfilaments and microtubuli were not proteolytically degraded but were found to be present as aggregated filaments in the apoptotic bodies. We also show that loss of membrane asymmetry and cytokeratin aggregation are independent processes, since $\mathbb{N}$-ethylmaleimide induced phosphatidylserine exposure does not cause cytokeratin disassembly. Vice versa, phorbol-12myristate-13-acetate induced cytokeratin filament aggregation does not result in phosphatidylserine exposure.

\subsection{Introduction}

Apoptosis is a genetically programmed and physiological mode of cell death, which plays an important role in morphogenesis and normal tissue remodeling, where it is one of the factors that maintain the balance between cell proliferation and cell loss (Fesus et al., 1991; Kerr et al., 1987; Wyllie, 1993). In many neoplasms, this balance is lost, partly as a result of changes in the apoptotic process (Kerr et al., 1987; Dive and Wyllie, 1994; Saraf and Bowen, 1988; Wyltie et al., 1980). In contrast to cell death due to necrosis, a form of cell death accompanied by cellular swelling, blebbing and increased membrane permeability (Majno and Joris et al., 1995), the apoptotic process does not elicit an inflammatory response, nor does it damage adjacent cells (Fesus et al., 1991).

During apoptosis cells undergo several morphological and biochemical changes. It has been described that in early stages cytoplasmic $\mathrm{Ca}^{2+}$ levels change and the cell volume decreases, while contact with neighboring cells and the extracellular matrix is lost. The chromatin is cleaved into oligonucleosomal fragments, due to $\mathrm{Ca}^{2+} / \mathrm{Mg}^{2+*}$ dependent endonuclease activation, and condenses into peripheral granular caps. The apoptotic plasma membrane shows several changes, such as loss of sialic acid residues from membrane glycoproteins and loss of microvilli and cell-cell junctions (Wyllie, 1993; Savill et al., 1993). Eventually, the cell surface forms buds, resulting in the formation of apoptotic bodies, that are recognized and phagocytozed by macrophages or neighboring cells. (Wyllie, 1993). Recently it was shown that structural changes in the plasma membrane of the apoptatic cell are functional in signaling the process of cell death to the environment. Koopman 
et al. (1994) showed that loss of phospholipid asymmetry, which results in exposure of phosphatidyserine (PS) residues at the outer plasma membrane leaflet and may serve as a trigger for phagocytosis, occurs early during apoptosis and precedes loss of plasma membrane integrity. This PS exposure can be used to detect apoptosis in vital, non-fixed cells by allowing FITClabeled annexin $V$ to bind to PS, which is exposed at the outer membrane leaflet (Homburg et al., 1995; Vermes et al., 1995; Martin et al., 1995a).

Changes in the cytoskeletal organization have been described to occur during apoptosis (Dive and Wyllie, 1993; Allen, 1987). Recently, Tinnemans et al. (1995) showed that in apoptotic cells cytokeratin filaments aggregate at an early stage of the process, while at a later stage the cytokeratin skeleton is degraded. Pittman et al. (1994) and Ireland and Pittman (1995) claimed that reorganization of microtubules might be an integral part of the apoptotic process and activation-induced apoptosis results in proteolytic cleavage of fodrin, probably catalyzed by calpain (Martin et al., 1995b).

Guenal et al. (1997) reported that during an early stage of apoptosis actin mRNA levels decrease, followed by proteolytic cleavage of actin.

Indications for a relationship between membrane lipid asymmetry and cytoskeletal alterations came from studies with platelets and erythrocytes. Verhallen et al. (1987) showed that a correlation exists between calpainmediated cytoskeletal breakdown and expression of platelet procoagulant activity, suggesting involvement of the cytoskeleton in the maintenance of membrane lipid asymmetry.

Recently, Buja et al. (1993) discussed this concept in relation to apoptosis, by speculating that disintegration of cytoskeletal filaments, which normally stabilize and modulate the function of the plasma membrane by connecting it to the cellular interior, results in membrane alterations.

In the present study we show that in our model systems the intermediate filaments cytokeratin and vimentin are degraded after induction of apoptosis in two human tumor cell lines, while actin and tubulin on the other hand do not show proteolytic cleavage. We also show that intermediate filament disruption and PS exposure occur simultaneously during early apoptosis, but provide evidence for the fact that both phenomena are unrelated, since induction of loss of membrane asymmetry alone does not result in disassembly of the cytoskeleton, while on the other hand, specific destruction of the cytoskeletal structures does not result in PS exposure at the outer surface of cells.

\subsection{Materials \& methods}

\section{Cell culture}

The human non-small cell lung cancer cell line MR65, a kind gift from Dr. Gropp (Philips Universitäts Klinik, Marburg, Germany), was grown as a monolayer cultured in Eagle's modified minimal essential medium (EMEM, Gibco, Paisley, Scotland) supplemented with $10 \mathrm{mM}$ HEPES (Gibco), 10\% newborn calf serum (Gibco), 2 mM L-glutamin (Serva, Heidelberg, Germany), $1 \%$ non-essential amino acids (Gibco) and $50 \mu \mathrm{g} / \mathrm{ml}$ gentamycin (AUV, Cuyk, The Netherlands). The human neuroblastoma cell line CHP21.2 (Schlesinger et al., 1976), was cultured in Dulbecco's madified Eagle's medium (Gibco) supplemented with $1 \% \mathrm{~L}$-glutamin (Serva), $10 \%$ newborn calf serum (Gibco) 
and $0.1 \%$ gentamycin (AUV). Cells were grown for 16 hours in a $25 \mathrm{~cm}^{2}$ cell culture flask (Costar Europe Ltd., Badhoevedorp, The Netherlands) and were harvested by scraping in culture medium using a rubber policeman. In some experiments, cells were grown for 16 hours on 8 well glass slides (Nutacon, Schiphol-Oost, The Netherlands), coated with $35 \mu \mathrm{g} / \mathrm{ml}$ rat tail collagen.

\section{Treatment of the cells}

Apoptosis was induced by treating exponentially growing MR65 and CHP212 cells with $200 \mu \mathrm{M}$ olomoucine (Abraham et al., 1995) or $50 \mu \mathrm{M}$ roscovitine added to the cell culture (generous gifts of Dr. L. Meyer, C.N.R.S., Station Biologique, Roscoff, France). Olomoucine and roscovitine were dissolved in dimethylsulfoxide (DMSO), the final DMSO concentration in the medium was $0.005 \%$. Mock treated cultures received 0.005\% DMSO. At various periods of time, cells were harvested by collecting both the floating and the adherent cells. Cytokeratin filament disruption in MR.65 cells was induced according to the method of Tolle et al. (1987). Briefly, phorbol-12-myristate-13-acetate (PMA; Sigma, St. Louis, USA) was added to the culture medium for 1 hour at a final concentration of $0.15 \mu \mathrm{M}$. The cells were subsequently incubated in cold phosphate buffered salline (PBS, pH 7.4) for 1 hour." Aminophospholipid exposure was achieved by incubating exponentially growing MR65 cells with N-ethylmaleimide (NEM; Sigma, St. Louis) for 1 hour at a final concentration of $5 \mathrm{mM}$ (Dachary - Prigent et al., 1993).

\section{Antibodies}

The following primary monoclonal antibodies were used:

- Monoclonal antibody RCK102 (Eurodiagnostica, Arnhem, The Netherlands, 1:5 dilution for immunocytochemistry), reactive with cytokeratins 5 and 8 (Ramaekers et al., 1987) and CAM 5.2 (Becton Dickinson, 1:5 dilution for western blotting), reactive with cytokeratins 7 and 8 (Smedts et al., 1990).

- Monoclonal antibody RV202 (1:5 dilution for immunocytochemistry and undiluted for western blotting), reactive with vimentin (Ramaekers et all., 1987).

- Monoclonal antibody E7 (1:10 dilution for immunocytochemistry and western blotting), directed against B-tubulin, obtained from the Developmental Studies Hybridoma Bank, maintained by the Department of Pharmacology and Molecular Sciences, Johns Hopkins University, School of Medicine, Baltimore, MD, USA and the Department of Blology, University of Iowa, lowa City, IA, USA).

- Monoclonal antibody AC-15 (1:500 dilution for immunocytochemistry and 1:3000 dilution for western blotting), reactive with $B$-actin (Sigma, St. Louis, USA).

- Monoclonal antibody IIB5 (1:50 dilution for immunocytochemistry), directed against bromodeoxyuridine (Schutte et al., 1987).

As secondary antibodies R-phycoerythrin (RPE)-conjugated Fab fragments of goat anti-mouse immunoglobulins (DAKO A/S, Glostrup, Denmark, 1:10 dillution), Cy3-conjugated goat anti-mouse immunoglobulins (Jackson ImmumoResearch Laboraties, Inc., West Grove, USA, 1:500 dillution), FITCconjugated streptavidin (DAKO A/S, 1:100 dilution), FITC conjugated Fab2 fragments of rabbit anti-mouse immunoglobulins (DAKO A/S, $1: 100$ dilution) and Texas Red conjugated Avidin (Vector Laboratories, Burlingame, CA, USA) 
were used. All the antibodies were appropriately diluted in PBS containing 1 $\mathrm{mg} / \mathrm{ml}$ bovine serum albumin (BSA, Sigma, St. Louis).

As negative control an irrelevant monoclonal antibody (IIB5) was used instead of the primary antibody in an exponentially growing cell culture.

\section{Annexin V labeling}

To detect PS exposure, annexin V-biotin (APOPTEST-BIOTIN) or annexin VFITC (and APOPTEST-FITC) (Nexins Research B.V., Hoeven, The Netherlands) was incubated with the cells, as described elsewhere (van Engeland et al., 1996). Briefly, $5 \mu \mathrm{g} / \mathrm{ml}$ labeled annexin $V$ was added to the vital culture medium. After incubation for three minutes at room temperature (RT) the supernatant was collected and the detached cells were rinsed twice with culture medium. The adherent cells were rinsed twice with culture medium and were harvested by scraping with a rubber policeman. For staining in suspension, the detached and adherent cell fractions were pooled. Cells grown on glass slides were labeled with annexin $V$-biotin for three minutes and were rinsed before fixation in $100 \%$ methanol.

\section{Immunocytochemistry}

Cells growing on glass slides: After the annexin $V$ incubation step, slides were fixed for 5 minutes in cold methanol $\left(-20^{\circ} \mathrm{C}\right)$, rinsed in PBS and subsequently incubated with the primary antibodies for 1 hour at noom temperature in the dark. After 2 washing steps with PBS, the primary antibody was visualized by incubating the slides with Cy3-conjugated goat anti-mouse immunoglobulins or FITC-conjugated rabbit anti-mouse immunoglobulins for 1 hour at room temperature. Annexin $V$ binding was visualized by incubating the slides with FITC-conjugated streptavidin or Texas Red-conjugated avidin. Finally the slides were embedded in glycerol 11 , 4 -di-azobicyclo- $(2,2,2)$-octane (DABCO), (9 parts of glyceral, 1 part of $0.2 \mathrm{M}$ Tris- $\mathrm{HCl} \mathrm{pH} 8.0,0.02 \% \mathrm{NaN}_{3}$ and $2 \%$ DABCO pH 8.0) containing $0.5 \mu \mathrm{g} / \mathrm{ml} 4^{\prime}, 6$ diamidino-2-phenylindole (DAPI, Sigma).

Cell suspensions: Annexin $V$ labeled cells in suspension were fixed for 5 minutes in cold methanol, pelleted, washed with PBS/BSA and incubated with the primary antibody for 1 hour at room temperature in the dark. After 2 wasting steps with PBS/BSA, these cell suspensions were incubated with RPE-conjugated goat anti-mouse immunoglobulins and FITC-conjugated streptavidin for 1 hour at room temperature in the dark. Finally the cells were stained with propidium iodide $\left(\mathrm{PI}_{*}\right.$ final concentration $\left.5 \mu \mathrm{g} / \mathrm{m} \|\right)$ and analyzed by flow cytometry.

\section{Flow cytometry}

For flow cytometric analysis a FACSort (Becton Dickinson, San Jose, CA, USA) equipped with a single argon ion laser was used. The exciting light was 488 $\mathrm{nm}$ and the emission filters were 515-545 bp (green; FITC), 572-588 bp (orange; phycoerythrin) and $600 \mathrm{lp}$ (red; PI). Data of a minimum of 10,000 cells per sample were stored in list mode. Electronic compensation was used to eliminate bleed through of fluorescence. Data amalysis was performed with the standard Lysis and Cellfit Software (Becton Dickinson, San Jose, CA, USA). To quantitate individual cell populations (i.e. vital, apoptotic, dead and damaged) in the cell suspensions, approximately $0.5-1 \times 10^{6}$ unfixed cells 
were stained with FITC-conjugated streptavidin to detect annexin $V$ binding and PI for vital nuclear staining. Annexin $\mathrm{V}^{*} / \mathrm{PI}$ cells represent the early apoptotic cells. Damaged cells, introduced by the scraping method, appear in the annexin $\mathrm{W} / \mathrm{Pl}$ * fraction, while necrotic and late apoptotic cells are positive for both annexin $V$ and PI. Undamaged, vital cells remained negative for both annexin $V$ and PI (van Engeland et al., 1996). As a standard procedure for all three color analyses, data were gated on pulse processed PI signals to exclude doublets and larger aggregates. Quadrant settings were based on the negative control, allowing less than $1 \%$ positivity.

\section{Confocal scanning laser microscopy}

Cells on glass slides were analyzed using the MRC600 confocal scanning laser microscope (Bio-Rad, Hemel Hempstead, UK), equipped with an air-cooled Argon-Krypton mixed gas laser and mounted onto an Axiophot microscope (Zeiss, Oberkochen, Germany). The laser scanning microscope was used in dual parameter setup, according to the manufacturers specification, using dual wavelength excitation at $488 \mathrm{~nm}$ and $568 \mathrm{~nm}$. Emission spectra were separated by the standard sets of dichroic mirrors and barrier filters. All scans were recorded in photon counting mode. In order to record DAPI fluorescence, mercury arc illumination was used.

\section{Gel electrophoresis and western blotting}

After induction of apoptosis with roscovitine for 8 hours in MR65 cells and 6 hours in CHP212 cells, the floating cell fraction (the apoptotic fraction) was collected, washed with PBS and resuspended in lysis buffer $(62.5 \mathrm{mM}$ Tris/ $\mathrm{HCl}$ pH 6.8, $12.5 \%$ glycerol (Gibco), $2 \%$ Nonidet P-40 (Fluka Chemie, Buchs, Switzerland), $2.5 \mathrm{mM}$ phenylmethylsulfonyl fluoride (Aldrich), 1.25 mM EDTA, $12.5 \mu \mathrm{g} / \mathrm{ml}$ leupeptin (Sigma) and $116 \mu \mathrm{g} / \mathrm{mll}$ aprotinin (Sigma)), and were incubated on ice for 30 minutes. As a control, non-treated, exponentially growing cells were used. Then an equal volume of SDS-sample buffer (Laemmli, 1970) was added and the samples were boiled for 5 min. One-dimensional sodium dodecyl sulphate polyacrylamide gel electrophoresis (SDS-page) with extracts of 40,000 cells per lane was performed according to Laemmli (Laemmli, 1970) using gels containing $10 \%$ polyacrylamide (BioRad laboratories, Hercules, USA) and $0.1 \%$ SDS (Merck). Gels were run on the Mini-protean II system (Bio-Rad Laboratories) for approximately 45 minutes at $200 \mathrm{~V}$. For Western blotting, the method described by Towbin et al. (1979) was used. Transfier was performed in blotting buffer $(192 \mathrm{~mm}$ glycine, $25 \mathrm{mM}$ Tris, $20 \%$ methanol) for 1 hour at $100 \mathrm{~V}$. The nitrocellulose membranes (Schleicher and Schuell, Dassel, Germany) were incubated with the primary antibody against actin, tubulin, vimentin and cytokeratin. Actin and tubulin detection was performed using alkaline phosphatase and NBT/BCIP detection using $0.41 \mathrm{M}$ nitro blue tetrazolium (Sigma) and 0.45 mM 5-bromo-4-chloro-3-indolyl phosphate (Sigma). Cytokeratin detection was performed using alkaline phosphatase and enhanced chemiluminescence (ECL-kit, Amersham, Bucks., UK). RX Fuji Medical X-ray films (Fuji, Tokyo, Japan) were used for the visualization of the luminescent signals. Detection of vimentin was performed using peroxidase and TMB detection using the method of speel et al. (1994), modified for protein detection on blot. 


\subsection{Results}

In order to investigate plasma membrane alterations and structural changes in the cytoskeleton in apoptosis, olomoucine induced CHP212 cell cultures were labeled with annexin $V$-biotin and after fixation, the cells were staned with anti-cytoskeleton antibodies. The MR65 cell line, with slightly different induction kinetics, was used to confirm the results obtained with the CHP212 celll line. As evaluated by fluorescence microscopy, $95 \%$ of the annexin $V$ positive cells showed condensed chromatin and a structurally altered cytoskeleton distribution. $5 \%$ of the annexin $V^{+}$cells appeared to be normal cells with numerous annexin $V^{-\frac{1}{t}}$ apoptotic vesicles attached to the plasma membrane of the normal cells. In apoptotic cells, most of the actin fifigure 5.1a) and tubulin (data not shown) immunoreactivity was retained in both cell lines, and almost no actin and tubulin cells were observed. However, all the annexin $V^{+}$apoptotic cells showed an aberrant staining pattern, with aggregated actin and tubulin found to be included in the apoptotic bodies. In contrast to the microtubules and microfilaments, vimentin filaments (figure 5.1c and d) were disassembled into dot-like aggregates in the annexin $V^{\text {t* }}$ apoptotic CHP212 cells. In order to investigate whether this dot-like aggregation was specific for intermediate filaments, another member of the intermediate filament family, l.e. cytokeratin, was studied in MR65 cells. Cytokeratin staining in apoptotic MR65 (figure 5.1f) cells showed the same aggregation pattern as vimentin showed in CHP212 cells. In part of the annexin $\mathrm{V}^{*}$ cells a decrease in anti-cytokeratin and anti-vimentim immunofluorescence was observed, but almost no cytokeratin and vimentin cells were observed. Thus, reorganization of microtubules and microfilaments and disassembly of intermediate filaments was always accompanied by PS exposure, as measured by annexin $\mathrm{V}$ binding and by condensation of DNA.

In order to quantify cytoskeletal antigen expression of apoptotic cells in time, we performed multivariate flow cytometric anallyses at one hour time intervals. Prior to fixation, part of the cells was labeled with annexin V-FITC and PI in a vital assay. This assay revealed that after 6 hours of induction approximately $90 \%$ of the annexin $\mathrm{V}^{*}$ apoptotic cells were $\mathrm{PI}$, indicating that the plasma membrame integrity was still intact at this stage of the apoptotic process. The other part of the cell culture was labeled with biotinylatedannexin $V$, harvested and fixed for 5 minutes, prior to immunocytochemistry. The numbers of a) annexin $\mathrm{V}^{\text {tw }} /$ cytoskeleton $^{+}$, b) annexin $\mathrm{V} /$ cytoskeleton: c) annexin $V^{+} /$cytoskeleton $^{-}$and d) annexin $V^{\prime \prime} / c y t a s k e l e t o n^{*}$ cells were quantified as function of time after induction of apoptosis by olomoucine. Figure 5.2 shows the cytograms of annexin $V(x$-axis) and actin immunofluorescence ( $y$-axis) of control CHP212 cells (figure 5.2a) and after 6 hours of olomoucine treatment (figure 5.2b). The majority of cells (77\%) in the control culture is annexin $V /$ actin $^{+}$. In this control culture only $1-2 \%$ of the cells was annexin $\mathrm{V}^{+}$, these cells represent the spontaneous apoptotic cells. After 6 hours of olomoucine induction, several $(13 \%)$ annexin $V^{\prime} /$ actin cells were observed, and although part of the cells lost some immunoreactivity, the majority of the annexin $V^{*}$ cells is positive for actin immunofluorescence $(32 \%)$. Tubulin protein expression in apoptosis shows slightly different Kinetics. After 6 hours of olomoucine induction (figure 5.2 ) $25 \%$ of the cells is annexin $\mathrm{V}^{+} /$tubulin ${ }^{+}$, while $26 \%$ appears as annexin $\mathrm{V}^{+} /$tubulin. The same 
results regarding actin and tubulin immunofuorescence were obtained with the MR65 cell line (data not shown). Analysis of the intermediate filament protein vimentin in the CHP212 cell line (figure $5.2 \mathrm{e}$ and $5.2 \mathrm{f}$ ) revealed that only a small population of annexin $V^{+} /$vimentin $^{*}$ cells ( $18 \%$ could be observed after 6 hours of olomoucine induction. On the other hand, the annexin $\mathrm{V}^{+} /$vimentin population of cells is much larger (28\%). Cytokeratin analysis (figure $5.2 \mathrm{~g}$ and $5.2 \mathrm{~h}$ ) in MR65 cells was studied after 8 hours of induction, because of the somewhat slower induction kinetics of olomoucine in this cell line. After 8 hours of apoptosis induction, the annexin $V^{*} /$ cytokeratin ${ }^{*}$ fraction is $34 \%$, the annexin $V^{*} /$ cytokeratin fraction is almost the same $(33 \%)$. A significant amount of cells was damaged during the scraping procedure that was used to harvest the cells for flow cytometry. This explains the high amount of double negative cells (approximately $25 \%$ ) in the control and in the induced cell cultures. The complete results of the time-course analysis are summarized in figure 5.3.
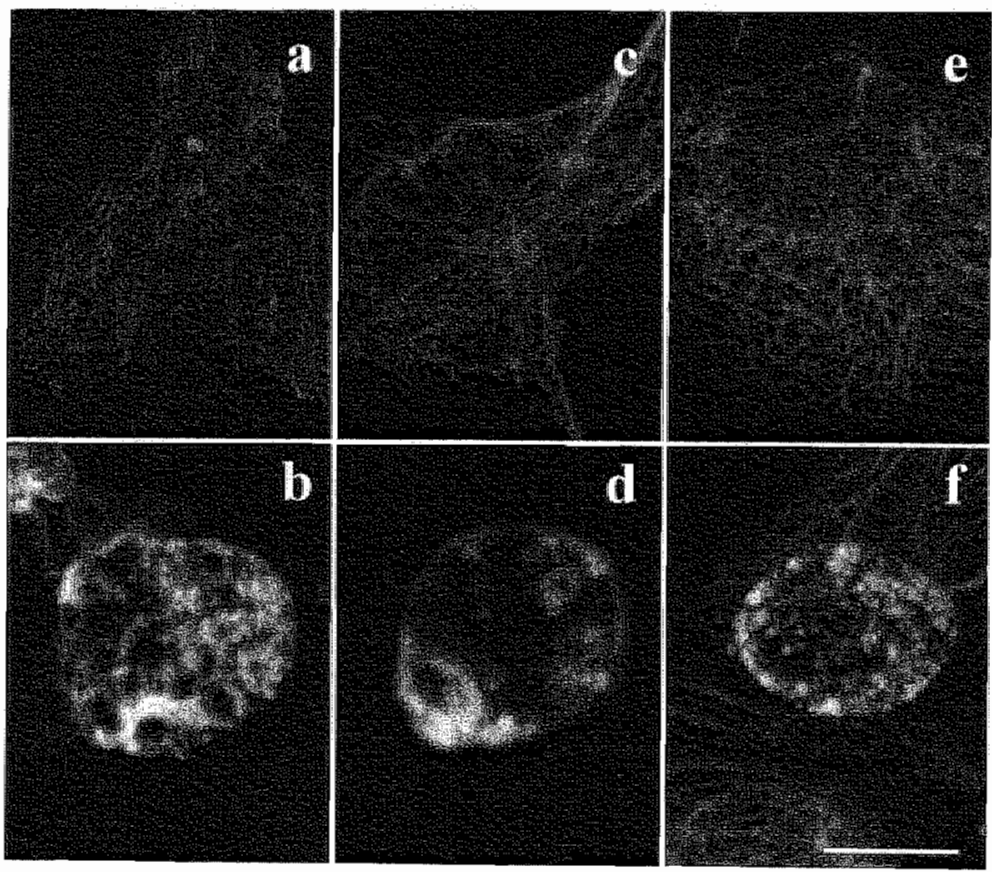

Figure 5.1: Merged confocal scanning laser microscopy images of control and apoptotic cells. (a) Two control CHP212 cells with normal actin filaments. (b) An apoptotic $\mathrm{CHP} 212$ cell with actin filament redistribution (red) and annexin $V$ binding (green). (c) A normal CHP212 cell with filamentous vimentin and (d) vimentin aggregation (red) and annexin $V$ binding (green) in an apoptotic CHP212 cell. cytokeratin staining in MR65 cells is shown in $\mathrm{f}$. This figure shows an annexin $\mathrm{V}^{*}$ (green) apoptotic MR65 cell with aggregated cytokeratin filaments next to nonapoptotic cells with normal cytokeratin filaments. A control cell, stained with the anticytokeratin antibody, is shown in e. Note that the non-apoptotic cells are negative for annexin $V$. Bar indicates $5 \mu \mathrm{m}$. For color illustration see page 136 . 

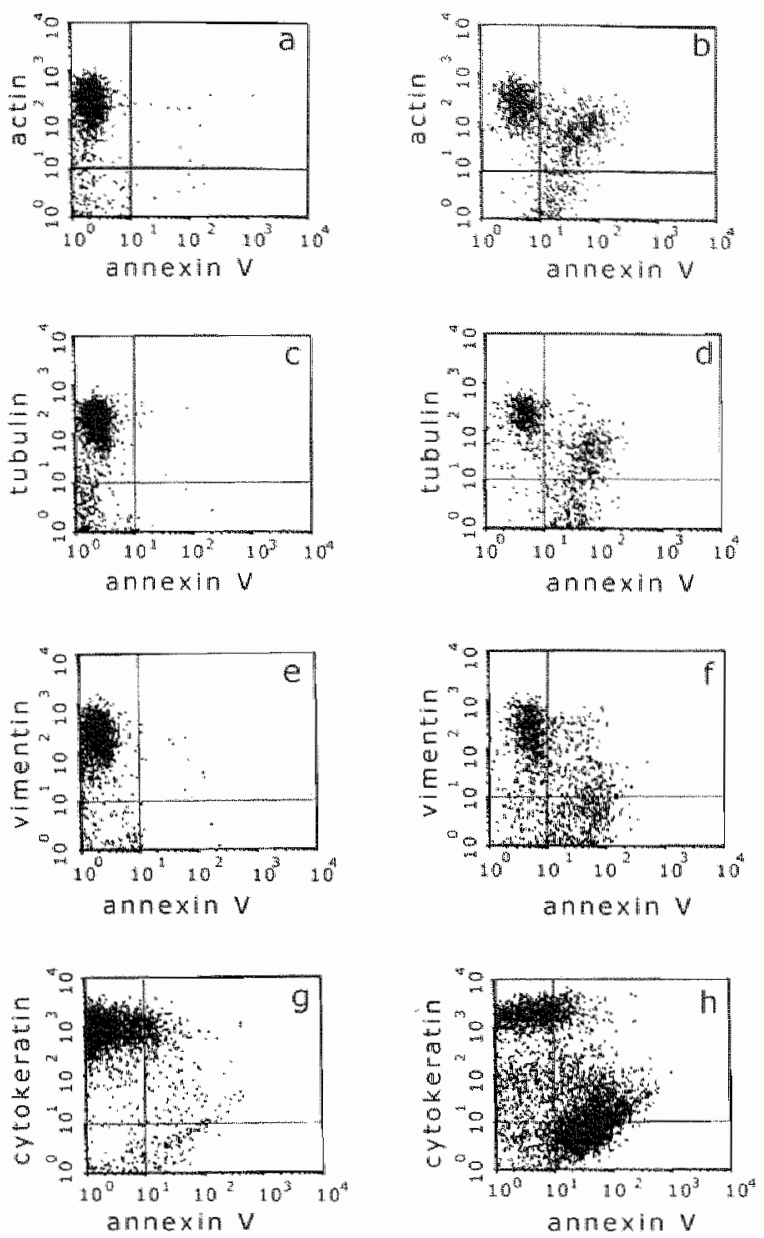

Figure 5.2: Fiow cytograms of control ( $a, c$ and $e$ ) and apoptotic ( $b$, d and $f) C H P 212$ cells after fixation and staining for the presence of actin ( $a$ and b), tubulin ( $c$ and $d$ ) and vimentin (e and f) and control MR65 cells ( $g$ ) and apoptotic (h) MR65 cells after fixation and staining for the presence of cytokeratin. Anmexin $V$ binding is shown on the $x$-axis and cytoskeleton immunofluorescence is showm on the $y$-axis. Quadrant settings were based on the negative control. In the control cultures only a few annexin $V$ cells (the spontaneous apoptotic cells) were observed. After 6 hours of olomoucine induction, approximately 50-60\% of the cells have become apoptotic. The annexin $\mathrm{V}^{*} /$ actin ${ }^{*}$ fraction was $32 \%$ although a portion of the cells lost actin immunoreactivity. The annexin $V / a c t i n$ fraction was $13 \%$. Tubulin staining showed that after 6 hours of induction $26 \%$ was annexin $V^{*} /$ tubulin, while $25 \%$ of the cells was annexin $\mathrm{V}^{*} /$ tubulin*. Vimentin immunoreactivity rapidly decreased after induction of apoptosis and after 6 hours of induction approximately $28 \%$ of the cells was anmexin $\mathrm{V}^{+} /$vimentin , while only $18 \%$ remained annexin ${ }^{*} / v i m e n t i n *$. Staining of cells with cytokeratin shows that after 8 hours of induction approximately $30 \%$ of the cells was annexin $V^{*} /$ cytokeratin", while $30 \%$ was annexin $V^{*} /$ cytokeratin. 

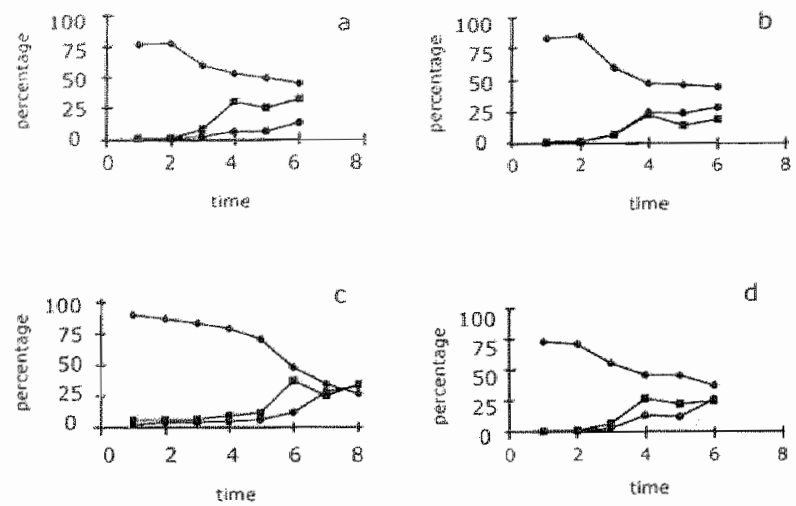

Figure 5.3: Time-course analysis of cytoskeletal proteins and PS exposure after induction of apoptosis with olomoucine. Time (hours) on the $x$-axis and percentage of cells $(\%)$ on the $y$-axis. ( $a, b$ and c) Actin, tubulin and vimentim analyses, respectively, in CHP212 cells and (d) cytokeratin analysis in MR65 cells. (.) annexin V/cytoskeleton ${ }^{*}$ cells; ( annexin $V^{*} /$ cytoskeleton ${ }^{+}$cells; (*) annexin $V^{*} / c y$ toskeleton cells.

Western blotting was used to study the breakdown of cytoskeletal proteins in apoptosis. These experiments (figure 5.4) showed that after roscovitine treatment of CHP212 and MR65 cells, no clear quantitative changes in actin ( $43 \mathrm{kD}$ band) and tubulin ( $58 \mathrm{kD}$ band) proteins could be detected as compared to the contral cultures and no degradation products were present (figure $5.4 \mathrm{a}$ and $5.4 \mathrm{~b}$ ). In contrast, cytokeratin (figure 5.4c) and vimentin (figure 5.4d) degradation was observed in MR65 and CHP212 cells respectively, with clear degradation products of approximately $48 \mathrm{kD}$ and $46 \mathrm{kD}$ in addition to the intact $53 \mathrm{kD}$ cytokeratin 8 , and two vimentin degradation products of $50 \mathrm{kD}$ and $43 \mathrm{kD}$ in addition to the control band of $57 \mathrm{kD}$.

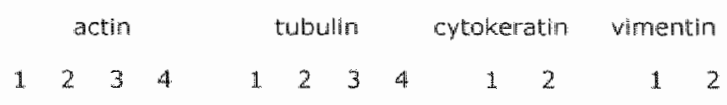

$94 \mathrm{KD}$
$67 \mathrm{KD}-$

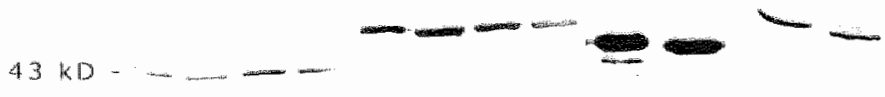

$30 \mathrm{KO}$

a b $\quad$ b $\quad d$

Figure 5.4: Westem blotting showed no quantitative changes and no degradation products of actin (a) and tubulin (b) in apoptotic MR65 cells (lane 1) and apoptotic CHP212 cells (lane 3). For comparison, control cellis of MR65 (lane 2) and CHP212 (lane 4) are shown. The immunoblots of cytokeratin in MR65 cells (c) and vimentin in CHP212 cells (d) show several degradation products after roscowitine treatment (lane 1 ). For comparison, control cells are shown in lane 2 . 
In order to investigate whether intermediate filament disruption inewitably leads to PS exposure, cytokeratin aggregation was induced by treating MR65 cells with PMA. After 1 hour of incubation, cells were treated with cold PBS and stained for the presence of cytokeratin and PS. Figure 5.5 a shows a CSLM image of a cell with disassembled cytokeratin filaments, similar to the pattern observed in apoptotic cells. This cell however, did not show annexin $V$ binding. Conversely, to investigate whether artificial PS exposure leads to cytokeratin filament disruption, we treated MR65 cells for various periods of time with NEM, thereby inhibiting, amongst others, the aminophospholipid translocase activity. PS exposure of the outer plasma membrane leaflet was rapidly induced, showing maximal levels of staining after half an hour of treatment with NEM. These cells have an intact cytoplasmic membrane, since they do not take up PI (data not shown). The CSLM analysis of these NEM treated cells shows that an annexin $V^{+}$interphase cell expresses a normal filamentous cytokeratin network (figure $5.5 \mathrm{~b}$ ). These observations were confirmed by bivariate annexin V/cytokeratin flow cytometric analysis of NEM treated cells (data not shown).
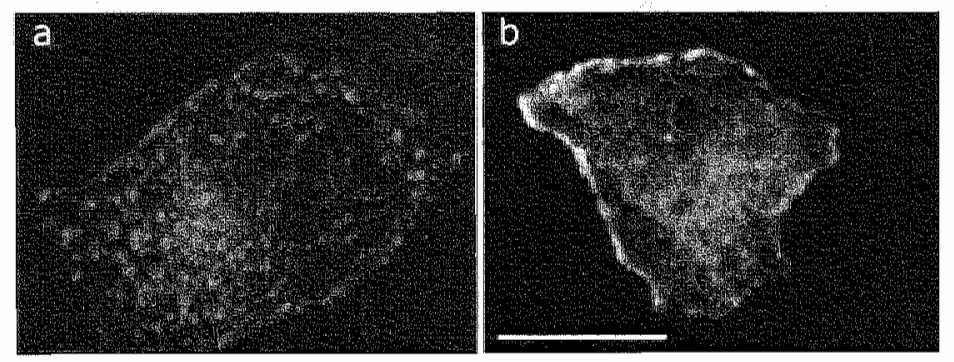

Figure 5.5: (a) Merged CSLM image of an MR65 cell showing cytokeratin disiruption after incubation with PMA and subsequent treatment with cold PBS. Cytokeratin antibody binding is shown in red and annexin $V$ binding in green. Note that cells with aggregated cytokeratin filaments do not show annexin $V$ binding. (b) Merged CSLM image of an MR65 cell after NEM treatment for 4 hours. After incubation with annexin $V$-biotin, cells were fixed and stained with an antïcytokeratin antibody (red) and streptavidin-FITC to wisualize annexin $v$ binding (green). Note that artificilly induced PS exposure at the outer leaflet of the piasma membrane, detected by annexin $V$ binding, does not induce cytokeratin disruption. Bar indicates 10 . m. For color illustration see page 136.

\subsection{Discussilon}

In this study we examined lass of membrane phospholipid asymmetry and cytoskelletal changes during apoptosis and a possible causal melationship between these two phenomena in human tumor cell lines. In these cell cultures apoptosis was induced with olomoucine or roscovitine. Administration of these cyclin dependent kinase inhibitors increased the number of apoptotic cells in these cell lines within a few hours, resulting in dramatic 
changes in the cytoskeleton filaments. The distribution patterns of these cytoskeletal structures in the induced apoptotic cells were identical to the staining patterns observed in spontaneously occurring apoptotic cells. This indicates that the changes observed in the drug treated cells are not artificial. Furthermore, the cytokeratin staining patterns strongly resembled those seen after induction of apoptosis by cycloheximide (Tinnemans et al., 1995), indicating that these changes are independent of the mode of induction of apoptosis.

When apoptotic cells were characterized on basis of nuclear morphology, all cells showing the characteristic pattern of chromatin condensation also showed affinity for annexin $\mathrm{V}$, indicating that these cells have exposed PS on their outer membrane leaflet (see also van Engeland et al., 1996).

In the present study, we show a correlation between loss of membrane asymmetry on the one hand, and aggregation and subsequent degradation of intermediate filaments and reorganization of microfilaments and microtubules on the other hand. In the cells grown on glass slides the majority of the apoptotic cells showed aggregated intermediate filament staining patterns and redistribution of actin and tubulin, but almost no cytoskeletal cells were observed. By flow cytometric analysis however, a significant part of the annexin $\mathrm{V}^{+}$apoptotic cells appeared negative for cytoskeletal filaments. An explanation for this discrepancy is that many of the cells which are further downstream in the apoptotic process and which have lost their cytoskeletal flaments, detach from the glass slides during the washing procedures and escape thereby from observation. In contrast, for flow cytometric analyses, both adhering and floating cells were harvested quantitatively.

As reported by others (Allen, 1987; Pittman et al., 1994; Irelland and Pittman, 1995) we found that actin and tubulin organization showed gross alterations, but we could not detect proteolytic cleavage products in apoptotic cells with the antibodies we used. Very recently, Guenal and coworkers (1997) reported that late in apoptosis actin is cleaved in a rat embryo fibroblast system infected with a temperature sensitive SV40 mutant and a temperature shift induction system. Brown et al. (1997) as well showed that actin is cleaved in an $\mathrm{N}$-terminal region during constitutive apoptosis in neutrophils. It has also been demonstrated that actin is a substrate for the pro-apoptotic cysteine protease interleukine 1 B-converting enzyme (Guénal et al., 1997; Kayalar et al., 1996) and for the activated form of CPP32/apopain (Mashima et al., 1997).

In our model system we studied predominantly cells in an early phase of apoptosis, i.e. annexin $\mathrm{V}^{+}$cells with no loss of membrane integrity, and did not see actin proteolysis. It is possible that actin proteolysis in our model system occurs only in very late stages of apoptosis. It also might be possible that actin proteolysis in apoptosis is a cell system and/or apoptosis induction system dependent event, as also holds true for DNA degradation into aligonucleosomal fragments. A third possibility is that although actin contains cleavage sites for ICE-like proteases, actin is only degraded in in vitro systems and not in wivo in human cells due to lack of access of the proteases to actin or due to the presence of other factors that prevent degradation (Song et al., 1997). An apparent discrepancy between the results obtained by western blotting and flow cytometry exists. Although we observed a substantial fraction of both tubulin and actin apoptotic cells using flow cytometry, western blatting did not indicate proteolytic cleavage of both 
molecules, i.e. appearance of specific breakdown products or loss of staining intensity. This apparent discrepancy might be explained by selective loss of small, possible monomeric actin and tubulin molecules during staining in suspension. In contrast, intermediate filament degradation, as we observed for vimentin and cytokeratin filaments, seems to be a general event during early apoptosis. This fact is supported by recent observations made by Lazebnik et al. (1993), Neamati et al. (1995) and Oberhammer et al. (1994), who showed in several cell systems that other members of the intermediate filament protein family, $\|_{\text {. }}$. the nuclear lamins, are degraded by an ICE-like protease in parallel with chromatim condensation during apoptosis. Furthermore, Rao and co-workers (1996) identified specific lamin cleavage sites for ICE-like proteases.

Degradation of cellular proteins by proteases seems to be a common part of apoptosis and is likely mediated by members of the ICE and ICE-like famlly of proteases. Activation of these proteases is likely linked to the activation of proteases like calpain, cathepsins $B$ and $D$ and collagenase and proteins which are cleaved during apoptosis include poly(ADP.ribose)polymerase (Lazebnik et al., 1994), lamins (Neamatil et al., 1995), topoisomerases I and II (Casiola-Rosen et al., 1994) and histone H1 (Kaufmann, 1989).

Disassembly of cytoskeletal proteins could also be caused by other mechanisms than proteolysis, as for example by (hyper)phosphorylation. It is known that cytokeratin and vimentin readily depolymerize into aggregates when phosphorylated (Coulombe, 1993). It is also reported that phosphorylation of microtubuli-binding proteins inhibits the ability to stabilize and polymerize microtubules and that increased phosphorylation of actinassociated proteins leads to alterations in microfilament distribution (Wickstrom et al. 1995). In our model system, this possible (hyper)phospharylation is most likely not caused by cyclin dependent kinases, due to the use of the apoptosis inducers roscovitine and olomoucine, which are cyclin dependent kinase inhibitors. Another candidate for protein phosphorylation in apoptosis is, for example, protein kinase C. Recently, protein phosphorylation in apoptosis has been described, for example NuMA phosphorylation in dexamethasone treated thymocytes has been reported by Weaver et al. (1996). Also lamin phosphorylation in apoptosis has been reported (Ucker et al., 1994).

Since the first signs of intermediate fllament aggregation coincide with PS exposure at the outer plasma membrane leaflet, the question about a causal relationship arose $i_{\text {. }}$. whether degradation of the cytoskeleton is a prerequisite to surface exposure of PS during apoptosis. Such relationship has been suggested to exist during PS exposure by activated platelets (Verhallen et al., 1987; Smeets et al., 1994) but was recently challenged by others (Gaffet et al., 1995; Dachary-Prigent et al., 1995).

In the underlying study we demonstrate that in MR65 cells the phorbolester PMA, capable of intermediate filament phosphorylation (Cadrin et al., 1992; Deery, 1993), induces cytokeratin aggregation, similar to the process observed during induced or spontaneous apoptosis. Western blotting of cells treated with this phorbolester showed that PMA treatment did not lead to proteolytic cleavage of cytokeratin, as observed in apoptotic cells. Therefore, it is tempting to assume that cytokeratin disruption in both cases is caused by (hyper) phosphorylation. However, disruption of the cytokeratin cytoskeleton perse did not lead to PS exposure. PMA did also not affect microfilament 
or microtubule distribution patterns. Vice versa, it is shown that NEM induced PS exposure in MR65 cells does not inevitably lead to rearrangements in cytokeratin fllaments. However, it can not be excluded that treatment of these cells with NEM interferes with other cellular processes, since the mode of action of this compound may not be limited to the inhibition of the aminophospholipid translocase (Dachary-Prigent et al., 1993). Other evidence that no causal relationship between loss of membrane phospholipid asymmetry and cytokeratin degradation exists comes from our observations that in mitotic cells no PS exposure is seen (data not shown), while depolymerization of lamin and vimentin proteins occur. This depolymerization is due to hyperphosphorylation of these substrates by cyclin dependent kinases and not due to proteolysis.

In conclusion, our results indicate differential degradation kinetics of several cytoskeletal components during apoptosis. In early apoptosis we observed intermediate filament aggregation and proteolytic degradation and although actin and tubulin reorganization occurred, proteolytic cleavage of the microfilaments and microtubuli was not detected. We also conclude that PS exposure and cytokeratin degradation, which occur almost simultaneously during early apoptosis, are independent processes.

\section{Acknowledgments}

The author's thank Cecile Maassen for technical assistance and Dr. L. Meijer (Station Biologique, Roscoff, France) for providing us with olomoucine and roscovitine. This study was supported by a grant to $M$. van Engeland from Universiteitsfonds Limburg/SWOL.

\subsection{References}

- Abraham, R.T., Acquarone, M., Andersen, A, Asensi, A., Belle, R., Berger, $F_{\text {., }}$ Bergounioux, C., Brunn, G., Buquet-Fagot, C., Fagot, D., Glab, N., Goudeau, H., Goudeau, M., Guerrier, P., Houghton, P.J, Hendriks, H., Kloareg, B., Lippai, M., Marie, D. Maro, B., Meijer, L., Mester, J., Mulner-Lorillon, O., Poulet, S.A., Schierenberg, E., Schutte, B., Vaulot, D. and Verhac, M.H. 1995. Cellular effects of olomoucine, an Inhibitor of cyclin dependent kinases. Biol. Cell 83:105-120.

- Allen, T.D. 1987. Ultrastructural aspects of cell death. In Perspectives on mammalian cell death. Potten, C. editor (Oxford: Oxford Science Publications) pp. 39-65.

- Brown, S.B., Bailey, K. and Savill, J. 1997. Actin is cleaved during constitutive apoptosis. Biochem. 3. 323:233-237.

- Buja, L.M., Eigenbrodt, M.L. and Eigenbrodt, E.H. 1993. Apoptosis andnecrosis: Basic types and mechanisms of cell death. Arch. Pathol.Lab. Med. 117:1208-1214.

- Cadrin, M., McFarlane-Anderson, N., Aasheim., L.H., Kawahara, H., Franks, D.J., Marceau, N. and French, S.W. 1992. Differential phosphorylation of CK8 and CK1.8 by 12-0-tetradecanoyl-phorbol-13-acetate in primary cultures of mouse hepatocytes. Cell Signal. 4:715-722.

- Casciola Rosen, L.A., Miller, D.K., Anhalt, G.). and Rosen, A, 1994. Specific cleavage of the $70-\mathrm{KDa}$ protein component of the U1 small nuclear ribonucleaprotein is a characteristic biochemical feature of apoptotic cell death. J. Biol. Chem. 269:3075730760 .

- Coulombe, P.A. 1993. The cellular and molecular biology of keratins: beginning a new era. Curr. Opin. Cell Biol. 5:17-29. 
- Dachary-Prigent, J., Freyssinet, J.M., Pasquet, J.M., Carron, J.C. and Murden, A.T. 1993. Annexin $V$ as a probe of aminophospholipid exposure and platelet membrane vesiculation. Blood 10:2554-2565.

- Dachary-Prigent, J., Pasquet, 3.M., Freyssinet, J.M., Nurden, A.T. 1995. Calcium involvement in aminophospholipid exposure and microparticle formation during platelet activation: a study using $\mathrm{Ca}^{2+}$-ATPase inhibitors. Biochemistry 34:11625" 11634.

- Deery, W.J. 1993. Role of phosphorylation in keratin and vimentin filament integrity in cultured thyroid epithelial cells. Cell Motil. Cytoskeleton. 26:325-339.

- Dive, C. and Wyllie, A.H. 1993. Apoptosis and cancer chemotherapy. In Frontiers in pharmacology and therapeutics: Cancer chemotherapy. Hickman, J.A. and Tritton, T.R. editors. (Oxford: Blackwell Scientific Publications) pp. 21-56.

- van Engeland, M., Ramaekers, F.C.S. „Schutte, B. and Reutelingsperger, C.P.M. 1996. A novel assay to measure loss of plasma membrane asymmetry during apoptosis of adherent cells in culture Cytometry $24: 131-139$.

- Fesus, L., Davies, P...A., Piacentini, M. 1991. Apoptosis: molecular mechanisms in programmed cell death. Eur. 7. Cell. Biol. 56:170-177.

- Gaffet, P., Bettache, N., Bienvenue, A. 1995. Phosphatidylserine exposure on the platelet plasma membrane during A23187-induced activation is dependent of cytoskeleton reorganization. Eur. J. Cell. Biol. 67:336-345.

- Guénal, 1., Risler, Y., Mignotte, B. 1997. Down-regulation of actin genes precedes microfliament network disruption and actin cleavage during p53-mediated apoptosis. J. Cell. Sci. 110:489-495.

- Homburg, C.H., de Haas, M, von dem Borne, A.E., Verhoeven A.J., Reutelingsperger, C.P.M. and Roos, D. 1995. Human neutrophils lase their surface FC gamma RIII and acquire annexin $V$ binding sites during apoptosis in vitro. Blood 85:532-540.

- Ireland, C.M. and Pittman, S.M. 1995. Tubulin alterations in taxol-induced apoptosis parallel those observed with other drugs. Biochem. Pharmacol, 49:1491-1499.

- Kayalar, C., Ord, T., Testa, M.P., Zhong, L.T. and Bredesen, D.E. 1996. Cleavage of actin by interleukin I beta-converting enzyme to reverse DNAse I inhibition. Proc. Natl. Acad.Sci. USA. 93:2234-2238.

- Kaufmann, S.H. 1989. Induction of endonucleolytic DNA cleavage in human acute myelogenous leukemia cells by etoposide, camptothecin, and other cytotoxic anticancer drugs: a cautionary note. Cancer Res. 49:5870-5878.

- Kerr, J.F.R., Searle, J. and Harmon, B.V. 1987. Apoptosis. In: Perspectives on mammalian cell death. Potten, C.S. editor. (Oxford: Oxford Science publications) pp. 93-128.

- Koopman, G., Reutelingsperger, C.P.M., Kuijten, G.A.M., Keehnen, R.M.J., Pals, S.T. and van Oers, M.H.J. 1994. Annexin V for flow cytometric detection of phospliatidylserine expression on B cells undergoing apoptosis. Blood 84:1415-1420.

- Laemmli, U.K. 1970 . Cleavage of structural proteins during the assembly of the head of bateriophage T4. Nature 227:680-685.

- Lazebnik, Y.A., Cole, S., Cooke, C.A., Nelson, W.G. and Earnshaw, W.C. 1993. Nuclear events of apoptosis in vitro in cell-free mitotic extracts: a model system for analysis of the active phase of apoptosis. J. Cell Biol. 123:7-22.

- Lazebnik, Y.A., Kaufmann, S.H., Desnovers, S., Poirier, G.G. and Eamshaw, W.C. 1994. Cleavage of ploy(ADP-ribose) polymerase by a proteinase with properties like ICE. Nature 371:346-347.

- Majno, G. and Joris, 1. 1995. Apoptosis, oncosis and necrosis. An overview of cell death. Am. J. Pathor. 146:3-15.

- Martin, S.J., Reutelingsperger, C.P.M., McGahon, A.J., Rader, J,, van Schie, R.C.A.A., LaFace, D.M. and Green, D.R. 1995a. Early redistribution of plasma membrane phosphatidy/serine is a general feature of apoptosis regardless of the initiating stimulus. Inhibition by overexpression of Bcl-2 and Abl. J. Exp. Med. 182:1545-1557.

- Martin, S.3., O'Brien, G.A., Nishioka, W.K., McGahon, A.J., Mahboubi, A., Saido. T.C. and Green, D.R. 1995b. Proteolysis of fodrin (non-erythroid spectrin) during apoptom sis 3. Bioi. Chem. 270:6425-6428. 
Mashima, T, Naito, M., Noguchi, K., Miller, D.K, Nicholson, D.W. and Tsuruo, T.1997. Actin cleavage by CPP32/apopain during the development of apoptosis. Oncogene 14:1007 1012.

- Neamati, N., Fernandez, A., Wright, S., Kiefer, J. and McConkey, D.J. 1995.

Degradation of lamin 81 precedes oligonucleosomal DNA fragmentation in apoptotic thymocytes and isolated thymocyte nuclei J. Immunol. 154:3788-3795.

- Oberhammer, F.A., Hachegger, $K$. Fröschi, G., Tlefenbacher, R. and Pavelka, M. 1994. Chromatin condensation during apoptosis is accompanied by degradation of lamin $\mathrm{A}$ and $\mathrm{B}$ without enhanced activation of cdc2 kinase. J. Cell Biol. 126:827-837.

- Pittman, S.M. Strickland, D. and Ireland, C.M. 1994. Polymerization of tubulin in apoptotic cells is not cell cycle dependent. Exp. Cell. Res, 215:263-272.

- Ramaekers, F.C.S., Huysmans, A., Schaart, G., Moesker, O. and Vooijs, P. 1987. Tissue distribution of keratin 7 as monitored by a monoclonal antibody. Exp. Cell Res. $170: 235-249$.

- Rao, L... Perez, D. and White, E. 1996. Lamin proteolysis facilitates nuclear events during apoptosis J. Cell Biol. 135:1441-1455.

- Saraf, C.E. and Bowen, I.D. 1988. Proportions of mitotic and apoptotic cells in a range of untreated experimental tumours. Cell Tissue kinet. 21:45-49.

- Savill, J., Fadok, V., Henson, P. and Hasslet, C. 1993. Phagocyte recognizion of cells undergoing apoptosis. Immunal. Today. 141:131-136.

- Schlesinger, H.R., Gerson, J.M., Moorhead, P.S., Maguire, H. and Hummeler, K. 1976. Establishment and characterization of human neuroblastoma cell lines. Cancer Res. $36: 3094-3100$

- Schutte, B., Reynders, M.M.J., van Assche, C.L.M.V.J., Hupperets, P.S.J.G., Bosman, F.T. and Blijham, G.H. 1987. An improved method for the immunorytochemical detection of bromadeaxyuridine labeled nucle using flow cytometry. Cytometry $8: 372-376$.

- Smeets, E.F., Comfurius, P., Bevers, E.M. and Zwaal, R.F.A. 1994. Calcium-induced transbilayer scrambling of fluorescent phospholipid analogs in platelets and erythrocyles. Biochim. Blophys. Acta. 1195:281-286.

- Smedts, F., Ramaekers, F., Robben, H., Pruszczynski, M., van Muijen, G., Lane, B., Leigh, I. and Vooijs, G.P. 1990. Changing patterns of keratin expression during progression of cervical intraepithellal neoplasia. Am. J. Pathor. 136:657-668.

- Song, Q., Wei, T., Lees-Miller, S., Alnemri, E., Watters, D. and Lavin, M.F. 1997. Resistance of actin to cleavage during apoptosis. Proc. NaU. Acad. Sci. USA. 94:157162.

- Speel, E.J.M., Jansen, M.P.H.M., Rameekers, F.C.S. and Hopman, A.H.N. 1994. A novel triple-collour detection procedure for bright-field microscopy, combining in situ hybridization with immunocytochemistry. J. Histachem. Cytochem. 42:1299-1307.

- Tinnemans, M.M.F.J., Lenders, M.H.J.H., ten Velde, G.P.M., Ramaekers, F.C.S. and Schutte, B. 1995. Alterations in cytoskeletal and nuclear matrix associated proteins during apoptosis. Eur. J. Cell Biol. 68:35-46.

- Tölle, H.G., Weber, K. and Osborn, M. 1987. Keratin filament disiruption in interphase and mitotic cells-how is it induced? Eur. 1. Cell. Biol. 43:35-47.

Towbin, H., Staehelin, T. and Gordon, J. 1979. Electrophoretic transfer of proteins from polvactylamide gels to nitrocellulose sheets: procedure and some applications. Proc. Natl. Acad. Scl. USA. 76:4350-4354.

- Ucker, D.S., Wilson, J.D. and Hebshi, L.D. 1994. Target cell death triggered by cytotoxic T lymphocytes: a target cell mutant distinguishes passive pore formation and active cell suicide mechanisns. Mol. Cell. Biol. 14:427-436.

- Verhallen, P.F.J. Bevers, E.M., Comfurius, P. and Zwaal, R.F.A. 1987. Correiation between calpain-mediated cytoskeletal degradation and expression of platelet procoagulant activity. A role for the platelet membrane-skeleton in the regulation of memebrane lipid asymmetry? Biochim. Biophys. Acta. 903:206-217.

- Vermes, I., Haanen, C., Steffens-Nakken, H. and Reutelingsperger, C.P.M. 1995. A novel assay for apoptosis: flow cytometric detection of phosphatidylserine expression on early apoptotic cells using fluorescein labeled annexin $V . J$. Immunol. Methods $184: 39-51$. 
- Weaver, V.M., Carson, C.E., Walker, P.R., Chaly, N., Lach, B., Raymond, Y., Brown, D.L. and Sikorska, M. 1996. Degradation of nuclear matrix and DNA cleavage in apoptotic thymacytes. J. Cell Sci. 109:45-56.

- Wickstrom, M.L. Khan, S.A., Haschek, W.M.,Wyman, J.F., Eriksson, J.E., Schaeffer, D.J. and Beasiley, V.R. 1995. Alterations in microtubules, intermediate filaments and micrafilaments induced by microcystin-LR in cultured cells. Toxicol. Pathol, 23:326337.

- Wyllie, A.H. 1993. Apoptosis (the 1992 Frank Rose Memorial Lecture) Br. J. Cancer. 67:205-208.

- Wyllie, A.H., Kerr, J.F.R. and Currie, A.R. 1980. Cell death: The significance of apoptosis. Int. Rev.Cytol.68:251-06. 



\section{Differential cleavage of nuclear lamin proteins during apoptosis}

Manon van Engeland, Helma J.H. Kuijpers, Yves Raymond, Christopher J. Hutchison, Bert Schutte, Frans C.S. Ramaekers and Anton H.N. Hopman

\section{Contents}
6.1 Introduction
6.2 Materials \& methods
6.3 Results
6.4 Discussion
6.5 References 


\section{Abstract}

Nuclear lamins form a network of intermediate-sized filaments underlying the inner nuclear membrane. Two subtypes of lamins can be distinguished, i.e. Atype lamins, which comprise lamin $A_{\text {, lamin }} \mathrm{A \Delta} 10$ and lamin $C_{\text {, }}$ and $B$-type lamins, which comprise lamin B1 and lamin B2. During apoptosis lamins are proteolytically cleaved, which facilitates disassembly of the nucleus. In this study the behavior of the different lamin subtypes during apoptosis is examined in the human tumor cell line MR65. For this purpose, different antibodies, detecting epitopes $\mathrm{N}$ - and C-terminal of the caspase cleavage sites, were used in flow cytometry, western blotting and immunocytochemistry of cells induced to undergo apoptosis by roscovitine. We found that after induction of apoptosis, B-type lamins are cleaved almost completely, while only a fraction of the A-type lamins is cleaved. Furthermore, it was observed that Atype lamins are less extractable from apoptotic cells than B-type lamins. In a population of apoptotic cells a granular A-type lamin structure was observed between the condensed chromatin. To explain the resistance of part of the A-type lamins to proteolytic cleavage and solubilization during apoptosis, a model for nuclear disassembly during apoptosis is proposed.

\subsection{Introduction}

Apoptosis is accompanied by characteristic biochemical and morphological changes such as DNA fragmentation, membrane budding and disassembly of the cell into apoptotic bodies (Wyllie et al., 1980). These changes are the result of caspase cleavage of stress response proteins, apoptosis inhibiting proteins and structural proteins (Green, 1998; Thornberry and Lazebnik, 1998). Amongst the structural proteins cleaved by caspases are the nuclear lamins (Lazebnik et al., 1995; Rao et al., 1996; Takahashi et al., 1996).

Lamins form a network of filaments at the nucleoplasmic site of the nuclear membrane. They are bellieved to stabilize the nuclear envelope and to determine the structural organization of the interphase nucleus (Moir and Goldman, 1993). Lamins belong to the intermediate filament protein family and exist of an aminoterminal globular head, a central rod domain, which consists of three coiled subdomains $1 \mathrm{a}, 1 \mathrm{~b}$ and 2, connected by non-helical linkers, and a carboxyterminal globular domain (Georgatos et al., 1994; Nigg, 1992a; Moir et al., 1995). Lamins form homodimers, which interact via their central rod domain. These homodimers form polymers by longitudinal and lateral associations (Nigg, 1992b). Mammalian lamins can be divided into A- and B-type lamins. The B-type lamin isoforms B1 and B2 are closely related in sequence but are products of different genes (Höger et al., 1990), while lamin $A$, lamin $A \Delta 10$ and lamin $C$ originate from a single gene due to alternative splicing (Lin and Worman, 1993; Machiels et al., 1996).

Although intranuclear localization (Moir et al., 1994) and binding to nuclear matrix attachment regions has been reported (Ludérus et al., 1992), B-type lamins are believed to be localized predominantly at the nuclear membrane. A-type lamins on the other hand, are reported to be present at the periphery of the nucleus, but also intranuclearly, where they form a nucleoskeleton (Hozak et al., 1995; Neri et al., 1999).

Characteristic degradation of lamin proteins during apoptosis has been 
reported in several cell types and in response to varying apoptosis inducing agents (Kaufmann, 1989; Oberhammer, et al., 1994; Lazebnik et al., 1995; Weaver et al., 1996; Rao et al., 1996; Takahashi et al., 1996; Casiano et al., 1996; Neamati et al., 1995; McConkey, 1996; Zhivotowsky et al., 1997). Caspase-6 (Mch2) has been identified as the protease responsible for endogenous and recombinant lamin A degradation (Takahashi et al., 1996; orth et al., 1996; Fernandes-Alnemri et al., 1995; Alnemri et al., 1996). Caspase-6 exists as a zymogen in the cytosol and after proteolytic cleavage by caspase- 3 into a large ( $p 18$ ) and a small (p11) subunit, an active caspase tetramer is able to cleave lamin $A$ and lamin $C$ at a conserved VEID domain (Srinivasula et al., 1996; Takahashi et al., 1996, Rao et al., 1996). For Btype lamins the conserved cleavage site is VEVD (Rao et al., 1996).

This cleavage site is located in the middle of the rod domain (amino acids 227-230), a domain that contains chromatin binding sites (Glass et al., 1993) and is of importance for lamin assembly (Mckeon, 1991). In addition, McConkey (1996) and Zhivotowsky et al. (1997) provide evidence for the existence of an enzyme, capable of lamin B1 cleavage, which is activated by $\mathrm{Ca}^{2+}$ and is located at the nuclear scaffold (McConkey, 1996; Zhivotovsky et al., 1997). In contrast to caspase-6, which has to be translacated from the cytosol to the nucleus, the nuclear scaffold associated protease is present in the nucleus at the onset of apoptosis.

In this study, it was examined whether the different localization and supramolecular organization of A- and B-type lamins in the nucleus influences their degradation during apoptosis. For this purpose, human MR65 cells were induced to undergo apoptosis and the behavior of the different lamin subtypes was examined by flow cytometry, western blotting and immunocytochemistry. It was observed that during apoptosis, a fraction of the A-typelamins remains uncleaved, while $B$-type lamins are cleaved almost completely. In addition, A-type lamins were less extractable from apoptotic cells then B-type lamins. Furthermore, a population of apoptotic cells with a granular, A-type lamin structure was observed, probably representing the intranuclear lamin skeleton that is observed by Hozak et al. (1995). These results indicate a differential degradation of A- and B-type lamins during apoptosis, most probably caused by the different supramolecular organization of the different lamin subtypes in the nucleus.

\subsection{Material \& methods}

\section{Cell culture}

The human non small cell lung cancer cell line MR65 (a gift from Dr. Gropp, Philips Universitäts Klinik, Marburg, Germany) was grown as a monolayer in Eagle's modified minimal essential medium (EMEM, Gibco, Paisley, Scotland) supplemented with $10 \%(\mathrm{v} / \mathrm{V})$ heat-inactivated newborn calf serum (Gibco), $10 \mathrm{mM}$ Hepes (Gibco), $2 \mathrm{mM}$ L-glutamine (Serva, Heidelberg, Germany), 1\% $(\mathrm{v} / \mathrm{v}$ ) non essential amino acids (Gibco) and $50 \mu \mathrm{g} / \mathrm{ml}$ gentamycine (AUV, Cuyk, The Netherlands). Apoptosis was induced by treating exponentially growing cells $\left(1 \times 10^{6}\right.$ cells $/ \mathrm{ml}$ ) with $50 \mu \mathrm{M}$ roscovitine (a kind gift of Dr. L Meijer, C.N.R.S., Station Biologique, Roscoff, France) for 6 hours. Roscovitine was dissolved in DMSO. Mock treated cultures received $0.005 \%$ DMSO.

After induction of apoptosis, annexin V/propidium iodide (PI) staining of 
vable cells was performed according to wan Engeland et al. (1996), which revealed that $30 \%$ of the cells has become apoptotic.

\section{Antibodies}

The following primary antibodies were used (see also figure 6.1):

\section{Lamin A:}

- Mouse monocional antibody 133 A2 (Hozak et al., 1995) is raised against the amino acid sequence 598-611, located in the C-terminus of lamin $A$, which is absent in lamin $C$. The 133A2 antibody was diluted 1:500 for immunocytochemistry and 1 : 1000 for western blotting.

\section{Lamin A/C:}

- Mouse monoclonal antibody $\times 67$, which reacts with the first 28 amino acid stretch in the $N$-terminal head domain of both lamins $A$ and $C$ (kindly provided by Dr. G. Krohne, Wuerzburg, Germany). This antibody did not show a reaction on fixed cells in immunacytochemistry. For western blotting the $\times 67$ antibody was diluted $1: 100$.

- Mouse monoclonal antibody Jol2, reacts with an epitope lying between amino acids 464 and 572 in the C-terminal tail domain of lamins $A$ and $C$ (Dyer et al., 1997). Jol2 antibody was diluted 1:10 for immunocytochemistry and 1:50 for western blotting.

- Mouse monoclonal antibody 41CC4, recognizes human lamins $A$ and $C$ (Burke et al., 1983) (kindly provided by Dr. G. Warren, Heidelberg, Germany). 41CC4 was used undiluted in immunocytochemistry and western blotting. The epitope of this antibody is not known.

- Mouse monoclonal antibody R27 (Zatloukal et al., 1992), reacts with lamins $A$ and $C$ (obtained from $G$. Krohne, Heidelberg, Germany). R27 antibody was used undiluted in immumocytochemistry and in western blotting. The epitope of the antibody is not known.

\section{Lamin B1:}

- Mouse monoclonal antibody 11905 (Machiels et al. 1995), is directed against lamin B1. 119D5 antibody was used 1:500 in immunocytochemistry and 1.250 in western blotting. The epitope of this antibody is located $C$ terminal of the caspase cleavage site.

- Guinea Pig polyclonal antibody GP5, is raised against lamin B1. GP5 antibody was used 1:1000 in immunocytochemistry and western blotting.

\section{Lamin B2:}

- Mouse monoclonal antibody LN43 (Bridger et al. 1993) is raised against lamin B2 (kindly provided by Dr. E. B. Lane, Dundee, UK). LN43 antibody was used undiluted in immunocytochemistry and western blotting. The epitope of the antibody is located C-terminal of the caspase cleavage site.

- Mouse monoclonal antibody X223 (Höger et al., 1990) is reactive with lamin B2 (kindly provided by G. Krohne, Heidelberg, Germany). $\times 223$ antibody was used undiluted in immunocytochemistry and western blotting. The epitope of the antibody is located N-terminal of the caspase cleavage site. 


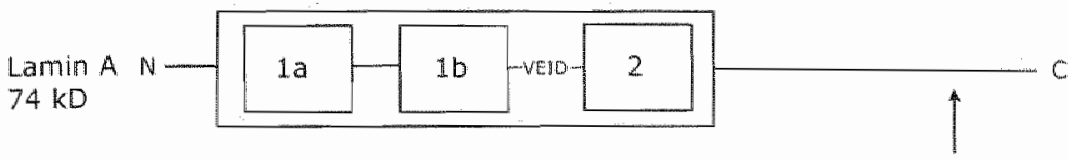

$133 \mathrm{A2}$
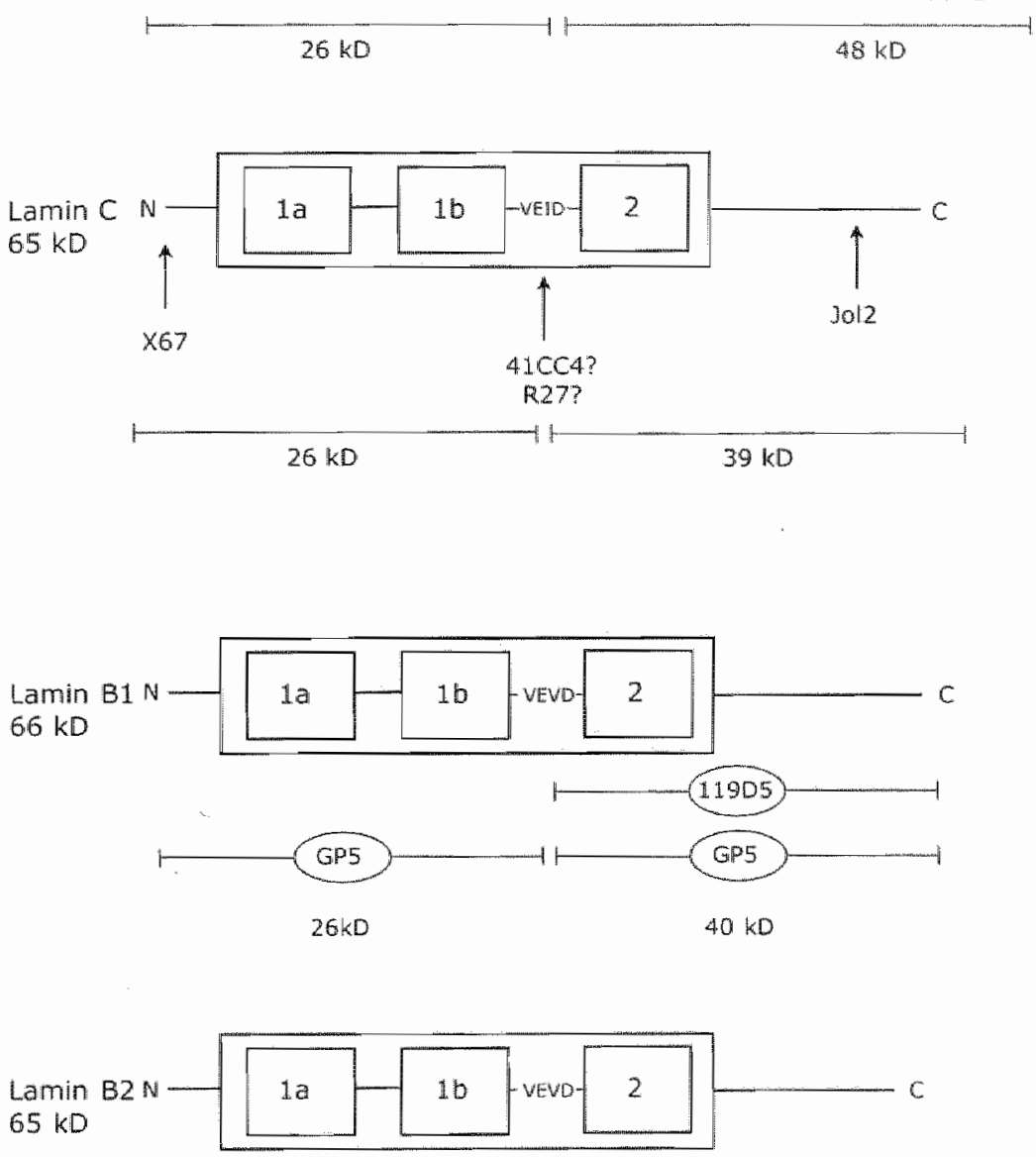

Figure 6.1: Schematic drawing of the secondary structure of lamins $A, C, B 1$ and $B 2$. The amino- (N) and carboxy- (C) temini, the welical rod domain containing the subdomains 1 $a, 1$ b and 2, the caspase cleavage site (VEID for A-type lamins and VEVD for B-type lamins) and the epitopes of the antibodies are indicated. Furthermore, the predicted size of the fragments generated by caspase- 6 cleavage is indicated. 


\section{Flow cytometry}

Annexin $V$ labeling and harvesting of apoptotic cells in culture was performed as described by van Engeland et al. (1996). Then, the cells were washed in PBS, pelleted and fixed in cold methanol $(-20 \mathrm{C})$ for 5 minutes. After washing in PBS and PBS/BSA (1\%), cells were incubated with the primary antibody for 1 hour at room temperature. After two washing steps with PBS/BSA, the cell suspensions were incubated with phycoerythrin (RPE)-conjugated goat-antimouse immunoglobulins to detect the primary antibody and FITC-conjugated streptavidin to detect biotinylated-annexin $V$. For flow cytometric analysis a FACSort (Becton Dickinson, San Jose, CA) equipped with a single argon ion laser was used. The exciting light was $488 \mathrm{~nm}$ and the emission filters were 515-545 bp (green:FITC), 572-588 bp (orange:phycoerythrin) and 600 bp (red:PI). Data of a minimum of 10,000 cells per sample were stored in list mode. Electronic compensation was used to eliminate bleed through of fluorescence. Data analysis was performed using Cell Quest software (Becton Dickinson). As a standard procedure for all three coloir analyses, data were gated on pulse-processed PI signals to exclude doublets and larger aggregates. Quadrant settings were based on the negative control, allowing less than $1 \%$ positivity. As negative control PBS was used in stead of the primary antibody. To determine the decrease in lamin fluorescence of apoptotic cells, the ratio between the mean lamin fluorescence of annexin $V /$ lamin ${ }^{+}$cells and annexin $\mathrm{V}^{+}$/lamin ${ }^{+}$cells was calculated.

\section{Immunocytochemistry}

Control and roscovitine treated MR65 cells were harvested by trypsinization, resuspended in EMEM containing 50\% fetal calif serum and cytocentrifuged onto glass slides ( 5 minutes, $600 \mathrm{ppm}$ ). After air drying for 2 hours, cells were fixed according to two protocols: 1) permeabilization and fixation with $100 \%$ methanol $\left(-20^{\circ} \mathrm{C}\right)$, followed by two acetone dips (room temperature), and 2) mild formaldehyde fixation (1\% formaldehyde in PBS, 5 minutes, room temperature), wash in $\mathrm{PBS}$ and permeabilization in $1.00 \%$ methanol ($20^{\circ} \mathrm{C}$ ) followed by two acetone dips (room temperature). Primary antibodies were diluted in PBS containing 1\% BSA and incubated for 60 minutes at room temperature. Slides were washed 3 times in PBS before incubation with the secondary antibody. For the mouse monodonal antibodies the secondary antibody was a FITC-conjugated rabbit anti-mouse antibody (DAKO, 1:50 dilution). After 3 PBS washing steps, the guinea pig polyclonal antibody GP-5 was incubated with a rabbit anti guinea pig antibody (DAKO, 1:500 dilution), followed by a FITC-conjugated swine anti rabbit antibody (DAKO, 1:100 dilution). Slides were washed in PBS, incubated with PBS containing 0.5 $\mu g / m$ propidium lodide (PI) and $100 \mu \mathrm{g} / \mathrm{ml}$ RNAse A. Finally, the slides were embedded in glycerol/1,4-diazobicyclo $(2,2,2)$ octane (DABCO) ( 9 parts of glyceral, 1 part of $0.2 \mathrm{M} \mathrm{Tris-HCl}, \mathrm{pH} 8.0,0.02 \% \mathrm{NaN}_{3}$ and $2 \% \mathrm{DABCO} \mathrm{pH}$ 8.0) containing $0.5 \mathrm{Hg} / \mathrm{ml}$ PI. Microphotographs were recorded with the In Situ Image System (version 3.30, Metasystems $\mathrm{GmbH}_{*}$ Altlussheim, Germany) using a black and white CCD camera.

\section{Cell fractionation for gel electrophoresis and western blotting}

Control MR.65 cells were harvested by scraping the cells in culture medium. Floating, apoptotic cells were collected by shaking. After pelleting, cells were resuspended in $0.5 \%$ Triton-X100 in RSB-buffer $(10 \mathrm{mM} \mathrm{NaCl}, 1.5 \mathrm{mM} \mathrm{MgCl}$, 
$10 \mathrm{mM}$ Tris- $\mathrm{HCl}, \mathrm{pH} 7.4$ ) containing $0.5 \mathrm{mM}$ phenylmethylsulphonyl chloride (PMSC), for 10 minutes at $4 \circ$. After pelleting by centrifugation ( 5 minutes, $4^{\circ} \mathrm{C}, 1500 \mathrm{~g}$ ), the sediment fraction was washed in RSB/PMSC and pelleted again. The pellet was incubated with RSB buffer containing $110 \mathrm{mM} \mathrm{NaCl}, 1$ $\mathrm{mg} / \mathrm{ml}$ DNAse I (Sigma) and $50 \mu \mathrm{g} / \mathrm{ml}$ RNAse A (Sigma) for 20 minutes at room temperature. After washing in RSB/PMSC and pelleting, the pellet, containing the cytoskeleton/nuclear matrix fraction, was resuspended in SDSsample buffer and samples were bolled for 5 minutes. One-dimensional sodium dodecyl sulfate polyacrylamide gell electrophoresis (SDS-PAGE) with extracts of 40,000 cells per lane was performed according to Laemmli (1970), using gels containing 13\% polyacrylamide (Bio-Rad Laboratories, Hercules, CA) and 0.1\% SDS (Merck). Gels were run on the Mini-protean II system (Bio-Rad Laboratories) for approximately 45 minutes at $200 \mathrm{~V}$. For western blotting, the method described by Towbin (1979) was used. Transfer to nitrocellulose membranes was performed in blotting buffer $1192 \mathrm{~mm}$ glycine, $25 \mathrm{mM}$ Tris, $20 \%$ methanol) for 1 hour at $100 \mathrm{~V}$. The nitrocellulose membranes (Schleicher \& Schuell, Dassel, Germany) were incubated with the primary lamin antibodies and detection was performed using alkaline phosphatase and enhanced chemiluminescence (ECL-kit, Amersham, Bucks., UK). RX Fuji medical $x$-ray films (Fuji, Tokyo, Japan) were used for the wisualization of the luminescent signals.

\section{Cell fractionation and nuclear matrix preparation for immunocyto- chemistry}

Cell fractionations were carried out in the presence of $0.5 \mathrm{mM} \mathrm{PMSC}$ and 5 $\mathrm{mM} \mathrm{N}$-ethylmaleimide to reduce proteolytic degradation and disulphide bridge formation, respectively. These agents were added from freshly prepared stock solutions. Ribonuclease A (RNAse A) (Sigma) was preincubated for 15 min at $100^{\circ} \mathrm{C}$ to reduce possible protease activity. Centrifugation steps were carried out for 5 minutes at $1500 \mathrm{~g}$ and $4 \circ \mathrm{C}$. The procedure for isolation of nuclear matrices, carried out at $0-4^{\circ} \mathrm{C}$, is as follows: cells were harvested on NKM buffer (130 $\mathrm{mM} \mathrm{NaCl}, 5 \mathrm{mM} \mathrm{KCl}, 7.5 \mathrm{mM} \mathrm{MgCl}_{2}$ ) and pelleted by centrifugation. Each of the following steps in the procedure was preceded by washing the pellet with RSB. Subsequently, the pellet was suspended in hypertonic buffer (RSB with $0.3 \mathrm{M}$ sucrose) and after addition of 0.05 volume $10 \%$ Triton $X-100$ in RSB, the suspension was gently swilled in ice $(25 x)$ and centrifuged to sediment the cytoskeleton and nuclear matrix fraction. After washing, these were resuspended in RSB and, after addition of 0.1 volume of a freshly prepared solution of $5 \%$ sodium deaxycholate (DOC) $/ 10 \%$ Tween 40 in RSB, homogenized by 10 strokes of a motor-driven teflon pestle in a Potter tissue homogenizer. The nuclei were pelleted, washed and resuspended in $H R S B\left(110 \mathrm{mM} \mathrm{NaCl}, 10 \mathrm{mM}\right.$ Tris-acetate $\left.\mathrm{pH} 7.4,1.5 \mathrm{mM} \mathrm{MgCl}_{2}\right)$ and incubated with $1 \mathrm{mg} / \mathrm{ml}$ deoxyribonuclease I (DNAse I) (Sigma) and 50 $\mu \mathrm{g} / \mathrm{ml}$ RNAse A for 1.5 minutes at $20^{\circ} \mathrm{C}$. During the digestion step $\mathbb{N}$ ethylmaleimide was omitted, but immediately after the incubation it was added again to a final concentration of $5 \mathrm{mM}$. The DNA depleted nuclei were spun down, washed and gently resuspended in $0.4 \mathrm{M}\left(\mathrm{NH}_{4}\right)_{2} \mathrm{SO}_{4}, 50 \mathrm{mM}$ Trisacetate, $\mathrm{pH} 7.4 .1 .5 \mathrm{mM} \mathrm{MgCl}$ for 10 minutes on ice. The nuclear matrix preparation was pelleted, washed, resuspended in RSB and stained in suspension according to the protocol described in the above paragraph. 


\section{Confocal scanning laser microscopy}

A drop of the supension of lamin-stained nuclear matrices on a glass slide was analyzed using the MRC 600 confocal scanning laser microscope (BioRad, Hemel Hempstead, UK), equipped with an air-cooled argon-krypton mixed-gas laser and mounted onto an Axiophot microscope (Zeiss). The laser scanning microscope was used according to the manufacturer's specifications. All scans were recorded using Kalman filtering. Z-series were generated by collecting a stack consisting of 60 opticall sections using a step size of $0.1 \mu \mathrm{m}$ in the z-direction. Stacks of images were used for side-by-side stereo projectioni using Confocal Assistance software (Bio-Rad).

\subsection{Results}

\section{Flow cytometry}

Flow cytometric studies (figure 6.2) showed that the majority of cells in control cultures annexin $V^{\prime \prime}$ and positive for lamin $A / C$ (figure 6.2a), lamin B1 (figure 6.2c) and lamin B2 (figure 6.2e). Only a few annexin $V$ positive, spontaneous apoptotic cells are abserved. After induction of apoptosis, $94 \%$ of the annexin $\mathrm{V}^{+}$, apoptotic cells is lamin $\mathrm{A} / \mathrm{C}^{+}$, although the level of immunofluorescence has decreased $55 \%$ compared to non-apoptotic cells (figure $6.2 \mathrm{~b}$ ). $57 \%$ of the apoptotic cells is positive for lamin B1, although the immunoftuorescence of these cells has decreased $70 \%$ compared to nonapoptotic cells (figure 6.2d). Staining with the lamin B2 antibody LN43 revealed that $77 \%$ of the annexin $\mathrm{V}^{+}$apoptotic cells is lamin $\mathrm{BZ}^{+}$, although the immumofluorescence of these cells has decreased $58 \%$, compared to control cells (figure 6.2f).

\section{Western blotting}

The results of the western blot experiments are shown in figure 6.3 and are summarized in table 6.1. Using the Swiss-Prot Database in combination with the known caspase-cleavage sites (Rao et al., 1996), lamin fragments generated by caspase- 6 can be calculated. Since the epitope of several antibodies is known, the relative size of the individual fragments to be detected can be predicted (see figure 6.1).

\begin{tabular}{clcc}
\hline Lamin subtype & Antibody & $\begin{array}{c}\text { Mr } \\
\text { intact protein } \\
(\mathrm{kD})\end{array}$ & $\begin{array}{c}\text { Mr } \\
\text { caspase cleavage } \\
\text { product(s) (kD) }\end{array}$ \\
\hline A & 133 A2 & 74 & 48 \\
A & Jol2 & $74 / 65$ & $48 / 39$ \\
& R27 & $74 / 65$ & - \\
& $41 C C 4$ & $74 / 65$ & - \\
B1 & X67 & $74 / 65$ & 26 \\
& GP5 & 66 & $40 / 26$ \\
B2 & $119 D 5$ & 66 & 40 \\
& X223 & 65 & 39 \\
\hline
\end{tabular}

Table 6.1: Results from the western blotting experiments using antibodies against different lamin subtypes. The observed relative molecular weight (Mr) of the intact proteins and the caspase cleavage products are shown. 

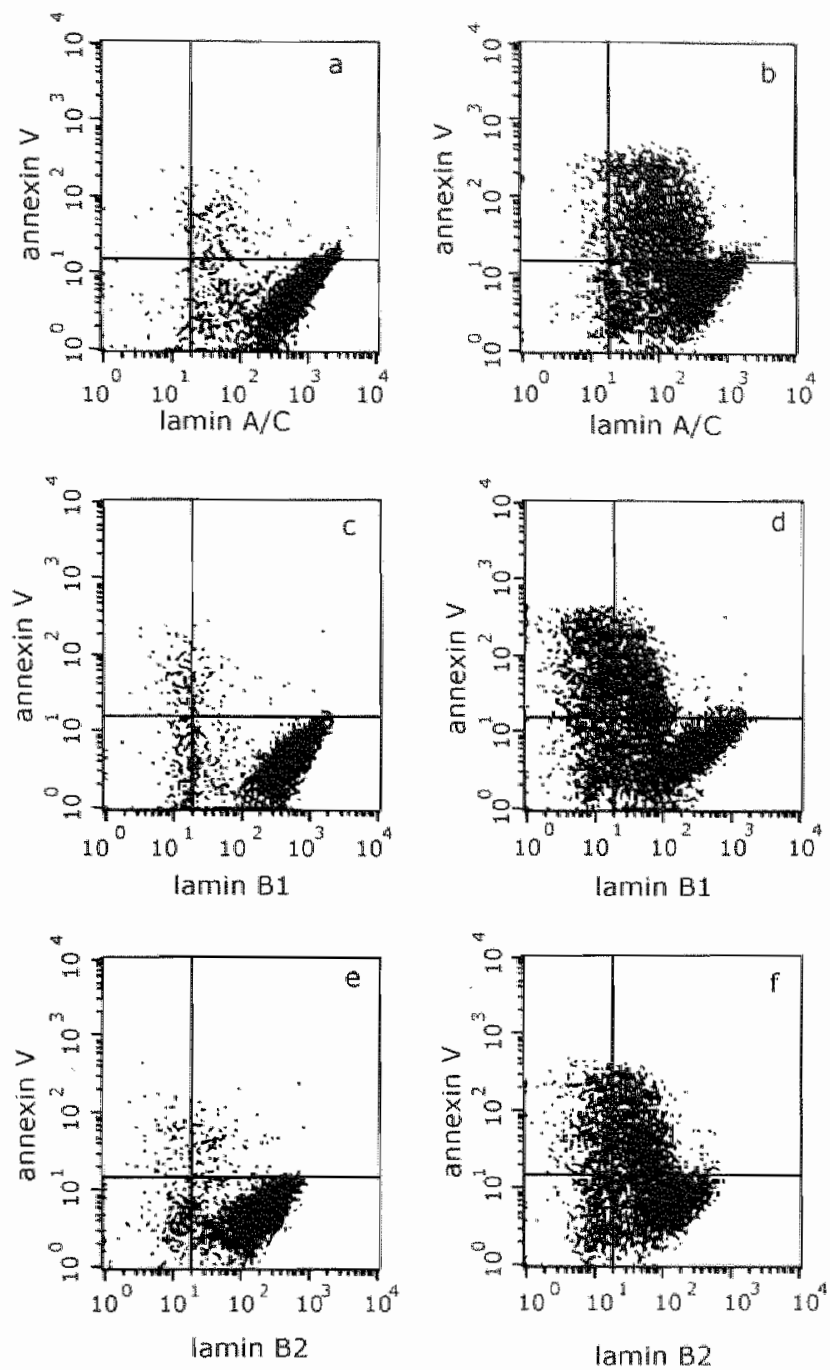

Figure 6.2: Flow cytograms of control $(a, c$ and $e)$ and roscovitine induced $(b, d$ and g) MR65 cells after fixation and staining for the presence of lamin A/C (R27 antibody) (a and b), lamin B1 (11905 antibody) ( $c$ and $d$ ) and lamin B2 (LN43 antibody) (e and f). Lamin fluorescence is shown on the $x$-axis and annexin $V$ binding is shown on the $y$ axis. Quadrant settings were based on the negative control. In control cultures only a few annexin $\checkmark$ positive cells (the spontaneous apototic cells) were observed. After 6 hours of induction with roscovitine, approximately $40-50 \%$ of the cells has become apoptotic. Of the apoptotic cells, $6 \%$ has become negative for lamin $A_{1} / C_{,}, 43 \%$ has become negative for lamin B1 and $23 \%$ thas become negative for lamin B2. Of the lamin positive apoptotic cells, the lamin immunofluorescence has decreased $55 \%$, $70 \%$ and $58 \%$ compared to non-apoptotic cells, for lamin A/C, lamin B1 and lamin B2 respectively. 
The $133 \mathrm{~A} 2$ antibody, raised against the C-terminal tail domain of only lamin $A$, detects the intact $74 \mathrm{kD}$ lamin A protein in control cells. In apoptotic cells an intact $74 \mathrm{kD}$ protein band and the expected $48 \mathrm{kD}$ fragment are detected. The $\times 67$ antibody is raised against an amino acid stretch in the $\mathrm{N}$-terminal head domain of lamins $A$ and $C$. In control cells the $74 \mathrm{kD}$ lamin $A$ and the 65 $\mathrm{kD}$ lamin $C$ protein bands are detected. In apoptotic cells, the expected $26 \mathrm{kD}$ proteolytic fragment is detected, in addition to the bands representing the intact lamin A and C. Surprisingly, the lamin A/C antibodies 41CC4 and R27 (epitopes not known) only show the intact lamin $A$ and $C$ protein bands in apoptotic cells (although decreased in intensity) and do not detect a caspase cleavage fragment. This may indicate that the epitope recognized by $41 C C 4$ and R.27 is destroyed during apoptosis, suggesting that the epitope contains, or is in close vicinity to the caspase cleavage site. On the other hand, the antibody Jol2, raised against an amino acid stretch in the C-terminal tail present in both lamin $\mathrm{A}$ and $\mathrm{C}$, does detect the expected apoptotic fragments of approximately 48 and $39 \mathrm{kD}$, in addition to the intact protein bands of 74 and $65 \mathrm{kD}$. For $\mathbb{B}$-type lamins, the western blot results are shown in figure 6.3b. The monoclonal lamin B1 antibody 119D5 detects the expected $66 \mathrm{kD}$ band in control cells. In apoptotic cells, the band corresponding to the intact protein has almost completely disappeared, while a strong $40 \mathrm{kD}$ caspase cleavage fragment can now be detected. The polyclonal lamin B1 antibody GP5 detects the intact $67 \mathrm{kD}$ protein in control cells, while in apoptotic cells a $67 \mathrm{kD}$ protein in addition to two caspase cleavage fragments of $40 \mathrm{kD}$ and 26 $\mathrm{kD}$ is observed. The lamin B2 antibody LN43 detected the expected $65 \mathrm{kD}$ band in control cells and a strong $39 \mathrm{kD}$ fragment in apoptotic cells. The intact protein can hardly be detected any more in apoptotic cells using the LN43 antibody. The lamin B2 antibody $\times 223$ detected a $26 \mathrm{kD}$ fragment in apoptotic cells.

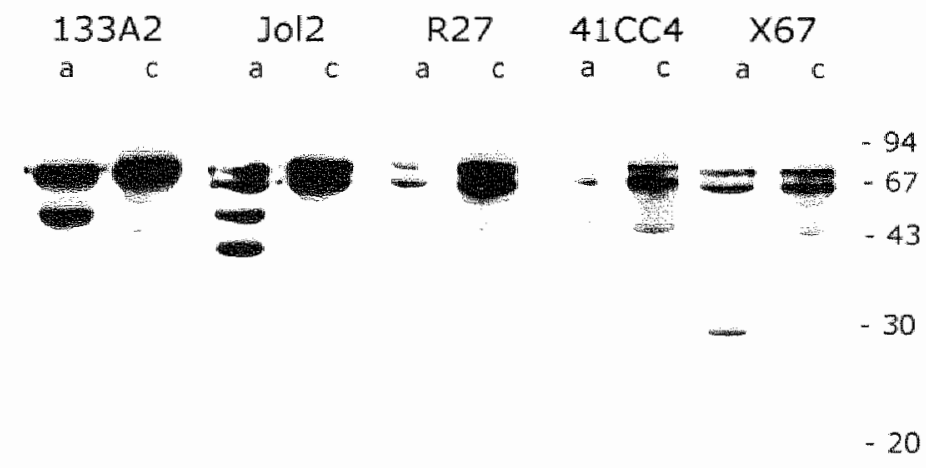

Figure 6.3a: Immunoblotting of contral (c) and apoptotic (a) MR65 cells with A-type lamin antibodies. In apoptotic cells only a fraction of A-type lamins is cleaved. 


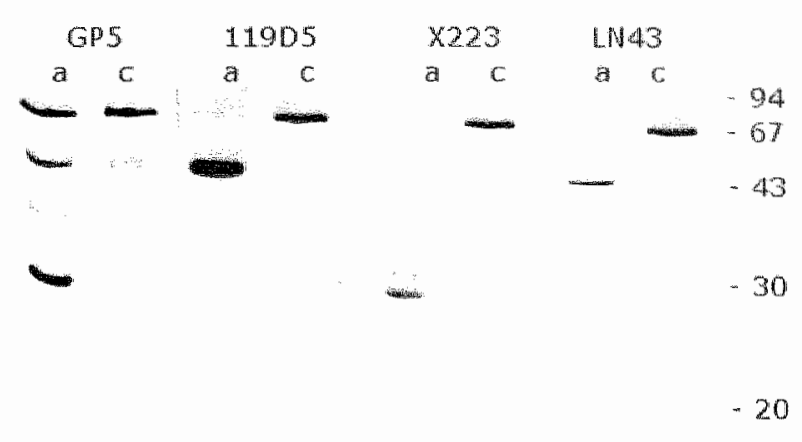

Figure 6.3b: Immunoblotting of control (c) and apoptotic (a) MR65 cells with B-type lamin antibodies. It is observed that $B$-type lamins are cleaved almost completely in apoptotic cells.

\section{Immunocytochemistry}

To study the distribution of individual lamin proteins during apoptosis, immunocytochemical studies were performed on MR65 cells. After harvesting, cells were cytocentrifuged onto glass slides and fixed in methanol/acetome or $1 \%$ formaldehyde.

\section{A-type lamins}

Methanol/acetone fixed control cells, stained with A-type lamin antibodies show a laminar fluorescence pattern surrounding the nucleus. In the majority of cells, the lamina is clearly visible (figure $6.4 a$ ). In a fraction (10\%) of the cells, the lamina is weakly stained or almost undetectable. On the other hand, in formaldehyde fixed control cells, the A-type lamina is less intensely stained with the A-type lamin antibodies, while a very diffuse nuclear staining is observed in all cells. Cells induced to undergo apoptosis showed several Atype lamin distribution patterns. Approximately $70 \%$ of the apoptotic cells showed a lamima-like structure surrounding condensed DNA (figure 6.4b), sometimes in addition to a diffuse staining between the condensed DNA. Approximately $20 \%$ of the apoptotic cells showed aranular lamin structure lying between the condensed chromatin (figure $6.4 d$ ), sometimes in addition to diffuse staining between the condensed DNA (figure $6.4 c$ ), while $10 \%$ of the apoptotic cells were lamin $A / C$ negative. These different distribution patterns were observed with all the A-type lamin antibodies and both fixation procedures. The antibodies R27 and 41CC4 did not detect lamins A and C after formaldehyde fixation, while the $\times 67$ antibody did not detect lamins $A$ and $C$ in immunocytochemistry after methanal/acetone and formaldehyde fixation. 


\section{B-type lamins}

Methamol/acetone fixed control cells, stained with lamin B1 and lamin B2 antibodies, all show a lamina surrounding the nucleus (figure 6.5a), while almost no lamin negative cells are observed. After formaldehyde fixation, the lamina is less intensely stained and a more diffuse staining pattern is observed. After induction of apoptosis and methanol/acetone fixation, only $20 \%$ of the cells is positive for lamin $\mathrm{B1}$, detected with the antibody 11905 . After formaldehyde fixation, the percentage of lamin B1 positive cells in the apoptotic population increased to $60 \%$. The lamin B1 positive cells showed a diffuse fluorescence between the condensed DNA, in addition to a lamina-like staining surrounding the condensed DNA (figure 6.5b). The fluorescence signal of the lamin B1 positive apoptotic cells has decreased significantly compared to the signal observed in non-apoptotic cells. Using the antibodies LN43 and X223, to detect lamin B2, the same distribution patterns were observed in apoptotic cells as using antibodies raised against lamin $\mathrm{B} 1$, although less lamin B2 negative cells were observed after methanol/acetone fixation (figure $6.5 \mathrm{c}$ and $6.5 \mathrm{~d}$ ).
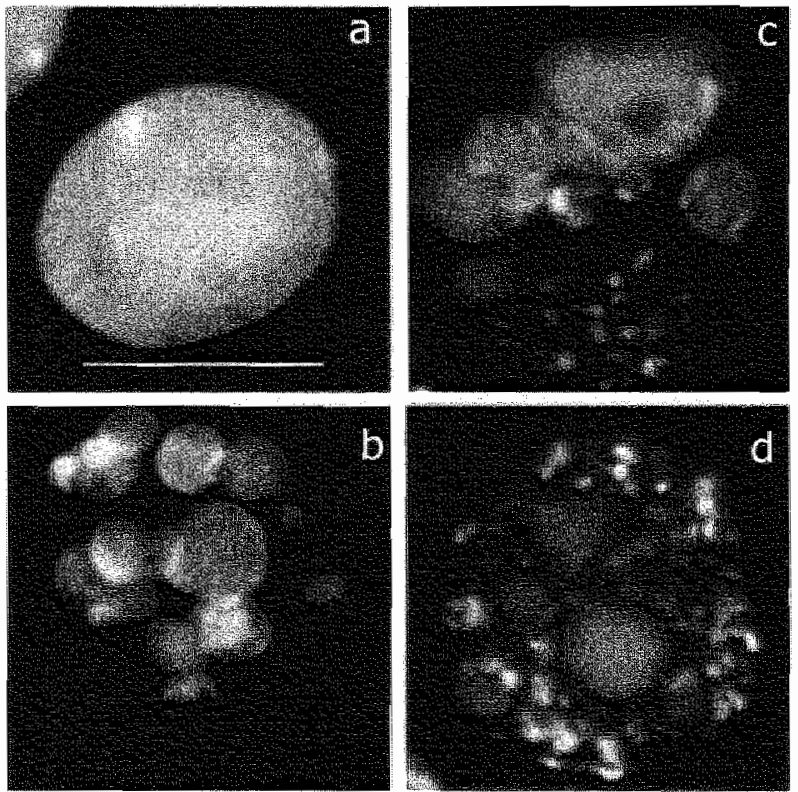

Figure 6.4: Immunocytochemistry of MR65 cells using A-type lamin antibodies. Lamins are shown in green, whille the PI counterstaining of the nucleus is shown in red. Figure 6.4a shows a non-apoptotic cell stained with the lamin A antibody $133 \mathrm{A2}$ after methanol fixation. Figure $6.4 \mathrm{~b}$ shows an apoptotic cell stained with the A-type lamin antibody $133 \mathrm{~A} 2$ showing a lamina-like structure surrounding the condensed DNA. Figure $6.4 \mathrm{~d}$ shows an apoptotic cell stained with the lamin A/C antibody Jol2, which detects a granular structure lying between the condensed DNA. In figure $6.4 \mathrm{C}$ an apoptotic cell with a lamina-like A-type lamin staining in addition to a granular structure is shown (antibody Jol2). Bar indicates $15 \mathrm{~mm}$. For color illustration see page 137 . 

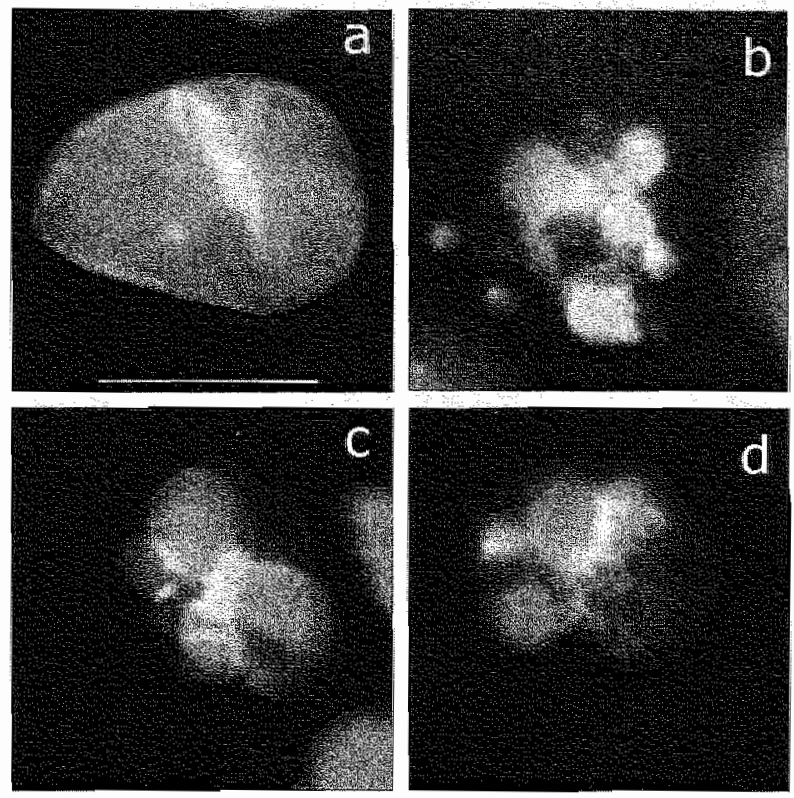

Figure 6.5: Immunocytochemistry of MR65 cells using B-type lamin antibodies. Lamins are shown in green, while the PI counterstaining of the DNA is showm in red. Figure 6.5a shows a non-apoptotic cell stained with the lamin B2 antibody $\mathrm{LN}_{4}$, $_{\text {, }}$ showing a laminar staining pattern. In figure $6.5 b$ an apoptotic cells is shown, with diffuse lamin B1 fluorescence (antibody 119D5) between the consensed DNA. Figure $6.5 \mathrm{c}$ shows an apoptotic cells stained with the lamin $B 2$ antibody $\times 223$, showing a lamina-like staining surrounding the condensed DNA, while figure $6.5 \mathrm{~d}$ shows diffuse lamin B2 fluorescence next to the condensed chromatin (LN43 antibody). Bar indicates $15 \Perp \mathrm{m}$. For color illustration see page 137 .

\section{Nuclear matrix preparations}

Nuclear matrices were prepared from control cultures and roscovitine treated cultures and were stained with lamin antibodies. Of the control matrices stained with A-type lamin antibodies, the majority shows a lamina-like staining, while approximately $10 \%$ shows a granular structure, resembling the structure observed in a subset of apoptotic cells (figure 6.6). These percentages were similar for matrices obtained from control and roscovitine treated cell cultures. This granular structure was not observed when matrices were stained with B-type lamin antibodies. 

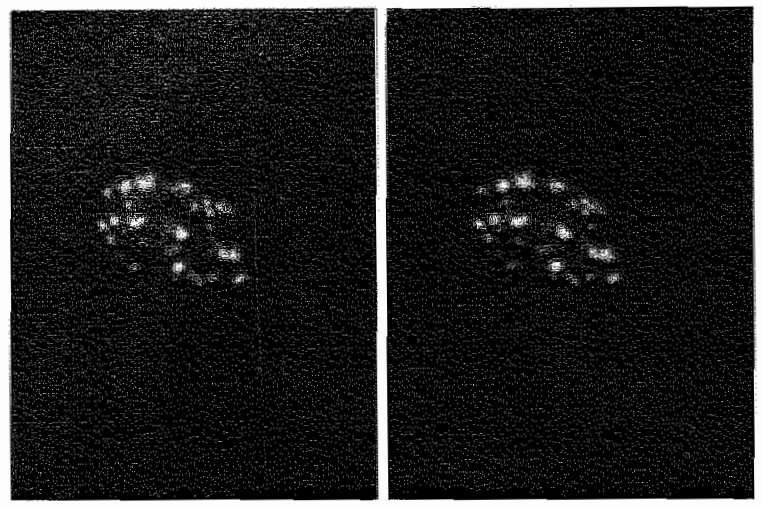

Figure 6.6: Side by side stereo projection of aptical sections obtained by confocal laser scanning microscopy of a MR65 cell nuclear matrix stained with the lamin A/C antibody jol2. The observed staining pattern resembles the granular A-type lamin structure observed in apoptotic cells. The magnification is $230 x$.

\subsection{Discussion}

\section{Diffential degradation of $\mathrm{A}$ - and $\mathrm{B}$-type lamins during apoptosis}

The results obtained in this study provide evidence that $A$ - and $B$-type lamins are differentially degraded during apoptosis. This conclusion is based on the following observations: 1) Western blotting experiments indicate that after induction of apoptosis B-type lamins are cleaved almost completely, while part of the A-type lamin proteins remains intact. 2) In general, the immunofluorescence sigmal of A-type lamins is stronger than the immunofluorescence signal of B-type lamins in apoptotic cells. 3) Comparison of fixation techniques revealed that methanol/acetone fixation extracted part of the B-type lamins, in particular lamin B1, from apoptotic cells, in contrast to A-type lamins, which are not extracted. 4) In part of the apoptotic cells, an intranuclear, granular A-type lamin structure is observed, which is never seen for $B$ type lamins.

It was observed that after induction of apoptosis B-type lamins are cleaved almost completely, while part of the A-type lamins remains uncleaved.

This phenomenon is also observed by Mandal et al. (1996), who showed that B-type lamins are cleaved already 2 hours after Fas induction in Hela cells, while A-type lamins are not cleaved 4 hours after induction of apoptosis. Considering that caspase- 6 is the enzyme responsible for cleavage of all lamin subtypes during apoptosis, it is remarkable that B-type lamins are cleaved preferentially compared to A-type lamins. An explanation for these observations may be that B-type lamins are localized predominantly at the periphery of the nucleus and are thus accessible for caspase-6. A-type lamins on the other hand, are reported to be present intranuclearly, in addition to a peripheral localization (Hozak et al, 1995; Neri et al, 1999). Whille the peripheral A-type lamins are accessible, the intranuclear A-type lamins may be protected from caspase cleavage due to the dense configuration of the chromatin and/or postranslational modifications. 
In non-apoptotic cells, this intranuclear A-type lamin scaffold can hardly be detected with antibodies due to the density of the chromatin. However after removal of chromatin by standard nuclear matrix preparation techniques, the accessibility of the intranuclear A-type lamins is increased and a structure resembling the granular structure observed in apoptotic cells can be detected.

Based on these results we propose the following model. During apoptosis, lamins are cleaved by caspase-6. However, the intranuclear A-type lamins are inaccessible for caspase- 6 due to the dense chromatin configuration and strong interactions with other nuclear matrix constituents. At the same time, DNA is degraded by caspase activated DNAse (CAD) (Enari et al., 1998). Cleavage and condensation of DNA into apoptotic micronuciei may then unmask the nuclear matrix, consisting amongst others of intranuclear A-type lamin and nuclear matrix DNA (see chapter 7).

This residual nuclear matrix is then accessible for futher degradation. It can thus be concluded that during the process of apoptosis, the chromatin is reorganized and partially removed allowing the immunocytochemical detection of the A-type lamin skeleton.

Although protection of intranuclear A-type lamins from caspase-6 cleavage is a plausible explanation for the difference in A- and B-type lamin degradation, it can not be excluded that different enzymes are responsible for cleavage of A-type versus B-type lamins. The nuclear scaffold protease, suggested by McConkey (1996) and Zhivotovsky et al. (1997) which is present in the nucleus at the onset of apoptosis, may have a preference for B-type lamins, while caspase-6, which has to be translocated from the cytosol to the nucleus, has a preference for A-type lamins. Although we, and others (Hozak et al., 1995; Neri et al., 1999) never observed a granullar, intranuclear Btype lamin structure, B-type lamins have been reported to be present intranuclearly in mid to late S-phase cells (Moir et al., 1994).

In conclusion, our results indicate that cleavage of $A$ - and $B$-type lamins during apoptosis is dependent on the supramolecular organization of these proteins in the mucleus. Furthermore, the process of apoptosis can be used to study the organization of the nucleus.

\section{Acknowledgments}

We thank Dr. G. Krohne (University of Würzburg, Germany), Dr. G. Warren (Heidelberg, Germany) and Dr. E.B. Lane (University of Dundee, U.K.) for antibodies and Dr. L. Meyer (Station Biologique, Roscoff, France) for roscovitine.

\subsection{References}

- Alnemri, E.S., Livingston, D.J., Nicholsan, D.W., Salvesen, G., Thornberry, N.A., Wong. W.W. and Yuan, J. 1996. Human ICE/CED-3 protease nomenclature. Cell 87:171.

- Bridger, J.M., Kill, I., O'Farrel, M. and Hutchison C.J. 1993. Internal lamin structure within Gi nuclei of human dermal fibrablasts. 1. Cell Sci. 104:297-306.

- Burke, B., Tooze, G. and Warren, G. 1983. A monoclonal antibody which recognizes each of the nuclear lamin polypeptides in mammalian cells. EMBO J. 2:361-367. 
- Casiano, C.A., Martin, S.Ju, Green, D.R. and Tan, E.M. 1996. Selective cleavage of nuclear autoantigens during C095 (Fas/APO-1)-mediated $T$ cell apoptosis. J. Exp. Med. 184:765-770.

- Dyer, J.A., Kill, 1.R., Pugh, G. Quinlan, R.A., Lane, E.B. and Hutchison, C.J. 1997. Cell cycle changes in A-type lamin associations detected in human dermal fibroblasts using monoclonal antibodies. Chromosome Res. 5:383-394.

- Enari, M., Sakahira, H., Yokomaya, H., Okawa, K., Iwamatsu, A. and Nagata, S. 1998. A caspase-activated DNAse that degrades DNA during apoptosis, and its inhibitor CAD. Nature 391:43-50.

- van Engeland, M. Ramaekers, F.C.S., Schutte, B. and Reutelingsperger, C.P.M. 1996. A novel assay to measure loss of plasma membrane asymmetry during apoptosis of adherent cells in culture. Cytometry 24:131-139.

- Fernandes-Alnemri, T., Litwack, G. and Alnemri, E.S. 1995. Mch2, a new member of the apoptotic Ced-3/ICE cysteine protease gene family. Cancer Res. 55:2737-2742.

- Georgatos, S.D., Meler, J. and Simos, G. 1994. Lamins and lamin-associated proteins. Curr. Opin. Cell Biol, 6:347-353.

- Glass, C.A., Glass, J.R., Taniura, H., Hasel, K.W., Blevitt, J.M. and Gerace, L. 1993. The a-helical rod domain of human lamins $A$ and $C$ contains a chromatin binding site. EMBO J. 12:4413-4424.

- Green, D.R. 1998. Apoptotic pathways: the roads to ruin. Cell 94:695-698.

- Höger, T.H., Zatloukal, K., Waizenegger, I., and Krohne, G. 1990. Characterization of a second highly conserved $B$-type lamin present in cells previously thought to contain only a single B-type lamin. Chromosoma 99:379-390.

- Hozak, P. Sasseville, A.M.J., Raymond, Y. and Cook, P.R. 1995. Lamins proteins form an internal nucleoskeleton as well as a peripheral lamina in human cells. J. Cell $5 \mathrm{c}$. $108: 635-644$.

- Kaufmann, S.H. 1989. Induction of endonucleolytic DNA cleavage in human acute myelogenous leukemila cells by etoposide, camptothecin, and other cytotoxic anticancer drugs: a cautionary note. Cancer Res. 49:5870-5878.

- Laemmli, U.K. 1970 . Cleavage of structurall proteins during the assembly of the head of bacteriophage T4. Nature 227:680-685.

- Lazebnik, Y.A., Takahashi, A., Moir, R.D., Goldman, R.D., poirier, G.G., Kaufmann, S.H. and Earnshaw, W.C. 1995. Studies of the lamin proteinase reveal multiple parallel biochemical pathways during apoptotic execution. Proc. Natl. Acad. Sci. USA. 92:9042-9046.

- Lin, F. and Worman, H.J. 1993. Structural organization of the human gene encoding nuclear lamin A and nuclear lamin C. J. Biol. Chem. 268:16321-16326.

- Ludérus, M.E.E., de Graaf, A., Mattia, E., den Blaauwen J.L., Grande, M.A., de Jong, $L$. and van Driel, R. 1992. Binding of matrix attachment regions to lamin B1. Cell $70: 949-959$.

- Machiels, B.M., Broers, J.L.V., Raymond, Y., de Ley, L., Kuijpers, H.J.H., Caberg, N.E.H. and Ramaekers, F.C.S. 1995. Abnormal A-type lamin organization in a human lung carcinoma cell line. Eur. J. Cell Blol. 67:328-335.

- Machiels, B.M., Zorenc, A.H.G., Endert, J.M., Kuijpers, H.J.H., van Eys, G.J.J.M., Ramaekers, F.C.S, and Broers, J.L.V. 1996. An alternative splicing product of the lamin $\mathrm{A} / \mathrm{C}$ gene in lung carcinomas lacks exon 10. J. Biol. Chem. 16:9249-9253.

- Mandal, M. Maggirwar, S.B., Sharma, N., Kaufmann, S.H., Sun, S.C. and Kumar, R. 1996. $\mathrm{BCl}-2$ prewents CD95 (Fas/APO-1)-induced degradation of lamin $\mathrm{B}$ and polv(ADP-ribose) polymerase and restores the NF-KB signaling pathway. J. Biol. Chem. 271:30354-30359.

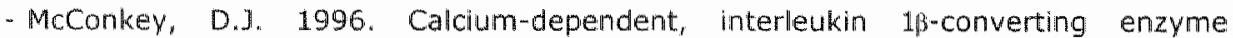
inhibitor-insensitive degradation of lamim B1 and DNA fragmentation in isolated thymocyte nuclei. J. Biol. Chem. 271:22398-22406.

- Mckeon, F. 1991 Nuclear lamin proteins: domains required for nuclear tangeting, assembly, and cell-cycle-regulated dynamics. Curr. Opin. Cell Biol. 3:82-86.

- Moir, R.D. and Goldman, R.D. 1993. Lamin dynamics. Curr. Opin. Cell Biol. 5:408411. 
- Moir, R.D., Montag-Lowy, M. and Goldman, R.D. 1994. Dymamic properties of nuclear lamins: lamin B is associated with sites of DNA replication. \%. Cell Biof. 125:1201. 1212.

- Moir, R.D. Spann, T.P. and Goldman, R.D. 1995. The dynamic properties and possible functions of nuclear lamins. Int. Rev. Cytol. 162B:141-182.

- Neamati, N., Fernamdez, A., Wright, S. Kiefer, J. and McConkey, D.J. 1995. Degradation of lamin B1 precedes oligonucleosomal DNA fragmentation in apoptotic thymocytes and isolated thymocyte nuclel. I. Immunol. 154:3788-3795.

- Neri, L.M., Raymond, Y., Giordano, A., Capitani, S. and Martelli, A.M. 1999. Lamin A is part of the internal nucleoskeleton of human erythroleukemia cells. J. Cell. Physiol. $178: 284-295$.

- Nigg, E.A. 1992a. Assembly-disassembly of the nuclear lamina. Curr. Opin. Cell Biol. 4:105-109.

- Nigg. E.A. 1992b. Assembly and cell cycle dynamics of the nuclear lamina. Semin. Cell Biol. 3:245-253.

- Oberhammer, F.A., Hochegger, K., Fröschl, Tiefenbacher, R. and Pavelka, M. 1994. Chromatin condensation during apoptosis is accompanied by degradation of Lamin $A$ and $B$, whithout enhanced activation of cdc2 kinase. J. Cell Biol. 126:827-837.

- Orth, K., Chinnaiyan, A.M., Garg, M., Froelich, C.J. and Dixit, V.M. 1996. The CED3/ICE-like protease Mch2 is activated during apoptosis and cleaves the death substrate lamin A. J. Biol. Chem. 271:16443-16446.

- Rao, L., Perez, D. and White, E. 1996. Lamin protelolysis facilitates nuclear events during apoptosis. J. Cell. Biol. 135:1441-1455.

- Srinivasula, S.M., Fernandes-Alnemri, T., Zangrilli, J., Robertson, N., Armstrong, R.C., Wang, L., Trapani, J.A., Tomaselli, K.J., Litwack, G. and Alnemri, E.S. 1996. The Ced-3/Interleukin $1 \beta$ converting enzyme-like homolog Mch6 and the lamin-cleaving enzyme Mch $2 \alpha$ are substrates for the apoptotic mediator CPP32. J. Biol. Chem. 271:27099-27106.

- Takahashi, A., Alnemri, E.S., Lazebnik, Y.A., Fernandez-Alnemri, T., Litwack, G., Moir, R.D., Goldman, R.D. Poirier, G.G., Kaufmann, S.H. and Earnshaw, W.C. 1996. Cleavage of lamin A by Mch2o but not CPP32: multiple interleukin $1 \beta$-converting enzyme- related proteases with distinct substrate recognition properties are active in apoptosis. Proc. Natl. Acad. Sci. USA. 93:8395-8400.

- Towbin, H., Staehelin, T. and Gordon, 1. 1979. Electrophoretic transfer of proteins from polyacrylamide gels to nitrocellulose sheets: procedure and some applications. Proc. Natl Acad. Sci. USA. 76:4350-4354.

- Thomberry, N.A. and Lazebnik, Y. 1998. Caspases: enemies within. Science 281:1312-1316.

- Weaver, V. M., Carson, C.E., Walker, P.R., Chaly, N., Lach, B., Raymond, Y", Brown, D.L. and Sikorska, M. 1996. Degradation of nuclear matrix and DNA cleavage in apoptotic thymocytes. I. Cell Sci. 109:45-56.

- Wyllie, A.H., Kerr, J.F.R. and Currie, A.R. 1980. Cell death: the significance of apoptosis. Int. Rev. Cytol. 68:251-306.

- Zatloukal, K., Denk, H., Spurej, G. and Hutter, H. 1992. Modulation of protein composition of nuclear lamina-reductions of lamins-B1 and lamins-B2 in livers of griseofulvin-treated mice. Lab. Invest. 66:589-597.

- Zhiwotovsky, B. Gahm, A. and Orrenius, S. 1997. Two different proteases are involved in the protedysis of lamin during apoptosis. Biochem. Biophys. Res. Commun. 233:96-101. 



\title{
Chromosome degradation during apoptosis
}

Manon van Engeland, Susan 1.J. Swiggers,

Jian Tajbakhsh, Peter Lichter, Frans C.S. Ramaekers

and Anton H.N. Hopman

\section{Contents}

\author{
7.1 Introduction \\ 7.2 Materials \& methods \\ 7.3 Results \\ 7.4 Discussion \\ 7.5 References
}




\section{Abstract}

A well-recognized biochemical aspect of apoptosis is cleavage of genomic DNA. In this study, the behavior of different chromosomal regions during apoptosis is examined by fluorescence in situ hybridization (FISH) in the human tumor cell lines MR65, Jurkat and U937. For detection of centromeric, subcentromeric, telomeric and subtelomeric chromosome regions, DNA repeat probes were used. To study the behavior of whole chromosome territories during apoptosis, paint probes for chromosomes 4 and 8 were applied. It is observed that during apoptosis, the DNA of individual chromosomes, which is localized in specific territories in the interphase nucleus, is dispersed over the apoptotic micronuclei. The same was seen for centromeric, subcentromeric, subtelomeric and chromosomal regions.

In contrast, the telomeric DNA repeat (TTAGGG) is not fragmented during apoptosis, but remains detectable as discrete, sometimes clustered, signals at the periphery of the apoptotic micronucleus. This study indicates that during apoptosis genomic DNA undergoes dramatic fragmentation and redistribution, but that at the same time telomeric DNA, which is part of the nuclear matrix, is protected from fragmentation.

\subsection{Introduction}

The biochemical hallmark of apoptosis is cleavage of genomic DNA into oligoand mononucleosomal DNA by (an) endogenous endonuclease(s). However, not all cell types undergo internucleosomal fragmentation. Whether internucleosomal DNA fragmentation in these cells is absent, inhibited or depends on the apoptosis inducing stimulus is not clear.

On the other hand, fragmentation into large $50-300 \mathrm{~kb}$ fragments (Bortner et al., 1995; Oberhammer et al., 1993) seems to occur in almost all cells undergoing apoptosis. The size of these large DNA fragments correlates with the size of the chromatin loop domains, which implies that DNA is cleaved at a wery high level of genome organization (Filipski et al., 1990; Lagarkova et al., 1995 ).

Various nucleases such as DNAse I, DNAse II, L-DNAse II, DNAse $\gamma_{\text {a }}$ a $97 \mathrm{kDa}$ DNAse and cyclophilins have been described as candidates responsible for DNA fragmentation in apoptosis (Peitsch et al., 1993; Barry and Eastman, 1993; Torriglia et al., 1998; Shiokawa et al., 1994; Pandey et al., 1997; Montague et al., 1997). Recently, an apoptosis specific, caspase-activated deoxyribonuclease (CAD/DFF440/CPAN) has been identified (Enari et al., 1998; Liu et al., 1997; Halenbeck et al., 1998). Furthermore, two noncaspase proteases, a $260 \mathrm{kDa}$ activity, which produces $30-50 \mathrm{~kb}$ DNA fragments, and a $25 \mathrm{kDa}$ activity, which additionally generates oligonucleosomal DNA fragments, have been described (Hughes et al., 1998).

Controversy exists about the nature of the DNA that is fragmented during apoptosis. Arends et al. (1990) reported that fragmented, free chromatin in apoptotic cells has features of transcriptionally active DNA, while chromatin that remains attached to the nucleus is incompletely digested. The transcriptionally active nature of fragmented DNA is also reported by chen et al. (1998) who showed manifestation of Gubanding patterns in mitotic chromosomes of early apoptotic cells, indicating that transcriptionally active genes 
are preferentially cleaved before oligonucleosomal fragmentation occurs. Hendzel and coworkers (1998) suggest that digestion of euchromatin occurs prior to degradation of condensed heterochromatin into oligonucleosomal DNA. Furthermore, it is suggested that the DNA fragmented during apoptosis is enriched in non-transcribed, repetitive sequences (Vodenicharov et al, 1996).

Because of this controversy, we decided to study the behavior of different DNA sequences during apoptosis in the human tumor cell lines MR65, Jurkat and U937.

It is shown that during apoptosis, centromeric, subcentromeric and subtelomeric DNA sequences, as well as whole chromosome territories are fragmented and dispersed over the condensed DNA of the apoptotic micronuclei. These results indicate that the majority of the genomic DNA is fragmented during apoptosis. In contrast, telomeric DNA, which is tightly connected to the nuclear matrix, and is therefore most probably protected from degradation, is not fragmented.

To explain these observations we suggest a model for chromosome degradation during apoptosis.

\subsection{Materials \& methods}

\section{Cell culture}

The human non-small cell lung cancer cell line MR65 (a gift from Dr. Gropp, Philips Universitäts Klinik, Marburg, Germany) was grown as a monolaver in Eagle's modified minimal essential medium (EMEM, Gibco, Paisley, Scotland) supplemented with $10 \%(\mathrm{~V} / \mathrm{v}$ ) heat-inactivated newborn calf serum (Gibco), 10 mM Hepes (Gibco), 2 mM L-glutamine (Serva, Heldelberg, Germany), 1\% $(\mathrm{v} / \mathrm{v}$ ) non essential amino acids (Gibco) and $50 \mu \mathrm{g} / \mathrm{ml}$ gentamycine (AUV, Cuyk, The Netherlands). MR65 cells were harvested by trypsinization. The human lymphoma cell line U937 (ATCC) and the T-cell leukemia cell line Jurkat (ATCC) were exponentially grown in RPMI 1640 medium (Gibco, Paisley, Scotland) supplemented with 10\% theat-inactivated fetal calf serum (Gibco), $2 \mathrm{mM}$ L-glutamine (Serva, Heidelberg, Germany) and $50 \mu \mathrm{g} / \mathrm{m}$ ) gentamycine (AUV, Cuyk, The Netherlands). All cell lines were cultured at $37 \% \mathrm{C}$ in $5 \% \mathrm{CO}_{2}$ in a humidified incubator.

\section{Treatment of the cells}

Apoptosis was induced by treating 4937 cells for 4 hours with $50 \mu \mathrm{M}$ etoposide (Calbiochem, La Jolla, CA). Jurkat cells were treated with a monoclonal antibody directed against Fas (clone $\mathrm{CH}-11$, Immunotech Coulter, France) for 4 hours at a final concentration of $100 \mathrm{ng} / \mathrm{ml}$. MR 65 cells were induced to undergo apoptosis with roscovitime $(50 \mu \mathrm{M})$, a cyclin dependent kinase inhibitor, for 6 hours. Roscovitine was a kind gift of Dr. L. Meijer (Station Biologique, CNRS, Roscaff, France). In all experiments the concentration of cells was $1 \times 10^{6}$ cells $/ \mathrm{ml}$ medium. Apoptotic cells were identified by nuclear morphology (chromatin condensation) and DNA fragmentation.

\section{DNA isolation}

Cells were washed and resuspended in phosphate buffered saline (PBS). Then cells were treated with $60 \mu \mathrm{g} / \mathrm{ml}$ protelnase K (Merck, Darmstadt, Germany) 
and $100 \mu \mathrm{g} / \mathrm{m}$ l RNAse A (Boehringer Manmheim, Germany) for 1 hour at 55 C. After 1 hour, fresh proteinase $K$ was added for another hour. Samples were extracted with equal volumes of phenol and chloroform:isoamylalcohol (24:1). Subsequently, DNA was precipitated overnight by $0.3 \mathrm{M}$ sodium acetate (final concentration) and $70 \%$ ethano. DNA was separated by gel electrophoresis on $1.5 \%$ agarose gels. After electrophoresis DNA was stained with Gelstar (FMC Corporation, Vallensbaek Strand, Denmark).

\section{DNA probes}

Subcentromeric DNA of chromosome 1 was detected with the DNA probe PUC1.77 (Cooke and Hindley, 1979), which detects satellite III repeat DNA in the pericentromeric region (1.12). To study all human centromeres, we used a biotinylated all human centromere probe (Oncor Appligene, Heidelberg, Germany), consisting of a selection of alphoid DNA sequences that target all human centromeres. The behavior of the telomeric repeat sequence (TTAGGG) was examined using a digoxygenin-labeled all human telomere probe (Oncor Appligene, Heidelberg, Germany). The human 1p-specific subtelomeric probe p1-79 (Buroker et al., 1987) was used to detect DNA in the subtelomeric region (1p36). All probes, except the all human centromere probe and the all human telomere probe, were labeled with biatim-11-dUTP in a nick translation assay. To study the behavior of whole chromosome territories biotinylated paint probes for chromosomes 4 (kindly provided by Dr. Gray, UCSF) and 8 (Li Biomedical Corporation, Arlington) were used.

\section{In situ hybridization}

After harvesting, cells were cytocentrifuged onto glass slides (Superfrost plus) and air-dried for 1 hour. Slides were fixed overnight in $70 \%$ ethanol and subsequently dehydrated in an ascending series of ethanol $(70 \%, 96 \%$, $100 \%$ ). Subsequently, cells were digested with pepsin (porcine stomach mucosa; $2500-3500 \mathrm{U} / \mathrm{mg}$ protein, Sigma) at a concentration of $100 \mu \mathrm{g} / \mathrm{ml}$ in $0.01 \mathrm{M} \mathrm{HCl}$ for 20 minutes at $37^{\circ} \mathrm{C}$. After washing in PBS and dehydration in an ascending series of ethanol $(70 \%, 96 \%, 100 \%)$ cells were fixed in $1 \%$ paraformaldehyde in PBS for 10 minutes at room temperature. Finally, cells were washed in PBS and dehydrated in an ethanol series.

DNA repeat probes, as described above, were hybridized in a hybridization buffer containing $60 \%$ formamide, $2 \times 55 \mathrm{C}, \mathrm{pH} 5.0,10 \%$ dextran sulfate, 0.2 $\mu \mathrm{g} / \mathrm{ml}$ herring sperm DNA and $0.2 \mu \mathrm{g} / \mathrm{ml}$ yeast tRNA. $10 \mu \mathrm{l}$ buffer containing 4 ng PUC 1.77 probe and $10 \mathrm{ng}$ of the other repeat probes was placed under a coversip $(20 \times 20 \mathrm{~mm})$. Of the commercially obtained probes 8 ul of the all human telomere probe and the all human centromere probe was used undiluted. Denaturation of the target DNA and the probe was performed at $70 \mathrm{C}$ for 3 minutes. Hybridization was performed overnight at $37 \% \mathrm{C}$. Post hybridization washes were performed in $2 \times S$ SC/Tween $20(0.05 \%) \mathrm{pH} 7.0$ at $42^{\circ} \mathrm{C}$ ( $3 \times 5$ minutes), $0.1 \times 55 \mathrm{C}$ at $60^{\circ} \mathrm{C}$ ( $3 \times 5$ minutes) and PBS at room temperature ( $3 \times 5$ minutes). Of the paint probes, $200-400 \mathrm{ng}$ DNA was diluted in hybridization buffer containing $50 \%$ formamide, $2 \times \mathrm{SSC}$ and $10 \%$ dextran sulfate. Denaturation of the target DNA was performed in $70 \%$ formamide, $2 \times S S C, 50 \mathrm{mM}$ sodium phosphate, $\mathrm{pH} 7.0$, for 3 minutes at $73^{\circ} \mathrm{C}$, followed by incubation in $50 \%$ formamide, $2 \times S S C, 50 \mathrm{mM} 50$ dium phosphate, $\mathrm{pH} 7.0$ for 1 minute at $73^{\circ} \mathrm{C}$ before applying the hybridization probe. Preannealing of denatured probe was allowed for 10 minutes. Hybridization 
was allowed to proceed overnight in a humid chamber at $37 \circ \mathrm{C}$. Posthybridization washes were consecutively performed in $50 \%$ formamide, $2 \times S S C$, pH

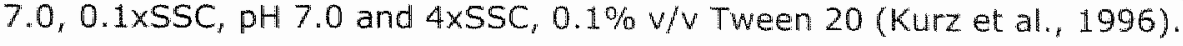

\section{Immunocytochemical detection}

Detection of the biotinylated DNA probes was performed using FITCconjugated avidin. Signal enhancement was achieved by using biotinylated goat antibody directed against avidin, followed by FITC-conjugated avidin. The digoxygenin-conjugated (TTAGGG) ${ }_{n}$ probe was detected using mouseanti-digoxygenin antibody, followed by TRITC-conjugated rabbit-anti-mouse antibody and TRITC-conjugated swine-anti rabbit antibody. The biotinylated paint probes were detected using Cy3-labeled streptavidin. The antibodies and FITC-conjugated avidin were diluted in $4 \times S S C$ containing $5 \%$ non-fat dry milk. Washing was performed in $4 \times$ SSC containing $0.05 \%$ Tween 20 . For detection of the paint probes, blocking was performed in $3 \%$ BSA, $4 \times S S C$, $0.1 \% \mathrm{v} / \mathrm{v}$ Tween 20 for 30 minutes at $37^{\circ} \mathrm{C}$. For detection, antibodies were diluted in $3 \%$ BSA, 4xSSC. Detection was done for 30 minutes at $37^{\circ} \mathrm{C}$ in a humid chamber. After dehydration, slides were incubated with $0.5 \mu \mathrm{g} / \mathrm{ml}$ DAPI/PBS for 15 minutes at room temperature and embedded in Vectashield (Vector Laboratories, Burlingame, CA), containing $0.5 \mu \mathrm{g} / \mathrm{ml}$ DAPI. To exclude that obtained signals are the result of background staining due to immunocytochemistry, we performed a competitive hybridization by adding $20 x$ excess of unlabeled PUC1.77 to the biotin-labeled PUC1.77. After hybridization and immunocytochemistry, the specific signals in control cells and the low intensity signals in the apoptotic cells had disappeared (data not shown), indicating that the signals observed with the labeled probe are not the result of background staining due to immunocytochemistry, but are specific signals. Results were evaluated using a fluorescence microscope (Leica). Microphotographs were recorded with the In Situ Image System (version 3.30, Metasystems $\mathrm{GmbH}$, Altlussheim, Germany) using a black and white CCD camera.

\subsection{Results}

\section{DNA fragmentation during apoptosis in MR65 cells, Jurkat cells and U937 cells.}

To confirm the apoptotic features of the cells and to study the mode of DNA degradation during apoptosis, DNA was isolated and analyzed by DNA gel electrophoresis. Figure 7.1 shows that during apoptosis 4937 cells and Jurkat: cells undergo internucleosomal DNA fragmentation, while in MR65 cells these fragments were not detected and DNA fragments in the high molecular weight range were observed.

\section{The behavior of whole chromosome territories during apoptosis}

The behavior of whole chromosome territories during apoptosis was studied using whole chromosome paint probes. While non-apoptotic cells clearly show chromosome territories of chromosomes 4 and 8 (figure 7.2a), apoptotic cells show dispersion of the FISH signals into multiple, low intensity granular structures, over the apoptotic micronuclei (figure 7.2b). The space between the condensed micronuclei is devoid of signal. 


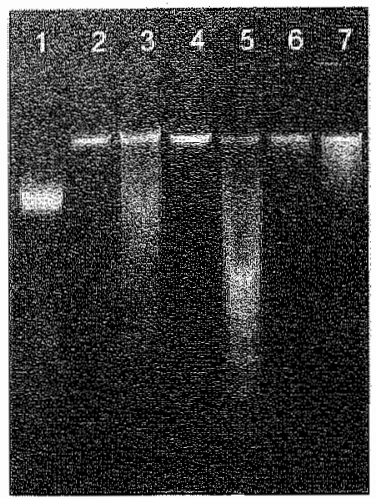

Figure 7.1: Agarose gel electrophoresis of DNA isolated from control and apoptotic MR65, Jurkat and 4937 cells. In lane 1 the 100 bp marker is shown. Lane 2 , 4 and 6 show DNA of non-apoptotic Jurkat, U937 and MR65 cells, respectively. Lane 3,5 and 7 show DNA of apoptotic Jurkat, 4937 and MR65 cells respectively. Note that Jurkat and U937 cells undergo internucleosomal DNA degradation, while MR65 cells only show DNA degradation into fragments in the high molecular weight range.
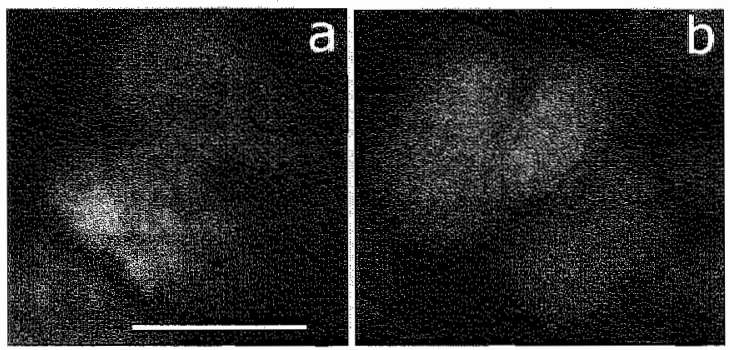

Figure 7.2: Jurkat cells hybridized with a paint probe detecting chromosme 8 , shown in red. DAPI counterstaining of the nucleus is shown in blue. Figure 7.2 a shows an nonapoptatic cell with the territories of chromosome 8 . Figure $7.2 \mathrm{~b}$ shows an apoptotic cell, with condensed DNA and dispersed signall for chromosome 8 over the apoptotic micronuclei. Bar indicates $1.0 \mathrm{~mm}$. For color illustration see page 138.

The behavior of subcentromeric, centromeric, telomeric $c_{p}$ and subtelomeric chromosomal regions during apoptosis

Hybridization of non-apoptotic cells with the probe detecting the subcentromeric region 1q12, shows 3-4 FISH signals, corresponding to the chromosome copy number for chromosome 1 , in the three tumor cell lines studied (figure $7.3 \mathrm{a}$ and 7.3b). In apoptotic cells, the discrete FISH signal cannot be detected anymore, but is visible as dispersed, low intensity signals, which colocalize with the condensed DNA of the apoptotic micronuclei, while the space between the apoptotic micronuclei is devoid of signal (figure 7.3a and $3 \mathrm{~b})$. This indicates that this subcentromeric DNA repeat sequence is extensively fragmented and redistributed during apoptosis.

Hybridization of the all human centromere probe on non-apoptotic cells shows multiple signals, corresponding to all centromeres (figure $7.3 \mathrm{c}$ ). In apoptotic cells the signals are completely dispersed over the apoptotic 
micronuclei (figure $7.3 \mathrm{~d}$ ). The same results were observed using the probe detecting a subtelomeric region of chromosome 1 . Non-apoptotic cells show 3-4 discrete FISH signals (figure 7.3e), while in apoptotic cells the FISH signal is dispersed over the apoptotic miconuclei (figure 7.3F). Disperion of DNA as observed in apoptotic cells was never observed in non-apoptotic cells of apoptosis induced cell cultures. To examine whether fragmentation and redistribution of subcentromeric DNA is specific for the process of apoptosis. cells induced to undergo necrosis with $0.6 \% \mathrm{H}_{2} \mathrm{O}_{2}$ were hybridized with the PUC1.77 probe. It was observed that during necrosis, when all cells are trypan blue positive, the centromeric signal is still detectable, albeit as fuzzy spots (figure $7.3 \mathrm{~g}$ ). Thus, during necrosis, DNA fragmentation as observed during apoptosis, does not occur. All the obtained results were identical for MR65 cells, U937 cells and Jurkat cells.
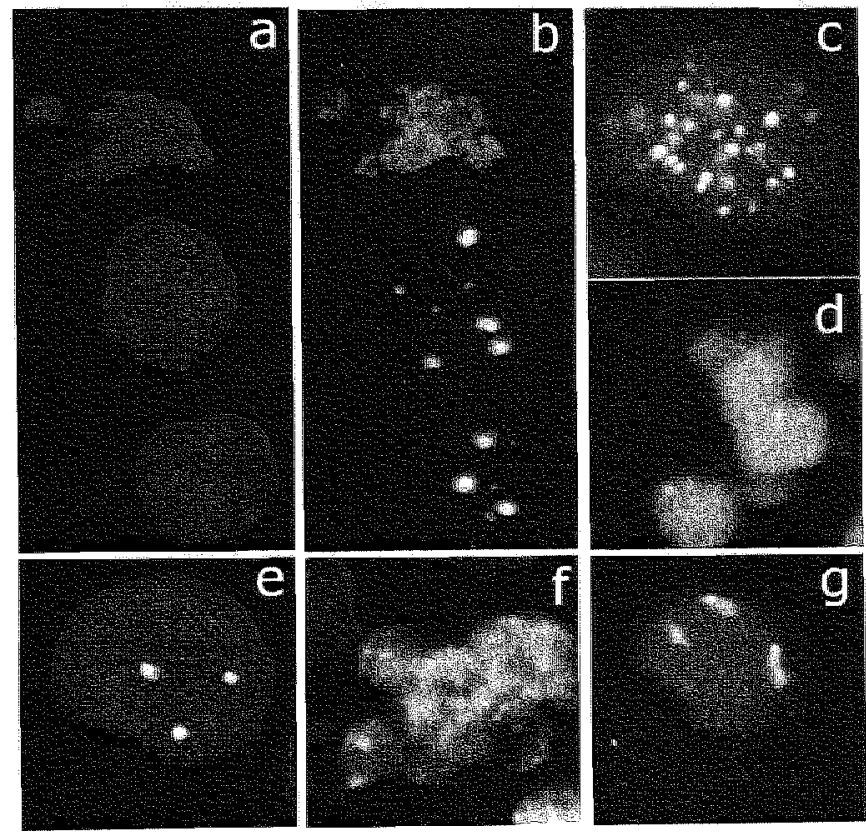

Fiqure 7.3: Results of the FISHmexperinents on MR65 cells (figure 7.3a, 7.3b amd 7.39 ), Jurkat cells (figure $7.3 \mathrm{c}$ and $7.3 \mathrm{~d}$ ) and 4937 cells (figure $7.3 \mathrm{e}$ and $7.3 \mathrm{f}$. Fire 7.3a shows the DA.PI staining (blue) of two non-apoptotic cells and an apoptotic MR6s cell (top). while figure $7.3 \mathrm{~b}$ shows hybridization of these cells with arobe detecting the subcentromeric regions of chromosome 1 (green). The non-apoptotic cells show discrete FISH signals. In the apoptotic cell, the signal is completely dispersed over the condensed micronucleil. In figure $7.3 \mathrm{c}$ a non-apoptotic Jurkat cell, hybridized with the probe detecting all human centromeres (green) is shown, while in the apoptotic cell (figure $7.3 d$ ), almost all the signals are completely dispersed over the condensed DNA. U937 cells hybridized with the subtelomeric probe 1 p36 show 3 discrete signals in nonapoptotic cells (figure7.3e), while in apoptotic cells the signal is dispersed over the apoptotic micronucle (figure7.3f). DNA fragmentation as observed during apoptosis does not occur during necrosis (figure 7.39 ). For color illustration see page 139. 
Hybridization of the telomeric repeat sequence (TTAGGG) on non-apoptotic cells shows many discrete signals (figure 7.4a). In apoptotic cells, the discrete FISH-signal can still be detected, although the number of spots is often decreased compared to the many small spots observed in non-apoptotic cells (figure $7.4 \mathrm{~b}$ ). In addition, part (30-40\%) of the apoptotic cells shows clustering of telomeric DNA, either between (figure $7.4 \mathrm{c}$ ) or at the outer surface of the apoptotic micronuclei (figure $7.4 \mathrm{~d}$ ).
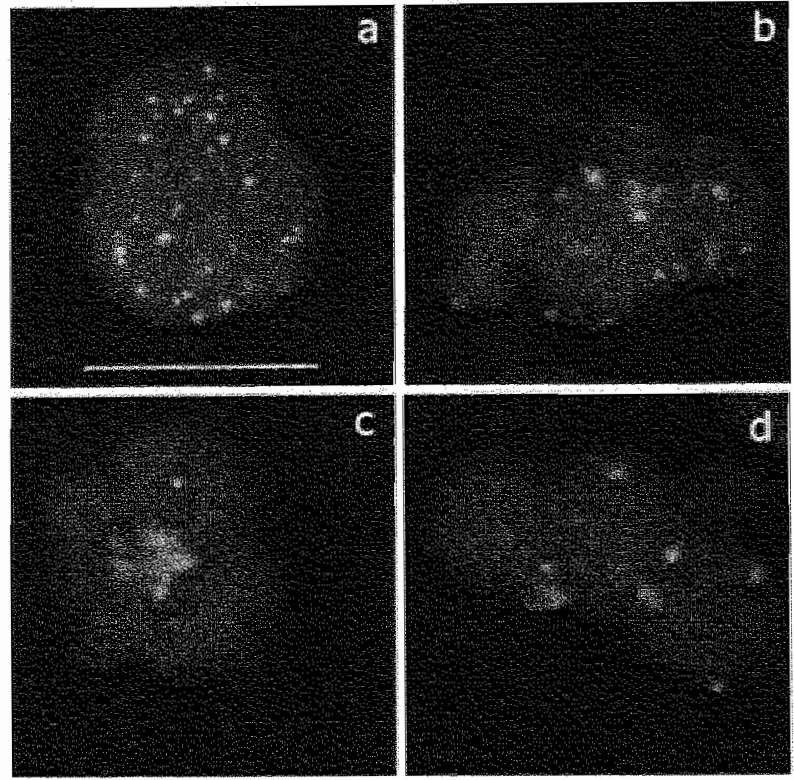

Figure 7.4: Non-apoptotic (figure 7.4a) and apoptotic (figure 7.4b, figure $7.4 \mathrm{c}$ and figure 7.4d) 4937 cells, hybridized with a probe detecting the telomere repeat sequence (TTAGGG) . A non-apoptatic cell shows many discrete FISH signals (figure $7.4 a$ ), while in apoptotic cells, the number of signals is decreased (figure $7.4 \mathrm{~b}$ ). In part of the apoptotic cells, the telomeres are clustered, either between (figure $7.4 \mathrm{c}$ ) or at the periphery of the apoptotic micronuclei (figure 7.4.d). Bar indicates $15: \mathrm{m}$. For color illustration see page 138 .

\subsection{Discussion}

This study shows that subcentromeric, centromeric and subtelomeric DNA sequences, as well as whole chromosome territories are dispersed over the apoptotic micronuclei during apoptosis in MR65 cells, Jurkat cells and U937 cells. This indicates that redistribution of these DNA sequences is independent of the mode of DNA degradation, i.e. generation of high molecular weight DNA fragments or internucleosomal DNA fragments and that DNA fragmentation occurs prior to DNA condensation. Since we never observed a dispersed FISH signal for any of the probes in cells induced to undergo apoptosis but having a normal nuclear morphology, it is suggested that DNA condensation occurs immediately after fragmentation and redistribution of the fragmented DNA. 


\section{Protection of the telomere repeats}

The telomeric DNA sequence (TTAGGG) is still detectable, which results in discrete FISH signals in the apoptotic micronuclei, although the number of spots has decreased as compared to the non-apoptotic cells. In part of the apoptotic cells, the TTAGGG DNA repeat sequence is clustered at the periphery or in the center of the condensed chromatin of the micronuclei.

The presence of discrete telomeric FISH signals in apoptotic cells indicates that the telomere repeat TAGGG, which is considered to be a component of the nuclear matrix (de Lange, 1992), is resistant to degradation by the apoptotic nuclease.

It is suggested that eukaryotic telomeres are resistant to exonucleolytic degradation, fusion and recombination because they form a nucleoprotein complex that protects the chromosome ends (de Lange, 1992). Our results indicate that telomeres are also resistant to endonucleolytic degradation by the apoptotic nuclease. Recently, two telomere binding proteins, designated TRF1 and TRF2, are identified (Bilaud et al., 1997; Broccoli, 1997; Chong et al., 1995; Smith and de Lange, 1997). TRF1 regulates telomere length while TRF2 maintains telomere integrity (van Steensel and de Lange, 1997; van Steensel et al., 1998). Karlseder et all. (1999) showed that inhibition of the TRF2 protein results in rapid p53-dependent. This indicates that TRF2 can protect telomeres from a response pathway, which can lead to apoptosis, pointing to a strong interaction of TRF2 and telomeric DNA.

Furthermore, some reparts describe that the ends of prophase chromosomes are located close to the nuclear envelope, indicating an interaction between telomeres and lamina proteins (Hochstrasser et al., 1986). However, Luderus et al. (1996) did not find an interaction between telomeric DNA and the nuclear lamina and found that mammalian telomeres occupy sites throughout the totall nuclear volume. However, A-type lamin proteins are not only observed in the peripherall lamina but also intranuclear (Hozak et al., 1995; Neri et al., 1999). Thus, an interaction between telomeres and lamin proteins cannot be excluded. Furthermore, it is found that A-type lamins can bind telomeric DNA in vitro (Shoeman and Traub, 1990), which suggests that Atype lamins can protect telomeric DNA from fragmentation by the apoptotic endonuclease.

Although protection of the telomeric. DNA by interactions with other proteins is a plausible explanation for resistance to degradation, and no evidence exists for sequence specificity of the apoptotic nuclease, it carnot be excluded that the apoptotic nuclease is not able to degrade the telomeric DNA sequence.

The difference in degradation between the subtelomeric DNA and the telomeric TTAGGG DNA sequence can be explained by a different chromatin structure: the subtelomeric DNA is in a normal mucleosomal conformation, while the telomeric DNA is present in the nuclear matrix (Luderus et all. 1996) and thus being inaccessible for the apoptotic nuclease.

\section{Clustering of telomeric DNA during apoptosis}

Our observations of telomere clustering are in agreement with the results shown by Mukhopadhyay et al. (1998) who reported increased telomere associations in cells undergoing p53-mediated apoptosis.

However, these authors also show telomeric associations of chromosomes and reduction of telomeric signals prior to nuclear condensation and 
fragmentation, which is in contrast to our study. This discrepancy may be the result of different apoptosis induction systems. Mukhopadhyay et al. (1998) induced apoptosis by overexpression of wild-type p53, which leads to shortening and subsequent association of telomeres, genetic instability and activation of the apoptosis pathway. In our study, apoptosis was induced either by Fas ligation, Topoisomerase II inhibition or by kinase inhibition. The phenomenon of clustering of nuclear components during apoptosis is also observed for nuclear pores, also components of the nuclear matrix (Falcieri et al., 1994; Reipert et al., 1996). Electron microscopy studies show that during apoptosis, nuclear pores migrate and cluster in the nuclear membrane areas to which diffuse chromatin is associated, while no pores can be demonstrated in the nuclear envelope portions surrounding the condensed chromatin (Falcieri et al., 1994). These authors suggest that the areas where the nuclear pores are located, e.g. the areas of diffuse chromatin, are places where active transcription occurs and that pores mediate nuclear transport until a late stage of apoptosis (Falcieri et al "1994).

\section{A model for chromosome fragmentation during apoptosis}

The results obtained in this study suggest the following model (figure 7.5). Very early in the degradation phase of apoptosis, repetitive DNA as well as unique DNA sequences in whole chromosomes are fragmented by the apoptotic nuclease and redistributed throughout the nuclear volume. Probably, these DNA sequences are easily accessible for the apoptotic nuclease. Also at this stage nuclear proteins are cleaved, while other nucleoproteins reorganize, resulting in extensive nuclear allerations.

DNA sequences, which are associated with the nuclear matrix, such as telomeric DNA, transcriptionally active DNA and replicating DNA, are protected from the apoptotic nuclease due to strong interactions with the constituents of this nuclear scaffold. Due to extensive alterations in nuclear organization, DNA fragmentation is immediately followed by chromatin condensation.

Due to condensation of the fragmented DNA into apoptotic micronuclei, the residual nuclear matrix becomes accessible for further degradation.

As a consequence, these nuclear scaffold structures are accessible for antibodies during a certain time span, which allows the immunocytochemical detection of the matrix (see chapter 6). In some cell types, the condensed DNA, present in the apoptotic micronuclei, may then be further digested into oligonucleosomal fragments. This model is consistent with the observation that DNA degradation alone is sufficient for generation of micronuclei (Hendzel et al., 1998). These authors also hypothesize that chromatin condensation during apoptosis is not the result of an active process but arises from release of structural and spatiall constraints on chromatin (Hendzel et al., 1998), which is also the basis of our model.

Although our model suggests that DNA fragmentation occurs prior to DNA condensation, we do not exclude that DNA condensation can accur without DNA fragmentation, as was recently reported by Sakahira et al. (1999). These authors suggest that, in addition to DNA fragmentation, a not yet identified factor is inwolved in chromatin condensation during apoptosis (Sakahira et al., 1999). 


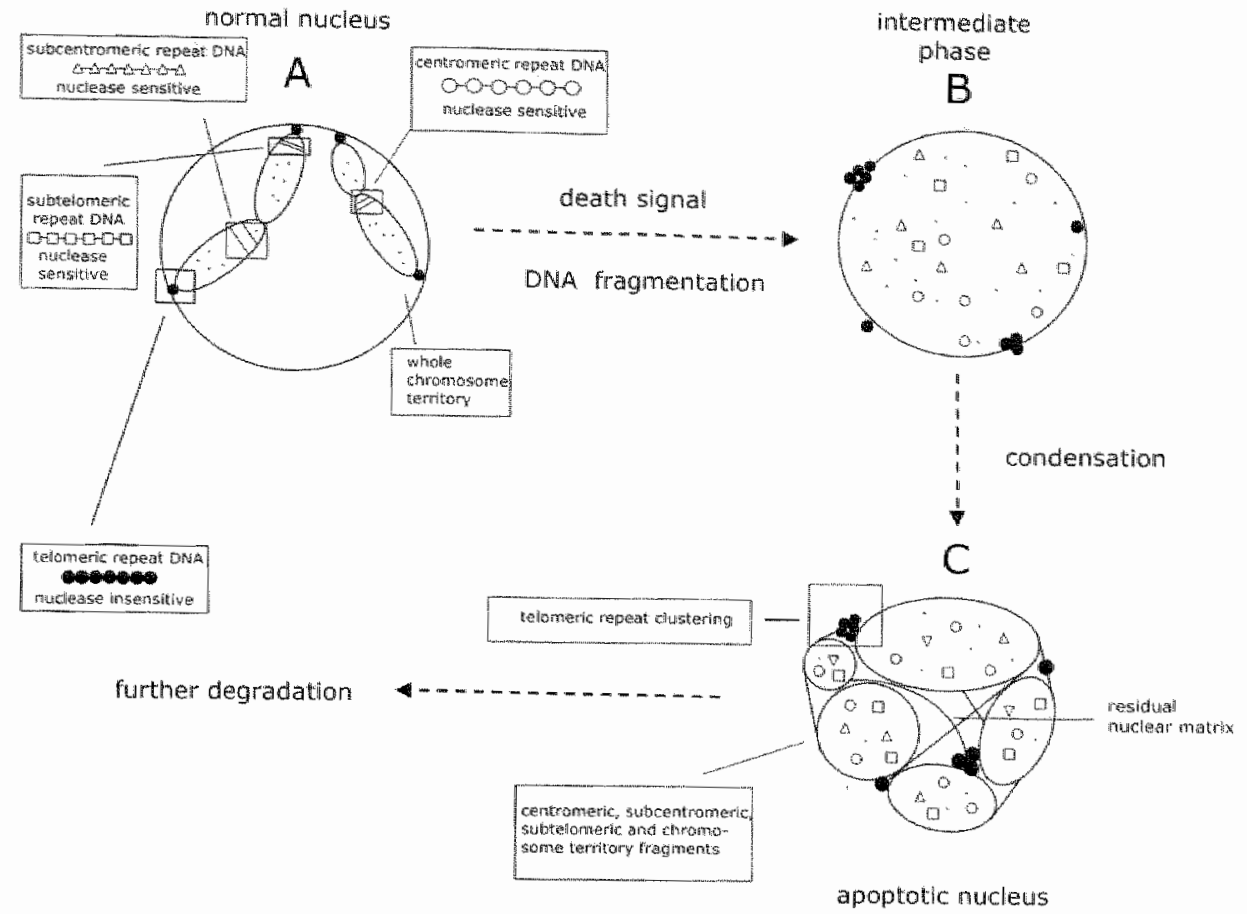

Figure 7.5: Model for DNA degradation during apoptosis. A) Schematic drawing of a normal interphase nucleus in which chromosome territories are shown. Telomeric DNA. is associated with the nuclear matrix. In an interphase cell the nuclear matrix is not visible. B) When a cell is induced to undergo apoptosis, the majority of the genomic DNA, including unique and repetitive DNA sequences, are fragmented immediately by the apoptotic nuclease. DNA sequences located in the nuclear matrix, e.g. telomeric DNA sequences, are not accessible for the apoptotic nuclease due to interactions with matrix components. Immediately after DNA fragmentation, chromatim condenses and a residual nuclear matrix becomes detectable (C).

In the light of our hypothesis, it would be of interest to study chromosome degradation in the model system used by these authors.

In conclusion, our study suggests that centromeric, subcentromeric, subtelomeric and nucleolar chromosome regions as well as whole chromosome territories are completely dispersed over the apopoptotic micronuclei, while tellomeric DNA is protected from cleavage during apoptosis. Further studies on fragmentation of nuclear matrix associated DNA and cleavage of nuclear matrix proteins should define the validity of our model. 


\subsection{References}

Arends, M.J. Morris, R.G. and Wyllie, A.H. 1990. Apoptosis: the role of the endonuclease. Am. i. Pathol. 136:593-608.

- Barry. M.A. and Eastman, A. 1993. Identification of deoxyribonudlease II as an endorluclease involved in apoptosis. Arch. Biochem. Biophys. 300:440-450.

- Bilaud, T., Brun, C., Ancelin, K., Koering, C.E., Laroche, T. and Gilson, E. 1997. Telomeric localization of TRF2, a nowel human telobox protein. Nat. Genet. 17:236m-239.

- Bortner C., Oldenburg, N.B.E. and Cidlowski, J.A. 1995. The role of DNA fragmentation in apoptosis. Trends Celf Bial. 5:21-26.

- Broccoli, D., Smogorzewska, A., Chong, L. and de Lange T. 1997. Human telomeres contain two distinct Myb-related proteins, TRF1 and TRF2. Nat. Genet, 17:231-235.

- Buroker, $\mathbb{N}_{.}$, Bestwick, R., Haight, G., Magenis, R.E. and Litt, M. 1987. A hypervariable repeated sequence on human chromosome 1p36. Hum Genet. 77:175-181.

- Chen, D.L., Swe, M. and Sit, K.H. 1998. G-band expression and megabase fragmentations in apoptosis. Exp. Cell Res. 240:293-304.

- Chong, L., van Steensel, B. van, Broccoli, D., Erdjument Bromage, H., Hanish, J., Tempst, P. and de Lange, T. 1995. A human telomeric protein. Science 70:16631667.

- Cooke, H.J. and Hindley, J. 1979. Cloning of human satellite III DNA: different components are on different chromosomes. Nucleic Acids Res. 6:3177-3197.

- Enari, M., Sakahira, H., Yokomaya, H., Okawa, K., Iwamatsu, A. and Nagata, S. 1998. A caspase-activated DNAse that degrades DNA during apoptosis, and its inhibitor CAD. Nature 391:43-50.

- Falcieri, E., Gobbi, P., Cataldi, A., Zamai, L., Faenza, I. and Vitale, M. 1994. Nuclear pores in the apoptotic cell. Histochem. J. 26:754-763.

- Filipski, 1. Leblanc, J., Youdale, T., Sikorska, M. and Walker P.R. 1990. Periodicity of DNA folding in higher order chromatin structures. EMBO J. 9:1319-1327.

- Halenbeck, R., MacDonald, H., Rouliston, A., Chen, T.T., Conroy, L. and Williams, L.T. 1998. CPAN, a human muclease regulated by the caspase-sensitive inhibitor DFF -45 . Curr Biol. 8:537-540,

- Hendzel, M.J., Nishioka, W.K., Raymond, Y., Allis, C.D., Bazeti-Jones, D.P. and Th'ng, J.P.H. 1998. Chromatin condensation is not associated with apoptosis. J. Biol. Chem. $273: 24470-24478$.

- Hochstrasser, M., Mathog, D., Giuenbaum, Y., Saumweber, H. and Sedat, J.W. 1986. Spatial organization of chromosomes in the salivary gland muclei of Drosophila melanogaster. J. Cell Biol. 102:112-123.

- Hozak, P. Sasseville, A.M.J., Raymond, Y. and Cook, P.R. 1995. Lamins proteins form an internal nucleoskeleton as well as a peripheral lamina in human cells. J. Cell Sci. $108: 635-644$.

- Hughes, F.M. Evans-Storms, R.B. and Cidlowski, J.A. 1998. Evidence that noncaspase proteases are required for chromatin degradation during apoptosis. Cell Death Differ. $5: 1017-1027$.

- Karlseder, J., Brocolol, D., Dai, Y., Hardy, S. and de Lange, T. 1999, p53- and ATMdependent apoptosis induced by telomeres lacking TRF2. Science 283:13:21-1325.

- Kurz, A., Lampel, S., Nickolenko, J.E., Bradl, J., Benner, A., Zirbel, R.M. and Lichter, P. 1995. Active and inactive genes localize preferentially in the periphery of chromosome territories. J. Cell Biol 135:1195-1205.

- Lagarkova, M.A., Iarovala, O.V. and Razin, S.V. 1995. Large scale fragmentation of mammalian DNA in the course of apoptosis preceeds via excision of chromosomal DNA loops and their oligomers. J. Biol. Chem. 270:20239-20141.

- de Lange, T. 1992. Human telomeres are attached to the nuclear matrix. EMBO J. $11: 717-724$.

- Liu, X., Zou, H., Slaughter, C. and Wang, X. 1997. DFF, a heterodimeric protein that functions downstream of caspase- 3 to trigger DNA fragmentation during apoptosis. Cell 89:175-184. 
- Luderus, M.E.E., van Steensel, B. Chong, L., Sibon, O.C.M. Cremers, F.F.M. and de Lange, T. 1996. Structure, subnuclear distribution, and nuclear matrix association of the mammalian telomeric complex. J. Cell Biol.135; 867-881.

- Montague, J.W., Hughes, F.M. and Cidlowski, J.A. 1997. Natiwe recombinant cyclophilins $A_{1} B$ and $C$ degrade DNA independently of peptidy/prolyl cis-trans-isomerase activity. $J$. Biol. Chem. 272:6677-6684.

- Mukhopadhyay, T. Multani, A.S., Roth, J.A. and Pathak, S. 1998. Reduced telomeric signals and increased telomeric associations in human lung cancer cell lines undergoing p53 mediated apoptosis. Oncogene 17:901-906.

- Neri, L.M., Raymond, Y., Giordano, A., Capitani, S. and Martelli, A.M. 1999. Lamin A is part of the internal nucleoskeleton of human erythroleukemia cells. 3. Cell. Physiol. $1.78: 284-295$.

- Oberhammer, F., Wilson, J.W., Dive, C., Morris, I.D., Hickman, J.A., Wakeling, A.E., Walker, P.R. and Sikorska, M. 1993. Apoptotic cell death in epithelial cells: cleavage of DNA to 300 and/or $50 \mathrm{~kb}$ Fragments prior to or in the absence of internucleosomal fragmentation. EMBO J. 12:3679-3684.

- Pandey, S., Walker, P.R. and Sikorska, M. 1997. Identification of a novel $97 \mathrm{kDa}$ endonuclease capable of internucleosomal DNA cleavage and its possible role in apoptosis. Biochemistry 36:711-720.

- Peitsch, M.C., Polzar, B., Stephan, H., Crompton, T, MacDonald, H.R., Mannherz, H.G.

and Tschopp, ]. 1993. Characterization of the endogenous deoxyribonuclease involved in nuclear DNA degradation during apoptosis (programmed cell death). EMBO J. 12:371377.

- Reipert, S., Reipert, B.M., Hickman, 1.A. and Allen, T.D. 1996. Nuclear pore clustering is a consistent feature of apoptosis in vitro. Cell Death Differ. 3:131-139.

- Sakahira, H., Enari, M., Ohsawa, Y. and Nagata, S. 1999. Apoptotic nuclear morphological change without DNA fragmentation. Curr. Biol. 20:543-546.

- Shiokawa, D., Ohyama, H., Yamadia, T., Takahashi, K. and Tanuma, 5. 1994. Identification of an endonuclease responsible for apoptosis in rat thymocytes. Eur. J. Biochem. $226: 23-30$.

- Smith, S. and Lange, T. de. 1997. TRF1, a mammalian telomeric protein. Trends Genet. $13: 21-26$.

- Shoeman, R.L. and Traub, P. 1990. The in vitro DNA-binding properties of purified nuclear lamin proteins and vimentin. J. Biol. Chem. 265:9055-9061.

- van Steensel and de Lange, T. 1997. Control of telomere length by the human telomeric protein TRF1. Nature 385:740-743.

- van Steensel, B. van, Smogorzewska, A. and de Lange, T. 1998. TRF2 protects human telomeres from end-to-end fusions. Cell 92:401-413.

- Torriglia, An Perami, P. Brossas, J.Y., Chaudun, E. Treton, J., Courtols, Y. and Counis, M.F. 1998. L-Dnase II, a molecule that links proteases and endonucleases in apoptosis, derives from the ubiquitous serpin leukocyte elastase inhlibitor. Mol Cell Biol. 18:3612-3619.

- Vodenicharov. D.M., Markova, D.Z. and Djondjurov, L.P. 1996. Spontaneous apoptosis in mouse F4N-S erythroleukemia cells induces a mon-random fragmentation of DNA. DNA Cell Biol. 15:287-296. 


\section{Summary \& general discussion}

\section{Contents}

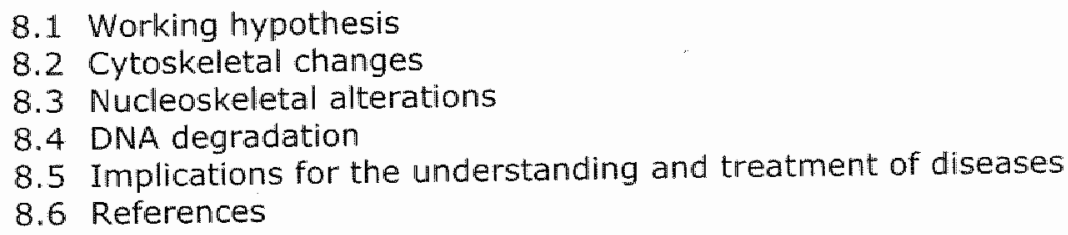

8.1 Working hypothesis

8.2 Cytoskeletal changes

8.3 Nucleoskeletal alterations

8.4 DNA degradation

8.5 Implications for the understanding and treatment of diseases

8.6 References 
Apoptosis is a physiological mechanism of cell death used by multicellular organisms to control cell number during development and morphogenesis, and to eliminate infected, mutated or damaged cells during adulthood (Steller, 1995; Vaux and Korsmeyer, 1999). When a cell receives a 'death signal', an intracellular death program is activated, which leads to coordinated proteolysis of cyto- and nucleoskeletal proteins, DNA degradation and membrane alterations. Subsequently, the dying cell is eliminated by phagocytes. In chapter 1 of this thesis, the concept of apoptosis is reviewed, while chapter 2 provides an overview of the molecular mechanisms of apoptosis. In the studies described in chapters 5, 6 and 7, cytoskeletal and nuclear changes during apoptosis in human tumor cell lines are examined. For reliable detection of apoptotic cells, the annexin V-affinity assay was used and optimized for detection of apoptosis in adherent cells (chapters 3 and 4).

\subsection{Working hypothesis}

The working hypothesis of this study was that cleavage and reorganization of cyto- and nucleoskeletal proteins and DNA during apoptosis is not only dependent on activation of enzymes that act on specific cleavage sites in these constituents, but also on the supramolecular organization of the cytoplasm and the nucleus.

The studies described in this thesis show the behavior of cyto- and nucleoskeletal changes during apoptosis in relation to alterations in the plasma membrane and the genome, respectively. These studies indicate that cleavage of specific cyto- and nucleoskeletal proteins and specific DNA sequences during apoptosis is dependent on cellular and nuclear organization, but also that different apoptosis events are not causally related to each other.

\subsection{Cytoskeletal changes}

In chapter 5 we show that of the cytoskeletal proteins, the intermediate filament proteins cytokeratin and vimentin are ciustered into dot-like aggregates in the cytoplasm and are proteolytically cleaved during apoptosis. However, only a part of the cytokeratin and vimentin proteins is proteolytically cleaved, pointing to a differential cleavage of these proteins. This can be explained by protection of the cleavage site for proteolysis or limited enzyme activity. Actin and tubulin proteins on the other hand are present as aggregated fillaments in the apoptotic bodies. In contrast to other studies (Mashima et al., 1995; Mashima et al., 1997; Kayalar et al., 1996; Brown et al., 1997; Guénal et al., 1997) we could not detect proteolytic degradation of actin by western blotting, possibly because the antibody we used cannot detect cleaved actin fragments because of modification or destruction of the epitope.

This phenomenon is also observed using different lamin antibodies (chapter 6). Another plausible explanation may be that actin cleavage during apoptosis is a differentiation-related, cell type-dependent process. 
During differentiation, the supramolecular organization of a cell changes significantly, which may lead to protection of substrates for caspase cleavage by interactions with other cellular constituents or by post-translational modifications. This is in agreement with recent observations that poly(ADP. ribose)polymerase (PARP), a protein which is extensively cleaved in most cell types, is not cleaved during hepatocyte apoptosis, despite high levels of caspase-3 like activity (Jones et al., 1999). Thus, our results and reports in literature indicate that cleavage of caspase substrates is dependent on the supramolecular organization of the cell, which changes during cellular differentiation.

Because it was speculated that disintegration of cytoskeletal filaments, which interact with the plasma membrane, results in loss of plasma membrane asymmetry (Buja et al., 1993; Verhallen et all., 1987), we investigated whether the interactions between the plasma membrane and the cytoskeleton influence each others reorganization during apoptosis. We show that cytoskeletal reorganization and PS exposure are not causally related. Cytokeratin rearrangement does not per se lead to PS exposure, while PS exposure does not cause cytokeratin reorganization (chapter $\mathbf{5}$ ). These observations indicate that different events of the apoptotic cascade can be uncoupled, which is confirmed by other studies. Hampton et al. (1996) reported that PS exposure in cell lines can be inhibited, while other apoptotic events, such as budding, cell shrinkage, nuclear fragmentation and fodrin cleavage, do occur. Uncoupling of apoptotic events indicates that these can be used independently from each other, for example during processes such as cellular remodeling, when only part of the apoptotic cascade is used. This is consistent with the observation that blood platelets and erythrocytes, which are derived from precursor cells undergoing (part of) the apoptotic cascade (Zauli et al., 1997; Vanags et al., 1997), do not expose PS during the maturation process.

\subsection{Nucleoskeletal alterations}

In addition to a partial degradation of cytoskeletal proteins, we also observed differential breakdown of nuclear lamins during apoptosis (chapter 6). Aand B-type lamins form a nuclear lamina underlying the inner nuclear membrane. While B-type lamins are almost completely cleaved, part of the A-type lamins remains uncleaved, at least until 6 hours after induction of apoptosis by roscovitine. Different timing of cleavage of A- and B-type lamins can be explained by the differential activation of two lamin cleaving enzymes, i.e. caspase-6 and the nuclear scaffold associated protease (Zhivotovsky et al., 1997). However, partial degradation of A- type lamins themselves, points to a limited accessibility of A-type lamins for caspase- 6 .

A population of apoptotic cells with an intranuclear A-type lamin scaffold structure is observed, most probably representing the lamin-skeleton that is observed by Hozak et al. (1995) by immuno-electron microscopy. We speculate that the intranuclear lamin A-network is not available for cleavage by proteases due to strong interactions with chromatin and/or other constituents of the nuclear matrix. Post-translational modifications of intranuclear A-type lamins, which might determine if a lamin molecule is 
located at the nuclear periphery or in the nuclear matrix (Hozak et all., 1995), may also explain pesistance of A-type lamins for caspase cleavage.

\subsection{DNA degradation}

In anglogy with resistance of part of the nuclear matrix proteins to proteolysis during apoptosis, also DNA sequences, which are thought to be associated with the nuclear matrix, are resistant to the apoptotic nuclease during apoptosis (chapter 7). Although the majority of unique and repetitive DNA sequences is fragmented during apoptosis, the telomere repeat sequence TTAGG is still detectable using a fluorescent in situ hybridization assay. To explain this phenomenon it must be kept in mind that this DNA sequence is a component of the nuclear matrix and is thus tightly connected with other nuclear matrix constituents, amongst which intranuclear A-type lamins, protecting this sequence from the apoptotic endonuclease. This implicates that other DNA sequences, which are present in the nuclear matrix and have interactions with matrix proteins, e.g. transcriptionally active DNA and replicating DNA, might also be protected.

\subsection{Implications for the understanding and treatment of diseases}

The studies described in this thesis suggest a differential degradation of cytoskeletal and nuclear constituents during apoptosis, indicating that the degradation phase of apoptosis is completed in a tightly controlled manner. Furthermore, these studies suggest that different events of the apoptotic machinery, such as cytokeratin reorganization and PS exposure can be uncoupled. These observations indicate that parts of the apoptotic cascade can be used independently from each other during cellular and nuclear remodeling. It is recently reported that downstream caspases play a role in cytoskeletal and nuclear remodeling during differentiation, cell migration (Weil et al., 1999; Braun et al., 1999; Watanabe et all., 1999) and presumably also during cell division.

The observations that caspases play a role in cellular processes, other than apoptosis, has implications for the treatment of neurodegenerative diseases, stroke, bacteriall meningitis, cardiovascular disorders and cancer.

The use of caspase-inhibitors for the prevention and treatment of neurodegenerative and cardiovascular diseases is examined in animal studies.

Although some studies show a positive effect of these inhibitors in preventing cellular damage (Schierle et al., 1999), it is still to be established whether the rescued cells are functional. Since not only apoptosis is inhibited by the application of such drugs, but also remodeling processes may be hindered, processes such as cell migration (Braun et al., 1999), cell differentiation and cell division may be influenced.

On the other hand, the majority of the cancer therapies is based on killing tumor cells by apoptosis. However, many tumor cells have become resistant for induction of apoptosis in response to chemotherapeutic agents due to modifications or overexpression of apoptosis inhibitors that act upstream in the apoptotic cascade. This explains the failure of therapies based on induction of apoptosis by DNA damage. Nowadays, ways to restore the ability of tumor cells to undergo apoptosis in response to chemotherapeutic agents 
are being investigated. Furthermore, activation of caspases leads directly to apoptosis and circumvents the need for upstream caspase activators. However, caspase activation may lead to changes in the cell's interior (the cytoskeleton) which may then increase the flexibility and migratory potential of the cells, i.e. characteristics of metastasizing cells. Metastasizing cells escape from primary tumors and transverse basal membranes and blood vessels, thereby often changing shape. Furthermore, tumors are often vascularized, which involves migration of endothelial cells. Immobilization of tumor cells and endothelial cells by means of inhibition of downstream caspases may prevent tumor vascularization and metastasizing of the tumor. The drawback of this intervention, namely inhibition of tumor cell apoptosis, may be circumvented by inducing cell death in tumor cells via caspaseindependent routes.

In addition, massive induction of apoptosis, as a response to chemotherapeutic agents, without effective elimination of the 'apoptotic waste' by phagocytosing cells exposes the immune system to apoptosis generated selfantigens (Piacentini and Collizi, 1999). As a result, autoimmune responses are often directed against proteins located in the apoptotic bodies, which often represent nucleoskeletal proteins. Furthermore, antibodies directed against DNA and PS are generated (Casiola-Rosen et al., 1994; CasiolaRosen et al., 1996; Utz et al., 1998).

Thus, during treatment of neurodegenerative diseases, cardiovascular disorders and cancer by means of caspase activation or caspase inhibition, one should be cautious for side effects involving remadeling.

\subsection{References}

- Braun, J.S., Novak, R., Herzag, K.H., Bodner, S.M., Cleveland, J.L. and Tuomanen, E.I. 1999. Neuroprotection by a caspase inhibitor in acute bacterial meningitis. Nat. Med. 5:298-302.

- Brown, S.B., Bailey, K. and Savill, J. 1997. Actin is cleaved during constitutive apoptosis. Biochem. J. 323:233-237.

- Buja, L.M., Eigenbrodt, M.L. and Eigenbrodt, E.H. 1993. Apoptosis and necrosis. Basic types and mechanisms of cell death. Arch. Pathol. Lab. Med. 1993: 117:1208-1214.

- Casciola-Rosen, L.A., Anhalt, G. and Rosen, A. 1994. Autoantigens targeted in systemic lupus erythematosus are clustered in two populations of surface structures on apoptotic keratinacytes. J. Exp. Med. 179:1317-1330.

- Casiola-Rosen, L., Rosen, A., Petri, M. and Schlissel, M. 1.996. Surface blebs on apoptotic cells are sites of enhanced procoagulant activity: implications for coagulation events and antigenic spread in systemic lupus erythematosus. Proc. Natl. Acad. Sci. USA. 93:1624-1629.

- Guénal, I., Risler, Y. and Mignotte, B. 1997. Down-regullation of actin genes precedes microfilament network disruption and actin cleavage during p53-mediated apoptosis. J. Cell Sci. 110:489-495.

- Hampton, M.B., Vanags, D.M., Porn-Ares, M.1. and Orrenius, S. 1996. Irvolvement of extracellular calcium in phosphatidylserine exposure during apoptosis. FEBS Lett. $399: 277-282$.

- Hozak, P., Sasseville, A.M., Raymond, Y. and Cook, P.R. 1995. Lamin proteins form an intermal nucleoskeleton as well as a peripheral lamina in human cells. J. Cell Sci. 108:635-644.

- Jones, R.A., Johnson, V.L., Hinton, R.H., Poirier, G.G., Chow, S.C. and Kass, G.E. 1999. Liver poly(ADP-ribose)polymerase is resistant to cleavage by caspases. Biochem. Biophys. Res. Commun. 256:436-441. 
- Kayalar, C., Ord, T., Testa, M.P., Zhong, L.T. and Bredesen, D.E. 1996. Cleavage of actin by interleukin $1 \beta$-converting enzyme to rewerse DNAse 1 inhibition. Proc. Natl. Acad. SCl. USA. 93:2234-2238.

- Mashima, T., Naito, M., Fujita, N., Noguchi, K. and Tsuruo, T. 1995. Identification of actin as a substrate of ICE and ICE-like protease and involvement of an ICE-like protease but not ICE in VP-16-induced 2937 apoptosis. Biochem. Biaphys. Res. comm. 217:1185-1192.

- Mashima, T., Naito, M., Noguchi, K., Miller, D.K., Nichoison D.W. and Tsuruo, T. 1997. Actin deavage by CPP-32/apopain during the development of apoptosis. Oncogene. 14:1007-1012.

- Piacentini, M. and Colizzi, V. 1999. Tissue transglutaminase: apoptosis versus autoimmunity. Immunology Today. 20:130-134.

- Schierle, G.S., Hansson, O., Leist, M., Nicotera, P., Widner, H. and Brundin, P. 1999. Caspase inhibition reduces apoptosis and increases survival of nigral transplants. Nat. Med. 5:97-100.

- Steller, H. 1995. Mechanisms and genes of cellular suicide. Science. 267:1445-1449.

- Utz, P.J. and Anderson, P. 1998. Post-translational protein modifications, apoptosis and the bypass of tolerance to autoantigens. Arthritis Rheum. 41: 1152-1160.

- Vanags, D.M. Orrenius, S. and Aguilar-Santelises, M. 1997. Alterations in Bcl-2/Bax protein levels in platelets form part of an ionomycin-induced process that resembles apoptosis. Br. J. Haematol. 99:824-831.

- Vaux, D.L. and Korsmever, S.1. 1999. Cell death in development. Cell. 96:245-254.

- Verhallen, P.F.J., Bevers, E.M., Confurius, P. and Zwaal, R.F.A. 1987. Correlation between calpain-mediated cytoskeletal degradation and expression of platelet procoagulant activity. A role for the plateler membrane skeleton in the regulation of membrane lipid asymmetry. Biochim. Biophys. Acta 903:206-217.

- Watamabe, Y. and Akaike, T. 1999. Possible involvement of caspase-like family in maintenance of cytoskeletal integrity. J. Cell. Physiol. 179:45-51.

- Weil, M., Raff, M.C. and Braga, V.M. 1999. Caspase activation in the terminal differentiation of human epidermal keratinocytes. Curr. Biol. 9:361-364.

- Zauli, G., Vitale, M., Falcieri, E., Gibellini, D., Bassini, A., Celeghini, C., Columbaro, M and Capitani, S. 1997. In vitro senescence and apoptotic cell death of human megakoryocytes. Blood 90:2234-2243.

- Zhivotovsky, B., Gahm, A. and Orrenius, S. 1997. Two different proteases are involved in the proteolysis of lamin during apoptasis. Biochem. Biophys. Res. Commun. 233:96-101. 


\section{Samenvatting}

In gezonde weefsels van meercellige organismen bestaat een nagenoeg perfecte balans tussen celproliferatie en celdood. Celdood kan plaatsvinden via twee verschillende routes, te weten apoptose en necrose. Necrose is een vorm van celdood die veroorzaakt wordt door acute beschadiging van de cel, bijvoorbeeld als gevolg van ischemie of chemische agentia. Deze beschadiging interfereert met de ATP synthese van de cel, waardoor de cel opzwelt en de celmembraan lek raakt. De daaropvolgende desintegratie wan de cel veroorzaakt een ontstekingsreactie in het omliggende weefsel. Als reactie op specifieke interne en externe signalen kan een cel 'zelfmoord plegen'. Dit proces van geprogrammeerde celdood wordt apoptose genoemd en wordt beschouwd als een fysiologisch fenomeen omdat deze vorm van celdood een belangrijke rol speelt tijdens de embryonale ontwikkeling, het elimineren van beschadigde cellen, de verdediging tegen virale infecties en het in stand houden van de organisatie van een weefsel. Tijdens apoptose wordt een cel stapsgewijs 'gedemonteerd' en verpakt als kleine celfragmenten omgeven door een celmembraan.

In hoofdstuk 1 worden de verschillen tussen apoptose en necrose besproken en wordt uitgelegd dat het proces van apoptose in 3 fasen verloopt, nll. 1) de inductiefase warin de cel het signaal krijgt om in apoptose te gaan, 2) de executiefase warin de enzymen worden geactiveerd die de cel 'demonteren" en 3) de degradatiefase waarin structurele eiwitten, apoptose-inhiberende eiwitten, stress respons eiwitten en DNA worden afgebroken. Het resultaat van bovengenoemde processen is een gestructureerde afbraak en verpakking van de apoptotische cel zadat deze uiteindelijk gefagocyteerd kan worden door naburige cellen of door fagocyten. Verder wordt in hoofdstuk 1 de werkhypothese van deze studie geponeerd, $\mathrm{nl}$. dat de supramoleculaire organisatie van het cytoskelet en het kernskelet als ook die van het DNA invloed heeft op de afbraak van deze componenten tijdens apoptose.

In hoofdstuk 2 worden de recente inzichten omtrent de inductie van apoptose, de signaal transductie routes en de degradatie fase vam apoptose op een rij gezet. Verder worden de eiwitten die eien belangrijke rol spelen in het proces van apoptose, zoals caspases en caspase-regulerende eiwitten besproken. De gevolgen van caspase-activatie voor het cytoskelet, de kern en de celmembraan van de individuele cel komen tevens aan de orde.

Om het proces valn apoptose goed te kunnen bestuderen is thet van belang om apoptotische cellen specifiek en gevoelig te kunnen identificeren. Apoptotische cellen kunnen worden herkend aan de hand van karakteristieke morfologische veranderingen, zoals chromatine aggregatie en de vorming van apoptotische celfragmenten. Verder kunnen ze worden geidentificeerd aan de hand van apoptose-specifieke, biochemische veranderingen zoals expressie van apoptose geassocieerde eiwitten, proteolyse van specifieke substraten en de vorming van specifieke neo-epitopen.

In hoofdstuk 3 wordt een overzicht gegeven van de annexine $V$ methode om apoptose te detecteren aan de hand van veranderingen in de verdeling van verschillende fosfolipiden over de celmembraan. In niet-apoptotische cellen zijn de fosfolipiden van de celmembraan asymmetrisch verdeeld over de dubbele lipidenlaag. Fosfatidylcholine en sphingomyeline zijn voornamelijk aanwezig aan de buitenzijide van de dubbellaag, terwijl fosfatidylserine (PS) voomamelijk aan de cytoplasmatische zijde van de billag is gelokaliseerd. 
Deze asymmetrie wordt in stand gehouden door een aminofosfolipiden translocase, die de amimofosfolipiden, en in het bijzonder PS van buiten naar binnen transporteert. Verder wordt de lokalisatie van PS in de cytoplasmatische zijde wan de bllaag ook gehandhaafd door associaties van PS met annexines, polyamines en membraanskelet-eiwitten zoals fodrine. Tijdens het proces van apoptose komt PS al vroeg voor op de buitenkant van de bilaag. Dit wordt waarschijnlijk veroorzaakt door remming van de translocase en activatie van een scramblase. Verder is het tevens mogelijk dat proteolyse van fodrine door caspase-3 bijdraagt aan de externalisatie van PS. Expositie van PS op de buitenkant van de celmembraan is een teken voor specifieke cellen, die op hun beurt een PS-receptor op hun celmembraan bezitten, om de apoptotische cel te fagocyteren. PS externalisatie tijdens apoptose is een mechanisme dat door de evolutie heen behouden is gebleven en dat is aangetoond in planten-, insecten-, en zoogdiercellen. PS expositie kan in wivo en in vitro gedetecteerd worden met behulp van annexine $V$. Annexine $V$ is een eiwit dat zeer specifiek aan PS kan binden in aanwezigheid van calcium. Door een label te koppelen aan annexine $V$ kan PS expositie in apoptotische cellen bestudeerd worden. Dit gelabelde annexine $V$ bindt aan geéxternaliseend PS op de apoptotische cel. Het kan niet binden aan niet-apoptotische cellen, waar PS alleen aan de cytoplasmatische kant van de bilaag is gelokaliseerd, omdat de fosfolipiden bilaag miet permeabel is voor annexine $V$. Echter, in necrotische cellen is de cytoplasmatische kant van de bilaag wel bereikbaar voor annexine $V$ omdat de celmembraan permeabel is geworden. Een cel membraan impermeabele DNA kleurstof, zoals propidium jodide (PI) dient derhalve gebruikt te worden in combinatie met annexine $V$ om onderscheid te maken tussen necrotische en apoptotische cellen. Voor cellen die gekweekt worden in suspensie is het relatief gemakkelijk om PS expositie the detecteren met annexine $V$. Echter, het detecteren van PS expositie in hechtende cellen is complexer. Deze hechtende cellen kunnen onmiddellijk na binding van fluorochroom-gelabeld annexine $V$ worden geanalyseerd met behulp van een fluorescentie microscoop. Om een celsuspensie te verkrijgen, bijwoorbeeld voor het analyseren van cellen met behulp van de flow cytometer, moeten deze cellen los gemaakt worden van de kweekfles worden, waarbij het gebruik van enzymen zoals trypsine en EDTA kan interfereren met het betrouwbaar detecteren van PS expositie. Om dit probleem te omzeilen is een methode ontwikkeld om PS expositie te detecteren in hechtende cellen, door de kweek eerst te labelen met annexine $V$ en daarna de cellen te oogsten door ze van de bodem van de kweekfles te schrapen (hoofdstuk 4). Hierdoor worden echter wel een aantal cellen beschadigd. Door een combinatie van annexine $V$ en PI te gebruiken wordt het technilsch mogelijk om vitale, apoptotische, necrotische en beschadigde cellen van elkaar te onderschelden en te kwantificeren via flow cytometrie.

Omdat in de literatuur gespeculeerd werd dat expositie van PS aan de buitenzijde van de bilaag veroorzaakt zou kunnen worden door afbraak wan cytoskelet eiwitten tijdens apoptose is een methode ontwikkeld om PS expositie en cytoskelet veranderingen gelijktijdig te detecteren in cellen. zodat deze hypothese getest kon worden (hoofdstuk 5). Na inductie vam apoptose werden cellen in kweek gelabeld met annexine $V$, vervolgens gefixeerd met methanol en tenslotte de cytoskelet eiwitten gedetecteend met behulp van antilichamen. Er werd gevonden dat de intermediaire filament eiwitten (cytokeratines en vimentine) uit elkaar vallen tot kleine fragmenten 
tijdens apoptose, terwijl actine en tubuline opgeslagen worden als geaggregeerde filamenten in de apoptotische celfragmenten. Verder hebben we laten zien dat cytokeratimes en vimentine proteolytisch worden geknipt tijdens apoptose, terwijl actine en tubuline intact blijven. Dit in tegenstelling tot enkele artikelen in de literatuur die rapporteren dat actine wel gedegradeerd wordt tijdens apoptose. Deze experimenten lieten ook zien dat aggregatie van cytokeratin filamenten en PS expositie gelijktijdig plaatsvinden tijdens apoptose, maar dat deze gebeurtenissen niet causaal aan elkaar gerelateerd zijin.

Om veranderingen in het kernskelet te bestuderen tijdens apoptose werd gekozen voor de lamine-eiwitten, die een lamina vormen onder de kernmembraan. In zoogdiercellen komen twee soorten lamines voor, nl. de A-type lamines, waar lamine A en lamine $C$ onder vallen, en B-type lamines, waar lamine B1 en lamine B2 toe behoren. Tijdens apoptose worden A- en B-type lamines geknipt door caspase-6. In hoofdstuk 6 is het gedrag van de verschillende lamine-eiwitten tijdens apoptose bestudeerd door gebruik te maken van immunocytochemie, flow cytometrie en western blotting. In een apoptotische cel blijken A-type lamines minder extraheerbaar te zijn dan Btype lamines. Verder hebben we gezien dat een deel van de A-type lamines niet geknipt wordt, dit in tegenstelling tot B-type lamines die bijna geheel geknipt worden tijdens apoptose. Ook werd een populatie apoptotische cellen aangetroffen die een A-type lamine netwerk vertoonden dat gelokaliseerd was tussen het gecondenseerde DNA. Deze resultaten kunnen verklaard worden door het verschil in lokalisatie van A-en B-type lamines in de kern. B-type lamines bevinden zich voornamelijk aan de periferie van de kern en zijn dus gemakkelijk toegankelijk voor caspase-6. A-type lamines vormen naast een lamina ook nog een intranucleair netwerk, dat onderdeel is van de kernmatrix. Deze intranucleaire A-type lamines zijn door hun lokalisatie waarschijnlijk onbereikbaar voor caspase-6 en blijven hierdoor intact.

Deze resultaten wijzen dus op een differentiële afbraak van lamine-eiwitten tijdens apoptose, veroorzaakt door een verschil in de lokalisatie van deze eiwitten in de kern.

In hoofdstuk 7 wordt gerapporteerd dat ook verschillende chromosomale regio's differentieel worden afgebroken tijdens apoptose. Door gebruik te maken van de in situ hybridisatie techniek kon worden aangetoond dat tijdens apoptose totale chromosoom territoria worden afgebroken, evenals de centromeer, sub-centromeer en subtelomeer DNA sequenties. Deze worden egaal verdeeld over het gecondenseerde DNA. Telomeer DNA daarentegen blijft intact en is detecteerbaar als geclusterde signalen aan het oppervlak of in het centrum van het gecondenseerde DNA. Een verklaring voor deze differentiele DNA degradatie kan zijn dat het telomeer DNA, dat interacties aangaat met de kernmatrix, hierdoor beschermo is tegen afbraak door nucleases terwijl de andere bestudeerde chromosoom regio's beter bereikbaar zijn voor nucleases.

Concluderend kan worden gezegd dat de resultaten van deze studie wijzen in de richting van een differentiële afbraak van cytow en kernskelet eiwitten. alsook van DNA tijdens apoptose en dat er aanwijzingen zijn verkregen dat deze differentiele afbraak veroorzaakt wordt door de supramoleculaire organisatie van de cell (hoofdstuk8). 



\section{Dankwoord}

't is een kwestie van geduld, veel proefjes doen en rustig wachten op de dag, dat je eindelijk promoveren mag. En dat ik mag promoveren is aan veel mensen te danken.

Allemaal bedankt!! Toch wil ik een aantal mensen nog iets zeggen. Allereerst wil ik de drie mannen bedanken die, ieder op hun eigen manier, met mij dit boekje hebben gemaakt.

Frans Ramaekers, als promotor was je een ware caspase-9 woor mijn onderzoek en mijn manuscripten: je activeerde de andere caspases (waaronder mijzelf), knipte grote stukken tekst en rearganiseerde veel data en ideeên. Ik heb enorm veel bewondering voor je gave om resultaten in een breder perspectief te zien en ik hoop dan ook dat ik dit een kllein beetje van je heb meegekregen.

Ton Hopman, je was de telomerase van mijn onderzoek: je zorgde ervoor dat de grote lijn vam mijn onderzoek intact bleef en je hebt me geleerd hoeveel je door een microscoop kunt zien, en hoeveel je kunt missen als je niet heell goed kijkt. Ik heb echt heel veel van je geleerd.

Bert Schutte, wat is een AlO en zijn promotieonderzoek zonder cytochroom C, dat enthousiast een hele cascade van ideeen en experimenten aan het rollen brengt? Ik heb nooit geweten dat cytochroom $C$ blauw is......

Chris Reutelingsperger van de vakgroep Biochemie, bedankt woor de samenwerking betreffende het membraan-anderzoek en voor die anmexine $V$.

Alle AIO's, post-docs, analisten, onhandige artsen en studenten die gedurende mijn promotieperiode in het FISH lab gewerkt hebben en nog werken: bedankt woor de gezelligheid.

Tourmaniac, helpdesk MCB en Henri, bedankt voor de hardware, de software en het geduldig te woord staan van deze amateur alls het paginanummer op de oneven pagina's opeens verdwenen was of als pagina 140 opeens pagina 15 heette. Nummer 81425 zal ik niet snel vergeten.

Mieke Henfling, jarenlang hebben we op maandag-, woensdag- en vrijdagmiddag van 17.00 tot 17.30 naast elkaar hebben zitten kwek(k)en in lab $5.231 \mathrm{a}$. Ik heb veel bewondering voor de manier waarop je met je cellen omgaat, ik kan de mijne dan ook met een gerust hart bij je achterlaten.

Helma Kuijpers, de vraag die ik zeker vijf keer per week aan je stelde luidde: hoe deden jullie dat vroeger dan? Uit je ongelooflijke geheugen kwam dan altijd onmiddellijk een antwoord en ondertussen werd al een nieuw gelletje gerunt. Het was me een waar genoegen om samen experimenten te doen. Bedarkt voor de roosvicee en ik hoop dat je, ook al zit ik nu lets verder weg, af en toe nog eens een dropje komt stelen.

Susan Swiggers, mijn 'allergie' voor studenten is verdwerien sinds jij een stage bent komen doen. Bedankt voor de hulp bij de experimenten die beschreven zijn in hoofdstuk 7 en veel succes met je elgen telomeren.

Een speciaal woond van dank aan mijn paranimfen, Marie-Helene Lenders en Joris Veltman.

Marie-Helene, tijdens de nasi en de vegetarische burgers heb je uren naar me geluisterd als ik mign el kwijt moest, en het enige dat je terug vroeg waren 10 dioxinevrije, Nederlandse eieren. Bedankt voor het feit dat je er gewoon altijd was.

Joris, we waren samen onderweg, halleluja, we hebben het samen gehaald, halleluja. Deze zin zegt alles over de afgelopen vier jaren, bedankt voor alles........

Monique, bedankt woor al die uurtjes op zaterdagmiddag waar ik mag zeggen wat ik wil.

Wans, Mariet en Arjan, ik kan maar een ding zeggen: een lievere familie kan een AIO zich niet wensen.

Lieve Jack, als ik aan ow denk, als ik ow wir zij, denk ik vandaag begint alles opnij, dan krieg ik t werm, dan krieg ik 't kalt, same met ow val ik um, wer ik alt. 



\section{Curriculum Vitae}

Manon van Engeland werd geboren op 14 december 1971 te Sittard. In 1991 behaalde zij het Atheneum B diploma aan de Scholengemeenschap Serviam te Sittard. In datzelfde jaar begon zij de studie Gezondheidswetenschappen, met als afstudeerrichting Biologische Gezondheidkunde, aan de Rijksuniversiteit Limburg (Universiteit Maastricht). Voor de scriptie, geschreven tijdens de afstudeerstage bij de vakgroep Moleculaire Celbiologie \& Genetica (Universiteit Maastricht), kreeg zij de studentenprijs 1995 van de Stichting Wetenschapsbeoefening Maastricht. In augustus 1995 werd het doctoraal diploma behaald. In september 1995 werd ze aangesteld als assistent in opleiding bij de vakgroep Moleculaire Celbiologie \& Genetica (Prof. Dr. F.C.S. Ramaekers, Dr. A.H.N. Hopman, Dr. B. Schutte). Gedurende deze periode werd het in dit proefschrift beschreven onderzoek uitgevoerd. Vanaf 1 november 1999 is zij werkzaam als post-doc bij de afdeling Pathologie van de Universiteit Maastricht (Prof. Dr. J.W. Arends, Dr. A. de Goeij). 


\section{List of publications}

van Engeland, M., Ramaekers, F.C.S., Schutte, B. and Reutelingsperger, C.P.M. 1996. A novel assay to measure loss of plasma membrane asymmetry during apoptosis of adherent cells in culture, Cytometry 24:131-139.

Machiels, B.M., Henfling, M.E.R., Schutte, B., wan Engeland, M., Broers, J.L.V., and Ramaekers, F.C.S. 1996. Subcelfular localization of proteasomes in apoptotic lumo tumor cells and persistence as compared to intermediate filaments. Eur. J. Cell Biol. $70: 250-259$.

van Engeland, M., Kuijpers, H.J.H., Ramaekers, F.C.S., Reutelingsperger, C.P.M. and Schutte, B. 1997. Plasma membrane alterations and cytoskeletal changes in apoptosis. Exp. Cell Res. 236:421-430.

Schutte, B., Nieland, L.J.W., van Engeland, M., Henfling, M.E.R., Meijer, L, and Ramaekers, F.C.S. 1997. The effect of the cyclin dependent kinase inhibitor olomoucine on cell cycle kinetics: Exp. Cell Res. 236:4-15.

van Engeland, M., Nieland, L.J.W., Ramaekers, F.C.S., Schutte, B. and Reutelingsperger, C.P.M. 1998. Annexin V-affinity assay: a review on an apoptosis detection system based on phosphatidylserine exposure: Cytometry $31: 1-9$.

van Engeland, M, van den Eijnde, S.M., Vermeij-Keers, $C_{\text {, }}$ Ramaekers, F.C.S., Reutelingsperger, C.P.M. and Schutte, B. Detection of apoptosis in ovarian cells in witro and in vivo using the amnexin V-affinity assay. In Methods in molecular medicine: ovarian cancer. Bartlett, ]. editor (Totowa: The humana Press Inc.) In press.

van Engeland, M., Schutte, B., Hopman, A.H.N., Ramaekers, F.C.S. and Reutelingsperger, C.P.M. Cytochemical detection of cyto- and nucleoskeletal changes during apoptosis. In Apoptosis: a practical approach. Studzinski, G. editor. (Oxford: Oxford University Press) In press.

van Engeland, M., Kuijpers, H.J.H., Raymond, Y., Hutchison C.J., Schutte, B., Ramaekers, F.C.S. and Hopman, A.H.N. Differential degradation of nuclear lamin proteins during apoptosis (to be submitted for publication).

van Engeland, M., Swiggers, S.J.J., Tajbakhsilh, Lichter, P. Ramaekers, F.C.S. and Hopmän, A.H.N. Chromosome degradation during apoptosis to be subrnitted for publication). 


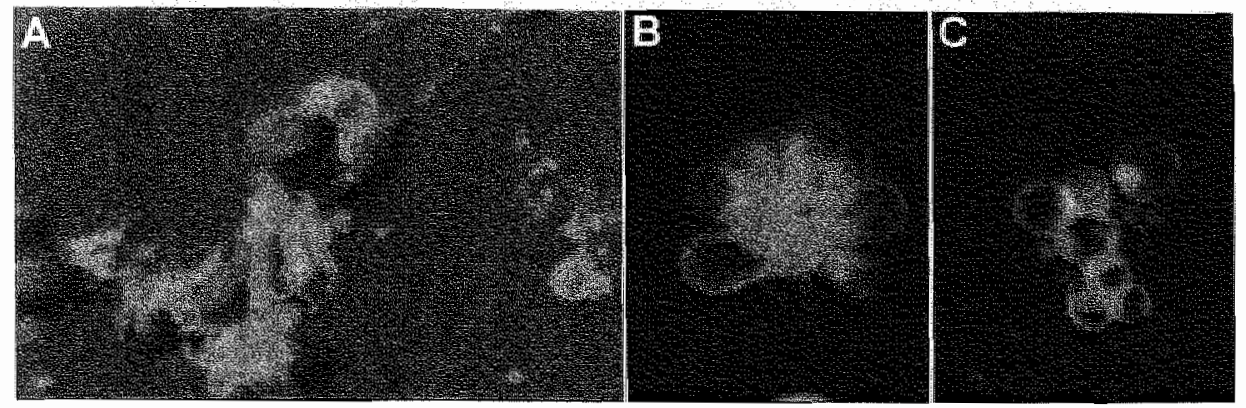

Figure 3.2: MR65 cells, grown on glass slides, are cultured in the presence of $200 \mu \mathrm{M}$ olomoucine. After 6 hours, the vital cultures were incubated with annexin V-FITC, PI and Hoechst 33342 . The cell cultures were subsequently analyzed using the Bio-Rad MRC600 confocal scanning laser microscope. A: Merged image of annexin $V$ fluorescence and differential interference contrast. Cells showing the characteristic bud formation are clearly annexin $\mathrm{V}^{\text {tw}}$, while vital adherent cells, including the metaphase in the center of the image, are annexin $V^{*}$. Note the presence of small annexin $V^{*}$ vesicles. B and C: Merged images of annexin V (green), PI (red) and Hoechst 33342 (blue) fluorescence of a single apoptotic (B) and a single dead (C) cell. Note that some buds are dievoid of nuclear remnants.
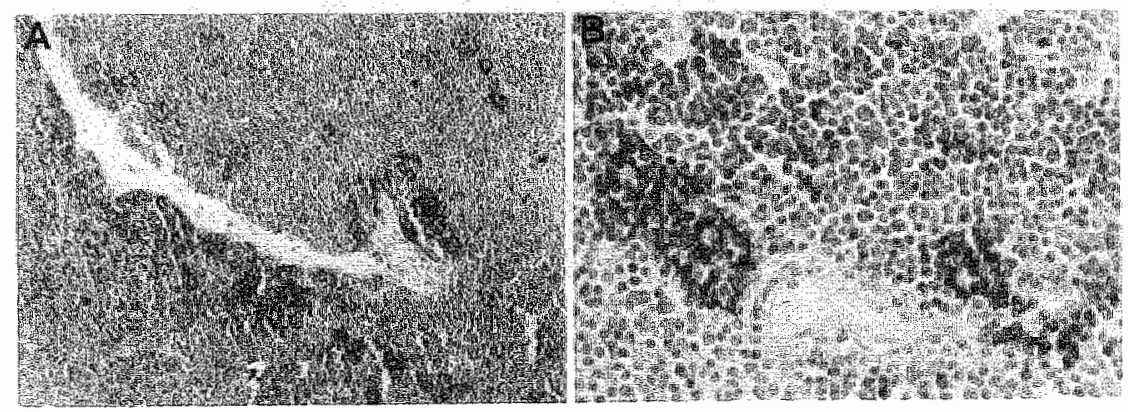

Figure 3.6: Exogenouslly applied annexin $V$ localization of formalin fixed, paraffirmembedded tissue sections of a mouse thymus. The mouse was in situ-labeled by injection of annexin $V$-biotin. The thymus was removed after 30 minutes and rourinely processed for paraffin embedding. Sections cleared from paraffin were incubated with peroxidase-labeled streptavidin to visualize annexin Vubiotin, bound to apoptotic cells. The low-magnification field (20x) shows that apoptosis occurs in discrete groups of cells and not randomly dispersed throughout the tissue (A). At higher magnification $(40 x)$ a clear membrane staining in the positive cells can be observed (B). for details, see van den Eijnde et al., 1997). 


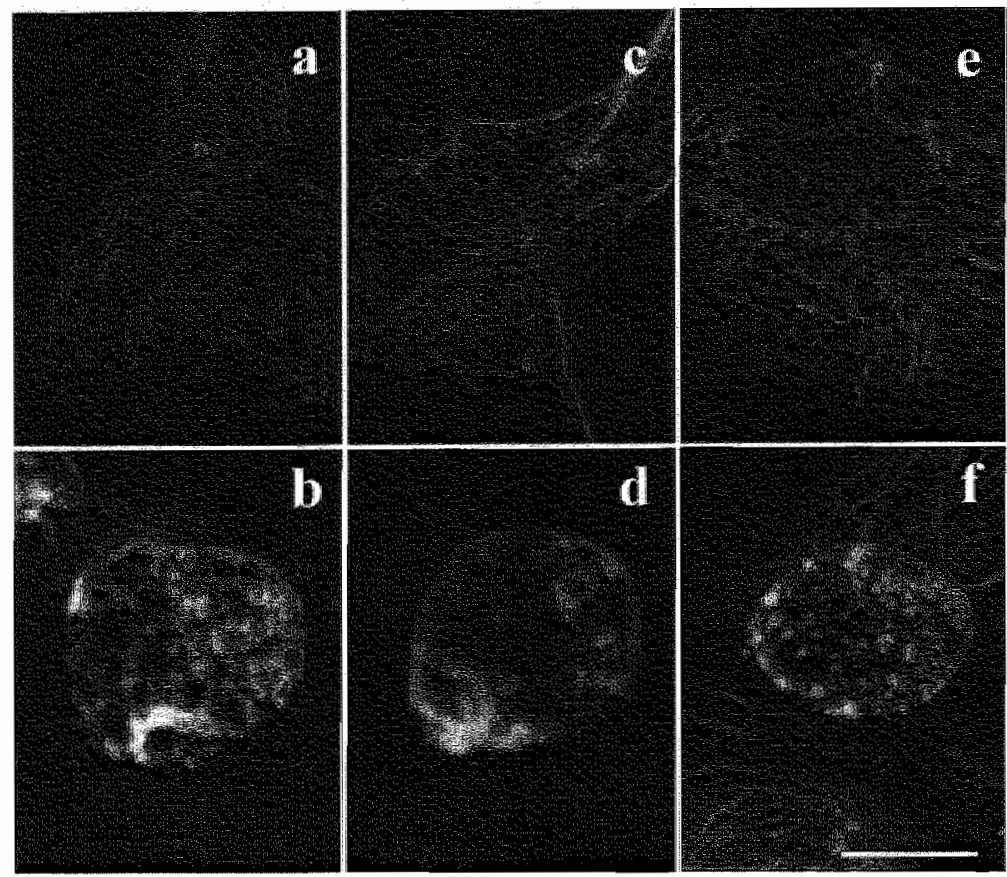

Figure 5.1: Merged confocal sicanning laser microscopy images of control and apoptotic cells. (a) Two control CHP212 cells with normal actin filaments. (b) An apoptotic CHP212 cell with actin filament redistribution (red) and annexin $\mathrm{V}$ binding (green). (c) A normal CHP212 cell with filamentous vimentin and (d) vimentin aggregation (red) and annexin $V$ binding (green) in an apoptotic CHP212 cell. Cytokeratin staining in MR65 cells is shown in $\mathrm{f}$. This figure shows an annexin $\mathrm{V}^{*}$ (green) apoptotic MR65 cell with aggregated cytokeratin filaments next to nonapoptotic cells with normal cytokeratin filaments. A control cell, stained with the anticytokeratin antibody, is shown in e. Note that the non-apoptotic cells are negative for annexin $\mathrm{V}$. Bar indicates $5 \mu \mathrm{m}$.
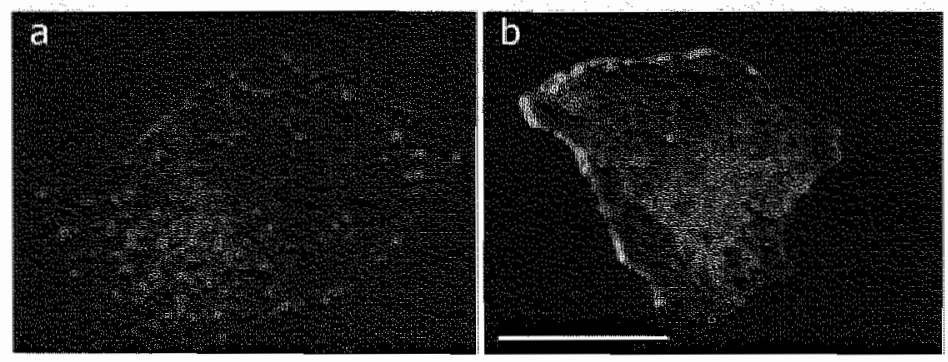

Figure 5.5: (a) Merged CSLM image of an MR65 cell showing cytokeratin disruption after incubation with PMA and subsequent treatment with cold PBS. Cytokeratin antibody binding is shown in red and annexin $V$ binding in green. Note that cells with aggregated cytokeratin filaments do not show annexin $V$ binding. (b) Merged CSLM image of an MR55 cell after NEM treatment for 4 hours. After incubation with annexin V-biotin, cells were fixed and stained with an anti-cytokeratin antibody (red) and streptavidin-FITC to visualize annexin $V$ binding (green). Note that artificially induced PS exposure at the outer leaflet of the plasma membrane, detected by annexin $V$ binding, does not induce cytokeratin disruption. Bar indicates $10 \mu \mathrm{m}$. 

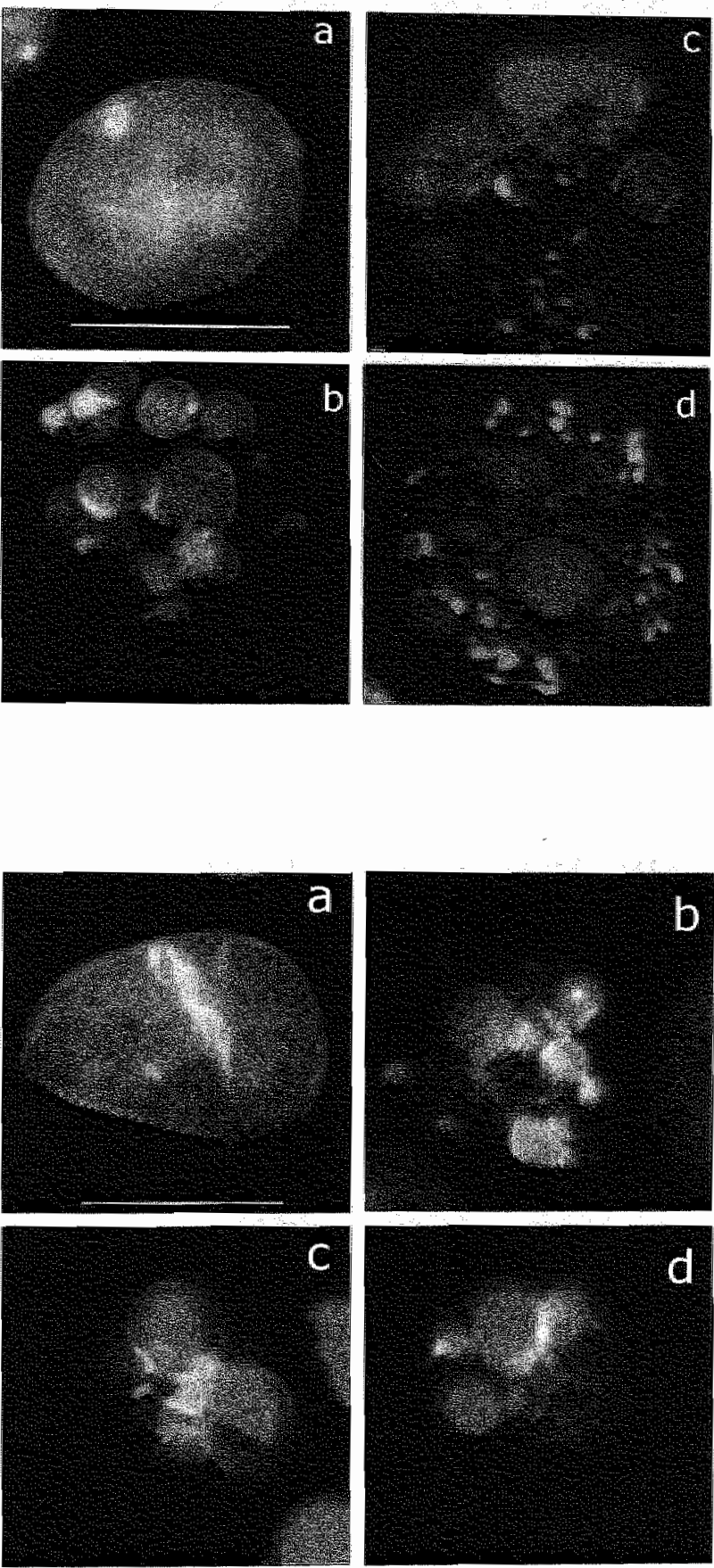

Figure 6.4: Immunocytochemistry of MR65 cells using A-type lamin antibodies. Lamins are shown in green, whille the PI counter. staining of the nucleus is shown in red. Figure 6.4a shows a non-apoptotic cell stained with the lamin A antibody $133 \mathrm{~A} 2$ after methanol fixation. Figure $6.4 b$ shows an apoptotic cell stained with the A-type lamin antibody $133 \mathrm{~A} 2$ sho. wing a lamina-like structure surrounding the condiensed DNA. Figure $6.4 d$ shows an apoptotic cell stained with the lamin A/C antibody Jol 2 , which detects a granular structure lying between the condersed DNA. In figure $6.4 \mathrm{c}$ an apoptotic cell with a lamina-iike A-type lamin staining im addition to a gra nular structure is shown (antibody jol2). Bar indicates $15 \mu \mathrm{m}$.

Figure 6.5: Immunocytochemistry of MR65 cells using B-type tamin antibodies. Lamins are shown in green, while the PI counterstaining of the DNA is shown in red. Figure 6.5a shows a non-apoptotic cell stained with the lamin $B 2$ antibody LN43, showing a laminar staining pattem. In figure $6.5 b$ an apoptotic cells is shown, with diffuse lamin B1 fluorescence (11905 antibody) between the consensed DNA. Figure $6.5 \mathrm{C}$ shows an apoptotic cells stained with the lamin $B 2$ antibody $\times 223$, showing a lamina-like stainirig surrounding the condensed DNA, while figure 6.5d shows diffuse lamin BZ fluorescence next to the condensed chromatin (LN43 antibody). Bar indicates 15 um. 


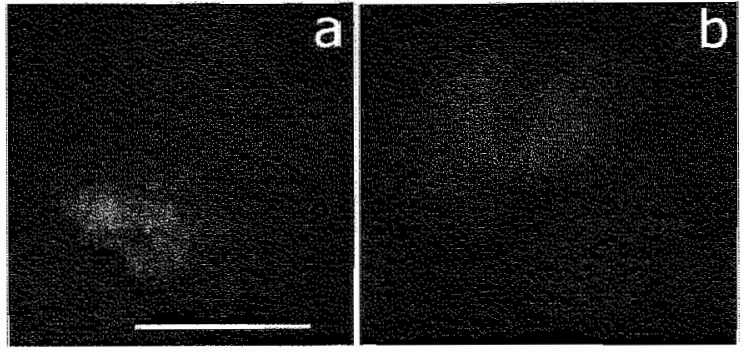

Figure 7.2: Jurkat cells hybridized with a paint probe detecting chromosme 8 , shown in red. DA.PI counterstaining of the nucleus is shown in blue. Figure 7.2 a shows a nonapoptotic cell with the territories of chromosome 8 . Figure $7.2 \mathrm{~b}$ shows an apoptotic cell, with condensed DNA and dispersed signal for chromosome 8 over the apoptotic micronuclei. Bar indicates $10 \mu \mathrm{m}$.
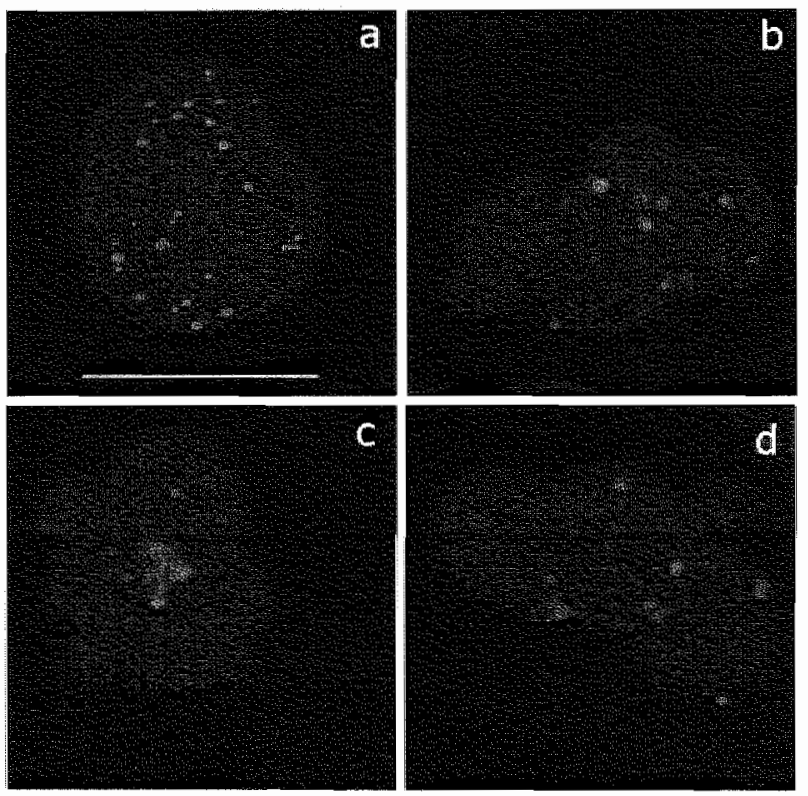

Figure 7.4: Non-apoptotic (figure 7.4a) and apoptotic (figure $7.4 \mathrm{~b}$, figure $7.4 \mathrm{C}$ and figure 7.4 d) $U 937$ cells, hybridized with a probe detecting the telomere repeat sequence (TTAGGG)n. A nom-apoptotic cell shows many discrete FISH signals (figure 7.4a), while in apoptotic cells, the number of signals is decreased (figure 7.4b). In part of the apoptotic cells, the telomeres are clustered, either between (figure 7.4c) or at: the periphery of the apoptotic micronuclei (figure 7.4d). Bar indicates $15 \mathrm{um}$. 

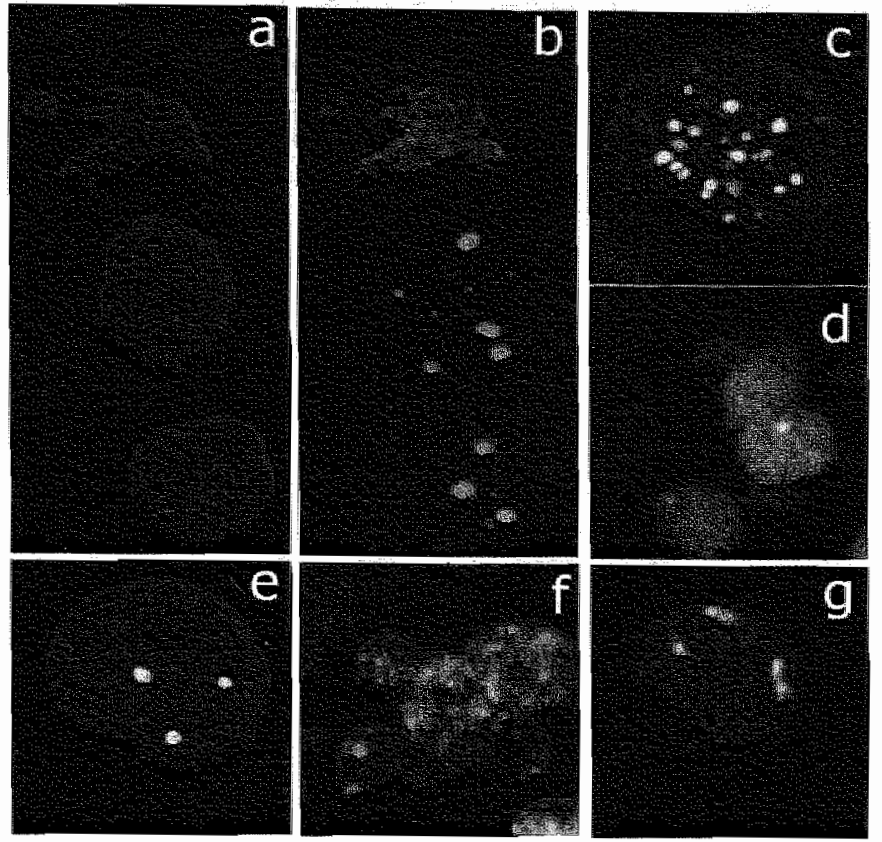

Figure 7.3: Results of the FISH-experiments on MR65 cells (figure 7.3a, 7.3b and $7.3 \mathrm{~g}$ ), Jurkat celis (figure $7.3 \mathrm{c}$ and $7.3 \mathrm{~d}$ ) and U93.7 cells (figure $7.3 e$ and $7.3 \mathrm{f}$ ). Figure 7.3a shows the DAPI staining (blue) of two non-apoptotic cells and an apoptotic MR65 cell (top), while figure 7.3b shows hybridization of these cells with a probe detecting the subcentromeric regions of chromosome 1 (green). The non-apoptotic cells show discrete FISH signals. In the apoptotic cell, the signal is completely dispersed over the condensed micronuclei. In figure $7.3 \mathrm{c}$ a non-apoptotic Jurkat cell, hybridized with the probe detecting all human centromeres (green) is shown, while in the apoptotic cell (figure $7.3 \mathrm{~d}$ ), almost all the signals are completely dispersed over the condensed DNA. U937 cells hybridized with the subtelomeric probe 1 p36 show 3 discrete signals in nonapoptotic cells (figure7.3e), while in apoptotic cells the signal is dispersed over the apoptotic micronuclei (figure7.30). DNA fragmentation as observed during apoptosis does not occur during necrosis (figure 7.39 ). 